NIST Special Publication 1013-1

\title{
Report of Experimental Results for the International Fire Model Benchmarking and Validation Exercise \#3
}

\author{
Anthony Hamins \\ Alexander Maranghides \\ Rik Johnsson \\ Michelle Donnelly \\ Jiann Yang \\ George Mulholland \\ Robert L. Anleitner \\ Building and Fire Research Laboratory
}

November 2003

revised June 2005

$\underline{\text { U.S. Department of Commerce }}$

Donald L. Evans, Secretary

Technology Administration

Michelle O'Neill, Acting Under Secretary for Technology

National Institute of Standards and Technology Hratch Smerjian, Acting Director 

NIST Special Publication 1013-1

\title{
Report of Experimental Results for the International Fire Model Benchmarking and Validation Exercise \#3
}

\author{
Anthony Hamins \\ Alexander Maranghides \\ Rik Johnsson \\ Michelle Donnelly \\ Jiann Yang \\ George Mulholland \\ Robert L. Anleitner \\ Building and Fire Research Laboratory
}


Certain commercial entities, equipment, or materials may be identified in this document in order to describe an experimental procedure or concept adequately. Such identification is not intended to imply recommendation or endorsement by the National Institute of Standards and Technology, nor is it intended to imply that the entities, materials, or equipment are necessarily the best available for the purpose.

For sale by the Superintendent of Documents, U.S. Government Printing Office Internet: bookstore.gpo.gov — Phone: (202) 512-1800 — Fax: (202) 512-2250 Mail: Stop SSOP, Washington, DC 20402-0001

National Institute of Standards and Technology Special Publication 1013-1 Natl. Inst. Stand. Technol. Spec. Publ. 1013-1, 175 pages (June 2005) 


\section{Report of Experimental Results for the International Fire Model Benchmarking and Validation Exercise \#3}

Manuscript Completed: November 2003

Date Published: May 2006

Prepared by
A. Hamins, A. Maranghides,
R. Johnsson, M. Donnelly, J. Yang,
G. Mulholland, R. L. Anleitner

National Institute of Standards and Technology

Building and Fire Research Laboratory

100 Bureau Drive

Gaithersburg, MD 20899

J. Dreisbach, NRC Project Manager

Prepared for:

Division of Risk Assessment \& Special Projects

Office of Nuclear Regulatory Research

U.S. Nuclear Regulatory Commission

Washington, DC 20555-0001

NRC Job Code Y6688

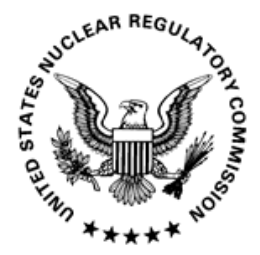




\begin{abstract}
The U.S. Nuclear Regulatory Commission (NRC) and the National Institute of Standards and Technology (NIST) are participating in an International Collaborative Fire Model Project (ICFMP) to assess and validate fire computer codes for nuclear power plant applications. This assessment is being conducted through a series of benchmarking and validation exercises. The goal of the present study is to provide data from a large-scale fire test series of a simulated nuclear power plant compartment conducted in summer 2003.

The experiments consisted of hydrocarbon spray fires varying from $350 \mathrm{~kW}$ to $2 \mathrm{MW}$ in heat

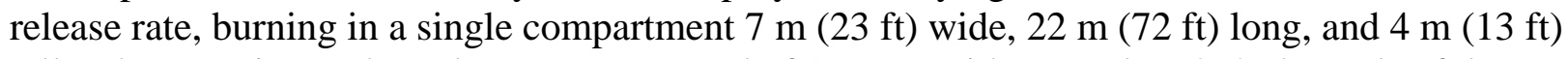
tall. The experimental results were composed of 15 tests with more than 370 channels of data per test.

This report includes a description of the measurement methods and experimental results for tests conducted as part of the International Fire Model Benchmarking and Validation Exercise \#3. The experimental data are available electronically to accompany this report. The data can be used as a comparison with fire models as part of the international benchmark exercise.
\end{abstract}




\section{FOREWORD}

As part of its Fire Risk Research Program, the U.S. Nuclear Regulatory Commission (NRC) collaborates with the National Institute of Standards and Technology (NIST) in a broader International Collaborative Fire Model Project (ICFMP) to assess and validate computer codes for fire modeling of nuclear power plant (NPP) applications. The aim of this collaborative project is to share information and resources, and jointly develop reports documenting the assessment and validation of fire modeling computer codes. Toward that end, the NRC, in collaboration with NIST, conducted realistic full-scale fire tests simulating a typical NPP compartment. This report provides data from these full-scale fire tests.

The NRC uses fire modeling and fire dynamics calculations in a number of regulatory applications. Licensees use these models and calculations to demonstrate compliance with, and to request exemptions to, the regulatory requirements for fire protection. The NRC uses them in the Significance Determination Process (SDP), a part of the NRC's inspection program. In addition, the NRC uses them in the risk-informed performance-based (RI/PB) voluntary fire protection licensing requirements established under 10 CFR 50.48(c). The RI/PB method is based on the National Fire Protection Association (NFPA) Standard 805, "Performance-Based Standard for Fire Protection for Light-Water Reactor Generating Plants.”

This report provides data and technical documentation that are referenced and included in draft NUREG1824, "Verification and Validation of Selected Fire Models for Nuclear Power Plant Applications," which was published for public comment in January 2006. This report documents some of the experimental data used in draft NUREG-1824, including experimental uncertainty estimates.

The results presented in this report were obtained from experiments using hydrocarbon spray fires varying from about $350 \mathrm{~kW}$ to $2 \mathrm{MW}$ in heat release rate (HRR), burning in a single compartment that was $7 \mathrm{~m}$ (23 ft) wide, $22 \mathrm{~m}$ (72 ft) long, and $4 \mathrm{~m}(13 \mathrm{ft})$ tall. The experimental results include more than 370 channels of data for each of the 15 tests conducted as part of this test series. This research provides valuable and extensive test data needed to assess the predictive capabilities of fire modeling tools, which may be used to evaluate fire hazards in NPPs and make regulatory decisions.

Carl J. Paperiello, Director

Office of Nuclear Regulatory Research

U.S. Nuclear Regulatory Commission 


\section{TABLE OF CONTENTS}

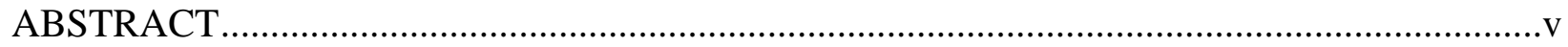

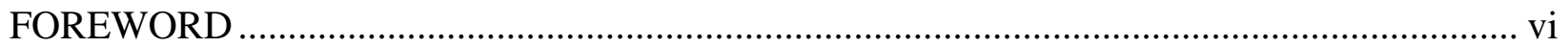

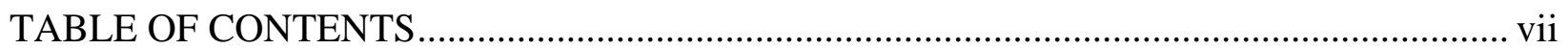

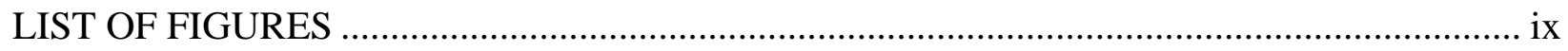

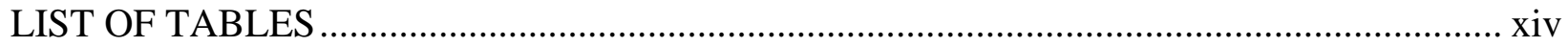

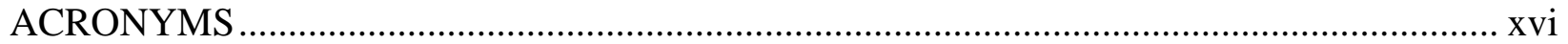

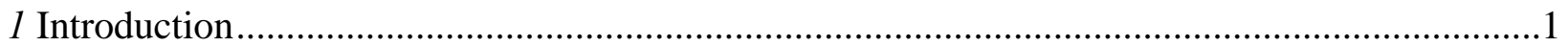

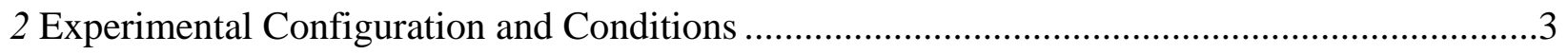

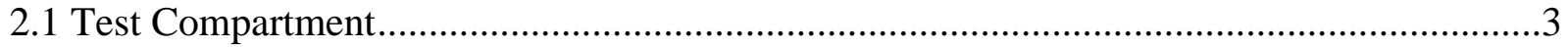

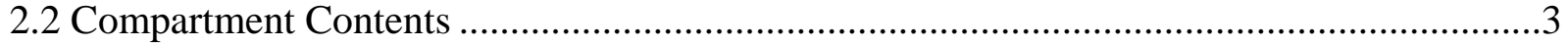

2.3 Compartment Openings and Ventilation ........................................................................ 7

2.4 Fuel Delivery System and Fire ...........................................................................

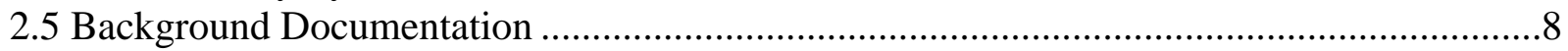

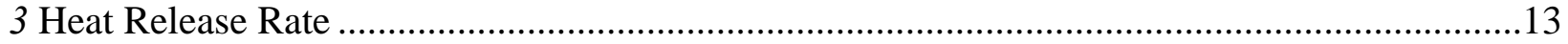

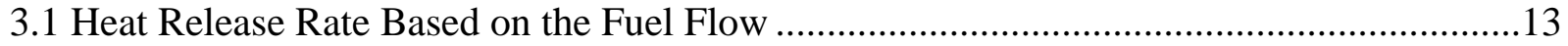

3.2 Heat Release Rate Based on Oxygen Consumption Calorimetry .....................................17

3.3 Energy Balance in the Compartment ...........................................................................25

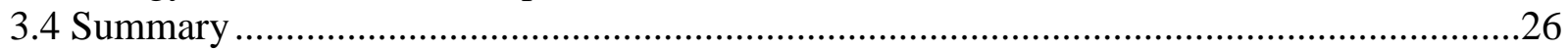

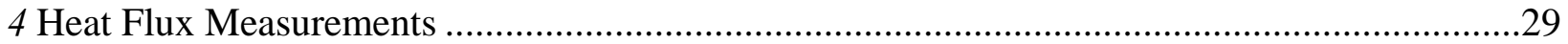

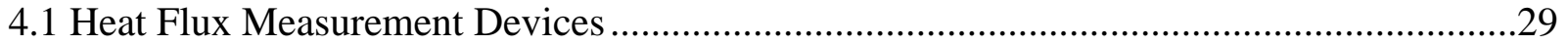

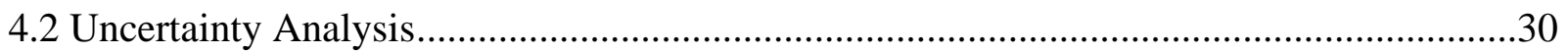

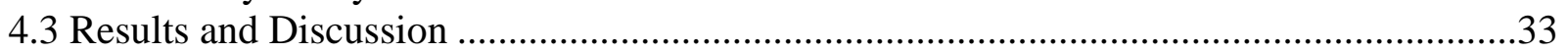

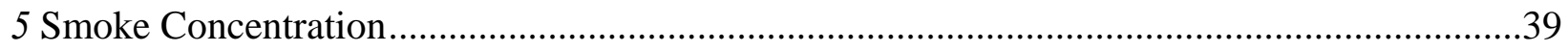

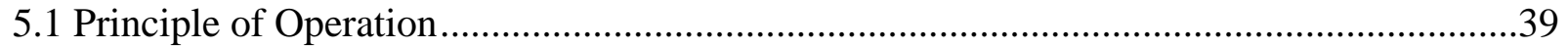

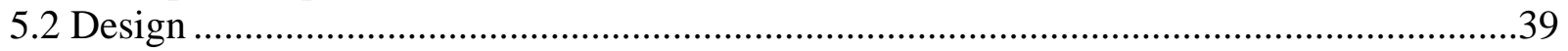

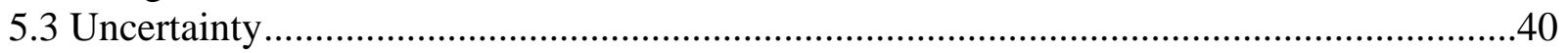

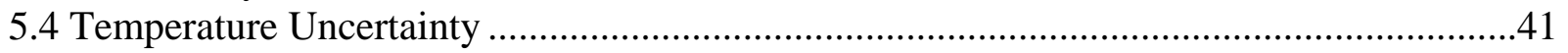

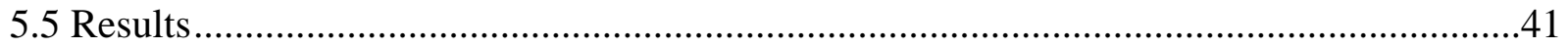

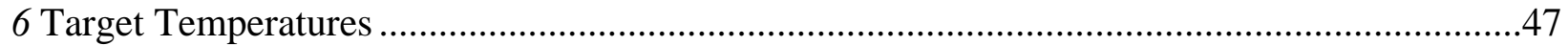

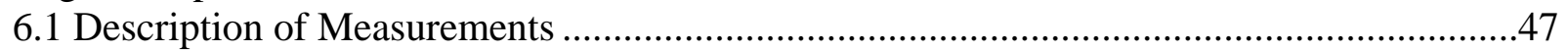

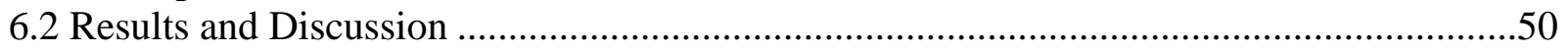

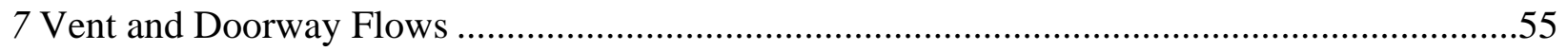

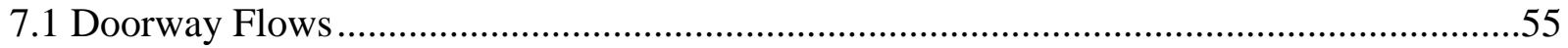

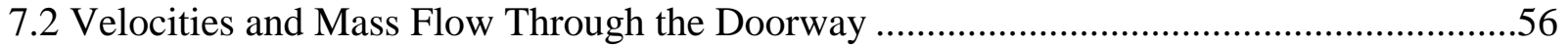

7.3 Heat Loss Through the Doorway ................................................................................61

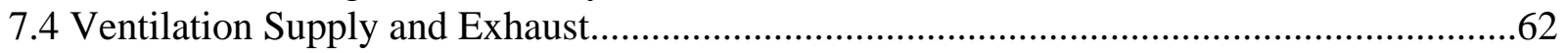

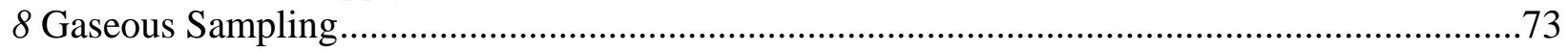

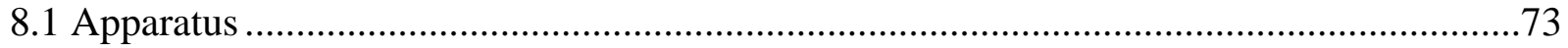

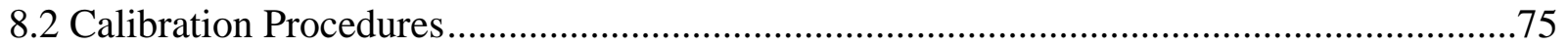

8.3 Sample Transport Time and Analyzer Response Characterization ..................................75

8.4 Estimated Expanded Uncertainty...........................................................................75

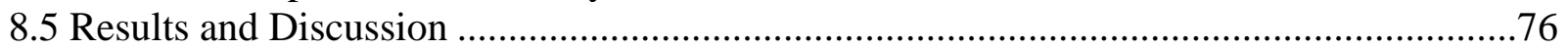

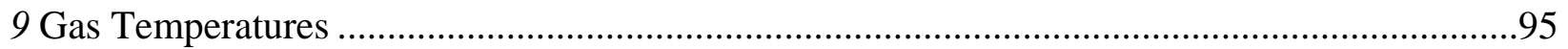

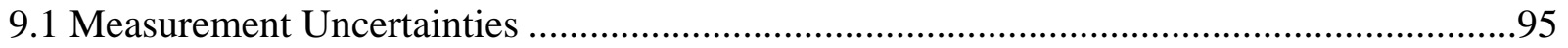


9.2 Hot Gas Layer Temperature.............................................................................................100

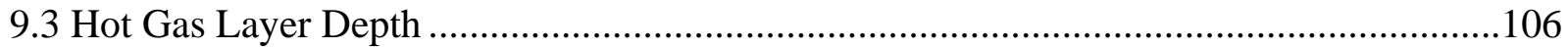

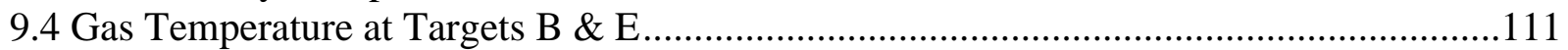

9.5 Gas Temperature at Target G....................................................................................115

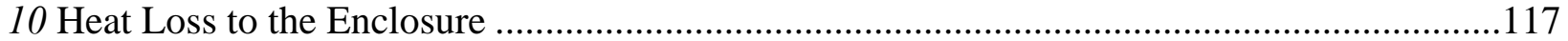

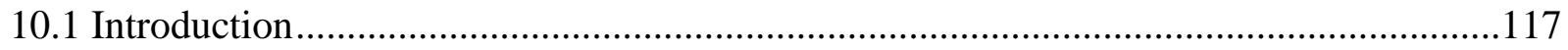

10.2 Measurement Design ..............................................................................................117

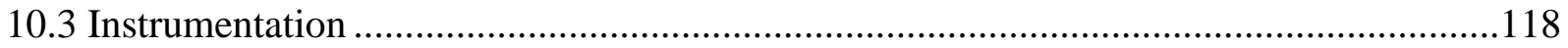

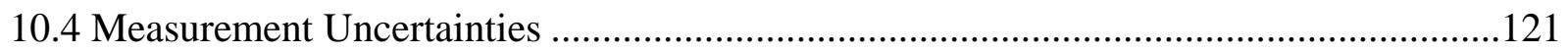

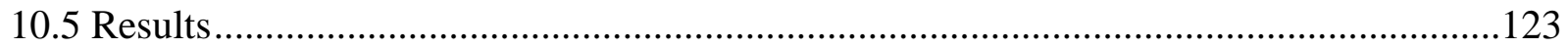

10.6 Contact Resistance Between Marinite Boards ................................................................128

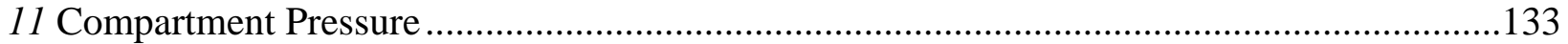

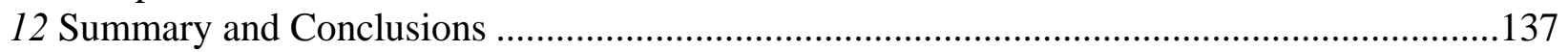

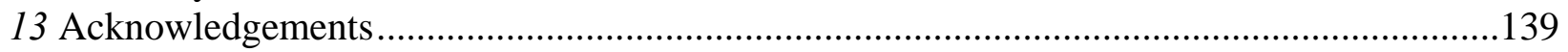

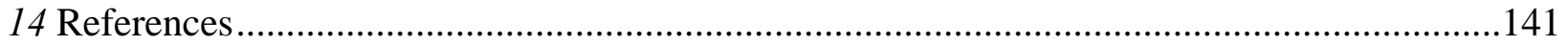

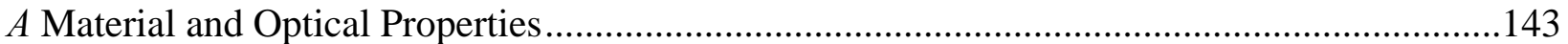

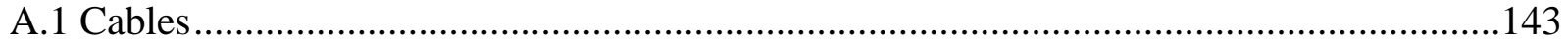

A.2 Properties of Gypsum, Marinite, Feraloy, and the PVC Slab E..........................................145

$B$ Ambient Humidity and Temperature during Testing ...............................................................147

C Compartment Leakage Area..............................................................................................149

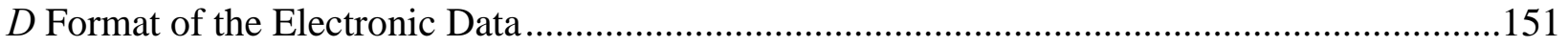

$E$ Inoperative Instruments during Test Series .........................................................................161

$F$ Response to Questions and Comments from July WPI international peer review Meeting ....165

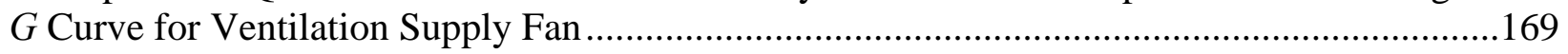

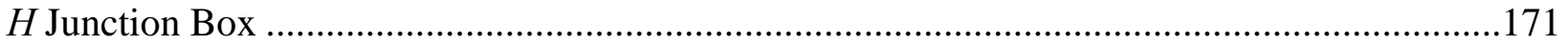

I Fuel Flow Correction....................................................................................................173

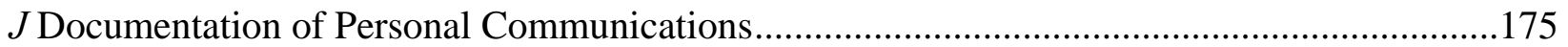




\section{LIST OF FIGURES}

Figure 2-1: Photo of the test compartment being instrumented before testing............................ 4

Figure 2-2: Compartment Isometric with thermocouple trees............................................. 9

Figure 2-3: Compartment Contents and Selected Instrumentation........................................... 10

Figure 2-4: Plan View of Compartment Mid-Section....................................................... 11

Figure 3-1: The calorimetric HRR data as a function of time during the calibration

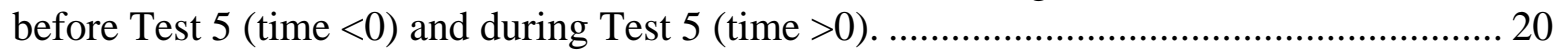

Figure 3-2: The calorimetric HRR during the open door experiments (Tests 3, 5,

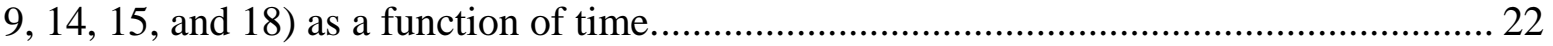

Figure 3-3: The measured HRR as a function of time for Tests 3 and 5. The solid

line shows the idealized fire HRR using gas flow rate............................................... 24

Figure 3-4: The rate of heat loss to surfaces, through the doorway, accumulated

by heating the gas in the compartment, and their sum as a function of time

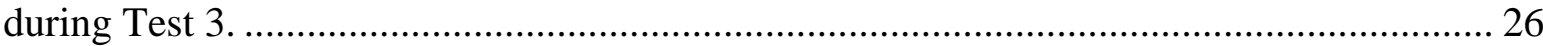

Figure 4-1: Photograph of two total (Gauges 4 and 6) and two radiative (Gauges 3

and 5) heat flux gauges partially insulated...................................................................... 31

Figure 4-2: Photograph of Gauges 9 and 10 and the vertical cable tray................................... 31

Figure 4-3: Cooling water system for total heat flux gauges.............................................. 32

Figure 4-4: Heat fluxes as a function of time for Gauges 3, 4, 5, and 6 in Test 2.................... 34

Figure 4-5: Heat fluxes as a function of time for Gauges 3, 4, 5, and 6 in Test 3.................... 35

Figure 4-6: Heat fluxes as a function of time for Gauges 3, 4, 5, and 6 in Test 4.................... 35

Figure 4-7: Radiative heat flux as a function of time for Gauge 10 in Test 2. The

total heat flux Gauge, 9, was not functioning during this test. .......................................... 36

Figure 4-8: Radiative and total heat flux as a function of time for Gauges 9 and 10

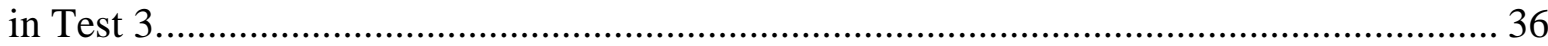

Figure 4-9: Radiative and total heat flux as a function of time for Gauges 9 and 10

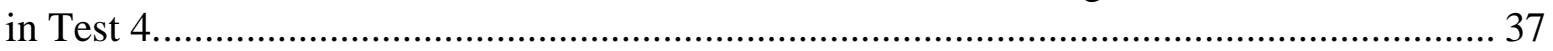

Figure 4-10: Radiative and total heat flux as a function of time for Gauges 1, 2, 7,

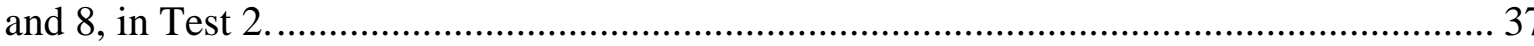

Figure 4-11: Radiative and total heat flux as a function of time for Gauges 1, 2, 7, and 8 , in Test 3 (Gauge 7 failed after $1000 \mathrm{~s}$ into the test)............................................. 38

Figure 4-12: Radiative and total heat flux as a function of time for Gauges 1, 2, 7 ,

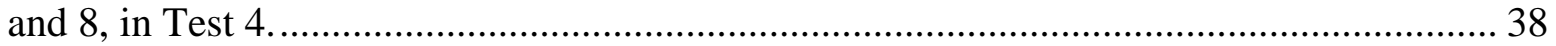

Figure 5-1: Smoke concentration and temperature as a function of time for Test 2. ................ 44

Figure 5-2: Smoke concentration and temperature as a function of time for Test 3.................. 44

Figure 5-3: Smoke concentration and temperature as a function of time for Test 4................. 45

Figure 5-4: Smoke concentration and temperature versus time for a $1 \mathrm{MW}$ (Test

2) and for a 2 MW (Test 13) blended heptane fire both with the door closed..................... 45

Figure 5-5: Smoke concentration versus time for toluene (Test 17) and for heptane

(Test 2) for a 1 MW test with door closed................................................................... 46

Figure 5-6: Comparison of smoke concentration and smoke temperature for two

replicate, $1 \mathrm{MW}$ tests with door closed (Test 2 and Test 8)........................................... 46

Figure 6-1: Thermocouples on the PVC slab (1 cm x $1 \mathrm{~cm} \times 5 \mathrm{~cm}$ long) measuring temperatures at the lower and upper surfaces and the slab center. 
Figure 6-2: Photograph looking towards the north wall with Target E present, a rectangular slab composed of PVC.

Figure 6-3: Photograph and schematic cutaway of a target cable instrumented

with bare-bead type $\mathrm{K}$ thermocouples on the surface and just under the outer

insulation. 48

Figure 6-4: The transient temperatures in slab E during Test 2......................................... 51

Figure 6-5: The transient temperature on Target B during Test 2...................................... 51

Figure 6-6: The transient temperature on the vertical cable, Target G, during Test 2

Figure 6-7: The transient temperature at three locations in slab E during Test 3..................... 52

Figure 7-1: Locations of instrumentation in the door opening. ............................................ 56

Figure 7-2: Velocities through the doorway measured at the centerline. ................................ 57

Figure 7-3: Velocities through the doorway measured on the south side................................. 58

Figure 7-4: Velocities through the doorway measured on the north side................................. 58

Figure 7-5: Mass flow into the compartment through the open doorway for Test 3.................. 60

Figure 7-6: Mass flow out of compartment through the upper portion of the

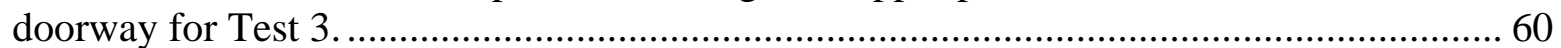

Figure 7-7: Net mass flow through doorway for Test 3..................................................... 61

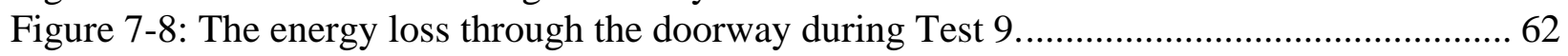

Figure 7-9: Location of velocity measurements in the supply vent during

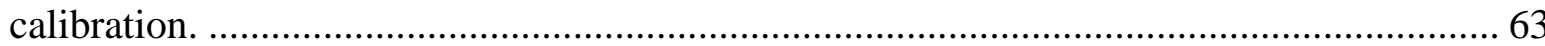

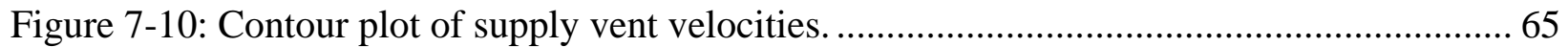

Figure 7-11: Flow visualization of the supply duct flow field using smoke (left),

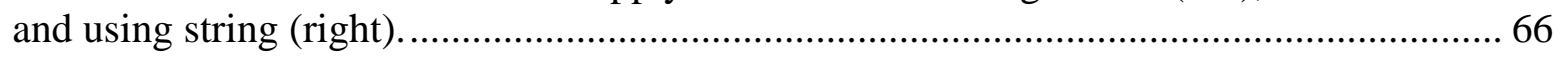

Figure 7-12: Mass flow through supply vent for NRC Test 4, 1 MW, door closed................... 66

Figure 7-13: Locations where exhaust velocities were measured. ........................................ 67

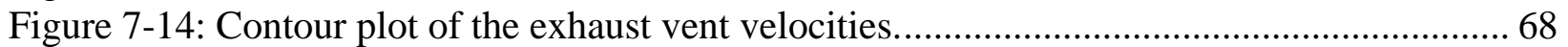

Figure 7-15: Mass flow through exhaust vent for NRC Test 10, $1 \mathrm{MW}$, door

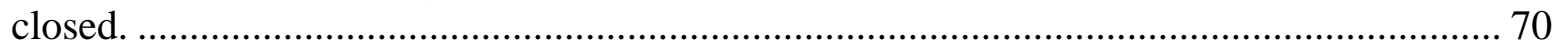

Figure 7-16: Energy flow through exhaust vent for NRC Test 10, $1 \mathrm{MW}$, door

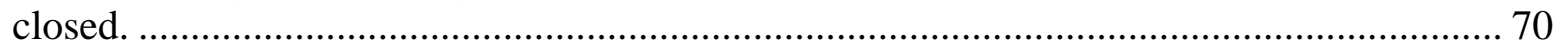

Figure 7-17: Energy flow through the exhaust vent for Test 5, compartment door

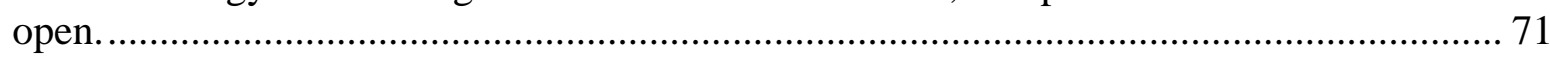

Figure 8-1: Lower Level Gaseous System components and configuration.............................. 74

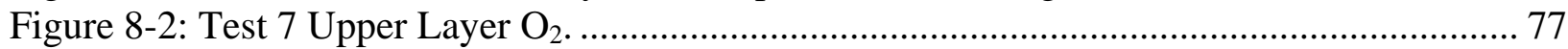

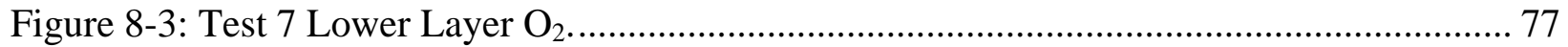

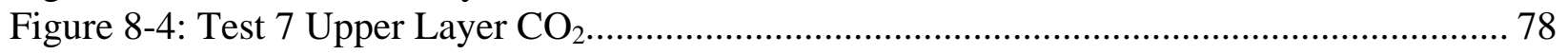

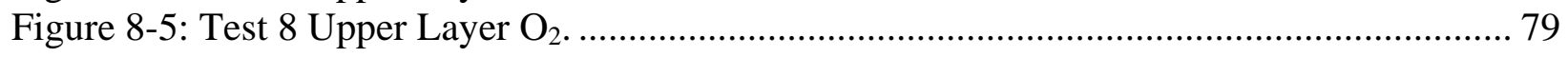

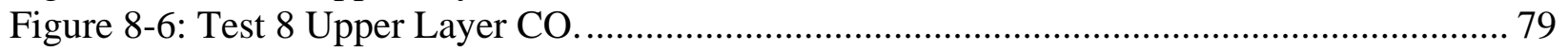

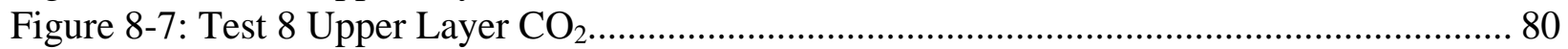

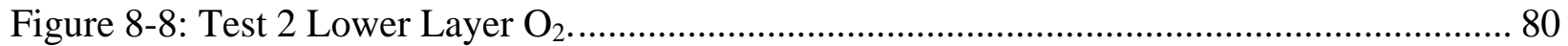

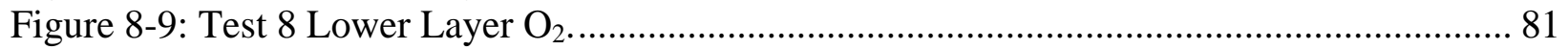

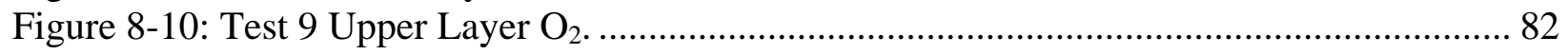

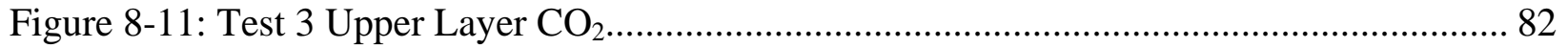

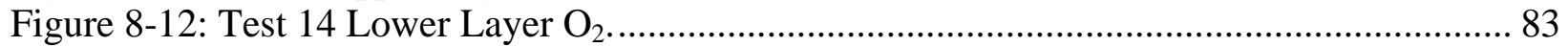

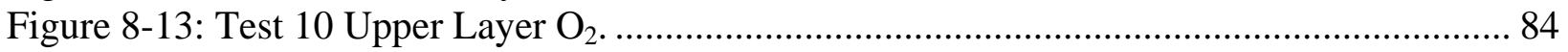




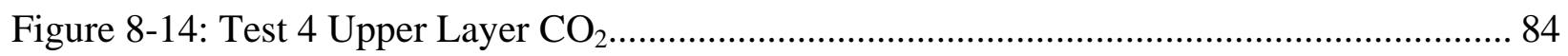

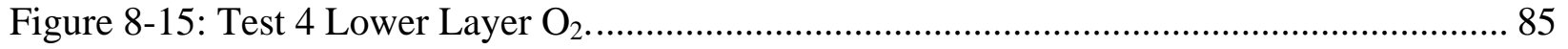

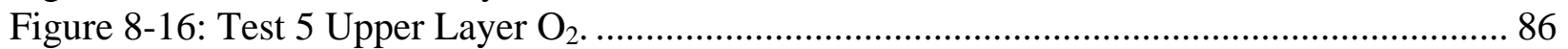

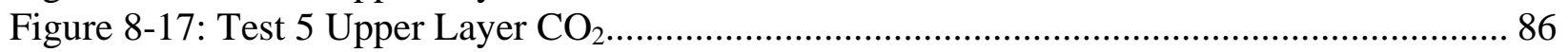

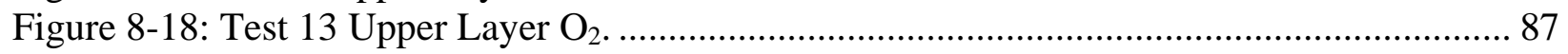

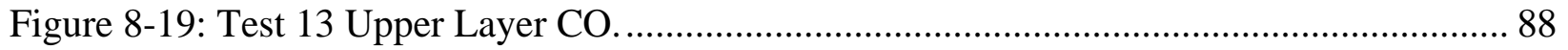

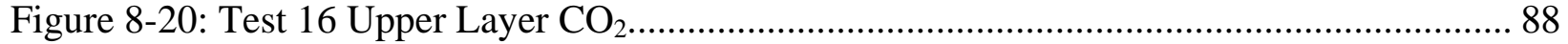

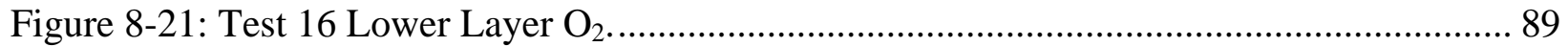

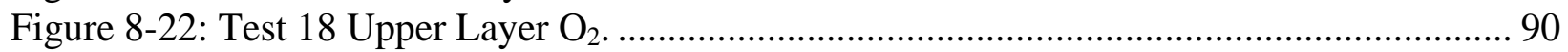

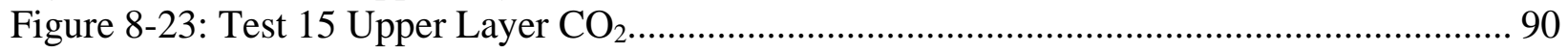

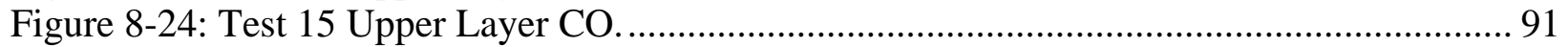

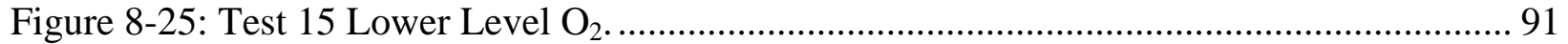

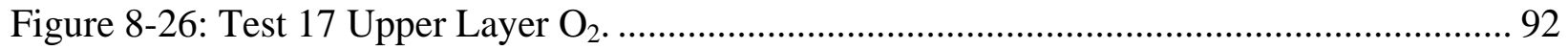

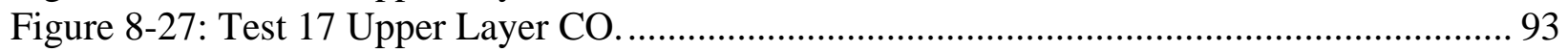

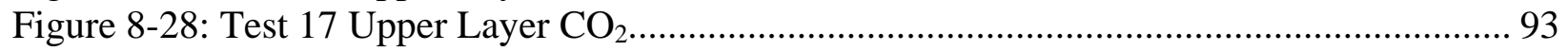

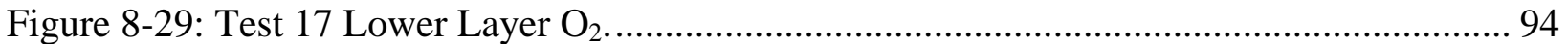

Figure 9-1: Temperature comparison as a function of time for aspirated (TA5,

TA6) and bare-bead thermocouples (T5-3, T5-8) located at $\mathrm{Z}=1.05 \mathrm{~m}$ and

$2.0 \mathrm{~m}$ on Tree 5 during Test 2..................................................................................... 97

Figure 9-2: Temperature differences as a function of time for aspirated (TA5,

TA6) and bare-bead thermocouples (T5-3, T5-8) located at Z= $1.05 \mathrm{~m}$ and

$2.0 \mathrm{~m}$ on Tree 5 during Test 2 .....

Figure 9-3: Temperature comparison as a function of time for aspirated (TA5,

TA6) and bare-bead thermocouples (T5-3, T5-8) located at Z=1.05 m and 2.0

$\mathrm{m}$ on Tree 5 during Test 3 .

Figure 9-4: Temperature differences as a function of time for aspirated (TA5,

TA6) and bare-bead thermocouples (T5-3, T5-8) located at $\mathrm{Z}=1.05 \mathrm{~m}$ and

$2.0 \mathrm{~m}$ on tree 5 during Test 3.

Figure 9-5: Temperature comparison as a function of time for aspirated (TA5,

TA6) and bare-bead thermocouples (T5-3, T5-8) located at Z= $1.05 \mathrm{~m}$ and

$2.0 \mathrm{~m}$ on Tree 5 during Test 4 .

Figure 9-6: Temperature differences as a function of time for aspirated (TA5,

TA6) and bare-bead thermocouples (T5-3, T5-8) located at Z= $1.05 \mathrm{~m}$ and

$2.0 \mathrm{~m}$ on Tree 5 during Test 4 .

Figure 9-7: The expanded uncertainty spread around nominal values of hot gas

layer temperature for all tests except Test 18.

Figure 9-8: Bare bead thermocouple temperatures as a function of time for Tree 7

during Test 2.

Figure 9-9: Bare bead thermocouple temperatures as a function of time for Tree 7 during Test 3.

Figure 9-10: Bare bead thermocouple temperatures as a function of time for Tree

7 during Test 4.

Figure 9-11: Bare bead thermocouple temperatures as a function of time for Tree

7 during Test 5

Figure 9-12: Hot gas layer temperature as a function of time for Tree 7 during

Tests 2, 8, 3, 9, 4, 10, and 5 calculated using the two-layer reduction method. 104 
Figure 9-13: Hot gas layer temperature as a function of time for Tree 7 during

Tests 1, 7, 2, 8, 13 calculated using the two-layer reduction method. 105

Figure 9-14: Hot gas layer temperature as a function of time for Tree 7 during

Tests 13, 16, 2, and 17 calculated using the two-layer reduction method. 105

Figure 9-15: Hot gas layer temperature as a function of time for Tree 7 during

Tests 3, 14, 18, and 15 calculated using the two-layer reduction method........................ 106

Figure 9-16: The expanded uncertainty spread around nominal values of the hot/cold gas layer interface height for all tests except Test 18. 108

Figure 9-17: Layer interface height as a function of time for Tree 7 during Tests 2,

$8,3,9,4,10$, and 5 calculated using the two-layer reduction method. 109

Figure 9-18: Layer interface height as a function of time for Tree 7 during Tests 1,

$7,2,8$, and 13 calculated using the two-layer reduction method.

Figure 9-19: Layer interface height as a function of time for Tree 7 during Tests

$13,16,2$, and 17 calculated using the two-layer reduction method.

Figure 9-20: Layer interface height as a function of time for Tree 7 during Tests 3,

14,18 , and 15 calculated using the two-layer reduction method.

Figure 9-21: Temperature versus time for the thermocouple located at position 8

on Tree 4 and also near Targets B and E for Tests 2, 8, 3, 9, 4, 10, and 5.

Figure 9-22: Temperature versus time for the thermocouple located at position 8

on Tree 4 and also near Targets B and E for Tests 1, 7, 2, 8, and 13.

Figure 9-23: Temperature versus time for the thermocouple located at position 8

on Tree 4 and also near Targets B and E for Tests 13, 16, 2, and 17 (labeled

$\mathrm{P} 1 \mathrm{~T} 13, \mathrm{P} 1 \mathrm{~T} 16, \mathrm{P} 1 \mathrm{~T} 2$, and $\mathrm{P} 1 \mathrm{~T} 17$, respectively).

Figure 9-24: Temperature versus time for the thermocouple located at position 8

on Tree 4 and also near Targets B and E for Tests 3, 14, 15, and 18 (labeled

P1T3, P1T14, P1T15, and P1T15b, respectively).

Figure 9-25: Temperature versus time for the thermocouple located at position 5

on Tree 2 and also near Target $G$ for Tests 2, 8, 3, 9, 4, 10, and 5 (labeled

P1T2, P1T8, P1T3, P1T9, P1T4, P1T10, and P1T5, respectively).

Figure 9-26: Temperature versus time for the thermocouple located at position 5

on Tree 2 and also near Target $G$ for Tests 1, 7, 2, 8, 13 (labeled P1T1, P1T7,

$\mathrm{P} 1 \mathrm{~T} 2, \mathrm{P} 1 \mathrm{~T} 8$, and P1T13, respectively).

Figure 9-27: Temperature versus time for the thermocouple located at position 5

on Tree 2 and also near Target $G$ for Tests 13, 16, 2, and 17 (labeled P1T13,

P1T16, P1T2, and P1T17, respectively).

Figure 9-28: Temperature versus time for the thermocouple located at position 5

on Tree 2 and also near Target $\mathrm{G}$ for Tests 3, 14, 15, and 18 (labeled P1T3,

P1T14, P1T15, and P1T15b, respectively).

Figure 10-1: A Vatell model BF-04 heat flux gauge installed on the South wall

along with a wall thermocouple.

Figure 10-2: North and south Wall Sensor Locations. ...................................................... 120

Figure 10-3: Ceiling and floor Sensor Locations.......................................................... 121

Figure 10-4: East and west wall sensor locations. ........................................................... 121

Figure 10-5: Net heat flux to the wall near N1 and N3 gauges versus time for

Tests 2 to 5 . 
Figure 10-6: Net heat loss rate to individual surfaces and the total sum for all

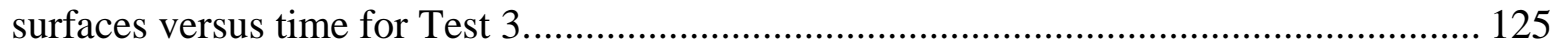

Figure 10-7: Net heat loss rate to individual surfaces and the total sum for all

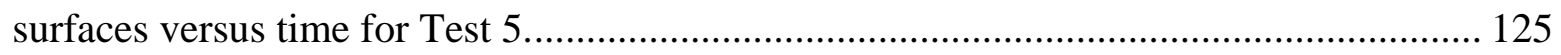

Figure 10-8: Net heat loss rate to individual surfaces and the total sum for all

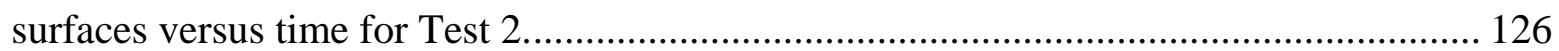

Figure 10-9: Net heat loss rate to individual surfaces and the total sum for all

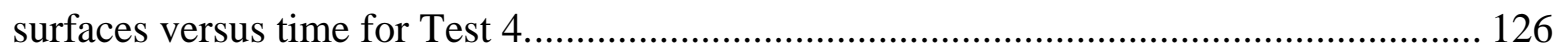

Figure 10-10: Rate of heat loss to the enclosure surfaces, through the doorway,

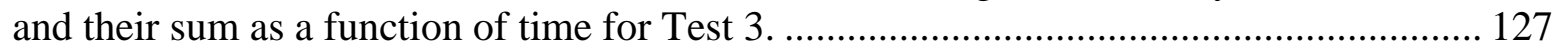

Figure 10-11: Net heat flux comparison of uncooled gauges N3 and N4 with

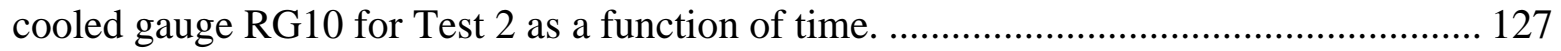

Figure 10-12: Net heat flux comparison of uncooled gauges N3 and N4 with cooled gauges FG9 and RG10 for Test 3 as a function of time.................................... 128

Figure 10-13: Interior installation of marinite thermocouples........................................... 129

Figure 10-14: Exterior installation of marinite thermocouples............................................. 130

Figure 10-15: Peak marinite temperatures for Tests 2 to 4 at five measurement

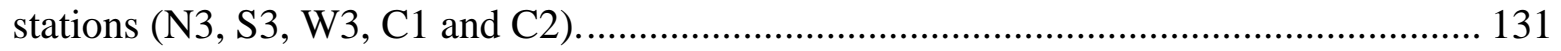

Figure 11-1: Differential pressure for Test 2, door closed, ventilation off............................... 134

Figure 11-2: Differential pressure for Test 4, door closed, ventilation on. .............................. 135

Figure A-1: Morphology of a 7/C \#14 AWG Control Cable (Cable 1 in Table A1).

Figure A-2: Morphology of a 7/C \#14 AWG Control Cable (Cable 2 in Table A$1)$.

Figure A-3: Morphology of a 3/C \#6 AWG Power Cable (Cable 3 in Table A-1). .................. 144

Figure A-4: Morphology of a 3/C \#6 AWG Power Cable (Cable 4 in Table A-1)................... 144

Figure G-1: The manufacturer supplied fan curve that relates the static pressure to the blowing volume for various values of the fan power.

Figure H-1: Thermocouples in and on the surface of the junction box $(30 \mathrm{~cm} \times 30$ $\mathrm{cm} \times 10 \mathrm{~cm}$ ) measuring temperatures in the box center and on the middle of the bottom and west surfaces.

Figure I-1: The measured fuel flow and nozzle temperature as a function of time during the $1 \mathrm{MW}$ closed door compartment experiment. 


\section{LIST OF TABLES}

Table 2-1: Test Matrix and Experimental Conditions. ............................................................. 5

Table 2-2: Observations Noted during the Test Series. .................................................... 6

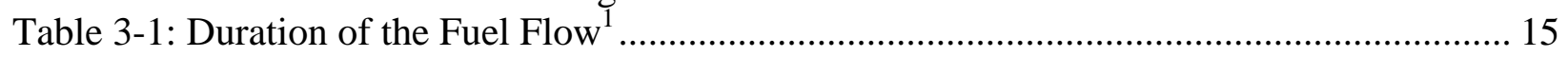

Table 3-2: The Ambient Temperature Fuel Flow Calibration, Associated HRR, and its value Corrected for Compartment Effects........................................................... 16

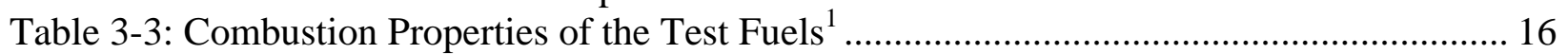

Table 3-4: Instruments for the $9 \mathrm{~m}$ x 12 m NIST Calorimeter System...................................... 18

Table 3-5: Summary of the calorimetry calibration results. .................................................... 21

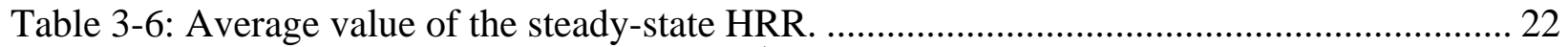

Table 3-7: The Estimated and Measured HRRs ${ }^{1}$ and their Ratio............................................... 24

Table 3-8: Estimated HRR during the Steady Burning Period in the Closed Door

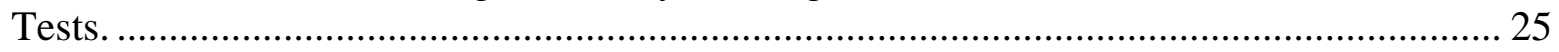

Table 3-9: Estimated HRRs during the steady burning period for all of the tests

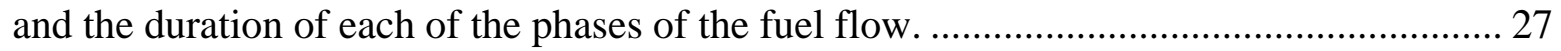

Table 4-1: Locations of total heat flux gauges and radiometers. .............................................. 30

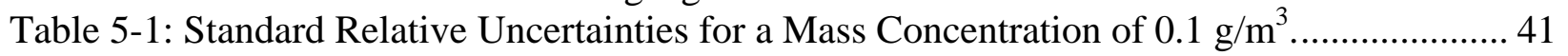

Table 5-2: Smoke and Temperature Results........................................................................ 43

Table 6-1: Thermocouple Physical Location and Orientation on Targets B, E, and

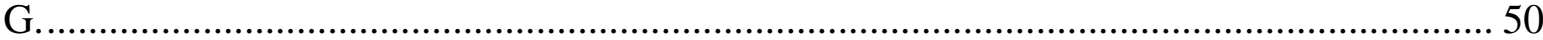

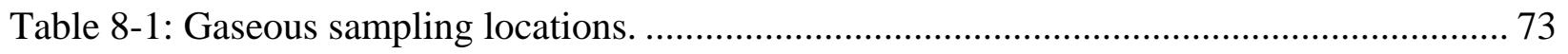

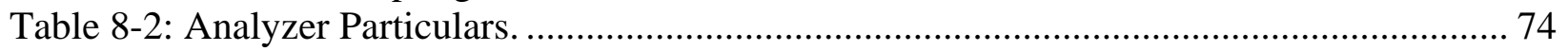

Table 8-3: Sample transport time and analyzer response.................................................... 75

Table 8-4: Estimated expanded uncertainty (with an expansion factor of two)......................... 76

Table 9-1: Calculated differences between aspirated and bare bead thermocouple temperature measurements and expanded temperature uncertainties............................... 96

Table 9-2: Hot gas layer temperature expanded uncertainty limits....................................... 100

Table 9-3: Hot gas layer interface height expanded uncertainty limits. ................................. 107

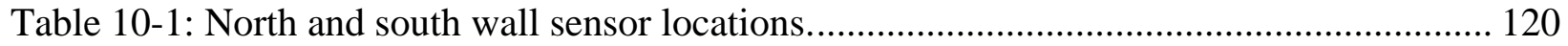

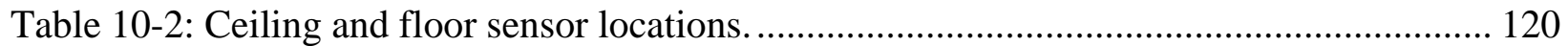

Table 10-3: East and west wall sensor locations. ................................................................ 121

Table 10-4: Overview uncertainties of net heat flux. ............................................................ 122

Table 11-1: Maximum compartment pressure differential. .................................................... 134

Table A-1: Cable types used in the experiments. ............................................................... 143

Table A-2: Material and optical properties of the cable materials.......................................... 145

Table A-3: Material and optical properties of marinite. ........................................................ 146

Table A-4: Material and optical properties of feraloy and gypsum at ambient

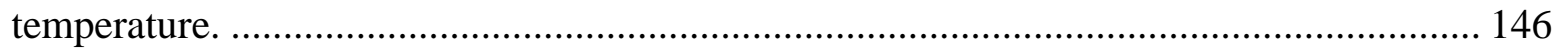

Table B-1: Humidity and temperature in the large fire lab............................................... 147

Table C-1: Measured Pressure, Leakage Area and Air Flow Rate.......................................... 149

Table C-2: Calculated C and n values, compartment equivalent leakage area and

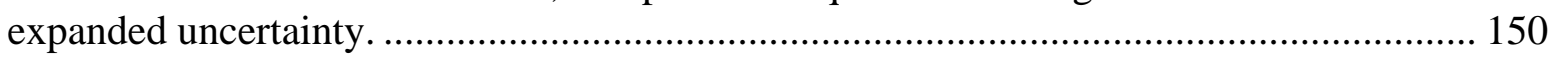

Table D-1: Instrument channel number, designation, units, and location. .............................. 152 
Table D-2: Instrument channel number, designation, units, and location for the

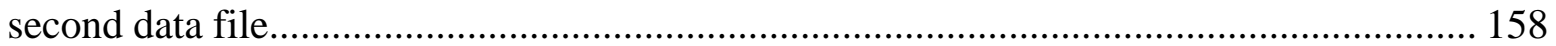

Table E-1: List of inoperative instruments during the test series. ............................................... 161

Table E-2: List of inoperative instruments during the test series................................................ 162

Table E-3: List of inoperative instruments during the test series. ................................................. 163 


\section{ACRONYMS}

ASTM

AWG

CSPE

FDS

FHA

FRA

HGL

HRR

ICFMP

NFPA

NIST

NPP

NRC

PVC

$\mathrm{RI} / \mathrm{PB}$

SDP

TC

WPI

XPE
American Society for Testing and Materials

American Wire Gauge

Chlorosulfinated Polyethylene

Fire Dynamics Simulator

Fire Hazards Analysis

Fire Risk Analysis

Hot Gas Layer

Heat Release Rate

International Collaborative Fire Model Project

National Fire Protection Association

National Institute of Standards and Technology

Nuclear Power Plant

Nuclear Regulatory Commission

Polyvinyl Chloride

Risk-Informed/Performance-Based

Significance Determination Process

Thermocouple

Worcester Polytechnic Institute

Crosslinked Polyethylene 


\section{INTRODUCTION}

This document contains experimental results, which are useful for comparison with fire models as part of Validation Exercise \#3 of the International Collaborative Fire Model Project (ICFMP). The objective of the collaborative project is to share the knowledge and resources of various international organizations to evaluate and improve the state of the art of fire models for use in nuclear power plant fire safety and fire hazard analysis. A total of five benchmarking and validation exercises have been conducted in the ICFMP, of which this report documents exercise \#3. NRC, in collaboration with NIST, conducted these experiments in summer 2003. A detailed description of the experimental procedures, configuration, and instrumentation is documented in this report.

The test configuration and fire scenarios have been selected to examine the following effects:

- Heat release rate (HRR)

- Natural ventilation with an open door

- Mechanical ventilation system operation

- A combination of mechanical and natural ventilation

- Distance between fire and target

- Heating of cables and a PVC slab directly in the plume region

The measurements include the following:

- Duration of fuel flows and HRRs

- Compartment pressure

- Radiative and total heat flux at various targets in the compartment

- Surface and core cable temperatures and PVC slab temperature

- Hot gas layer (HGL) temperature, depth, soot density, and concentrations of oxygen, carbon monoxide and carbon dioxide

- Gas temperature vertical profiles

- Total heat loss to the walls, ceiling, and floor

- Total heat loss from the door and mechanical exhaust vent

Visual and infrared video records of the experiments were also acquired, but are not presented in this report.

This report presents a portion of the data that was collected during the NRC/NIST test series. The experimental results were composed of 15 tests with more than 350 channels of data acquired per test at a sampling rate of $1 \mathrm{~Hz}$. The test duration was typically $1600 \mathrm{~s}$, yielding on the order of $10^{7}$ discrete pieces of data. Given limited resources, there is simply too much data to complete a comprehensive analysis of the results. Instead, representative measurement results and estimates of measurement uncertainty are provided in this report. The full set of data is available electronically from NIST. 
This report includes a description of the measurement methods and experimental results for the tests conducted as part of the ICFMP Benchmarking Exercise \#3. Section 2 of this report describes the experimental configuration including the experimental conditions, the fuel flow and details of the test compartment. The rest of the document focuses on the measurement methods and results. Section 3 describes the fuel flow and HRR measurements. Section 4 discusses the heat flux measurement results. Section 5 describes the smoke concentration measurements. Section 6 discusses the target temperature measurements. Section 7 describes the vent and doorway flows. Section 8 discusses gaseous sampling results. The gas temperature measurements are described in Section 9 and the heat loss to the enclosure is discussed in Section 10. Section 11 describes the measurement of the compartment pressure. Section 12 presents summary and conclusions. Section 13 acknowledges those that provided support for the experiments. The references cited in the text are listed in Section 14.

A large amount of information is also provided in the appendices of this report. Appendix A of this report provides information on the structure, and the thermal and optical properties of the "marinite" (calcium silicate) boards that composed the compartment walls and ceiling, Feraloy that composed a junction box located on the ceiling, gypsum boards that comprised the compartment floor, and polyvinyl chloride (PVC) and crosslinked polyethylene (XPE) thermoplastic that comprised cable jacket materials of the electrical cables that acted as "targets" during the fire experiments. Appendix B provides information on the ambient humidity and temperature during the test dates. Appendix C describes measurements of the intrinsic leakage associated with the compartment, which was measured before initiation of the first experiment and a number of times during the test series. Appendix D provides a discussion of the format of the companion electronic data. Appendix E lists non-functioning instrument channels. Appendix F lists response to questions and comments on this report from a July 2003 ICFMP peer review meeting at Worcester Polytechnic Institute (WPI). Appendix G provides the pressure curves for the ventilation supply fan used in the experiments. Appendix $\mathrm{H}$ describes the metal junction box placed in the ceiling of the compartment. Appendix I describes the method by which a correction was applied to the estimated fuel flow during the experiments. Appendix J provides documentation of personal communications cited in the text. 


\section{EXPERIMENTAL CONFIGURATION AND CONDITIONS}

The test matrix and experimental conditions are presented in Table 2-1. The table lists the test number, the nominal peak HRR $(\dot{Q})$, the type of cables present during the test, the fuel type, burner location, ventilation, and door condition. Observations made during the test series are listed in Table 2-2. The order of the tests is also listed. The observations highlight the melting of the cables and a small slab of PVC (Slab E, described in Section 6), as well as a number of instrumentation issues.

\subsection{Test Compartment}

Figure 2-1 is a photo of the compartment taken from the door in the west wall, looking east. The compartment was $7.04 \mathrm{~m}$ x $21.7 \mathrm{~m}$ x $3.82 \mathrm{~m}$ (23.1 ft x $6.60 \mathrm{ft}$ x $12.5 \mathrm{ft})$ in dimension, designed to represent a realistic-scale compartment in a nuclear power plant. The total compartment volume was $582 \mathrm{~m}^{3}\left(20,500 \mathrm{ft}^{3}\right)$. Looking in from the $2.0 \mathrm{~m}$ by $2.0 \mathrm{~m}(6.6 \mathrm{ft}$ by $6.6 \mathrm{ft})$ double door, Figure 2-1 shows the right (South), back (East), and left (North) walls. Walls and ceiling were covered with two layers of $12.7 \mathrm{~mm}$ (0.500 in) marinite boards, while the floor was covered with one layer of $12.7 \mathrm{~mm}$ (0.500 in) gypsum board on top of one layer of $18.3 \mathrm{~mm}$ (0.720 in)

plywood. The supply duct and horizontal cables are evident on the right of Figure 2-1, while the vertical cable tray and exhaust duct are on the left. Figures 2-2 - 2-4 are schematic drawings of the compartment in which the location of some of the compartment features are shown including the Targets (A-F), ventilation ducts, thermocouple trees, junction box, fire pan, and door.

\subsection{Compartment Contents}

The targets have been arranged to examine the following effects:

1. Modeling one cable versus cables bundled in a cable tray.

2. Modeling a cable as composed of a slab with uniform material versus a real cable geometry and composition.

3. Heating characteristics of cables with a large diameter versus smaller cables

4. Elevation of the target in the hot gas layer

5. Vertical versus horizontal cable target

6. Heating of a junction box on the ceiling

The fire was located in the center of the compartment at floor level for most of the tests. For a number of tests the fire pan was moved away from the center of the compartment (see Table 21).

The compartment contained three control cables (A, B, C), a horizontal (Target D) and a vertical cable tray (Target G) with control cables, a solid PVC slab "target” (E), and a single power cable 
(F). The control cables had seven conductors (7/C \# 14 American Wire Gauge, AWG). The power cable had three conductors (3/C \# 6 AWG). For the primary tests in the series, all the cables were constructed of XPE insulation and Hypalon jacket materials. For the replicate tests, all the cables were based on PVC jacket and PVC/Nylon insulation materials. Further information on the structure and the thermal and optical properties of the cables are discussed in Appendix A of this report.

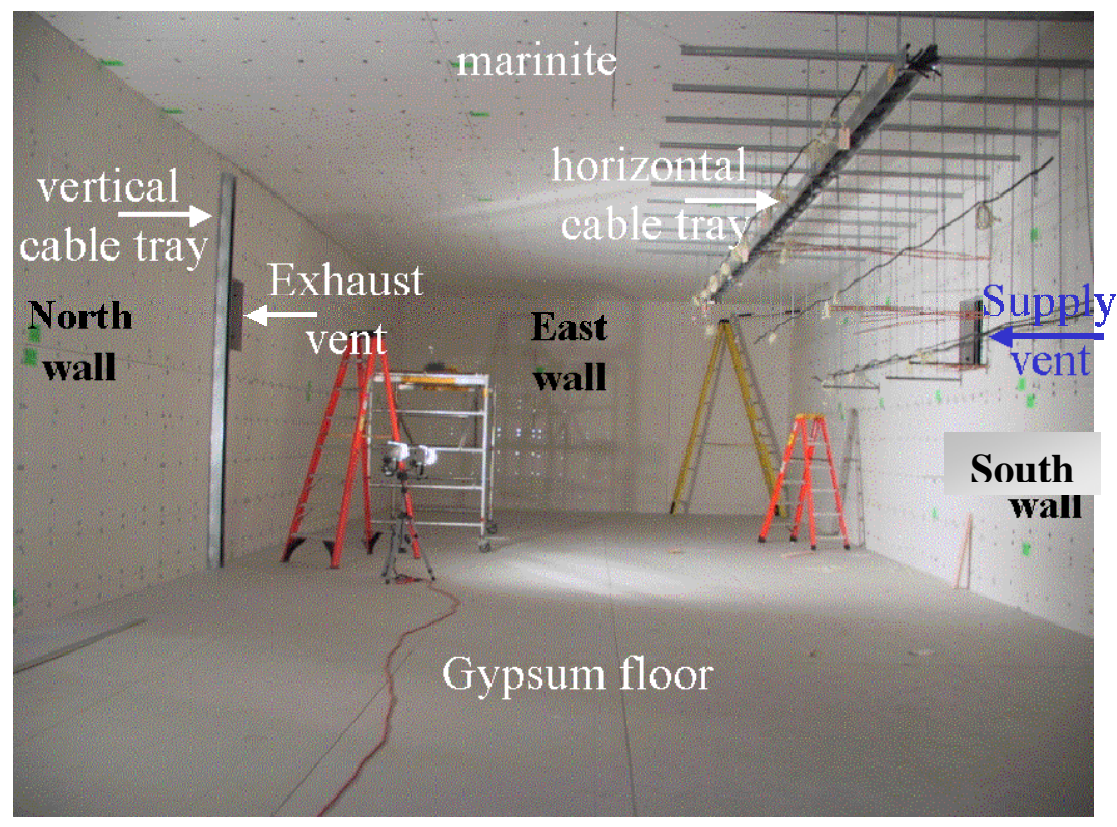

Figure 2-1: Photo of the test compartment being instrumented before testing. 
Table 2-1: Test Matrix and Experimental Conditions.

\begin{tabular}{|c|c|c|c|c|c|}
\hline Test & $\begin{array}{c}\text { Nominal Peak } \\
\dot{Q}(\mathrm{MW})\end{array}$ & $\begin{array}{l}\text { Cable } \\
\text { Type }\end{array}$ & Fuel; Burner Location & Door & Ventilation \\
\hline 1 & 0.35 & $\mathrm{XPE}^{1}$ & Heptane $^{3}$; Center & Closed & Off \\
\hline 2 & 1 & XPE & Heptane; Center & Closed & Off \\
\hline 3 & 1 & $\mathrm{XPE}$ & Heptane; Center & Open & Off \\
\hline 4 & 1 & XPE & Heptane; Center & Closed & On \\
\hline 5 & 1 & XPE & Heptane; Center & Open & On \\
\hline 6 & \multicolumn{5}{|c|}{ Not Conducted } \\
\hline 7 & Replicate Test 1 & $\mathrm{PVC}^{2}$ & Heptane; Center & Closed & Off \\
\hline 8 & Replicate Test 2 & XPE & Heptane; Center & Closed & Off \\
\hline 9 & Replicate Test 3 & XPE & Heptane; Center & Open & Off \\
\hline 10 & Replicate Test 4 & PVC & Heptane; Center & Closed & On \\
\hline 11 & Replicate Test 5 & \multicolumn{2}{|r|}{ Not Conducted } & & \\
\hline 12 & Replicate Test 6 & \multicolumn{2}{|r|}{ Not Conducted } & & \\
\hline 13 & 2 & $\mathrm{XPE}$ & Heptane; Center & Closed & Off \\
\hline 14 & 1 & XPE & $\begin{array}{l}\text { Heptane; } 1.8 \mathrm{~m} \text { from } \mathrm{N} \text { wall } \\
\text { on E-W centerline }\end{array}$ & Open & Off \\
\hline 15 & 1 & PVC & $\begin{array}{c}\text { Heptane } \\
1.25 \mathrm{~m} \text { from } \mathrm{S} \text { wall } \\
\text { on E-W centerline }\end{array}$ & Open & Off \\
\hline 16 & 2 & PVC & Heptane; Center & Closed & On \\
\hline 17 & 1 & PVC & Toluene, Center & Closed & Off \\
\hline 18 & 1 & XPE & $\begin{array}{c}\text { Heptane } \\
1.55 \mathrm{~m} \text { from } \mathrm{S} \text { wall } \\
1.50 \mathrm{~m} \text { E of centerline }\end{array}$ & Open & Off \\
\hline $\begin{array}{l}\text { 1. } X \\
\text { 2. } P \\
\text { 3. } H\end{array}$ & cling & hyle & $\begin{array}{l}\text { lation. } \\
\text { omers. }\end{array}$ & & \\
\hline
\end{tabular}


Table 2-2: Observations Noted during the Test Series.

\begin{tabular}{|c|c|c|c|}
\hline Test & Test Date & $\begin{array}{c}\text { Test } \\
\text { Order }\end{array}$ & Observations \\
\hline 1 & $6 / 5 / 03$ & 1 & No observations noted. \\
\hline 2 & 6/6/03 & 2 & No observations noted. \\
\hline 5 & 6/9/03 & 3 & $\begin{array}{l}\mathrm{N}_{2} \text { purge flow for soot laser was low for first } 5 \text { min after } \\
\text { ignition. } \\
\text { Slab E appeared melted after test. }\end{array}$ \\
\hline 4 & $6 / 10 / 03$ & 4 & Slab E not present. \\
\hline 3 & $6 / 10 / 03$ & 5 & Slab E not present. \\
\hline 8 & $6 / 11 / 03$ & 6 & $\begin{array}{l}\text { Slab E not present } \\
\text { Leakage around door during testing. } \\
\text { Cable burned at Ts-10 and Tc- } 11 \text { during test. }\end{array}$ \\
\hline 9 & $6 / 12 / 03$ & 7 & $\begin{array}{l}\text { Slab E not present. } \\
\text { Cable C appears charred after test. }\end{array}$ \\
\hline 13 & $6 / 12 / 03$ & 8 & Slab E not present. \\
\hline 14 & $6 / 13 / 03$ & 9 & $\begin{array}{l}\text { Wall flux gauges not functioning. } \\
\text { Slab E not present. } \\
\text { All cables melted during test. }\end{array}$ \\
\hline 18 & $6 / 16 / 03$ & 10 & $\begin{array}{l}\text { Smoke coming out of south wall-ceiling joint } 17 \text { min after } \\
\text { ignition. Doused with water at } 18 \text { min } 30 \mathrm{~s} \text {. } \\
\text { Flux Gauge } \# 8 \text { not functioning before test start. } \\
\text { Slab E not present. }\end{array}$ \\
\hline 7 & $6 / 18 / 03$ & 11 & $\begin{array}{l}\text { New PVC cables and slab E installed before test. } \\
\text { Biderectional Probes \#13 \& \#14 not functioning properly } \\
\text { before test start. }\end{array}$ \\
\hline 10 & $6 / 19 / 03$ & 12 & $\begin{array}{l}\text { Wall flux gauges (N6, S6, C4, C5, C8) not functioning before } \\
\text { test start. } \\
\text { Slab E and cables partially melted during test. }\end{array}$ \\
\hline 16 & $6 / 20 / 03$ & 13 & Flux Gauge \#8 not functioning before test start. \\
\hline 15 & $6 / 20 / 03$ & 14 & $\begin{array}{l}\text { Flux Gauge \#7 erratic behavior noticed } 730 \mathrm{~s} \text { after ignition. } \\
\text { vertical tray melted above } 2 \mathrm{~m} \text {. }\end{array}$ \\
\hline 17 & $6 / 27 / 03$ & 15 & $\begin{array}{l}\text { Fuel secured when loss of visibility completely obstructed the } \\
\text { fire. } \\
\text { Slab E not present. } \\
\text { Flux Gauge \#1 low water flow before test start. } \\
\text { Flux Gauge \#5 not working before test start. }\end{array}$ \\
\hline 6 & - & - & Not Conducted. \\
\hline 11 & - & - & Not Conducted. \\
\hline 12 & - & - & Not Conducted. \\
\hline
\end{tabular}


The compartment also contained the following:

- A ladder type cable tray (Target D) was $0.3 \mathrm{~m}(1.0 \mathrm{ft})$ wide and $0.1 \mathrm{~m}(0.3 \mathrm{ft})$ deep. The tray contained two layers of control cables constructed of XPE insulation and Hypalon jacket materials in the primary tests, and three layers of control cables constructed of PVC jacket and PVC/Nylon insulation materials in the replicate tests. The center of the bottom of the tray was located $2.0 \mathrm{~m}(6.6 \mathrm{ft})$ from the right wall, $3.2 \mathrm{~m}(10.5 \mathrm{ft})$ above the floor. It was 10.0 $\mathrm{m}$ (32.8 ft) long, extending from $5.85 \mathrm{~m}(19.2 \mathrm{ft})$ from the front wall to $5.85 \mathrm{~m}(19.2 \mathrm{ft})$ from the back wall.

- The bottom of the center of a rectangular slab target $(\mathrm{E})$ was located $1.25 \mathrm{~m}(4.10 \mathrm{ft})$ from the right wall, $2.7 \mathrm{~m}(8.9 \mathrm{ft})$ above the floor and centrally located between the front and back walls. The slab was composed of PVC and is detailed in Section 6 of this report.

- The bottom of the center of the power cable (F) was located $0.5 \mathrm{~m}(1.6 \mathrm{ft})$ from the right wall, $2.2 \mathrm{~m}(7.2 \mathrm{ft})$ above the floor and extended $10.0 \mathrm{~m}(32.8 \mathrm{ft})$, from $5.85 \mathrm{~m}(19.2 \mathrm{ft})$ from the front wall to $5.85 \mathrm{~m}(19.2 \mathrm{ft})$ from the back wall.

- The three control cables A, B and C were located at the same elevation and $0.1 \mathrm{~m}(0.3 \mathrm{ft})$ from the left edge of the power cable, slab target, and cable tray, respectively. They extended $10.0 \mathrm{~m}$ (32.8 ft), from $5.85 \mathrm{~m}(19.2 \mathrm{ft})$ from the front wall to $5.85 \mathrm{~m}(19.2 \mathrm{ft})$ from the back wall.

- The ladder type vertical cable tray $(\mathrm{G})$ was $0.3 \mathrm{~m}(1.0 \mathrm{ft})$ wide and $0.1 \mathrm{~m}(0.3 \mathrm{ft})$ deep. The tray contained one layer of control cables constructed of XPE (polyethylene) insulation and Hypalon jacket materials in the primary tests, and PVC (polyvinyl chloride) jacket and PVC/Nylon insulation materials in the replicate tests. The tray was located on the surface at the center of the north wall, extending from the floor to the ceiling.

- The junction box was a WCB Junction Box. It was heavy-duty, dust-tight, weatherproof, rain and watertight, with nominal inside dimensions, $30 \mathrm{~cm}$ length $\mathrm{x} 30 \mathrm{~cm}$ width $\mathrm{x} 10 \mathrm{~cm}$ depth $(1.0 \mathrm{ft} \times 1.0 \mathrm{ft} \times 0.3 \mathrm{ft})$. It had an approximate wall thickness of $0.7 \mathrm{~cm}(0.3 \mathrm{in})$. The junction box was mounted on the ceiling and located on the compartment centerline, with its center $17.7 \mathrm{~m}(58.1 \mathrm{ft})$ from the door. The box was made of Feraloy (see Appendix A for thermophysical properties and Appendix $\mathrm{H}$ for a more complete description).

\subsection{Compartment Openings and Ventilation}

A $2.00 \mathrm{~m}$ by $2.00 \mathrm{~m}$ (6.56 ft x $6.56 \mathrm{ft}$ ) door was present in the middle of the west wall (see Figure 2-2). The compartment was equipped with supply and exhaust forced ventilation, which was used during Tests 4, 5, 10, and 16, providing about 5 air changes per hour. The midpoint of the supply and exhaust vents was located $11.22 \mathrm{~m}$ (36.80 ft) from the door and $2.40 \mathrm{~m}(7.87 \mathrm{ft}$ ) above the floor. An exhaust duct of equal area to the supply duct was positioned on the opposite wall at a comparable location. The vents were square $(0.70 \mathrm{~m} \times 0.70 \mathrm{~m}$, or $2.3 \mathrm{ft} \times 2.3 \mathrm{ft})$ with an area of $0.50 \mathrm{~m}^{2}\left(5.4 \mathrm{ft}^{2}\right)$ each. The flow rates through the supply and exhaust ducts were measured in detail during breaks in the testing, in the absence of a fire and are discussed in detail in Section 7 of this report. During the tests, the flows were monitored with single bi-directional probes positioned in the ducts. 


\subsection{Fuel Delivery System and Fire}

The fuel system consisted of a fuel storage container and a Tuthill ${ }^{\circledR}$ sealless magnetic drive positive displacement gear pump. The pump was controlled by an alternating current (AC) Tech variable frequency driver. Fuel was delivered through one BETE ${ }^{\circledR}$ spray nozzle oriented downwards towards a $1.0 \mathrm{~m}$ by $2.0 \mathrm{~m}$ (3.3 ft by $6.6 \mathrm{ft}$ ) stainless steel pan positioned on the floor. A $90^{\circ}$ spray angle WL $3 / 4$ type nozzle was used for the $350 \mathrm{~kW}$ fire, and a similar angle WL-1 type nozzle was used for the larger fires. The fire pan was located at the center of the compartment for most of the tests (Tests 1 - 13, 16, and 17). In Test 14, the fire was centered 1.8 $\mathrm{m}(5.9 \mathrm{ft})$ from the North wall. In Test 15 , the fire was centered $1.25 \mathrm{~m}(4.10 \mathrm{ft})$ from the South wall. In Test 18, the fire was centered $1.55 \mathrm{~m}(5.09 \mathrm{ft})$ from the South wall. Physically, the fuel pan was $2.0 \mathrm{~m}(6.6 \mathrm{ft})$ long $x 1.0 \mathrm{~m}(3.3 \mathrm{ft})$ wide and $0.1 \mathrm{~m}(0.3 \mathrm{ft})$ deep. A single nozzle was used to spray liquid hydrocarbon fuels onto the pan. The test plan originally called for the use of two nozzles to provide the fuel spray. Experimental observation suggested that the fire was steadier with the use of a single nozzle. In addition, it was observed that the actual extent of the liquid pool was well-approximated by a $1.0 \mathrm{~m}$ ( $3.3 \mathrm{ft})$ circle about the center of the pan. The uncertainty in the location of the liquid fuel was about $\pm 0.1 \mathrm{~m}( \pm 0.3 \mathrm{ft})$.

\subsection{Background Documentation}

A number of previous documents have provided information on the values of the fuel flow, measured fuel flow rates, supply and exhaust ventilation flows, ambient conditions, and compartment leakage needed to fully specify the boundary conditions for implementation of fire models. Much of that information is presented here for the sake of comprehensiveness.

Knowledge of the optical and thermal properties of the "marinite" (calcium silicate) board, which composed the enclosure wall and ceiling material, is needed to fully document the experimental boundary conditions. Thermal property information including temperature dependent information on the specific heat $\left(c_{p}\right)$, the thermal diffusivity $(\alpha)$, and the thermal conductivity (K) of the marinite was determined using ASTM E1269 and ASTM E1461 [Taylor et al., 2003] and are listed in Appendix A.

The spectrally integrated value of the emissivity $(\varepsilon)$ for marinite is given in Appendix A. Analogous property information for the PVC and XPE cable jacket materials are also given in Appendix A. Material and Optical Properties of Feraloy, which composed a junction box located on the ceiling (see Figure 2-2), and gypsum, which comprised the compartment floor, are given in Appendix A. 


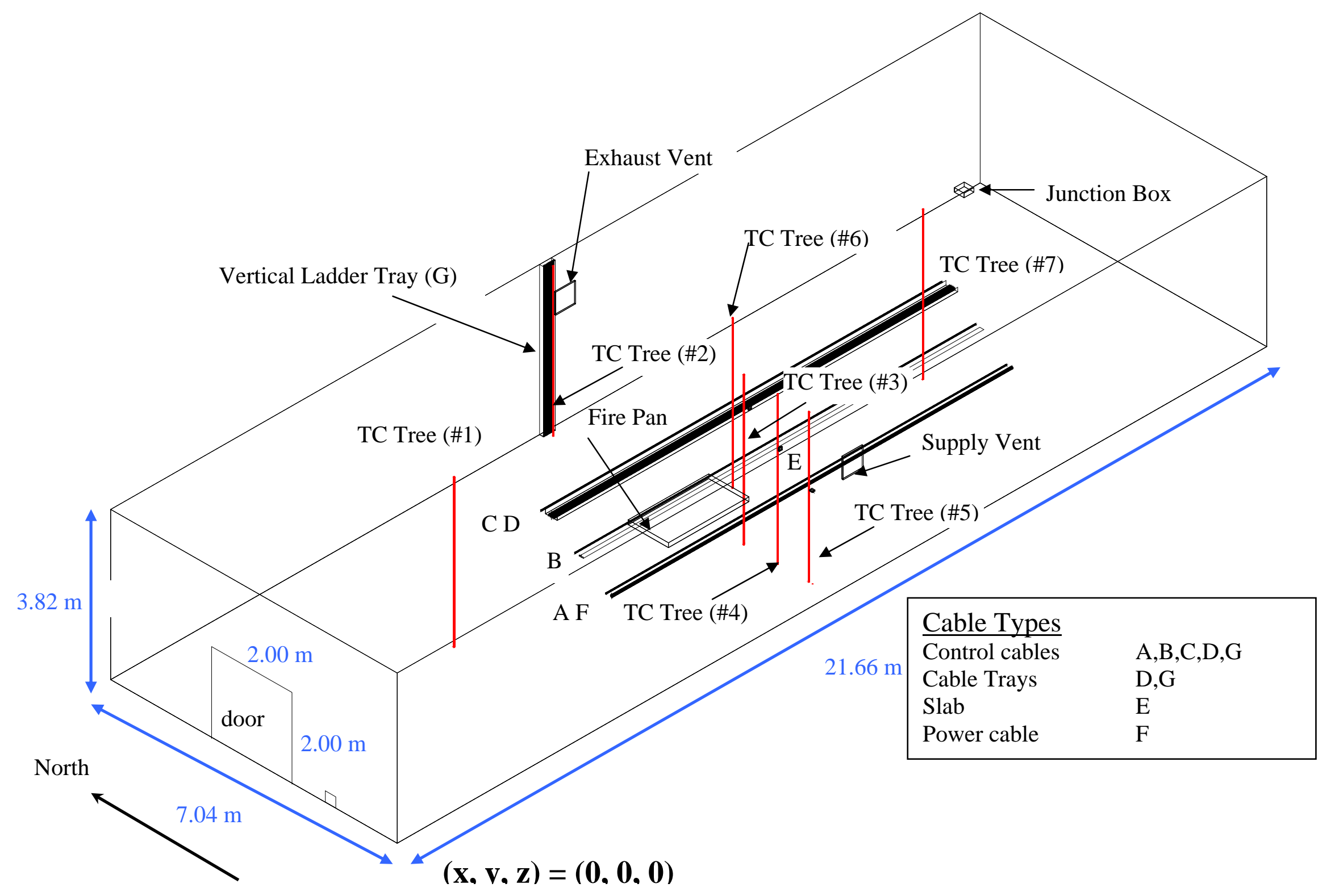

Figure 2-2: Compartment Isometric with thermocouple trees. 


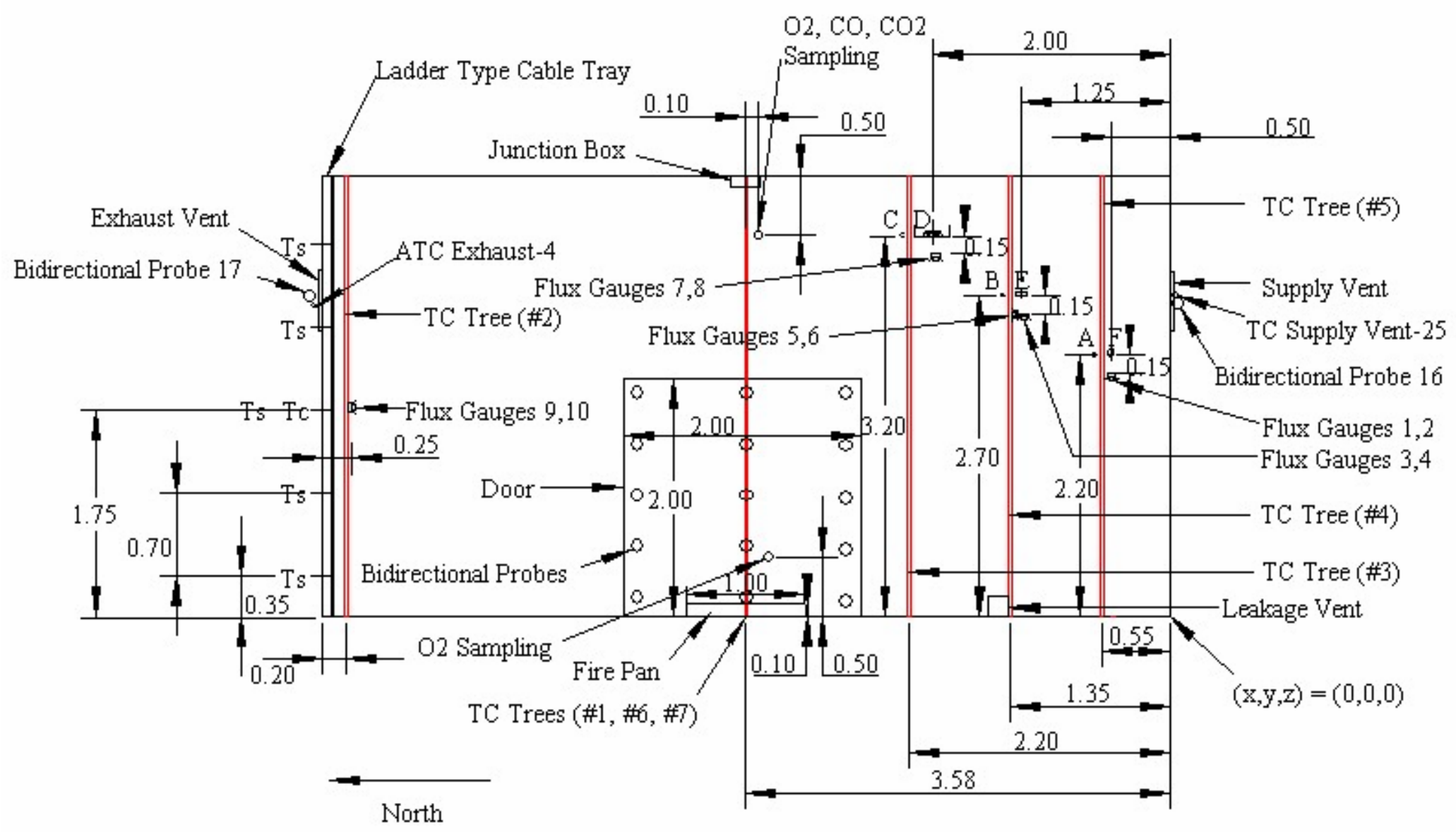

Figure 2-3: Compartment Contents and Selected Instrumentation 


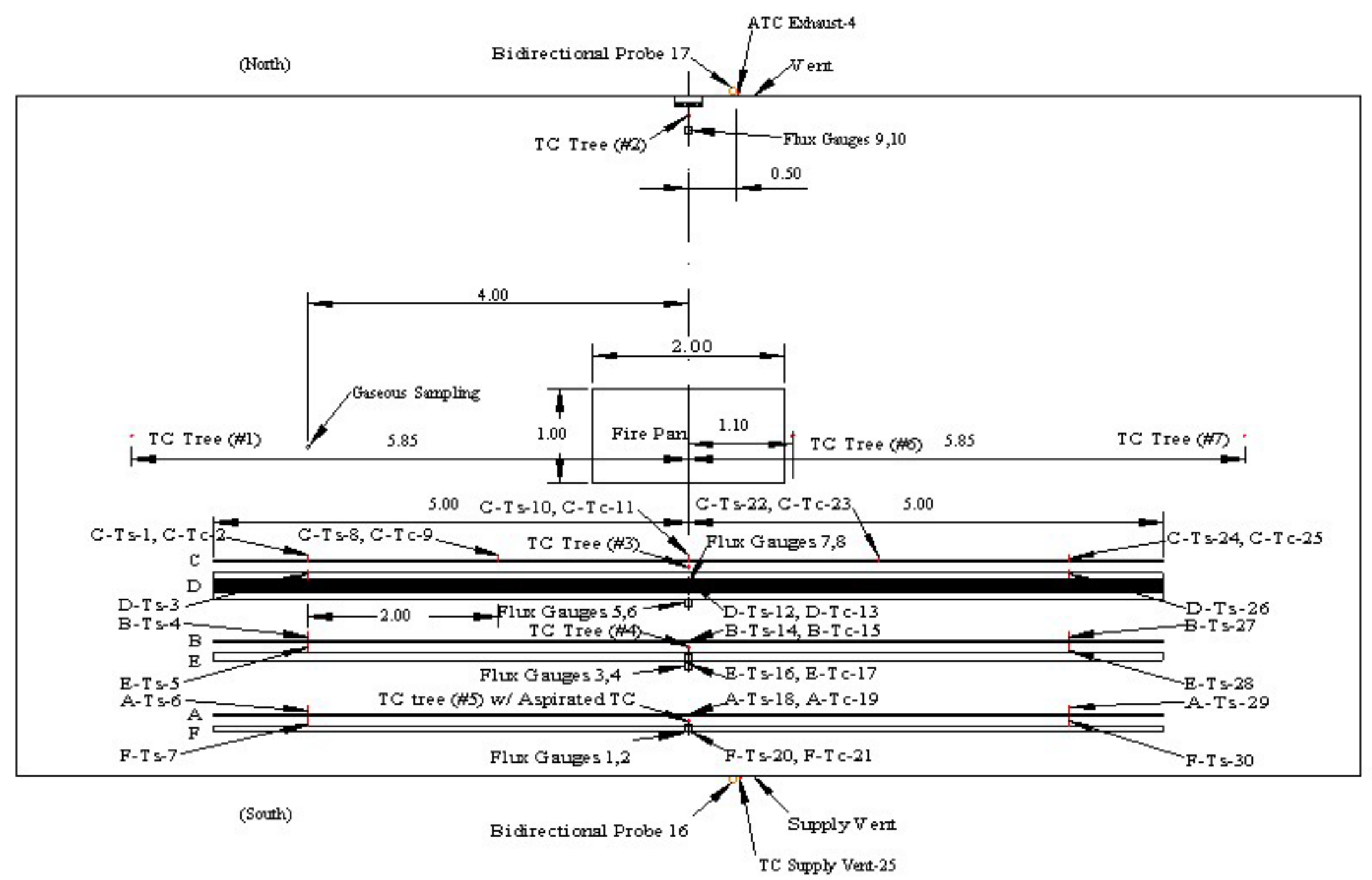

Figure 2-4: Plan View of Compartment Mid-Section 



\section{HEAT RELEASE RATE}

The total HRR is the most critical parameter that characterizes a fire. The HRR drives the thermal environment including the radiative and convective heat transfer, the hydrodynamic flow, the rate of fire spread and growth, the amount of smoke and toxic products, and ultimately, the hazard associated with a fire.

In this report, the HRR was measured two different ways. For all of the tests, it was estimated from the fuel flow. For the open door tests (Tests 3, 5, 9, 14, 15, and 18), it was measured using oxygen consumption calorimetry. As another consistency check, measurements of the convective and conductive heat losses from the compartment for one test (Test 3) were used to estimate the fire HRR.

\subsection{Heat Release Rate Based on the Fuel Flow}

The fuel system was designed to deliver a controlled amount of liquid fuel in the form of a spray. Table 3-2 includes the target fuel flow for each experiment, which was calibrated at ambient temperature. The fuel used in all but one of the tests was a commercially available blend of heptane isomers. In Test 17, toluene was used. A nominal HRR of $1 \mathrm{MW}$ was the target for all tests, except Tests 1 and 7 (350 kW), and Tests 13 and 16 (2 MW).

The fuel system has been previously described in detail [Hamins et al., 2003a; 2003b]. Typically, the transient fuel flow was composed of a nominal 3 min linear ramp-up from zero to a long steady burning period, followed by a 3 min linear ramp-down to zero flow. The exact duration of each of the periods is listed in Table 3-1.

The HRR $\left(\dot{Q}_{f}\right)$ shown in Table 3-2 was estimated as the product of the mass flow rate of fuel $(\dot{m})$, the heat of combustion of the fuel $\left(\mathrm{H}_{\mathrm{c}}\right)$, and the fuel combustion efficiency $\left(\chi_{\mathrm{a}}\right)$ :

$$
\dot{Q}_{f}=\chi_{\mathrm{a}} \cdot \dot{m} \cdot \mathrm{H}_{\mathrm{c}}
$$

Information on the global combustion properties of the hydrocarbon fuels tested here (including the heptane and the blend of commercially available heptane and toluene) were determined from a separate series of experiments, which measured the combustion efficiency, radiative fraction, and the yields of soot, $\mathrm{CO}$ and $\mathrm{CO}_{2}$ from a downward-oriented spray fire burning in a similar configuration to that used here, with the fire burning in the open [Hamins et al., 2003b]. For convenience, those results are summarized in Table 3-3. The heats of combustion of the test fuels are also listed in Table 3-3.

The uncertainty in $\dot{Q}_{f}$ (see Table 3-2) was dominated by the uncertainty in $\chi_{\mathrm{a}}$, and to a lesser extent by uncertainties associated with $\dot{m}$ and $\mathrm{H}_{\mathrm{c}}$. The uncertainty in $\chi_{\mathrm{a}}$ was described in detail 
in Hamins et al. [2003b]. It was assumed that $\chi_{a}$ was the same in the compartment fires as in the open burn calibration experiments. The uncertainties in this report, unless otherwise stated, are expressed as the expanded relative uncertainty with an expansion factor equal to two (i.e., $2 \cdot \sigma$, where $\sigma$ is the standard deviation), which represents a $95 \%$ confidence interval.

The mass flow rate of fuel is equal to the product of the measured volumetric flow rate of fuel $(\dot{V})$ and the fuel density $(\rho)$ :

$$
\dot{m}=\rho \cdot \dot{V}
$$

The estimated HRR assumes that the combustion efficiency in the compartment was the same as that measured during the free burn experiments, which were in the open. The fuel density $(\rho)$ for heptane and toluene was $688.5 \pm 0.4 \mathrm{~kg} / \mathrm{m}^{3}\left(43.00 \pm 0.02 \mathrm{lb} / \mathrm{ft}^{3}\right)$ and $871.2 \pm 0.5 \mathrm{~kg} / \mathrm{m}^{3}(54.40 \pm$ $\left.0.03 \mathrm{lb} / \mathrm{ft}^{3}\right)$, respectively [Hamins et al., 2003b]. The fuel flow $(\dot{V})$ was calibrated at ambient temperature before each experiment. An experiment was conducted at the end of the test series to determine the effect of compartment heat-up on the fuel flow rate. Appendix I describes the experimental procedure and results. The results showed that the fuel flow during the steady burning period of the experiment was larger, by a factor of about 1.09, than the fuel flow calibrated at ambient temperature. The correction factor was applied to the HRR estimated from the ambient temperature fuel flow calibration, and the corrected HRR is shown in Table 3-2. 
Table 3-1: Duration of the Fuel Flow ${ }^{1}$

\begin{tabular}{|c|c|c|c|c|}
\hline Test & $\begin{array}{l}\text { Ramp-Up } \\
\text { (min:sec) }\end{array}$ & $\begin{array}{c}\text { Steady State } \\
\text { Duration (min:sec) }\end{array}$ & $\begin{array}{c}\text { Ramp-Down } \\
\text { (min:sec) }\end{array}$ & $\begin{array}{c}\text { Total Duration } \\
\text { (min:sec) }\end{array}$ \\
\hline $1^{4}$ & $2: 28$ & $20: 02$ & $2: 30$ & $25: 00$ \\
\hline 2 & $3: 00$ & $7: 25$ & $0: 01$ & $10: 25^{2}$ \\
\hline 3 & $2: 58$ & 20:01 & $3: 03^{5}$ & $26: 03$ \\
\hline 4 & $2: 58$ & $10: 36$ & $0: 01$ & $13: 35^{2}$ \\
\hline 5 & $2: 58$ & $20: 01$ & $3: 03^{5}$ & $26: 03$ \\
\hline 7 & 2:09 & $20: 03$ & $2: 08$ & $24: 20$ \\
\hline 8 & $2: 56$ & $7: 14$ & $0: 01$ & $10: 13^{2}$ \\
\hline 9 & $2: 55$ & $20: 01$ & $3: 04^{5}$ & $26: 06$ \\
\hline 10 & $2: 56$ & $10: 50$ & $0: 01$ & $13: 47^{2}$ \\
\hline 13 & $2: 57$ & 3:07 & $0: 01$ & $6: 05^{2}$ \\
\hline 14 & $2: 56$ & $20: 05$ & $3: 06^{5}$ & $26: 07$ \\
\hline 15 & $3: 00$ & $20: 00$ & $3: 07^{5}$ & $26: 07$ \\
\hline 16 & $2: 57$ & $3: 25$ & $0: 01$ & $6: 23^{2}$ \\
\hline 17 & $3: 01$ & $1: 31$ & $0: 01$ & $4: 33^{3}$ \\
\hline 18 & $2: 58$ & 20:02 & $3: 07^{5}$ & $26: 07$ \\
\hline \multicolumn{5}{|c|}{$\begin{array}{l}\text { 1. The temporal measurement uncertainty estimated as } \pm 2 \mathrm{~s} \text {. } \\
\text { 2. The test was abruptly stopped when the oxygen concentration measurement in the lower layer was } \\
\text { less than or equal to } 15 \% \text {. } \\
\text { 3. The fuel flow was stopped after } 273 \mathrm{~s} \text { for safety reasons when loss of visibility completely } \\
\text { obstructed the fire. } \\
4 \text {. There was no ramp-down for the tests with the door closed, except Test } 1 \text {, as the fuel flow was } \\
\text { rapidly shut for safety reasons when the measured oxygen concentration in the lower layer of the } \\
\text { compartment was measured to be less than } 15 \% \text { by volume (on a dry basis). } \\
5 \text {. Fuel dripping from the nozzle sometimes added as much } 2 \mathrm{~s} \text { to } 7 \mathrm{~s} \text { to the duration of the ramp- } \\
\text { down, but the fire size during that period was typically very small (less than } 10 \mathrm{~kW} \text { ). }\end{array}$} \\
\hline
\end{tabular}


Table 3-2: The Ambient Temperature Fuel Flow Calibration, Associated HRR, and its value Corrected for Compartment Effects.

\begin{tabular}{|c|c|c|c|c|}
\hline Test & Fuel & Fuel Flow $(\mathrm{ml} / \mathrm{min})^{1}$ & $\dot{Q}_{f}(\mathrm{~kW})^{2}$ & $\begin{array}{l}\text { Corrected } \\
\dot{Q}_{f}(\mathrm{~kW})^{3}\end{array}$ \\
\hline 1 & Heptane & 697 & 360 & 390 \\
\hline 2 & Heptane & 2020 & 1040 & 1130 \\
\hline 3 & Heptane & 2040 & 1050 & 1140 \\
\hline 4 & Heptane & 2040 & 1050 & 1140 \\
\hline 5 & Heptane & 2040 & 1050 & 1140 \\
\hline 7 & Heptane & 676 & 350 & 380 \\
\hline 8 & Heptane & 2020 & 1040 & 1130 \\
\hline 9 & Heptane & 1990 & 1030 & 1120 \\
\hline 10 & Heptane & 2010 & 1040 & 1130 \\
\hline 13 & Heptane & 3950 & 2040 & 2220 \\
\hline 14 & Heptane & 2010 & 1040 & 1130 \\
\hline 15 & Heptane & 2010 & 1040 & 1130 \\
\hline 16 & Heptane & 3910 & 2020 & 2200 \\
\hline 17 & Toluene & 2200 & 1020 & 1110 \\
\hline 18 & Heptane & 2010 & 1040 & 1130 \\
\hline
\end{tabular}

Table 3-3: Combustion Properties of the Test Fuels ${ }^{1}$

\begin{tabular}{|c|c|c|c|c|c|c|}
\hline Fuel & $\mathrm{H}_{\mathrm{c}}(\mathrm{kJ} / \mathrm{g})^{2}$ & $\begin{array}{l}\text { Combustion } \\
\text { efficiency }^{3}\end{array}$ & $\begin{array}{l}\text { Radiative } \\
\text { fraction }^{3}\end{array}$ & Soot yield $^{3}$ & CO yield ${ }^{3}$ & $\mathrm{CO}_{2}$ yield $^{3}$ \\
\hline Heptane & 45.0 & $1.0 \pm_{0.14}^{0} 4$ & $0.44 \pm 0.07$ & $0.0149 \pm .0033$ & $<0.008$ & $3.03 \pm 0.12$ \\
\hline Toluene & 40.3 & $0.76 \pm 0.10$ & $0.40 \pm 0.09$ & $0.195 \pm 0.052$ & $0.070 \pm 0.017$ & $2.52 \pm 0.22$ \\
\hline \multicolumn{7}{|c|}{$\begin{array}{l}\text { 1. Reproduced from Hamins et al. [2003b]. } \\
\text { 2. The expanded relative uncertainty is typically } 5 \% \text { [Hamins et al., 2003b]. } \\
\text { 3. Hamins et al., 2003b. } \\
\text { 4. Physically, the combustion efficiency, } \chi_{\mathrm{a}} \leq 1 \text {, so that the uncertainty estimate is not symmetric. The } \\
\text { measurement uncertainty of } \chi_{\mathrm{a}} \text { is dominated by uncertainty in the radiative flux, the mass burning rate }(\dot{m}) \text {, and } \\
\mathrm{H}_{\mathrm{c}} \text {. }\end{array}$} \\
\hline
\end{tabular}




\subsection{Heat Release Rate Based on Oxygen Consumption Calorimetry}

The HRR $(\dot{Q})$ was measured using oxygen consumption calorimetry in the $9.0 \mathrm{~m}$ by $12.0 \mathrm{~m}$ (29 $\mathrm{ft}$ by $39 \mathrm{ft}$ ) exhaust hood in the NIST Large Fire Laboratory. The west side of the compartment included a door, which was located adjacent to one edge of the exhaust hood. When the compartment door was open, the products of combustion from the fire filled the upper layer of the compartment and then flowed out of the door, where they were completely captured by the exhaust hood. Measurements of the duct mass flow rate and the concentration of various gas species were used to infer the HRR of the fire. This form of fire calorimetry was first suggested by Huggett [1980], who exploited the finding that the amount of heat evolved from most organic materials per unit mass of oxygen consumed in their complete combustion is nearly constant. Thus, the oxygen deficit in the duct flow (relative to ambient air) is a measure of the HRR in the flow. Huggett showed that for most common materials containing $\mathrm{C}, \mathrm{H}, \mathrm{O}, \mathrm{N}$, the heat release per unit mass of oxygen is constant to within $\pm 5 \%$; this sets a fundamental accuracy limit in this method for materials that are not chemically characterized. For fuels that are characterized, such as those used in the experiments described here, this parameter can be estimated with greater accuracy. The value of the heat of combustion per mass of oxygen consumed, which was used in the calorimetry measurements, is described in Hamins et al. [2003b].

\subsubsection{Measurement Approach}

Bryant et al. [2003] describe the heat release measurement facility, instrumentation, calibration, measurement uncertainty and experimental procedures in detail. The calorimetry determination required about 40 measurements. Some of the instruments employed in the HRR measurement are listed in Table 3-4. Measurements of temperature and pressure occurred in the exhaust duct. Gas was sampled in the exhaust duct and transported to the instruments in a control room for measurements of oxygen, carbon dioxide, and carbon monoxide. Water vapor in the exhaust stream was trapped, and not measured. The relative humidity in the test bay area was measured. The computation of HRR $(\dot{Q})$ was made following Bryant et al. [2003; 2004]. The relationship that describes the HRR determination [Bryant et al, 2004]) is reproduced here:

$$
\begin{aligned}
& \dot{Q}=\left[E_{H C} \phi-\left(E_{C O}-E_{H C}\right) \frac{1-\phi}{2} \frac{X_{C O}}{X_{O 2}}\right] \frac{\dot{m}_{e}}{1+\phi(\alpha-1)}\left[\frac{\left(1-X_{H 2 O}^{o}\right) M_{O 2}}{M_{a i r}}\right] X_{O 2}^{o} \\
& \text { with } \\
& \phi=\frac{X_{O 2}^{o}\left(1-X_{C O 2}-X_{C O}\right)-X_{O 2}\left(1-X_{C O 2}^{o}\right)}{\left(1-X_{O 2}-X_{C O 2}-X_{C O}\right) X_{O 2}^{o}}
\end{aligned}
$$

$E_{H C}=$ heat of combustion of hydrocarbon fuel

$E_{C O}=$ heat of combustion of carbon monoxide

$\phi=$ oxygen depletion factor

$\dot{m}_{e}=$ mass flow rate in exhaust duct

$\dot{m}_{\text {air }}=$ mass flow rate of air 

$\alpha=$ combustion products expansion factor
$M_{i}=$ molecular weight of species i
$X_{i}=$ exhaust-gas concentration measurement of species i
$X_{i}^{o}=$ ambient-gas concentration measurement of species i

Bryant et al. [2003; 2004] discuss the above equation, the calibration procedures, and the methods used to determine the HRR and its uncertainty for calorimetry in the NIST $6 \mathrm{~m}$ by $6 \mathrm{~m}$ (20 ft by $20 \mathrm{ft}$ ) exhaust hood. The instrumentation and uncertainty analysis is analogous to Bryant et al. [2003; 2004] for calorimetry in the $9.0 \mathrm{~m}$ by $12.0 \mathrm{~m}$ hood (29 ft by $39 \mathrm{ft}$ ), which was used here. The largest contribution to the measurement uncertainty is due to the determination of the mass flow in the exhaust duct [Bryant et al., 2004]. Parker [1982] and Janssens and Parker [1995] discuss the details of the HRR calculation based on the extent to which the duct gas flow is characterized.

Table 3-4: Instruments for the 9 m x 12 m NIST Calorimeter System.

\begin{tabular}{|l|l|l|l|}
\hline \multicolumn{1}{|c|}{$\begin{array}{c}\text { Parameter } \\
\text { Measured }\end{array}$} & \multicolumn{1}{|c|}{ Instrument Type } & \multicolumn{1}{c|}{$\begin{array}{c}\text { Make and } \\
\text { Model }\end{array}$} & \multicolumn{1}{c|}{ Ranges } \\
\hline Oxygen & Paramagnetic & Servomex 540A & $0-21 \% \mathrm{v} / \mathrm{v}$ \\
\hline Carbon Dioxide & Infrared extinction & Siemens Ultramat 5E & $0-5 \%$ \\
\hline Carbon Monoxide & Infrared extinction & Siemens Ultramat 5E & $0-3 \%$ \\
\hline Relative Humidity & $\begin{array}{l}\text { Thin film } \\
\text { capacitance }\end{array}$ & Dickson THDx & $0-95 \%$ \\
\hline Temperature & Thermocouple & Omega K-type & $0-1250{ }^{\circ} \mathrm{C}$ \\
\hline Exhaust Velocity & Bi-directional probe & $\begin{array}{l}\text { MKS model 220 differential } \\
\text { pressure transducer }\end{array}$ & $0-10 \mathrm{~Pa}$ \\
\hline
\end{tabular}

\subsubsection{Calibration and Measurement Uncertainty}

Calibration burns using natural gas were conducted on several occasions during the test series to assure the accuracy of the HRR measurement $(\dot{Q})$ and to characterize its repeatability. Burning a substance such as a gaseous fuel at a controlled rate provides an independent measurement of HRR to compare to the measurement by oxygen consumption calorimetry. A natural gas burner with active flow control was employed [Bryant et al., 2003].

Calibration experiments were performed before Tests 3, 5, and 18. The burner was placed directly under the $9.0 \mathrm{~m}$ by $12.0 \mathrm{~m}$ (29 ft by $39 \mathrm{ft}$ ) exhaust hood. Figure 3-1 shows the calorimetry during the calibration immediately before and during Test 5 . In the figure, Test 5 began at time equal to zero $(\mathrm{t}=0)$, while the calibration was conducted before the experiment for $t<0$. The flow of natural gas to the burner was turned off during the experiment. The HRR expected from the natural gas burner was based on measurements of the mass flow of natural gas [Bryant et al., 2003; 2004] and Equations 3.1 and 3.2. During the calibration, the heat output of the burner was held constant for $2 \mathrm{~min}$ to $5 \mathrm{~min}$ at each setting. The expanded uncertainty of the natural gas HRR was estimated as $2 \%$, which was dominated by uncertainty in the caloric value 
of the natural gas. The caloric value varied by approximately $1.3 \%$ over a six-month period, as determined by examination of gas chromatographic concentration measurements provided by the natural gas supplier, the Washington Gas Company [Bundy, 2005].

The results of the calibration are summarized in Table 3-5, which lists $\dot{Q}_{f}$ estimated from the flow of natural gas, the calorimetric measurement $(\dot{Q})$, the background associated with the calorimetry, and the ratio of $\dot{Q}$ from the calorimetry to that expected from the natural gas flow, $\dot{Q}_{f}$. The calorimetric HRR measurements were corrected for baseline drift (see Table 3-5), which was likely due to the instability of the oxygen analyzer. For example, note that the value of $\dot{Q}$ in Figure 3-1 at $\mathrm{t}=-2000 \mathrm{~s}$ and at $\mathrm{t}=-500 \mathrm{~s}$ have different values. Table $3-5$ lists the estimated value of the changing baseline for each of the calibration settings. Table 3-5 also shows that the ratio of the calorimetry $\dot{Q}$ (with background corrected) to $\dot{Q}_{f}$ of the natural gas flow varied from 1.04 to 1.18 , with an average value of 1.11 and an estimated relative combined uncertainty of $15 \%$.

In Table 3-5, the measured $\dot{Q}$ was consistently higher than the expected HRR $\left(\dot{Q}_{f}\right)$ based on the natural gas mass flow rate by about $11 \%$. For this reason, the calorimetry results were reduced by a factor of 1.11. The reasons for the difference are not certain, but may be due at least in part to the nature of the flow field in the $9.0 \mathrm{~m}$ by $12.0 \mathrm{~m}$ exhaust hood ( $29 \mathrm{ft}$ by $39 \mathrm{ft}$ ), in which the velocity profile does not correspond to fully developed pipe flow at the downstream measurement station. 


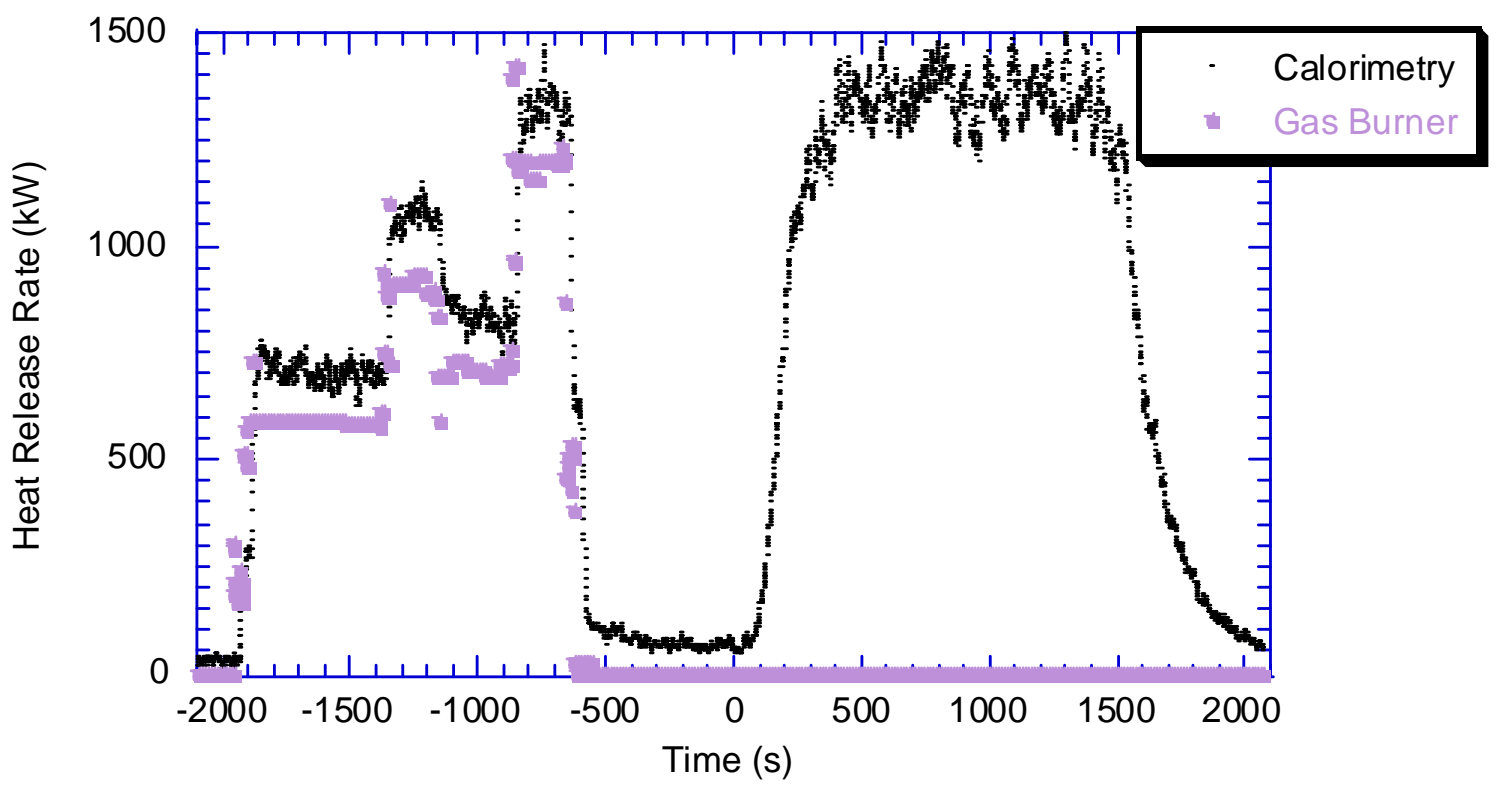

Figure 3-1: The calorimetric HRR data as a function of time during the calibration before Test $5($ time $<0)$ and during Test 5 (time $>0)$.

\subsubsection{Calorimetry Measurement Results}

Figure 3-2 shows the results of the oxygen depletion calorimetry measurement $(\dot{Q})$ for the open door tests (Tests 3, 5, 9, 14, 15, and 18) as a function of time after ignition. The results show that the experiments were repeatable. The values of $\dot{Q}$ were similar for all of the tests, except Test 5, which unlike the other tests had mechanical ventilation in addition to an open door. As expected, less of a delay in the HRR measurement occurred in the ramp-up during Test 5 , as the ventilation exhaust was directly pulled from the compartment, rather than from the exhaust in the $9.0 \mathrm{~m}$ by $12.0 \mathrm{~m}$ hood ( $29 \mathrm{ft}$ by $39 \mathrm{ft}$ ), so that the mixing and delay associated with combustion products filling the upper layer of the compartment occurred over a different time-scale. The larger value of the HRR during the ramp-down is also evident. 
Table 3-5: Summary of the calorimetry calibration results.

\begin{tabular}{|c|c|c|c|c|}
\hline \multirow{2}{*}{ Test } & \multirow{2}{*}{$\begin{array}{l}\dot{Q}_{f}(\mathbf{k W}) \\
\text { Gas Burner }^{1}\end{array}$} & \multicolumn{2}{|c|}{ Calorimetry } & \multirow{2}{*}{$\begin{array}{l}\text { Ratio }^{3} \\
\text { (Calorimetry/ Burner) }\end{array}$} \\
\hline & & $\dot{Q}(\mathbf{k} \mathbf{W})^{2}$ & Background (kW) & \\
\hline Test 3 & $\begin{array}{l}741 \\
505 \\
932\end{array}$ & $\begin{array}{l}769 \\
533 \\
983\end{array}$ & $\begin{array}{l}-70 \\
-40 \\
-50\end{array}$ & $\begin{array}{l}1.13 \\
1.13 \\
1.11\end{array}$ \\
\hline Test 5 & $\begin{array}{l}1190 \\
915 \\
714 \\
590\end{array}$ & $\begin{array}{l}1310 \\
1070 \\
831 \\
701\end{array}$ & $\begin{array}{l}70 \\
40 \\
45 \\
32\end{array}$ & $\begin{array}{l}1.04 \\
1.13 \\
1.10 \\
1.13\end{array}$ \\
\hline Test 18 & $\begin{array}{l}1190 \\
978 \\
565\end{array}$ & $\begin{array}{l}1300 \\
1130 \\
659\end{array}$ & $\begin{array}{l}10 \\
50 \\
-10\end{array}$ & $\begin{array}{l}1.08 \\
1.10 \\
1.18\end{array}$ \\
\hline Mean & - & - & - & 1.11 \\
\hline
\end{tabular}

The time-averaged values of $\dot{Q}$ during the steady burn period of the open door tests are listed in Table 3-6. It is of interest to compare this value (1190 kW $\pm 15 \%)$ to the mean of the corrected $\dot{Q}_{f}$ for the same six tests $(1130 \mathrm{~kW} \pm 10 \%)$, which are listed in Table 3-2. The mean values were not significantly different when uncertainty is considered.

Calorimetric measurements were not conducted during Tests 1, 2, 7, 8, 13, and 17, because both the ventilation and the door were closed (see Table 2-1). Calorimetry was conducted during Tests 4,10 , and 16, by making measurements of the ventilation exhaust flow. In those experiments, the door was closed, but the ventilation was on. The calorimetric measurements conducted during Tests 4, 10, and 16 are not considered an accurate representation of the transient fire HRR, $\dot{Q}$. For typical experiments that measure the exhaust products of a fire burning in the open, oxygen depletion calorimetry can be thought of as a measure of the fire HRR with a measurement response time on the order of $15 \mathrm{~s}$, which is principally limited by the oxygen analyzer time response [Bryant et al., 2003]. For the compartment experiments considered here, combustion products accumulated in the upper layer of the compartment, and the layer interface lowered until the products flowed, either through the open door as in Test 3, or through the ventilation exhaust duct as in Test 4. In either case, the volume of the test chamber affected the measurement of the fire HRR, as filling and mixing caused a timeaveraging and a delay in the calorimetry results. For the experiments with mechanical ventilation (Tests 4, 10, and 16), details of the mixing were unknown, and the calorimetric measurements should not be considered representative of the fire HRR. 


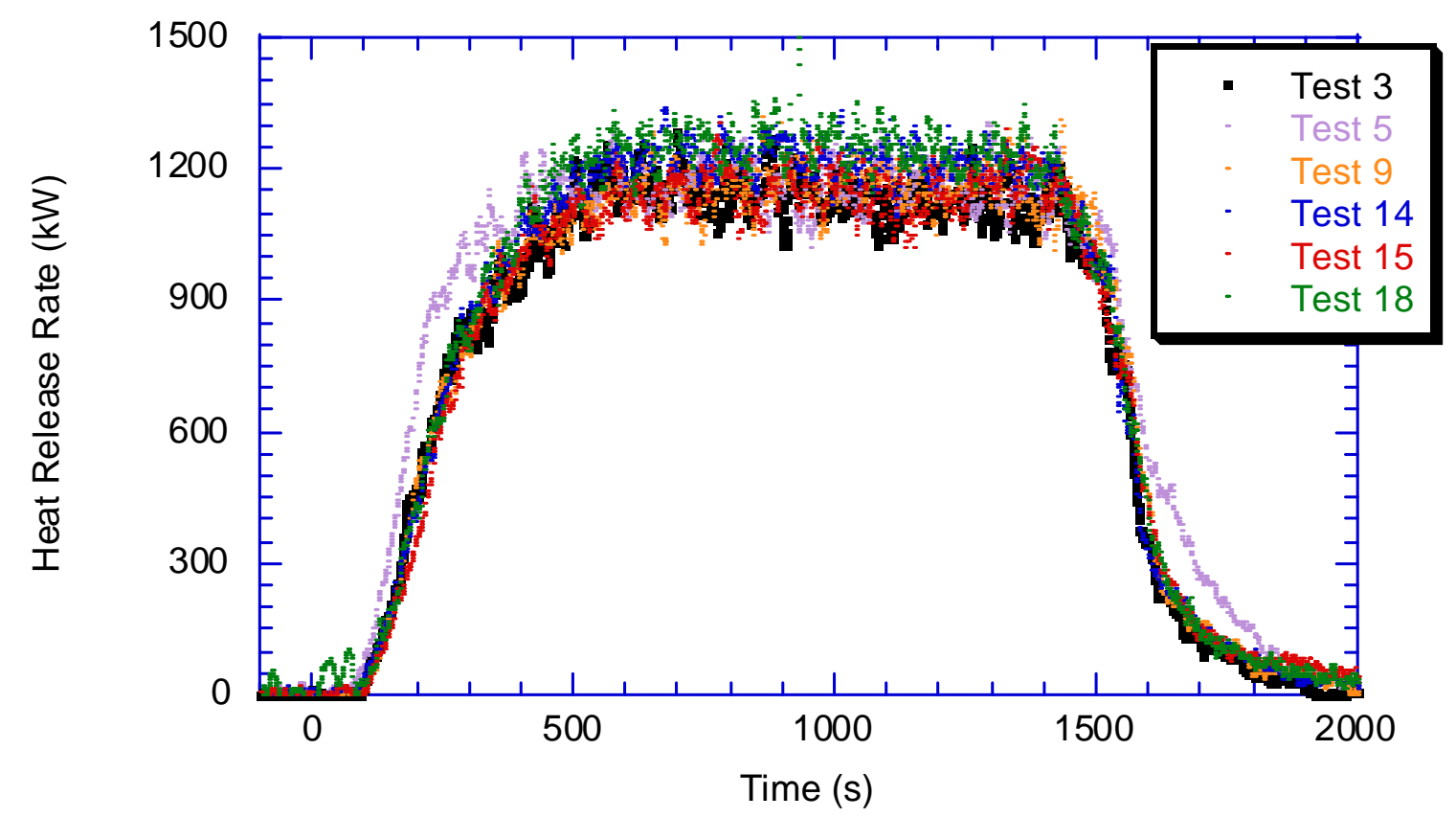

Figure 3-2: The calorimetric HRR during the open door experiments (Tests 3, 5, 9, 14, 15, and 18) as a function of time.

Table 3-6: Average value of the steady-state HRR.

\begin{tabular}{|l|c|}
\hline Test & Average $\dot{Q} \mathbf{( k W )}$ during steady burning \\
\hline Test 3 & 1140 \\
\hline Test 5 & 1160 \\
\hline Test 9 & 1160 \\
\hline Test 14 & 1230 \\
\hline Test 15 & 1260 \\
\hline Test 18 & 1150 \\
\hline \hline Mean & 1190 \\
\hline
\end{tabular}

1. The average value for each test was determined from the data in Figure 3-2, during the steady burning period from $600 \mathrm{~s}$ to $1400 \mathrm{~s}$; the combined relative expanded uncertainty is estimated as $\pm 15 \%$.

To highlight the character of the calorimetry results, Figure 3-3 compares the measured HRR $(\dot{Q})$ during Tests 3 and 5 . The nature of the HRR profiles is very similar for these two tests. In Test 3, a steady $\dot{Q}$ was observed after approximately 500 s. The delay is attributed to filling of 
the large volume of the test compartment. The $\dot{Q}$ in Test 4 was similar to that of Test 3 for the first 200 s of burning. In Test 5, $\dot{Q}$ also achieved a steady value. In this test, mechanical ventilation was included, and the HRR was measured for the total effluent, passing through the door and through the exhaust vent. The forced ventilation system probably caused some amount of mixing in the compartment, but from Figure 3-3, the effect of this on the HRR appears to be limited to a HRR that more nearly matches the idealization as the ramp-up (and ramp-down) time is reduced.

For the open door tests, it is presumed that the compartment volume did not affect the measured value of $\dot{Q}$ during the steady burning period. While it may be possible to de-convolute the HRR measured in the exhaust duct in an attempt to quantify the instantaneous HRR during the rampup and ramp-down of $\dot{Q}$, the uncertainty in the calculation would probably undermine the utility of the results. The solid line in Figure 3-3 shows the idealized fire HRR within the compartment during Test 3 . The curve was determined from the 50 s delay measured in the figure, and the information in Table 3-1, which includes a 180 s linear fuel ramp-up, $1201 \mathrm{~s}$ of steady burning, and a $180 \mathrm{~s}$ linear fuel ramp-down. The shape of the idealized curve appears to represent the Test 3 data fairly well, but is certainly different than the Test 4 measurement result, which was likely affected by mixing associated with the mechanical ventilation.

Table 3-7 shows the measured HRRs for the open door tests (taken from Table 3-6). The table also shows the average values of the estimated HRR from the ambient temperature fuel flow calibrations (taken from Table 3-2). The ratio of these two HRR values yields a factor with a mean value of 1.14 for the six open door tests. The standard deviation of the results is $4 \%$, indicating a reasonable level of repeatability. To provide a source term for the HRR during the steady burning period for the tests not listed in Table 3-7, it is recommended that the same factor (1.14) be applied as a correction to the estimated HRRs during the steady burning period determined from the ambient temperature fuel flow measurements (see Table 3-2). The resulting values are listed in Table 3-8. This approach, based on the open door test results, inherently assumes that the combustion efficiency and the fuel flow rate did not significantly differ for experimental conditions different from the open door tests. The time dependent HRR for the tests listed in Table 3-8, including the ramp-up, the steady burning period and the ramp-down, can be estimated using the information in Table 3-1 in a manner analogous to the estimate of $\dot{Q}$ for Test 3 that is shown in Figure 3-3. 


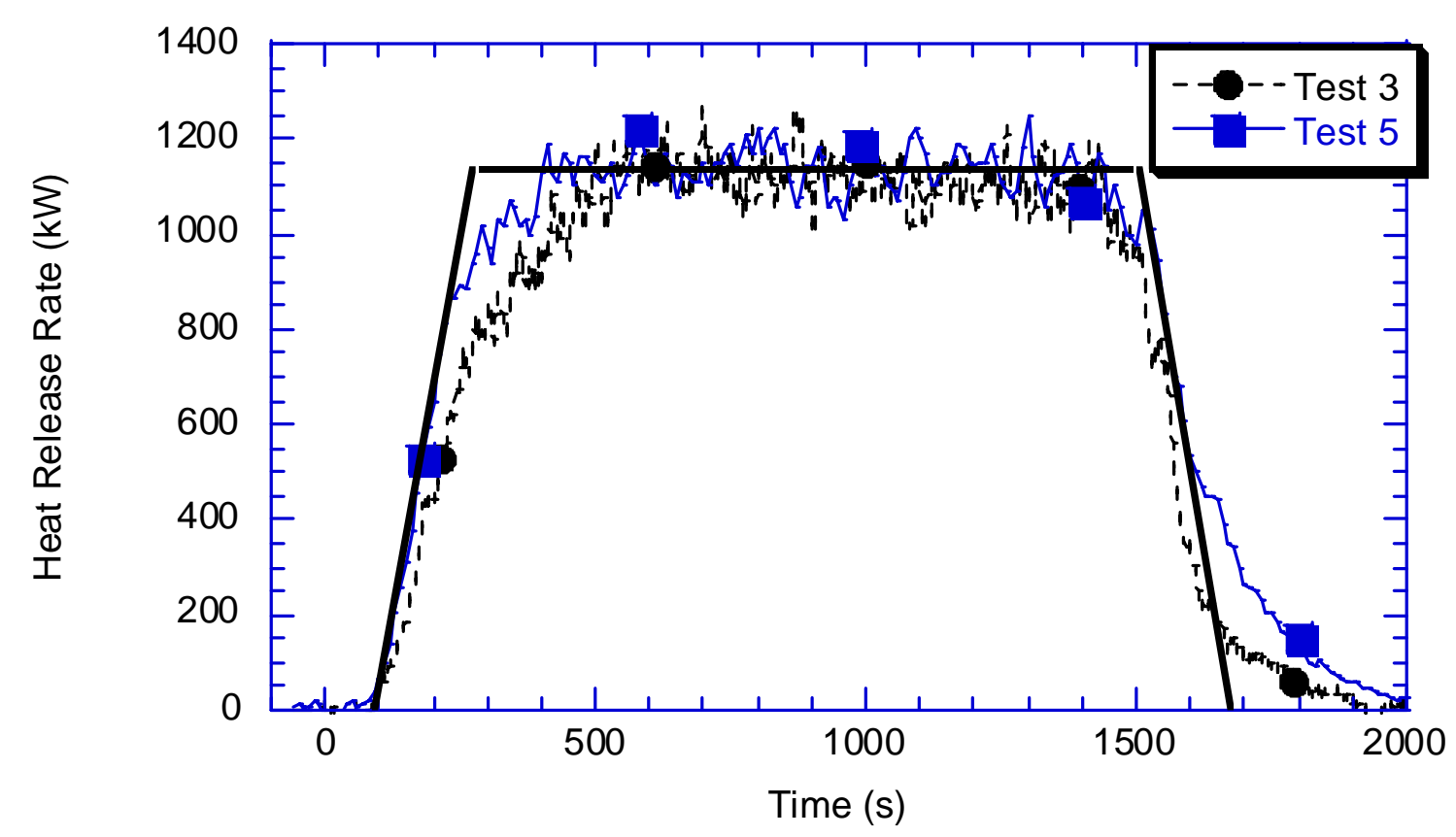

Figure 3-3: The measured HRR as a function of time for Tests 3 and 5 . The solid line shows the idealized fire HRR using gas flow rate.

Table 3-7: The Estimated and Measured HRRs ${ }^{1}$ and their Ratio.

\begin{tabular}{|c|c|c|c|}
\hline Test & $\begin{array}{l}\dot{Q}_{f}(\mathrm{~kW}) \text { from ambient } \\
\text { temperature fuel flow }{ }^{2}\end{array}$ & $\begin{array}{c}\dot{Q}(\mathrm{~kW}) \text { from the Measured } \\
\text { Calorimetric } \mathrm{HRR}^{3}\end{array}$ & Ratio $^{4}$ \\
\hline 3 & 1050 & 1140 & 1.09 \\
\hline 5 & 1050 & 1160 & 1.11 \\
\hline 9 & 1030 & 1160 & 1.13 \\
\hline 14 & 1040 & 1230 & 1.18 \\
\hline 15 & 1040 & 1260 & 1.21 \\
\hline 18 & 1040 & 1150 & 1.11 \\
\hline Mean & 1040 & 1180 & $\bar{~} 1.14$ \\
\hline \multicolumn{4}{|c|}{$\begin{array}{l}\text { 1. Reproduced from Tables 3-2 and 3-6. } \\
\text { 2. Combined relative expanded uncertainty is } 5 \% \text {. } \\
\text { 3. Combined relative expanded uncertainty is } 15 \% \text {. } \\
\text { 4. Combined relative expanded uncertainty is } 16 \% \text {. }\end{array}$} \\
\hline
\end{tabular}


Table 3-8: Estimated HRR during the Steady Burning Period in the Closed Door Tests.

\begin{tabular}{|c|c|c|}
\hline Test & Fuel & $\dot{Q}(\mathrm{~kW})^{1}$ \\
\hline 1 & Heptane & 410 \\
\hline 2 & Heptane & 1190 \\
\hline 4 & Heptane & 1320 \\
\hline 7 & Heptane & 440 \\
\hline 8 & Heptane & 1310 \\
\hline 10 & Heptane & 1310 \\
\hline 13 & Heptane & 2570 \\
\hline 16 & Heptane & 2550 \\
\hline 17 & Toluene & 1290 \\
\hline 1. The combined expanded relative uncertainty is estimated as $17 \%$. \\
\hline
\end{tabular}

\subsection{Energy Balance in the Compartment}

As another consistency check on the HRR results, measurements of the convective and conductive heat losses from the compartment for one test (Test 3) were used to estimate the fire HRR. This is discussed in more detail in Section 10 of this report.

Conservation of energy holds that the fire $\operatorname{HRR}(\dot{Q}(t))$ heats the gases within the compartment ( $\dot{Q}_{g}(t)$ ), is transported through the doorway $\left(\dot{Q}_{d}(t)\right)$, through the mechanical ventilation duct $\left(\dot{Q}_{v}(t)\right)$, and is transferred to compartment surfaces (by radiation and convection) $\left(\dot{Q}_{w}(t)\right)$ :

$$
\dot{Q}(t)=\dot{Q}_{g}(t)+\dot{Q}_{w}(t)+\dot{Q}_{d}(t)+\dot{Q}_{v}(t)
$$

Measurements were used to track these time-varying enthalpy components, and are discussed in Sections 7, 9, and 10 of this report. The value of $\dot{Q}_{g}(t)$ was estimated from thermocouple temperature measurements made at a series of heights on the thermocouple trees. A single door to the compartment was open during 6 of the 15 experiments. In those tests, $\dot{Q}_{d}(t)$ was characterized using an array of bidirectional probes and associated thermocouples. The value of $\dot{Q}_{w}(t)$ was also measured using a series of sensors placed at select locations on the compartment walls, floor, and ceiling.

Figure 3-4 considers the energy balance in the compartment during Test 3 as a function of time as represented by the energy loss to the compartment surfaces $\left(\dot{Q}_{w}\right)$, through the doorway $\left(\dot{Q}_{d}\right)$, heating the gas phase $\left(\dot{Q}_{g}\right)$, and the sum of these three terms. For comparison, the corrected calorimetric HRR $(\dot{Q})$ is also shown. Equation 3.3 states that the sum of the heat losses should be equal to the total HRR. Early in the experiment $(\mathrm{t}<300 \mathrm{~s})$, the calorimetric results lagged the sum of the enthalpy heat loss terms as the hot upper layer grew and obtained a quasi-steady 
temperature. The time lag was due to the measurement configuration in which the hot gases first filled the compartment and only then began to spill into the exhaust hood, where the HRR was measured.

The sum of the heat loss terms during the steady burning period (from about $400 \mathrm{~s}$ to about 1400 s) slowly increased. The mean value during the steady burning period was calculated as $1210 \mathrm{~kW}$, which is within experimental uncertainty of the time-averaged value of the calorimetric measurement $(1140 \mathrm{~kW})$ during the steady burning period and even closer to the mean value of the calorimetric measurements $(1180 \mathrm{~kW}$; Table $3-7)$ for the open door tests. The uncertainty in the sum of the heat losses was estimated as $12 \%$, while the uncertainty in the calorimetry was 15\%. The agreement between these two curves in Figure 3-4 was generally within the overlapping uncertainty limits.

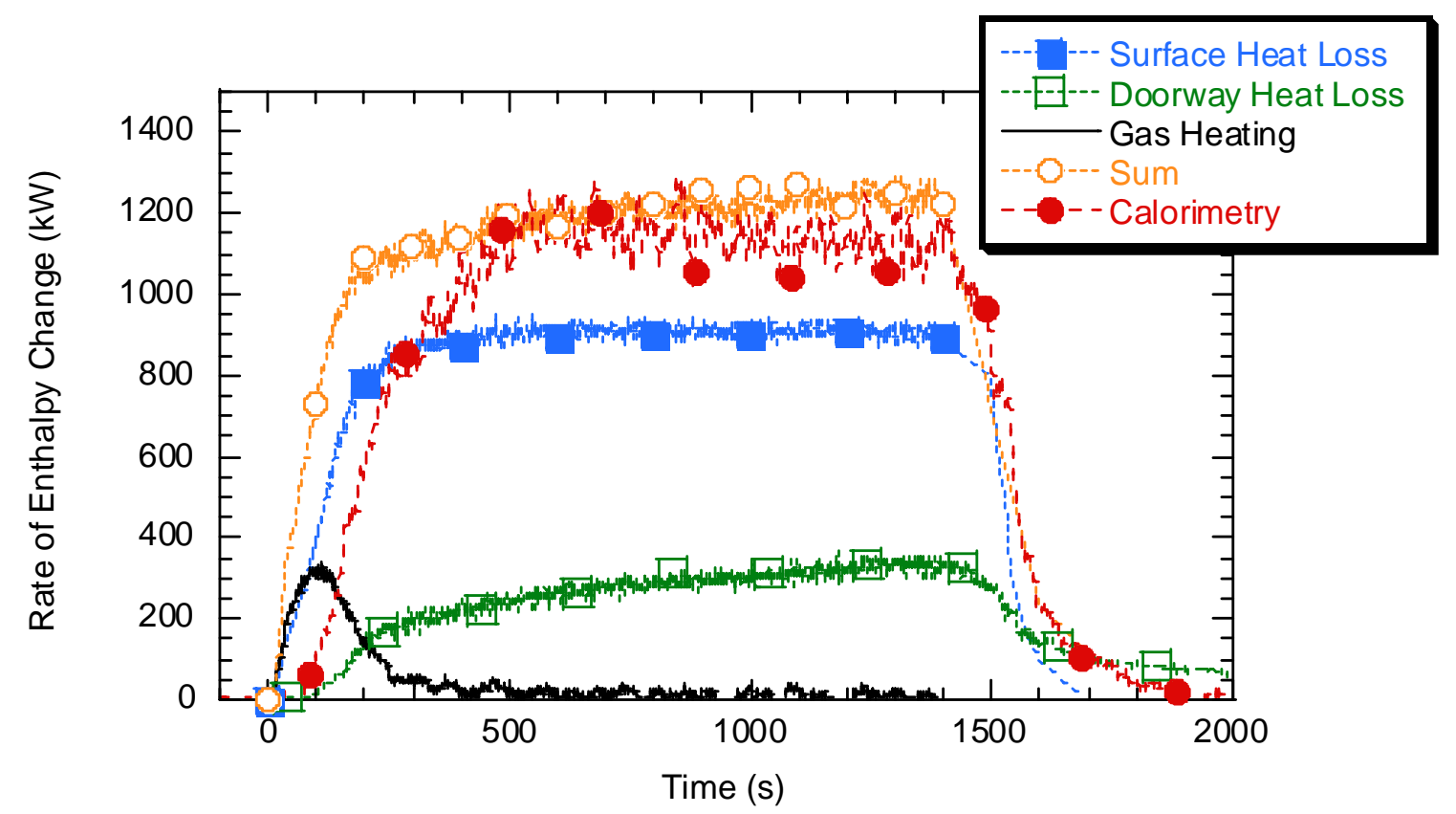

Figure 3-4: The rate of heat loss to surfaces, through the doorway, accumulated by heating the gas in the compartment, and their sum as a function of time during Test 3.

\subsection{Summary}

Two methods were used to estimate the fire HRR: a fuel flow rate measurement corrected for compartment heating effects and an oxygen calorimetry measurement. The two approaches give estimates of the HRR during the steady burning period (see Tables 3-2 and 3-9) that are within about $4 \%$ of each other, which is insignificant if measurement uncertainties are considered. A third approach was demonstrated for Test 3, which involved measurements of the heat losses from the compartment. These three approaches led to results that were consistent, within experimental uncertainty. 
Because the determination of the compartment heating effects on the fuel flow calibration was measured only once and for essentially only one test condition, the method involving oxygen calorimetry that was used during the six open door tests may be considered a more reliable way to estimate the fire HRR. This approach was taken. For each of the open door tests (Tests 3, 5, 9, 14, 15, and 18), the values of the recommended HRRs during the steady burning period were based on the product of the mean correction factor (with a value of 1.14; see Table 3-7) and the HRR associated with the ambient temperature fuel flow calibration (from Table 3-2 and Table 37). The same approach was taken for the closed door tests (Tests 1, 2, 4, 7, 8, 10, 13, 16, and 17), and the recommended HRRs during the steady burning period were taken from Table 3-8. Table 3-9 summarizes the recommended HRRs during the steady burning period for all of the tests. The table also lists the duration (from Table 3-1) of the ramp-up, the steady burning period, and the ramp-down.

Table 3-9: Estimated HRRs during the steady burning period for all of the tests and the duration of each of the phases of the fuel flow.

\begin{tabular}{|c|c|c|c|c|c|}
\hline Test & Fuel & $\dot{Q}(\mathrm{~kW})$ & $\begin{array}{c}\text { Ramp-Up } \\
\text { (min:sec) }\end{array}$ & $\begin{array}{l}\text { Steady Burning } \\
\text { Period }^{3} \\
\text { (min:sec) }\end{array}$ & $\begin{array}{c}\text { Ramp-Down } \\
\text { (min:sec) }\end{array}$ \\
\hline 1 & Heptane & $410^{1}$ & $2: 28$ & $20: 02$ & $2: 30$ \\
\hline 2 & Heptane & $1190^{1}$ & $3: 00$ & $7: 25$ & $0: 01$ \\
\hline 3 & Heptane & $1190^{2}$ & $2: 58$ & 20:01 & 3:03 \\
\hline 4 & Heptane & $1200^{1}$ & $2: 58$ & $10: 36$ & $0: 01$ \\
\hline 5 & Heptane & $1190^{2}$ & $2: 58$ & 20:01 & 3:03 \\
\hline 7 & Heptane & $400^{1}$ & $2: 09$ & $20: 03$ & $2: 08$ \\
\hline 8 & Heptane & $1190^{1}$ & $2: 56$ & $7: 14$ & $0: 01$ \\
\hline 9 & Heptane & $1170^{2}$ & $2: 55$ & 20:01 & $3: 04$ \\
\hline 10 & Heptane & $1190^{1}$ & $2: 56$ & $10: 50$ & $0: 01$ \\
\hline 13 & Heptane & $2330^{1}$ & $2: 57$ & $3: 07$ & $0: 01$ \\
\hline 14 & Heptane & $1180^{2}$ & $2: 56$ & $20: 05$ & $3: 06$ \\
\hline 15 & Heptane & $1180^{2}$ & $3: 00$ & $20: 00$ & $3: 07$ \\
\hline 16 & Heptane & $2300^{1}$ & $2: 57$ & $3: 25$ & $0: 01$ \\
\hline 17 & Toluene & $1160^{1}$ & $3: 01$ & $1: 31$ & $0: 01$ \\
\hline 18 & Heptane & $1180^{2}$ & $2: 58$ & $20: 02$ & $3: 07$ \\
\hline \multicolumn{6}{|c|}{$\begin{array}{l}\text { 1. The combined expanded relative uncertainty is estimated as } 17 \% \text {; see Table 3-8. } \\
\text { 2. The combined expanded relative uncertainty is estimated as } 17 \% \text {; the product of the mean correction } \\
\text { factor of } 1.14 \text { (see Table 3-7) and the ambient temperature fuel flow calibration (see Table 3-2). } \\
\text { 3. Taken from Table 3-1. }\end{array}$} \\
\hline
\end{tabular}





\section{Hear FUX MEASSURENENTS}

The objective of these measurements was to provide information on the incident heat flux to the cable trays and cables. Because of the physical size of the measurement devices, it was not possible to place them on or in the test cable trays and cables. Instead, the sensors were placed within close proximity, on the order of $10.0 \mathrm{~cm}$ (3.9 in) from the targets. Both radiative and total heat flux were measured. The difference between these results allows estimation of the convective heat flux.

\subsection{Heat Flux Measurement Devices}

Five Schmidt-Boelter total heat flux gauges and five ellipsoidal radiometers were used to measure the total and radiative heat fluxes near the cable trays and cables. A Schmidt-Boelter flux gauge uses a water-cooled thermopile as a sensor whose surface temperature is uniform and close to that of the cooling water used. The gauge is used to measure the combined convective and radiative heat fluxes to the sensor surface. The gauges (Medtherm Model GTW-15SB-6-60$40-484 \mathrm{~K}$ ) had a field of view of $180^{\circ}$. They are rated at $150 \mathrm{~kW} / \mathrm{m}^{2}$, and have a time response of approximately $0.1 \mathrm{~s}$ to $0.2 \mathrm{~s}$. The water used to cool the gauges was heated to $75^{\circ} \mathrm{C} \pm 3{ }^{\circ} \mathrm{C}(167$ ${ }^{\circ} \mathrm{F} \pm 6^{\circ} \mathrm{F}$ ) to prevent water vapor condensation on the gauge surface during fire tests using the cooling system described below. Soot deposition on the gauge surfaces was blown off using compressed air before each test. The five total heat flux gauges used here were designated as Total Heat Flux Gauge 2, Total Heat Flux Gauge 4, Total Heat Flux Gauge 6, Total Heat Flux Gauge 8, and Total Heat Flux Gauge 9.

The radiometers, which measure the radiative flux incident on the sensor surface, have a Schmidt-Boelter sensor at the base of an ellipsoidal cavity. The entrance to the cavity $(\approx 3 \mathrm{~mm}$ (0.12 in) in diameter) receives radiation incident over a $160^{\circ}$ field of view. The radiometers were cooled using room temperature water with a flow rate of at least $1.0 \mathrm{~L} / \mathrm{min}(0.3 \mathrm{Gal} / \mathrm{min})$. The sensors were $\mathrm{N}_{2}$-purged to prevent soot and water vapor from entering the cavity and subsequent deposition and condensation on the sensor surface. Three radiometers (Medtherm Model 64EP15SB-6-60-20544K, designated as Radiative Heat Flux Gauge 3, Radiative Heat Flux Gauge 5 and Radiative Heat Flux Gauge 7) were rated to $150 \mathrm{~kW} / \mathrm{m}^{2}$, and two radiometers (Medtherm Model 64EP-3-20544, designated as Radiative Heat Flux Gauge 1 and Radiative Heat Flux Gauge 10) at $30 \mathrm{~kW} / \mathrm{m}^{2}$.

The total flux gauges were re-calibrated at NIST using $75^{\circ} \mathrm{C} \pm 3^{\circ} \mathrm{C}\left(167^{\circ} \mathrm{F} \pm 6^{\circ} \mathrm{F}\right)$ cooling water. The radiometers could not be re-calibrated with the NIST radiant source due to focusing problems associated with the source; therefore, the manufacturer's calibration was used. Manufacturer calibration results for the total heat flux gauges are typically within $5 \%$ of the NIST calibration results, giving confidence in the given calibrations. 
The gauges and radiometers were mounted in pairs and placed adjacent to each other. The pairs were mounted, using steel wires, nearly flush to one side of a steel L-bracket through two drilled holes. Figure 4-1 is a photograph that shows the relative location of Gauges 3-6. The photo was taken from below the gauges, which were at nearly the same height above the floor. Figure 4-2 shows Gauges 9 and 10, which were located adjacent to the vertical cable tray. Signal and thermocouple wires from the gauges and cooling water supply and return lines were thermally protected using a thermal ceramic blanket and then wrapped with aluminum foil. A closed flow water-cooling system was used to circulate hot water through the total heat flux gauges (see Figure 4-3). Table 4-1 summarizes the location, orientation, and designation of the total heat flux gauges and radiometers used in this test series.

Table 4-1: Locations of total heat flux gauges and radiometers.

\begin{tabular}{|l|c|c|c|c|c|}
\hline Designation & Type & $\begin{array}{c}\mathrm{X}^{*} \\
(\mathrm{~m})\end{array}$ & $\begin{array}{c}\mathrm{Y}^{*} \\
(\mathrm{~m})\end{array}$ & $\begin{array}{c}\mathrm{Z}^{*} \\
(\mathrm{~m})\end{array}$ & Orientation \\
\hline Rad. Gauge 1 & Radiative & 10.81 & 0.44 & 2.05 & Pointing downward \\
\hline Total Gauge 2 & Total & 10.87 & 0.44 & 2.05 & Pointing downward \\
\hline Rad. Gauge 3 & Radiative & 10.81 & 1.25 & 2.52 & Pointing downward \\
\hline Total Gauge 4 & Total & 10.87 & 1.25 & 2.52 & Pointing downward \\
\hline Rad. Gauge 5 & Radiative & 10.81 & 1.40 & 2.54 & Pointing North Wall \\
\hline Total Gauge 6 & Total & 10.87 & 1.40 & 2.54 & Pointing North Wall \\
\hline Rad. Gauge 7 & Radiative & 10.81 & 2.00 & 3.04 & Pointing downward \\
\hline Total Gauge 8 & Total & 10.87 & 2.00 & 3.04 & Pointing downward \\
\hline Total Gauge 9 & Total & 10.81 & 6.85 & 1.75 & Pointing South Wall \\
\hline $\begin{array}{l}\text { Rad. Gauge 10 } \\
\text { * the uncertainty in the distance is } \pm 0.02 \\
\text { X m. distance from West wall }\end{array}$ \\
$\begin{array}{l}\text { Y distance from South Wall } \\
\text { Z = distance from floor } \\
\text { The pairing of total heat flux gauge and radiometer is highlighted. }\end{array}$ & Pointing South Wall \\
\hline
\end{tabular}

\subsection{Uncertainty Analysis}

The main sources of uncertainty pertaining to the total heat flux are: (1) the uncertainty of A/D conversion, (2) uncertainty in the calibration, and (3) uncertainty due to soot deposition on the sensing surface of the gauge. The uncertainty in $\mathrm{A} / \mathrm{D}$ conversion is inherent to the data acquisition system. It is system specific and is associated with the digitization of the analog signals from the gauge. This type of uncertainty was taken as negligible. The calibration from the manufacturer was obtained using water at $23^{\circ} \mathrm{C} \pm 3^{\circ} \mathrm{C}\left(73^{\circ} \mathrm{F} \pm 6{ }^{\circ} \mathrm{F}\right)$. The relative expanded uncertainty reported by the manufacturer is $\pm 3 \%$ of responsivity (the slope of the calibration curve) with a coverage factor of 2 . 


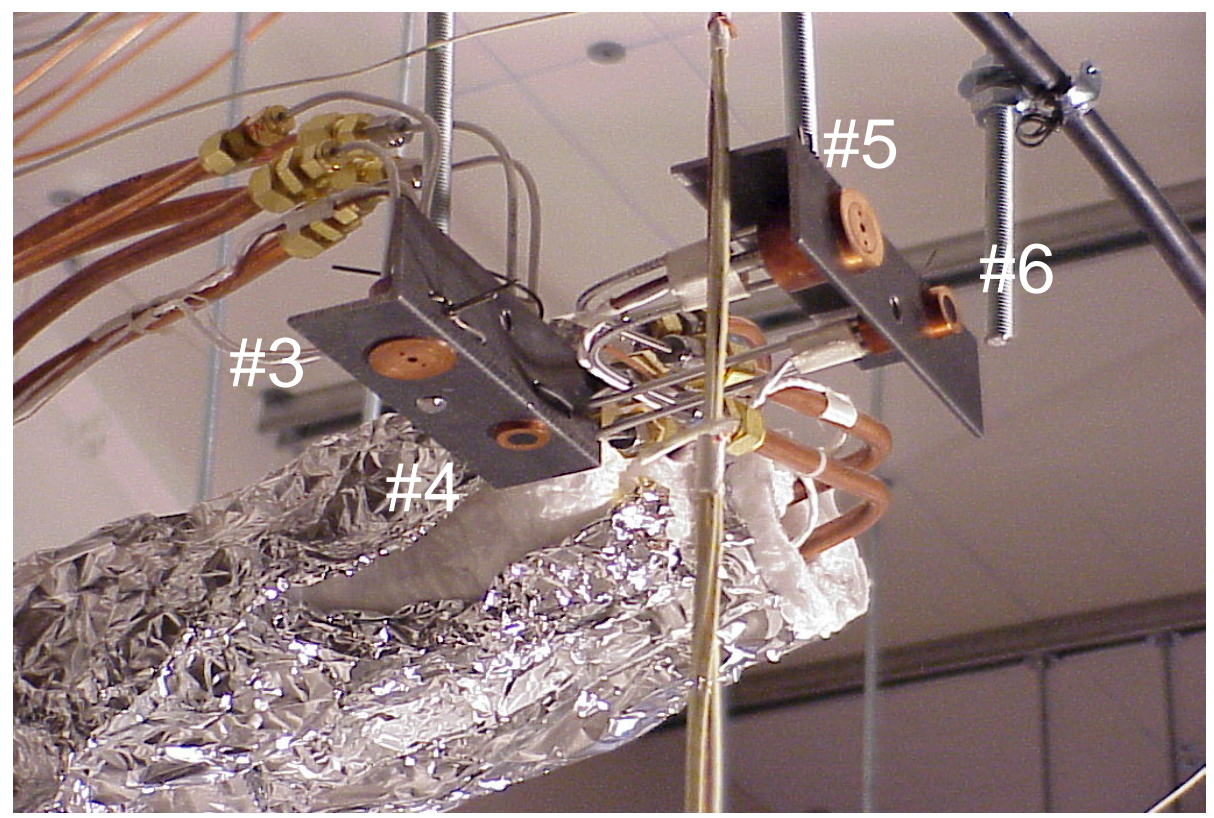

Figure 4-1: Photograph of two total (Gauges 4 and 6) and two radiative (Gauges 3 and 5 ) heat flux gauges partially insulated.

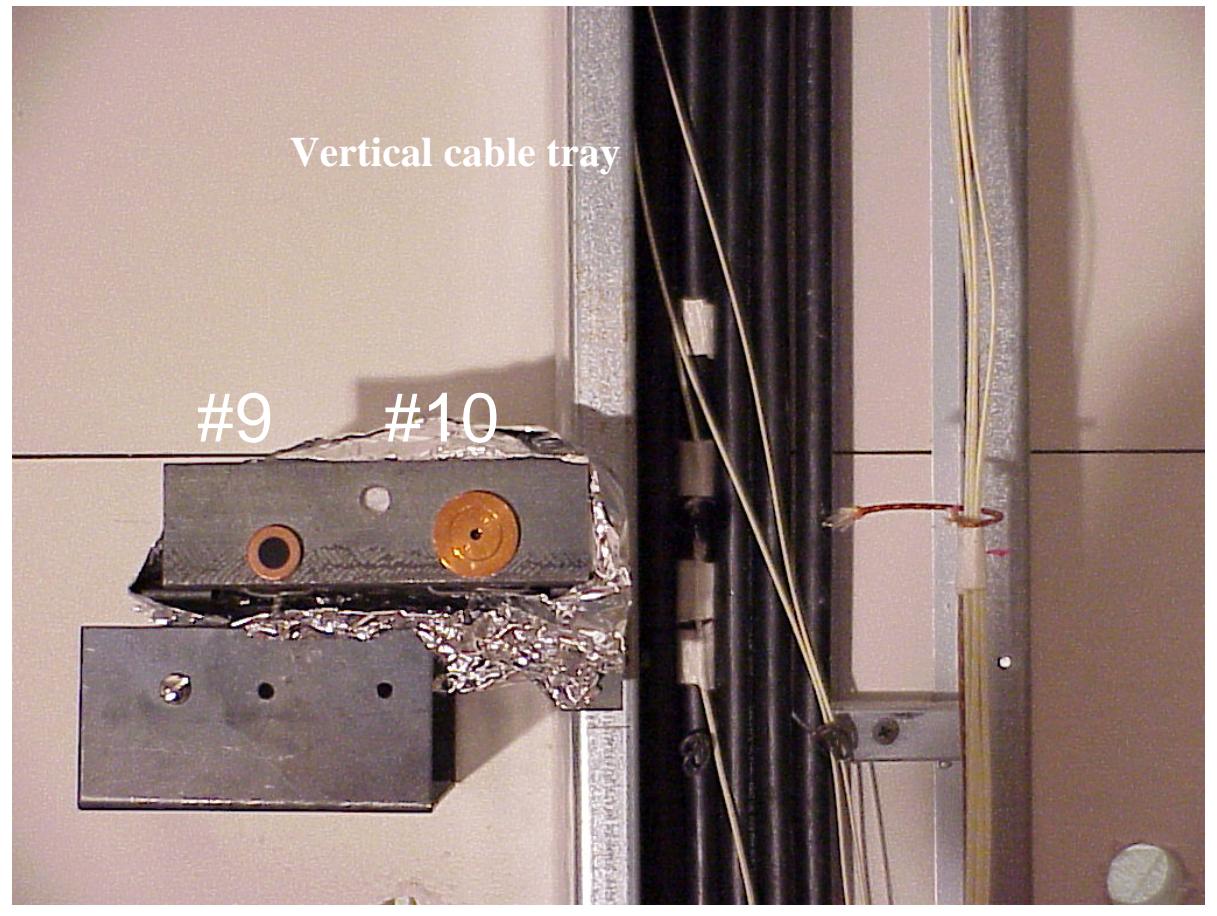

Figure 4-2: Photograph of Gauges 9 and 10 and the vertical cable tray. 


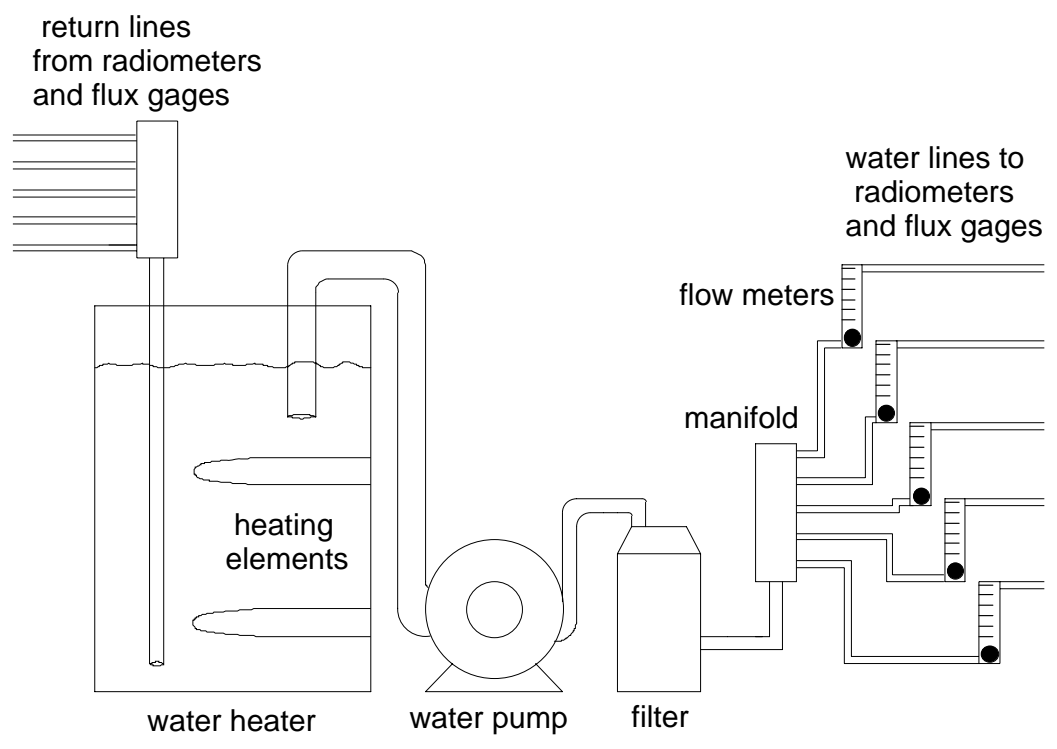

Figure 4-3: Cooling water system for total heat flux gauges.

A linear calibration curve is given as

$$
Y=a+b X
$$

where $X$ is the measured signal in $\mathrm{mV}$ and $Y$ is the calculated heat flux in $\mathrm{kW} / \mathrm{m}^{2}$. If the input $X \mathrm{~s}$ are uncorrelated and the NIST standard reference gauge used in the re-calibration has negligible uncertainty in the conversion factor (from $\mathrm{mV}$ to $\mathrm{kW} / \mathrm{m}^{2}$ ), the combined standard uncertainty $u_{c}$ of a predicted value $Y$ from the linear calibration curve can be readily obtained by applying the law of propagation of uncertainty.

$$
u_{c}=\sqrt{u_{a}^{2}+X^{2} u_{b}^{2}}
$$

where $u_{a}$ and $u_{b}$ are the standard uncertainties of the intercept and slope of the calibration curve respectively. The combined standard uncertainty associated with each measurement was estimated to be less than $0.1 \mathrm{~kW} / \mathrm{m}^{2}$ for all the results reported here.

For the total flux gauges, the uncertainty due to soot deposition is difficult to quantify. The amount of soot deposition depends on many parameters, such as the location of the gauge, the flow field and temperature fields near the gauge, the duration of a test, and the soot volume fraction.

There is no effect of soot deposition on the purged radiometers. The radiometer has two main sources of uncertainty including (1) a $160^{\circ}$ (less than $180^{\circ}$ ) field of view and (2) its calibration. If a uniform radiation field is assumed, a radiometer with a $160^{\circ}$ field of view would receive $3 \%$ less incident radiation than a hemispherical $\left(180^{\circ}\right)$ field of view. The calibration curve provided 
by the manufacturer was used. According to the manufacturer's specification, the radiometer has a relative expanded uncertainty of $\pm 3 \%$ in responsivity with a coverage factor of 2 .

\subsection{Results and Discussion}

Since the same general trends were observed for all the tests under similar experimental conditions, the discussion that follows focuses on Tests 2, 3, and 4. These three tests were selected for detailed discussion because they represent the three major experimental conditions (enclosure closed, enclosure opened, and enclosure closed with ventilation on) used in the test matrix. Experimental data is available electronically from NIST.

Figures 4-4 - 4-6 show the heat flux measurements from Gauges 3, 4, 5, and 6 for Tests 2, 3, and 4. Three similar prominent features are noted in the respective figures:

(1) Upon ignition, the heat fluxes slowly increased with time as the fire developed.

(2) After the fire reached quasi-steady state burning, the heat fluxes remained relatively constant.

(3) Upon termination of the fuel flow, the fire diminished in size and subsequently extinguished, and the heat fluxes decreased with time. Note that the heat fluxes did not return to their initial values before ignition over the duration of the measurement because the enclosure was still at elevated temperature after fire-out.

In Figure 4-4, the spikes from the pair of Gauges [5 and 6] are probably due to electronic noise.

After the fire in Test 2 was fully developed, the radiative fluxes accounted for approximately 50 $\%$ and $70 \%$ of the total heat flux for pairs [3 and 4] and [5 and 6], respectively. For Test 3, the radiative fluxes constituted approximately $60 \%$ and $60 \%$ of the total heat flux for the same corresponding pairs of gauges. For Test 4, the radiative fluxes constituted approximately $50 \%$ and $70 \%$, respectively. It is important to recognize that the convective component in the total heat flux measurement is based on the convective heat transfer to a "cold surface" total heat flux gauge maintained at $75^{\circ} \mathrm{C} \pm 3{ }^{\circ} \mathrm{C}\left(167^{\circ} \mathrm{F} \pm 6^{\circ} \mathrm{F}\right)$. The measured convective component is thus enhanced. During a fire test, the temperature of a target surface is not constant and is rising thus reducing the temperature gradient between the surface and the free stream. It is imperative to compare the measurements with the model predictions on the same basis. Model simulations should consider the flux gauge temperature.

Figures 4-7 - 4-10 show the temporal variation of the radiative and total heat fluxes for pair [10 and 9] in Tests 2, 3, and 4 respectively. The main features of these figures remain similar to those discussed in Figures 4-4 - 4-6, namely, the heat fluxes increased during the development phase of the fire, reached a quasi-steady state, and decreased upon the termination of the tests. In Figure 4-7, Gauge 9 was not functioning during Test 2 due to a bad connection between the signal wires and the computer interface.

Some peculiar behavior is noted in Figures 4-8 and 4-9. In Test 3, the door of the enclosure was open. For the first $200 \mathrm{~s}$ as the fire developed, the radiative flux was measured to be somewhat higher than the total heat flux. The difference was within the uncertainties associated with the measurements. However, the radiative flux was less than the total flux during the quasi-steady 
burning stage. In Test 4, similar behavior was observed. In this test, the ventilation system was on. In Test 4, the radiative flux was comparable to the total heat flux within experimental uncertainties as the fire developed and also during the quasi-steady burning stage. This effect could have been due to increased soot deposition on the sensor surface of the flux gauge, which would artificially indicate a lower than normal total heat flux measurement. The location of the gauge and possibly the ventilation system could also be contributing factors to these observations. Although post-test examination of Gauge 9 could not conclusively support the hypothesis of increased soot deposition, a thin soot layer was observed on the sensor requiring cleaning with a small burst of compressed air.

Figures 4-10 - 4-12 show the results of heat flux measurements in Tests 2, 3, and 4 for Gauges 1 , 2, 7, and 8 respectively. Again, features similar to Figures 4-4-4-6 are noted in these plots. The spikes at $\approx 600 \mathrm{~s}$ in Figure 4-10 were likely due to electronic interferences.

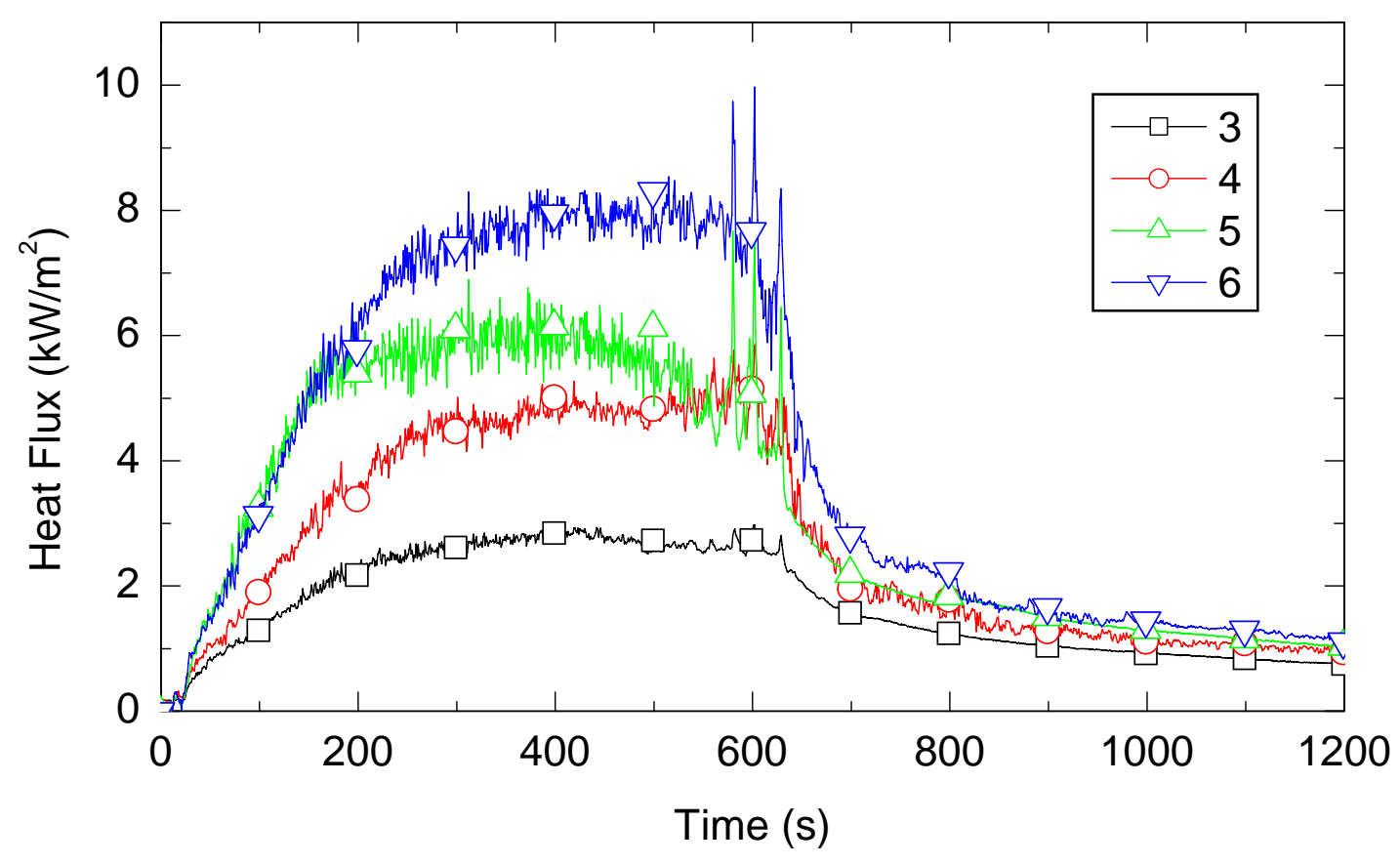

Figure 4-4: Heat fluxes as a function of time for Gauges 3, 4, 5, and 6 in Test 2. 


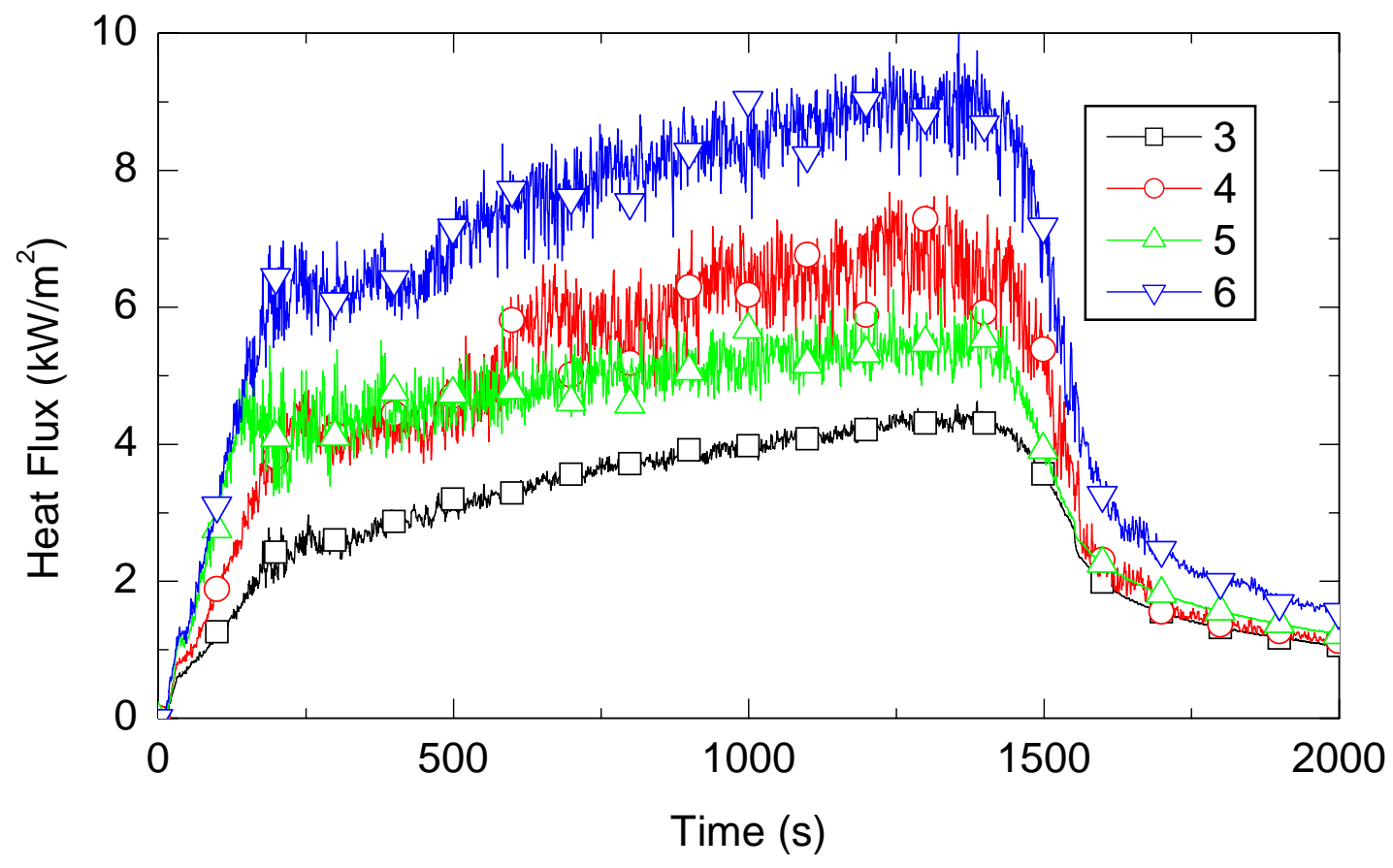

Figure 4-5: Heat fluxes as a function of time for Gauges 3, 4, 5, and 6 in Test 3.

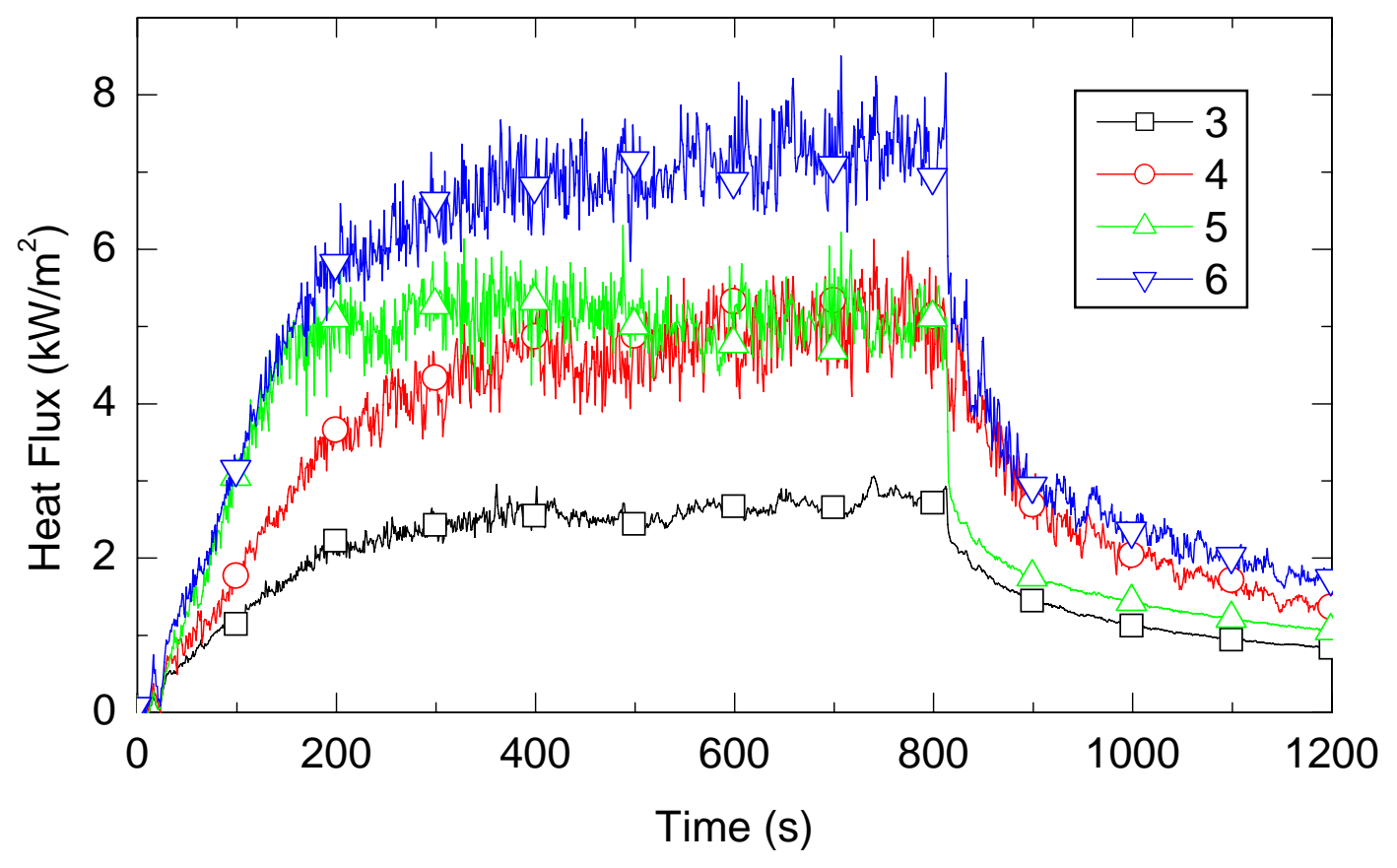

Figure 4-6: Heat fluxes as a function of time for Gauges 3, 4, 5, and 6 in Test 4. 


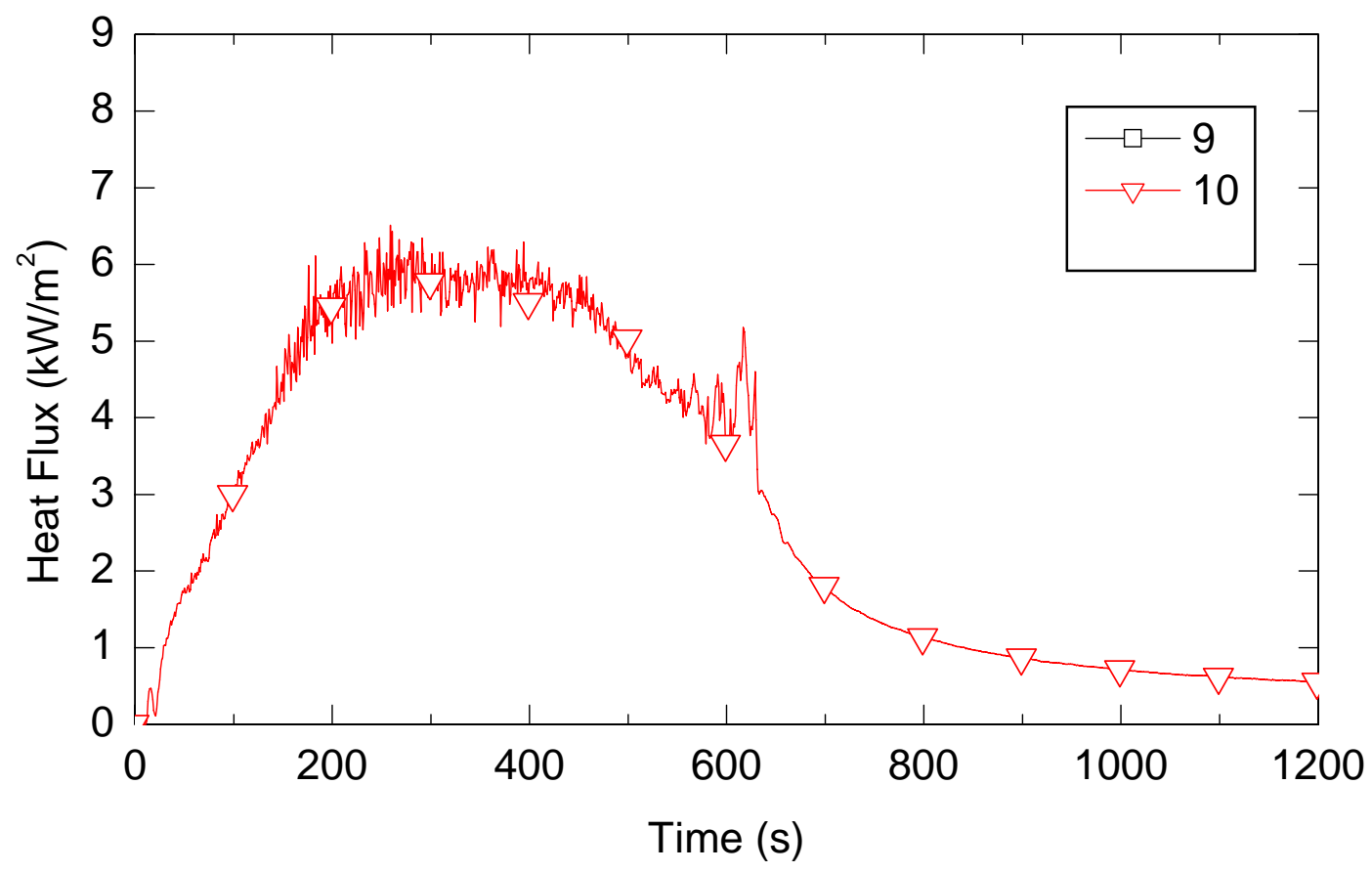

Figure 4-7: Radiative heat flux as a function of time for Gauge 10 in Test 2. The total heat flux Gauge, 9, was not functioning during this test.

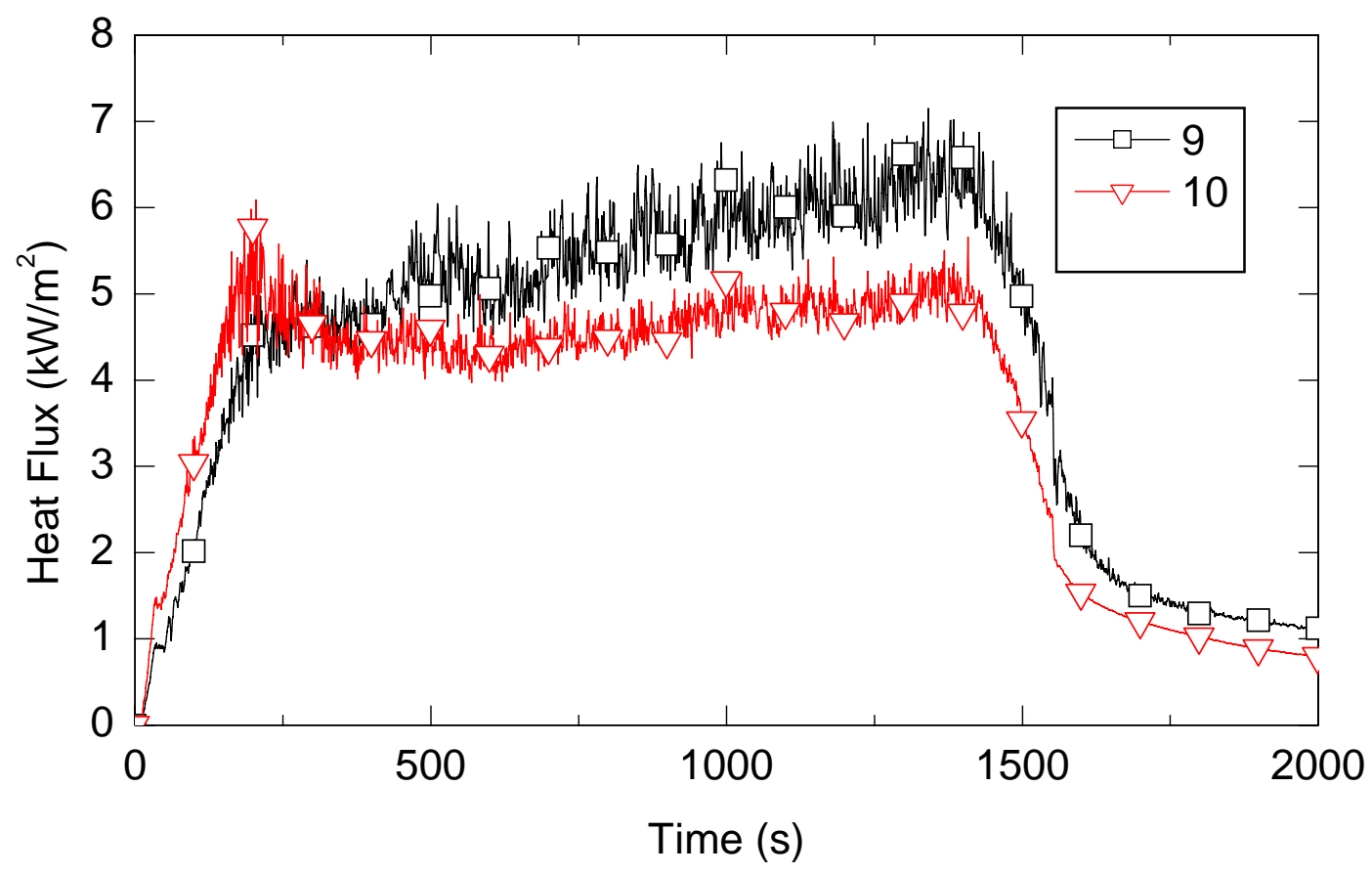

Figure 4-8: Radiative and total heat flux as a function of time for Gauges 9 and 10 in Test 3. 


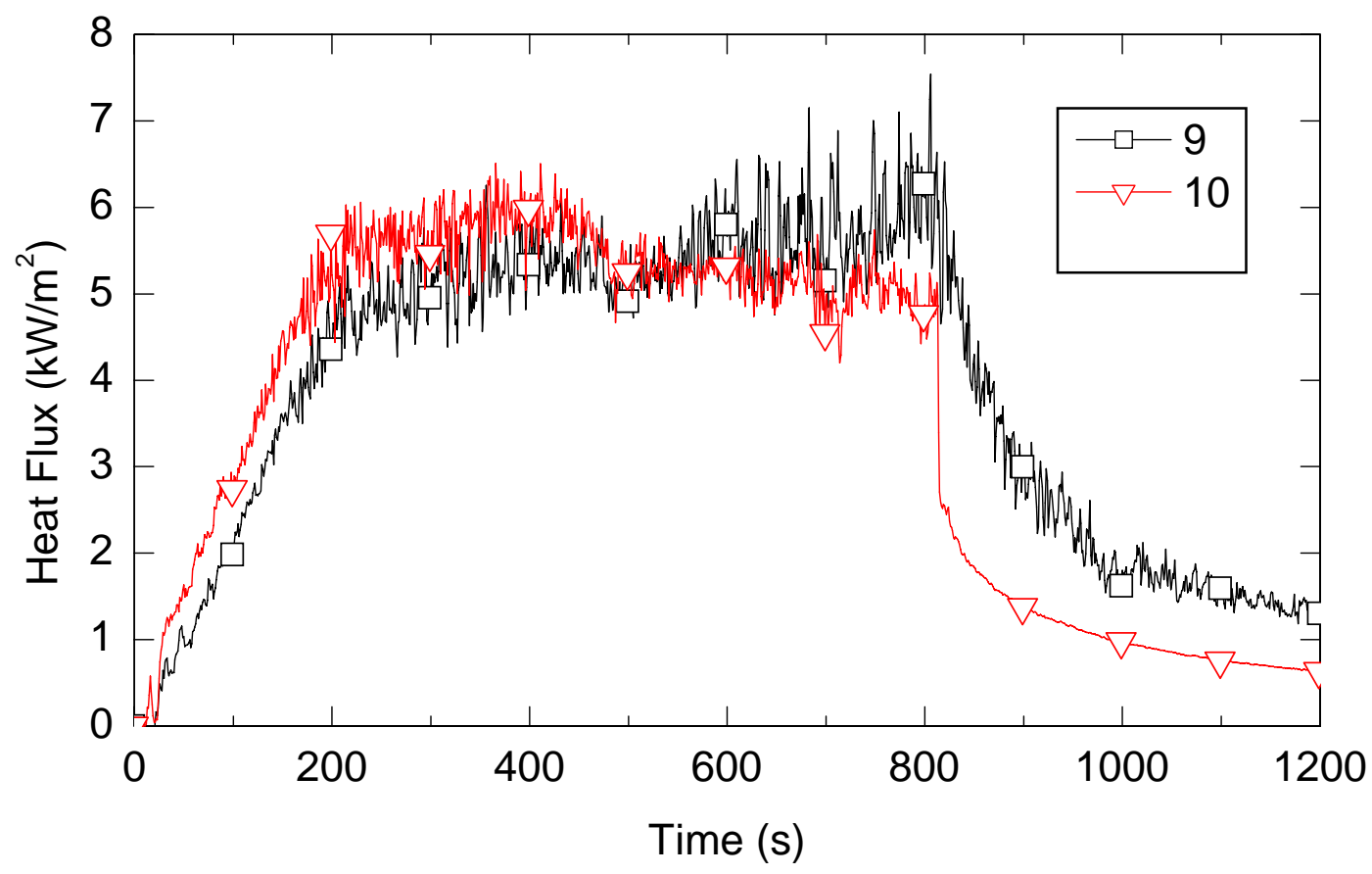

Figure 4-9: Radiative and total heat flux as a function of time for Gauges 9 and 10 in Test 4.

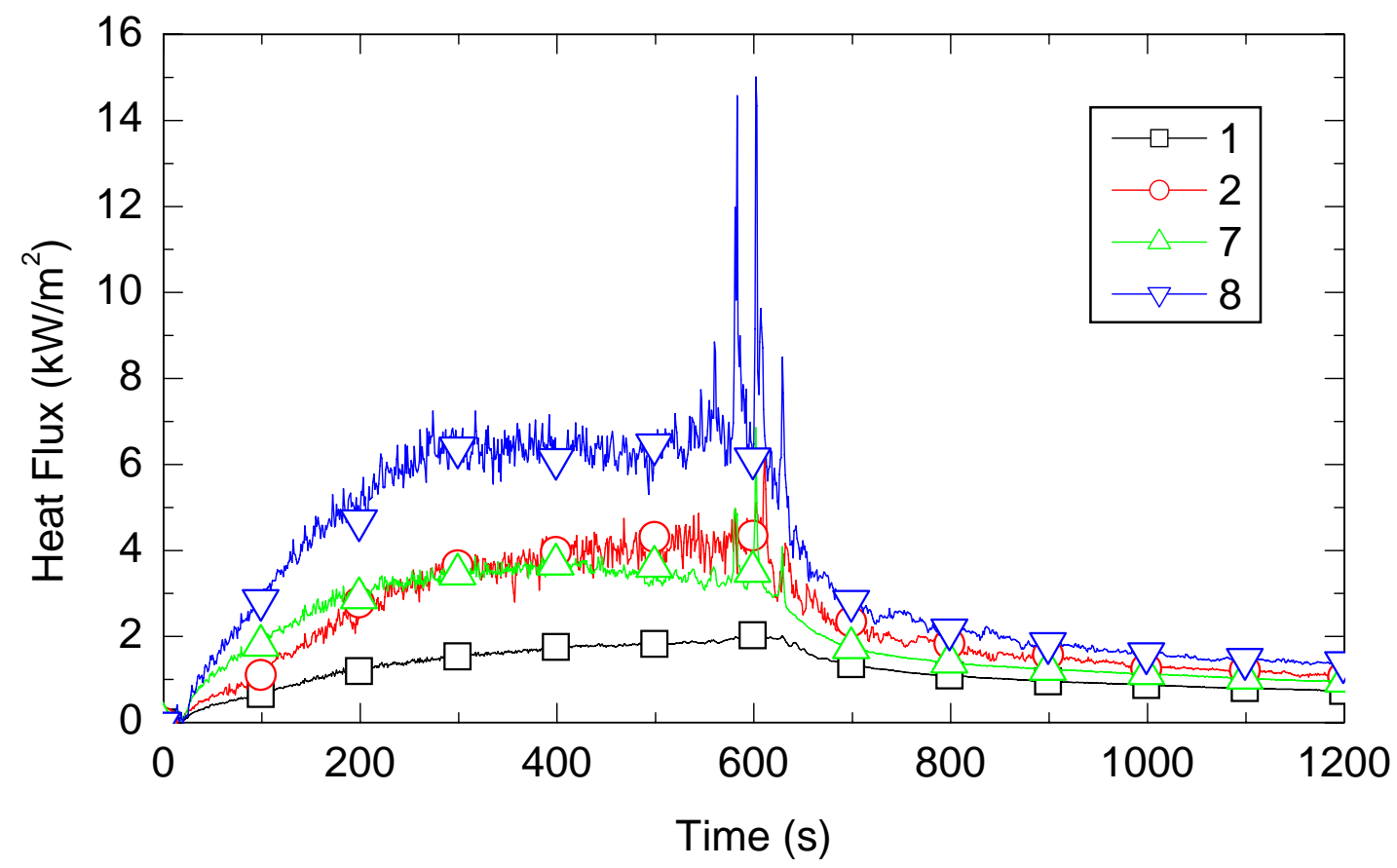

Figure 4-10: Radiative and total heat flux as a function of time for Gauges 1, 2, 7, and 8, in Test 2. 


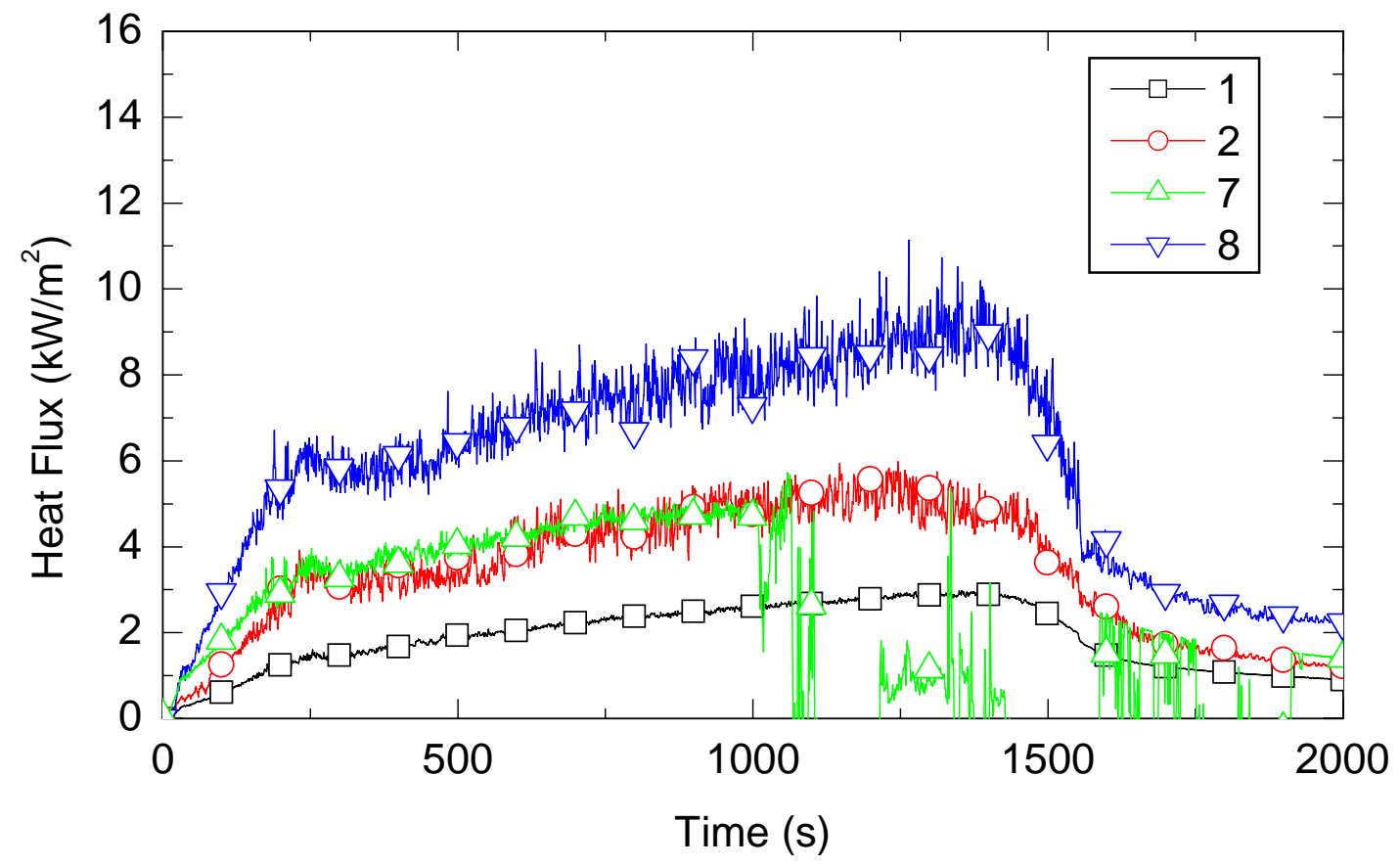

Figure 4-11: Radiative and total heat flux as a function of time for Gauges 1, 2, 7, and 8, in Test 3 (Gauge 7 failed after $1000 \mathrm{~s}$ into the test).

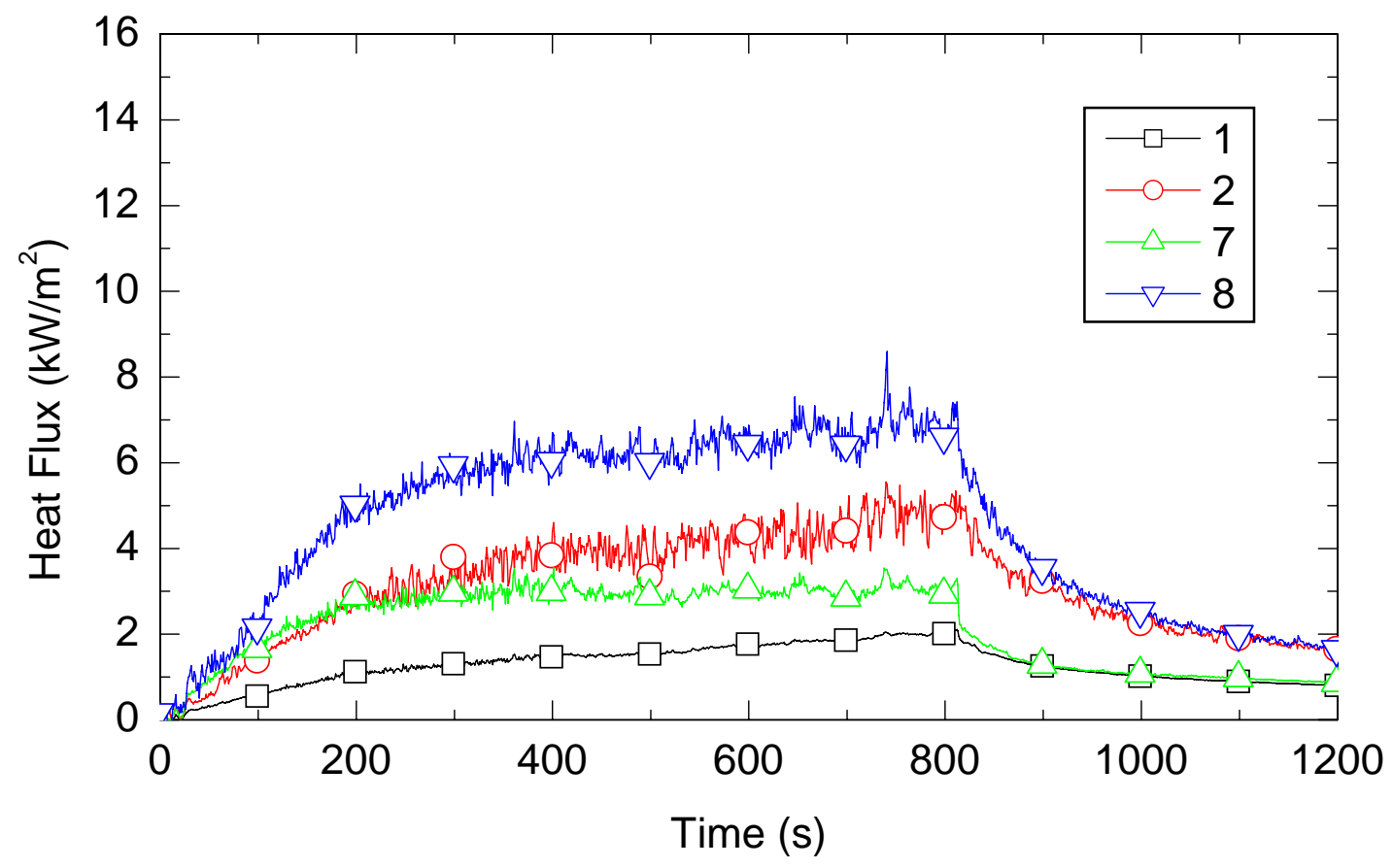

Figure 4-12: Radiative and total heat flux as a function of time for Gauges 1, 2, 7, and 8, in Test 4. 


\section{SMOKE CONCENTRATION}

\subsection{Principle of Operation}

The smoke concentration measurement was based on the strong light extinction characteristic of flame-generated smoke. This measurement was based on Bouguer's Law, which relates the ratio of the transmitted $(I)$ and incident $\left(I_{0}\right)$ intensities to the mass concentration of smoke $\mathrm{M}_{\mathrm{s}}$, the path length through the smoke, $\mathrm{L}$, and the specific extinction coefficient $\phi_{\mathrm{s}}$ via the following expression:

$$
\frac{I}{I_{0}}=\exp \left(-\phi_{s} M_{s} L\right)
$$

The ability to infer mass concentration from a light extinction measurement is made possible by the discovery that $\phi_{\mathrm{s}}$ is nearly universal for post-flame smoke produced from over-ventilated fires. Previous studies indicate little change in the smoke yield as the air becomes vitiated. Mulholland and Croarkin [2000] found that $\phi_{\mathrm{s}}$ has an average value of $8.7 \mathrm{~m}^{2} / \mathrm{g}\left(42,000 \mathrm{ft}^{2} / \mathrm{b}\right)$ at a wavelength of $632.8 \mathrm{~nm}$. The basic qualitative ideas that support this universality are that soot from all flames is basically carbon in the form of agglomerates with primary sphere sizes much smaller than the wavelength of light and a fractal dimension less than two. For these conditions the light absorption cross section is proportional to the mass and is the dominant contribution to the light-extinction coefficient. There was a smaller contribution from the light scattering crosssection, which depends on the agglomerate size.

Solving Eq. 1 for the mass concentration, one obtains the following result:

$$
M_{s}=\frac{\ln \left(I_{0} / I\right)}{\phi_{s} L}
$$

\subsection{Design}

The basic instrument components were a $0.5 \mathrm{~mW}$ randomly polarized He-Ne laser and a silicon detector with a small temperature coefficient and a uniform response over its $1.0 \mathrm{~cm} \times 1.0 \mathrm{~cm}$ area ( 0.4 in $\times 0.4$ in). Positioning the detector $40 \mathrm{~cm}$ (15.8 in) from the smoke end of the purge tube minimized the effect of scattered light from reaching the detector (acceptance angle for system is approximately $0.7^{\circ}$ ). The laser and detector were outside of the enclosure and the beam was directed through the south-east corner of the enclosure $20 \mathrm{~cm}$ (7.9 in) from the ceiling. The laser end of the optics was located $1.0 \mathrm{~m}(3.3 \mathrm{ft}$ ) west of the corner and the detector end was located $0.94 \mathrm{~m}(3.1 \mathrm{ft})$ north of the corner. Key design features included attachment of the optics 
to a rigid mounting bar and the use of purge air through a steel pipe to prevent smoke deposition on the window and to set the path length. The support bar was water-cooled and both the support bar and the steel pipe were insulated to minimize movement of the optics during the fire test. The standard instrument configuration had a $0.80 \mathrm{~m}(2.6 \mathrm{ft})$ path length for the heptane fires. Tubing attachments allowed for a $0.29 \mathrm{~m}(0.95 \mathrm{ft})$ path length for use with the very sooty toluene fire. With these path lengths, the smoke concentration range was approximately 0.02 $\mathrm{g} / \mathrm{m}^{3}\left(1.2 \times 10^{-6} \mathrm{lb} / \mathrm{ft}^{3}\right)$ to $0.4 \mathrm{~g} / \mathrm{m}^{3}\left(2.5 \times 10^{-6} \mathrm{lb} / \mathrm{ft}^{3}\right)$ for the $0.80 \mathrm{~m}(2.62 \mathrm{ft})$ path length and about $0.05 \mathrm{~g} / \mathrm{m}^{3}\left(3.1 \times 10^{-6} \mathrm{lb} / \mathrm{ft}^{3}\right)$ to $2.0 \mathrm{~g} / \mathrm{m}^{3}\left(1.3 \times 10^{-4} \mathrm{lb} / \mathrm{ft}^{3}\right)$ for the $0.29 \mathrm{~m}(0.95 \mathrm{ft})$ path length.

Several steps were taken to verify the instrument performance for each test. The transmitted laser beam intensity was monitored before and after the test to assess the amount of drift in the laser intensity and whether a significant amount of soot was depositing on the optical surfaces. A neutral density filter reduced the light intensity by a factor of about 2, which was near the peak attenuation for most of the tests. The filter was positioned in the laser beam before each test and the average reduction was 2.12 with a standard deviation of 0.06 . The laser beam was also blocked and the magnitude of the detector output decreased from a nominal $4.4 \mathrm{~V}$ to a signal of at most $2.0 \times 10^{-5}$. This indicated that the leakage of light to the detector was negligible.

\subsection{Uncertainty}

The major sources of uncertainty were the mass specific extinction coefficient, the path length, and the intensity ratio. The flow of purge air was selected as a compromise between keeping the smoke out of the pipe and blowing the smoke out of the measurement volume. The estimated standard uncertainty in the path length was $0.02 \mathrm{~m}(0.06 \mathrm{ft})$. The combined standard uncertainty for the universal specific extinction coefficient $\sigma_{\mathrm{s}}$ was $0.47 \mathrm{~m}^{2} / \mathrm{g}\left(2,300 \mathrm{ft}^{2} / \mathrm{lb}\right)$ [Mulholland and Croarkin, 2000]. The primary source of uncertainty in the intensity measurement was abrupt small changes in the laser intensity of about 0.2 volts as measured by the silicon detector compared to a nominal signal of 4.4 volts. For eight tests the smoke intensity was recorded after the smoke had been cleared from the room at the end of the tests. Such measurements assessed the effects of laser drift, smoke deposition, and heating effects on the alignment. The ratio of the initial to final voltage was computed and the mean of the eight tests was 1.000 with a standard deviation of 0.043 . A slightly more conservative value of 0.05 was used in computing the standard uncertainty in $\ln \left(\mathrm{I}_{0} / \mathrm{I}\right)$. Table $5-1$ lists the relative standard uncertainties based on a mass concentration of $0.10 \mathrm{~g} / \mathrm{m}^{3}\left(6.2 \times 10^{-6} \mathrm{lb} / \mathrm{ft}^{3}\right)$. Using the law of propagation of uncertainties, the relative combined uncertainty was determined and then the expanded uncertainty with a coverage factor of two was computed as 0.18 . For a mass concentration of $0.10 \mathrm{~g} / \mathrm{m}^{3}\left(6.2 \times 10^{-6}\right.$ $\left.\mathrm{lb} / \mathrm{ft}^{3}\right)$, the resulting expanded uncertainty was $0.018 \mathrm{~g} / \mathrm{m}^{3}\left(1.10 \times 10^{-6} \mathrm{lb} / \mathrm{ft}^{3}\right)$.

The calculated uncertainty given above was based on a uniform concentration over the path length. The actual experimental concentration varies over the path length and was changing with respect to time. To obtain the best comparison with experiment, the path length averaged concentration should be computed. 
Table 5-1: Standard Relative Uncertainties for a Mass Concentration of $0.1 \mathrm{~g} / \mathrm{m}^{3}$.

\begin{tabular}{|l|c|c|}
\hline Quantity & Nominal value & Standard relative uncertainty \\
\hline $\begin{array}{l}\text { Specific extinction } \\
\text { coefficient, } \mathrm{m}^{2} / \mathrm{g}\end{array}$ & $8.7 \mathrm{~m}^{2} / \mathrm{g}$ & 0.053 \\
\hline Path length, $\mathrm{m}$ & $0.8 \mathrm{~m}$ & 0.025 \\
\hline $\ln \left(\mathrm{I}_{0} / \mathrm{I}\right)$ & 0.70 & 0.07 \\
\hline
\end{tabular}

\subsection{Temperature Uncertainty}

A Type $\mathrm{K}$ thermocouple was used with a standard uncertainty of $2{ }^{\circ} \mathrm{C}\left(4{ }^{\circ} \mathrm{F}\right)$ based on the manufacturer's specification. The expanded uncertainty (95\% confidence interval) with a coverage factor of two is $4{ }^{\circ} \mathrm{C}\left(8^{\circ} \mathrm{F}\right)$.

The thermocouple measurement was a single point measurement made approximately at the midpoint of the optical path of the smoke meter. The grid cell including the thermocouple should be used for comparing with the thermocouple output rather than the path averaged value used for the smoke.

The response time for the 24 gauge thermocouples $(0.05 \mathrm{~cm}$, or 0.02 in diameter $)$ used in this study was about $1 \mathrm{~s}$ [OMEGA, 2000]. The time response was defined as the time for the temperature difference between the heated thermocouple and the cooler ambient to decrease by a factor 1/e. For the smoke results, the response time is less than $1 \mathrm{~s}$. This was one reason that the smoke measurement fluctuates more than the temperature measurement. The fluctuations in the smoke concentration data were computed as a standard deviation based on 10 measurements and are found to be about $2 \%$ of the mean concentration. The corresponding fluctuation for the temperature measurements were about $1 \%$ of the mean temperature (in Celsius) for temperatures in the range $150{ }^{\circ} \mathrm{C}$ to $300{ }^{\circ} \mathrm{C}$ (from $302{ }^{\circ} \mathrm{F}$ to $572{ }^{\circ} \mathrm{F}$ ).

\subsection{Results}

Smoke data were collected on all 15 tests and summary data are provided on all these tests. We focus our discussion on the effects of the ventilation conditions, fire size, and fuel type on the smoke results. The ventilation was varied in three tests involving a $1 \mathrm{MW}$ blended heptane spray burner located in the center of the enclosure. In Test 2 the door was closed, in Test 3 the door was open, and Test 4 the door was closed and ventilation was on. The temperature of the purge tube at the end nearest the laser was continuously monitored during the tests. Figures 5-1 - 5-3 show that the tube was heated by no more than $20^{\circ} \mathrm{C}\left(36^{\circ} \mathrm{F}\right)$ above ambient. The highest smoke concentration $\left(0.124 \mathrm{~g} / \mathrm{m}^{3} ; 7.70 \times 10^{-6} \mathrm{lb} / \mathrm{ft}^{3}\right)$ and highest smoke temperature $\left(240{ }^{\circ} \mathrm{C} ; 469{ }^{\circ} \mathrm{F}\right)$ were both observed during Tests 4 , when the door was closed. The smoke temperature was measured about $3.0 \mathrm{~cm}$ (1.2 in) off the axis of the laser beam near the midpoint of the optical path. 
During Test 2, the smoke concentration increased to its peak value about 7 min after ignition, decreased by about $30 \%$, and then increased again about the time the flame went out (Figure 51). This oscillatory behavior may result from first a weakening of the plume dynamics for the vitiated burning and then a cooling of the gases when the flame is extinguished resulting in an increased smoke concentration. Key results from this test and others are summarized in Table 52 including peak HRR and the peak temperature.

In Test 3, the smoke concentration increased rapidly to a relatively constant value of about 0.11 and then abruptly decreased by about $20 \%$ when the flame extinguished (Figure 5-2). Again, a small amount of oscillatory behavior was observed. The pattern was different for the case of ventilation with the door closed. The smoke concentration rose to a peak value and then decreased well before the flame extinguished. Figure 5-3 shows the results for Test 4, which had a somewhat smaller peak soot concentration than in Tests 2 or 3.

Two different fire sizes were used: $1 \mathrm{MW}$ and $2 \mathrm{MW}$. Test 2 was carried out with a $1 \mathrm{MW}$ HRR and Test 13 was carried out with a 2 MW HRR. The tests were identical in all other respects. The peak smoke concentration is about twice as high for the larger fire as one would expect (Figure 5-4). An oscillatory behavior of smoke concentration versus time is observed for the 2 MW fire as it was for the smaller fire. The fire was extinguished at about $360 \mathrm{~s}$ for Test 13 as the oxygen concentration decreased below $15 \% \mathrm{O}_{2}$ (by volume) in the lower layer; the corresponding time for Test 2 was $597 \mathrm{~s}$.

Test 17 was carried out using toluene. The test was identical to Test 2 in terms of heat release and every other parameter except the smoking tendency. Previous free burn tests for these two fuels indicated that the smoke yield was about 8 times larger for the mixture. As seen in Figure 5-5, the peak concentration for Test 17 is about a factor of 8 larger than Test 2. This result is consistent with the smoke yield results. No oscillatory time dependence is observed for the heptane/toluene mixture, though in this test, the burner was on for only 273 s compared to 625 for the heptane blend. The path length of the light extinction instrument was reduced from 80 $\mathrm{cm}(2.6 \mathrm{ft})$ to $29 \mathrm{~cm}(0.95 \mathrm{ft})$ for the much more concentrated smoke. There appears to be a higher fluctuation level for the smoke data for the toluene fire. Part of the increased fluctuation was a result of the much shorter path length.

There were four replicate tests for Tests 1-4. In all cases, the smoke concentrations and the smoke temperatures were of similar magnitude and followed the same trends for the repeat tests. Figure 5-6 shows that the rather complex time dependence for the smoke concentration observed for Test 2 with the closed door is also observed in Test 8 , which is carried out for the same conditions as Test 2. The peak smoke concentration for Test 2 is $0.124 \mathrm{~g} / \mathrm{m}^{3}\left(7.70 \times 10^{-6} \mathrm{lb} / \mathrm{ft}^{3}\right)$ compared to $0.105 \mathrm{~g} / \mathrm{m}^{3}\left(6.50 \times 10^{-6} \mathrm{lb} / \mathrm{ft}^{3}\right)$ for Test 8 (See Table 5-2). The expanded uncertainty for the peak concentrations in Tests 2 and 8 overlap. The repeatability of the peak smoke concentration (3\% difference) and peak temperature (less than $1 \%$ difference) are better for the open door experiments than for the closed door experiments with an average $25 \%$ difference for smoke concentration and $6 \%$ for temperature. For the closed door experiments, the peak smoke concentration and temperature are expected to be more variable than for the open door, because of a decreasing oxygen concentration in the lower layer and because of a more complicated flow 
especially for the case with the cross ventilation flow from the inlet. Even with this variability, the fact that the difference in the smoke concentrations for repeat tests is smaller than the expanded uncertainty in all cases but one, Test 4/Test 10 with the cross ventilation, enhances the confidence in the smoke measurement. A summary of the peak concentrations, temperatures, and the associated times are listed in Table 5-2.

Table 5-2: Smoke and Temperature Results.

\begin{tabular}{|c|c|c|c|c|c|c|}
\hline Test & $\begin{array}{c}\text { Burn } \\
\text { Time, s }\end{array}$ & $\begin{array}{c}\text { Peak } \\
\text { Smoke }^{1} \\
\text { Conc., g/m } \mathrm{m}^{3}\end{array}$ & $\begin{array}{c}\text { Peak } \\
\text { Time, s }\end{array}$ & $\begin{array}{c}\text { Expanded } \\
\text { Uncert., g/m³ }\end{array}$ & $\begin{array}{l}\text { Peak } \\
\text { Temp. }{ }^{1} \text {, } \\
{ }^{\circ} \mathrm{C}\end{array}$ & $\begin{array}{c}\text { Peak } \\
\text { Time, s }\end{array}$ \\
\hline 1 & 1500 & 0.045 & 1620 & 0.015 & 155 & 1375 \\
\hline 2 & 625 & 0.124 & 489 & 0.020 & 243 & 600 \\
\hline 3 & 1563 & 0.116 & 1010 & 0.020 & 236 & 1411 \\
\hline 4 & 815 & 0.082 & 499 & 0.017 & 213 & 832 \\
\hline 5 & 1563 & 0.089 & 1385 & 0.018 & 198 & 1400 \\
\hline $7(1)^{2}$ & 1332 & 0.060 & 1499 & 0.016 & 144 & 1360 \\
\hline $8(2)$ & 613 & 0.105 & 481 & 0.019 & 228 & 563 \\
\hline $9(3)$ & 1566 & 0.119 & 1010 & 0.020 & 235 & 1416 \\
\hline $10(4)$ & 827 & 0.061 & 493 & 0.016 & 202 & 812 \\
\hline 13 & 305 & 0.228 & 405 & 0.030 & 287 & 346 \\
\hline 14 & 1567 & 0.090 & 1619 & 0.018 & 232 & 1418 \\
\hline 15 & 1567 & 0.130 & 1792 & 0.021 & 240 & 1409 \\
\hline 16 & 383 & 0.151 & 330 & 0.023 & 254 & 370 \\
\hline $17^{3}$ & 273 & 1.007 & 275 & 0.178 & 160 & 272 \\
\hline 18 & 1567 & 0.114 & 1241 & 0.020 & 241 & 261 \\
\hline
\end{tabular}




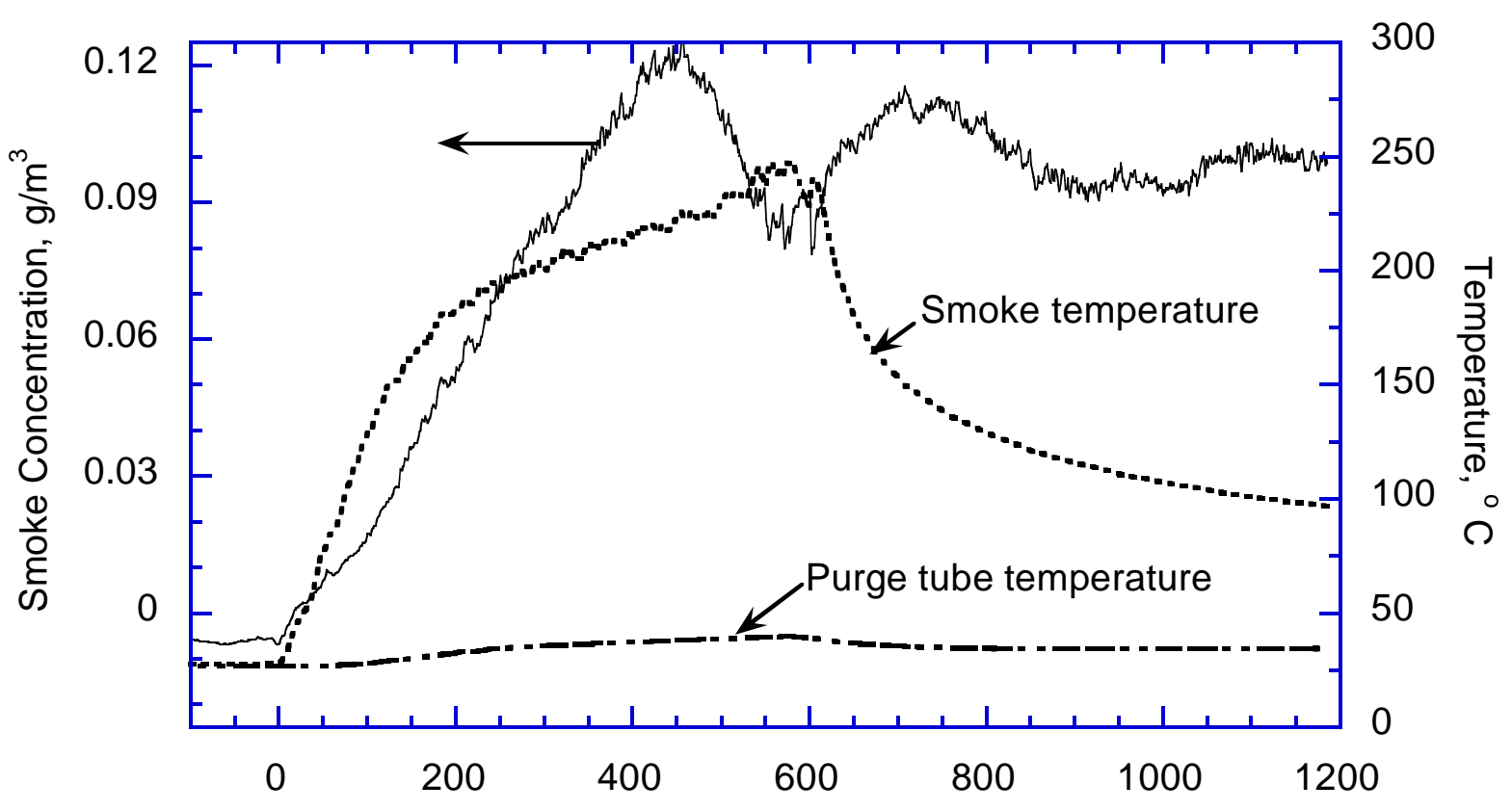

Time, $\mathrm{s}$

Figure 5-1: Smoke concentration and temperature as a function of time for Test 2.

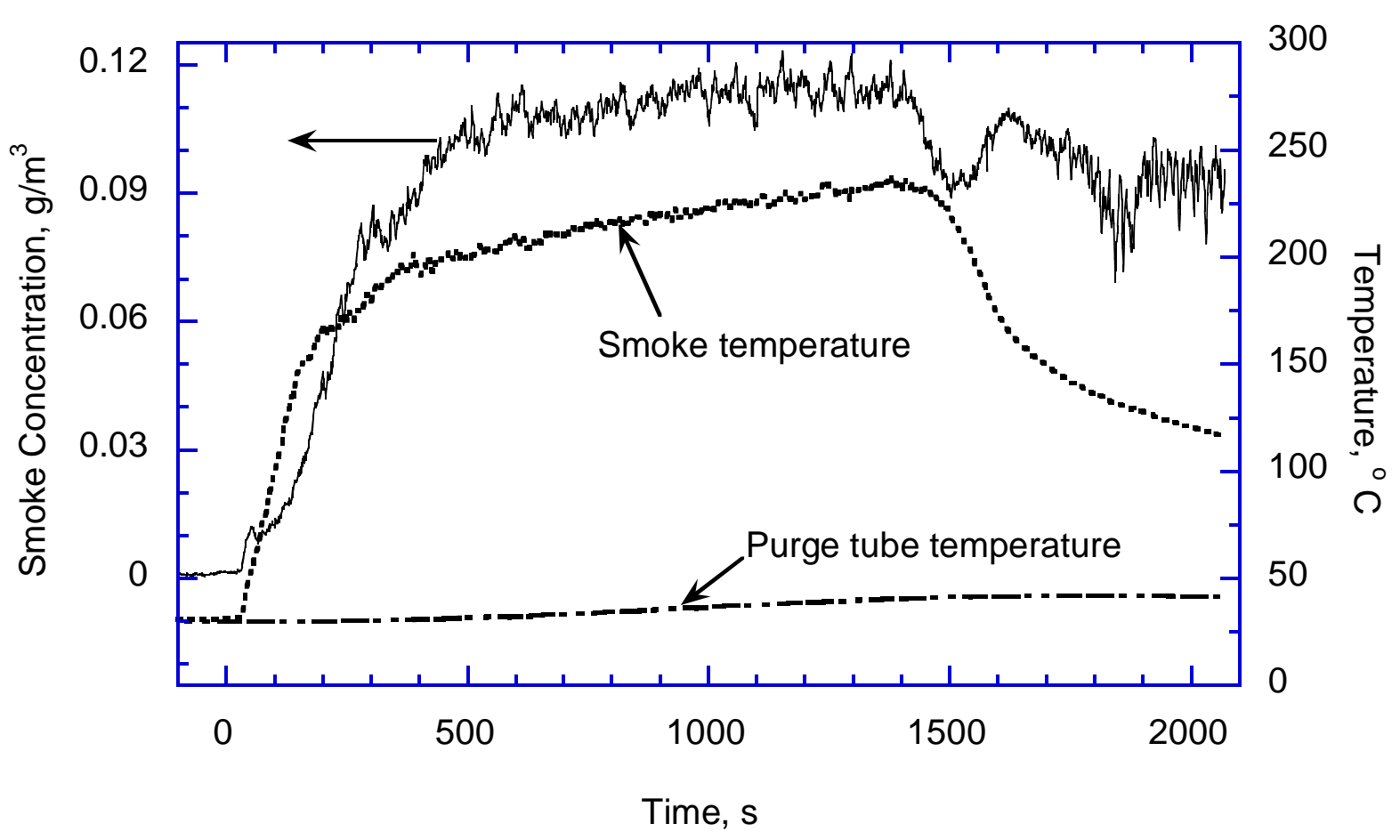

Figure 5-2: Smoke concentration and temperature as a function of time for Test 3. 


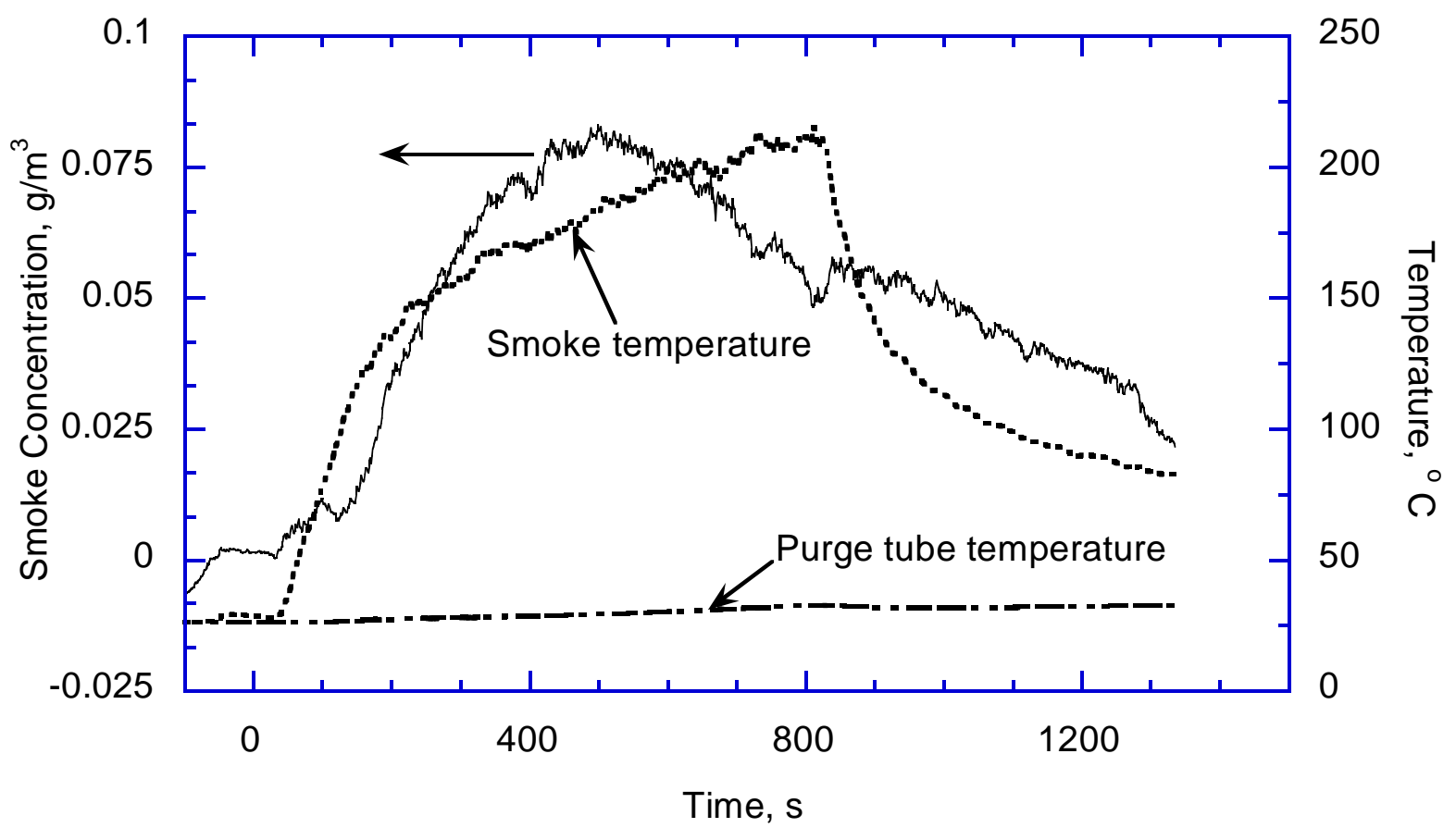

Figure 5-3: Smoke concentration and temperature as a function of time for Test 4.

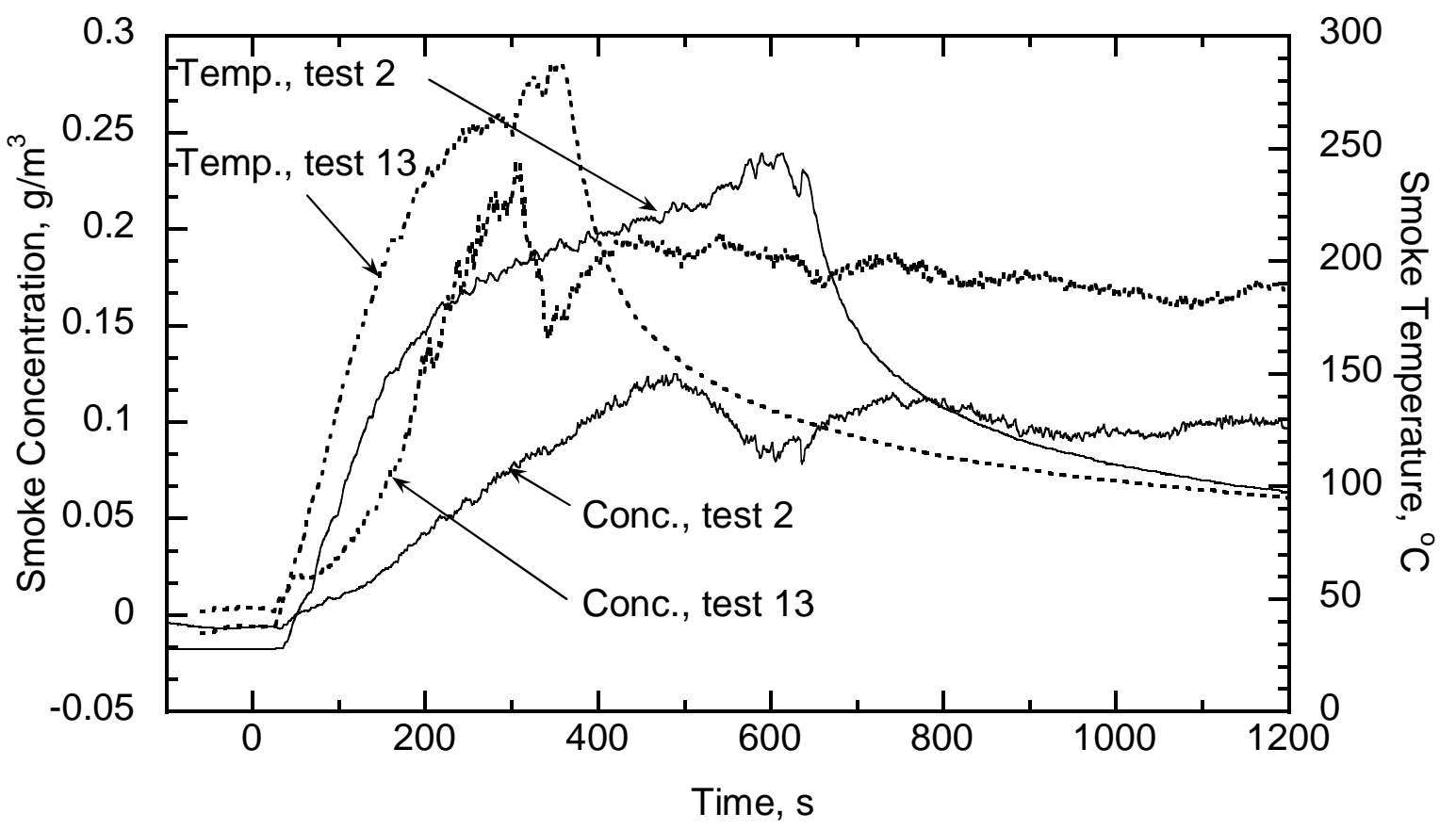

Figure 5-4: Smoke concentration and temperature versus time for a 1 MW (Test 2) and for a 2 MW (Test 13) blended heptane fire both with the door closed. 


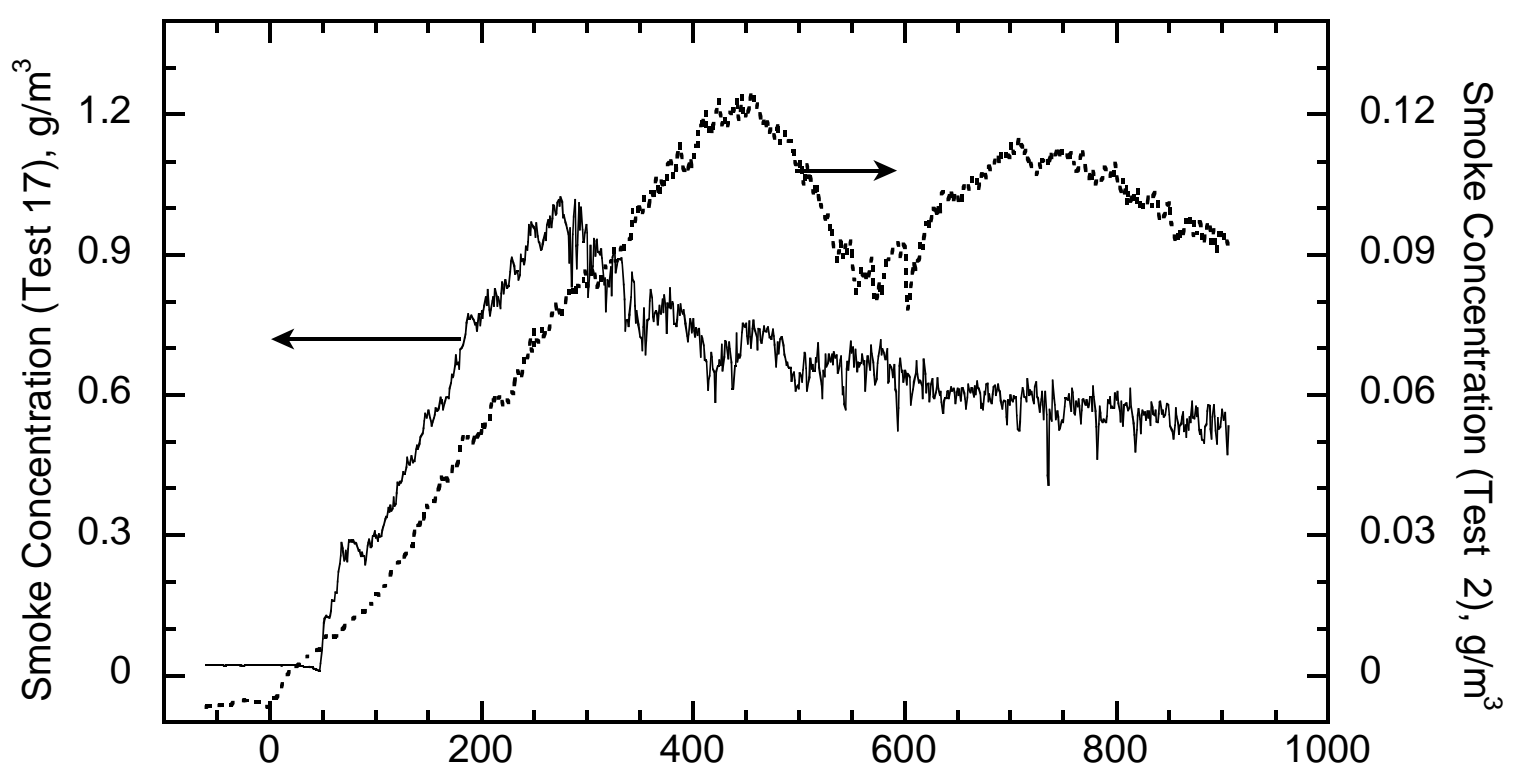

Time, $s$

Figure 5-5: Smoke concentration versus time for toluene (Test 17) and for heptane (Test 2) for a $1 \mathrm{MW}$ test with door closed.

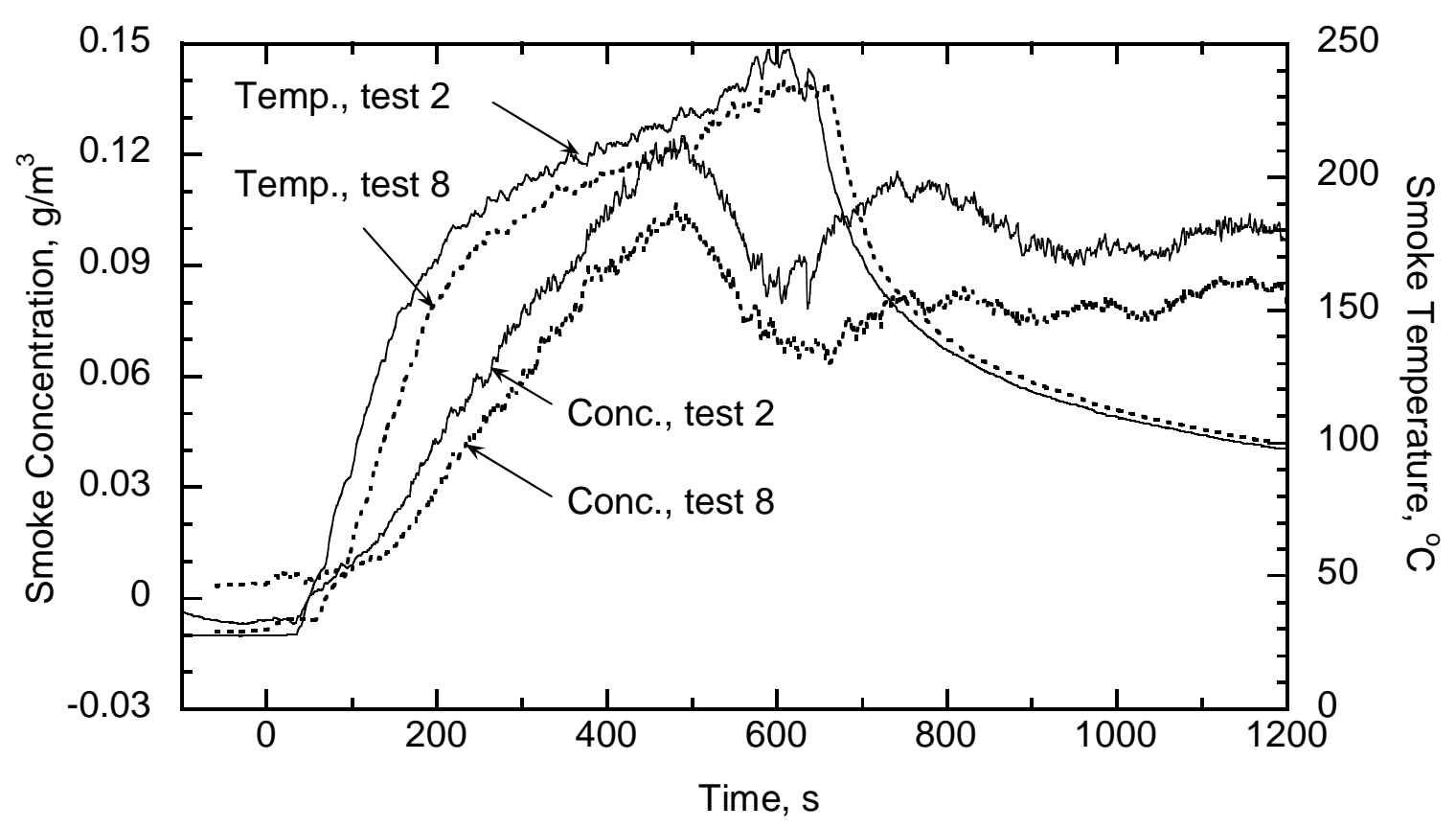

Figure 5-6: Comparison of smoke concentration and smoke temperature for two replicate, $1 \mathrm{MW}$ tests with door closed (Test 2 and Test 8). 


\section{TARGET TEMPERATURES}

\subsection{Description of Measurements}

The surface and core temperatures of Targets A-G were measured by type K thermocouples. Target E was a small rectangular slab $(1 \mathrm{~cm} \mathrm{x} 1 \mathrm{~cm} \times 5 \mathrm{~cm}(0.4$ in $\times 0.4$ in $\times 2$ in) long, with uncertainty equal to $\pm 0.001 \mathrm{~m}( \pm 0.003 \mathrm{ft})$ ) as shown in Figures 6-1 and 6-2, which was

manufactured at NIST using material from the outer jacket of the three conductor PVC cable. Three thermocouples were positioned on the slab to measure the temperature at the lower and upper surfaces and the slab center. Thermocouple E-TC-17 was a type K thermocouple with a $0.16 \mathrm{~cm}$ (0.06 in.) diameter stainless steel sheath, with a time response estimated as approximately $4 \mathrm{~s}$ [OMEGA, 2000]. The two type K thermocouples on the surface of Target $\mathrm{E}$ were composed of insulated bare bead 24 gauge wire, with an estimated time of $1 \mathrm{~s}$.

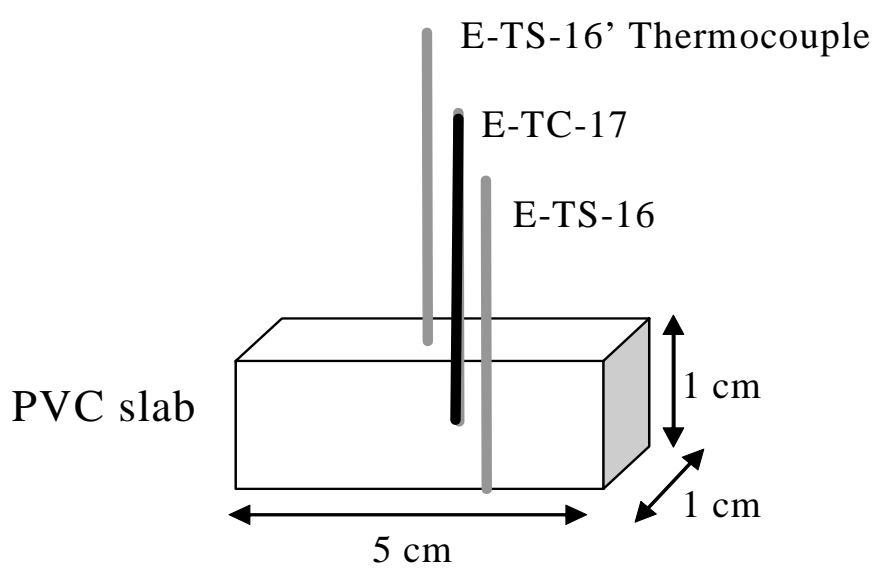

Figure 6-1: Thermocouples on the PVC slab $(1 \mathrm{~cm} \times 1 \mathrm{~cm} \times 5 \mathrm{~cm}$ long) measuring temperatures at the lower and upper surfaces and the slab center. 


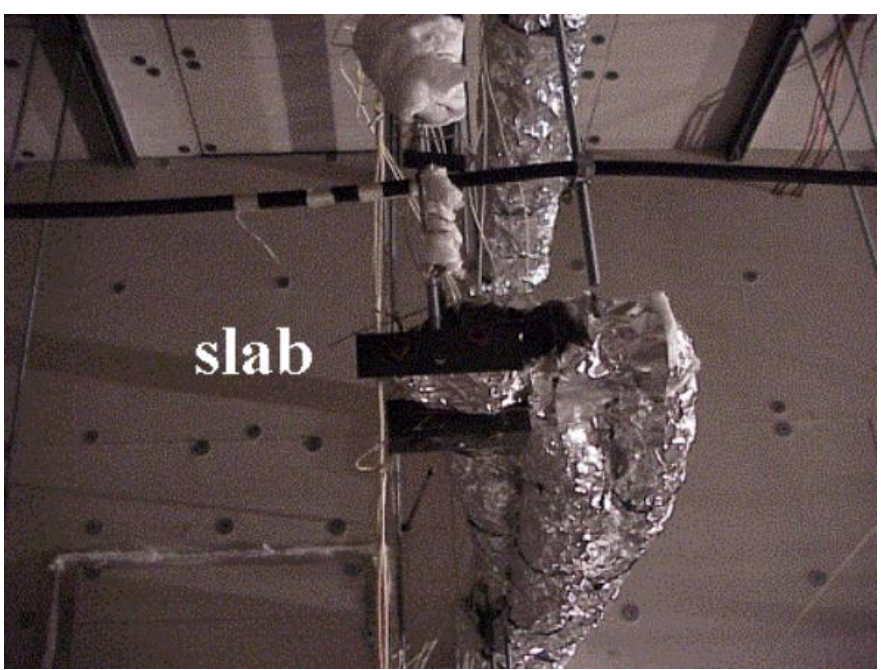

Figure 6-2: Photograph looking towards the north wall with Target E present, a rectangular slab composed of PVC.

Targets A-D and F were mounted horizontally. Target $\mathrm{G}$ was mounted vertically in a cable tray that contained control cables. For Test 7, 10, and 18, Targets A-D, F, and G were power and control cables constructed of nylon/PVC insulation and PVC jacket material. Target B was located at the same elevation and $0.1 \mathrm{~m}$ (3.9 in) from the left edge of the power cable, slab target, and cable tray respectively. The thermocouples were oriented such that they were at the bottom of the horizontal cables. Appendix A of this report describes the structure of the cable materials in detail. Appendix A also contains optical and thermophysical data for the XPE and PVC cable jackets, as well as the "marinate” calcium silicate board wall material.
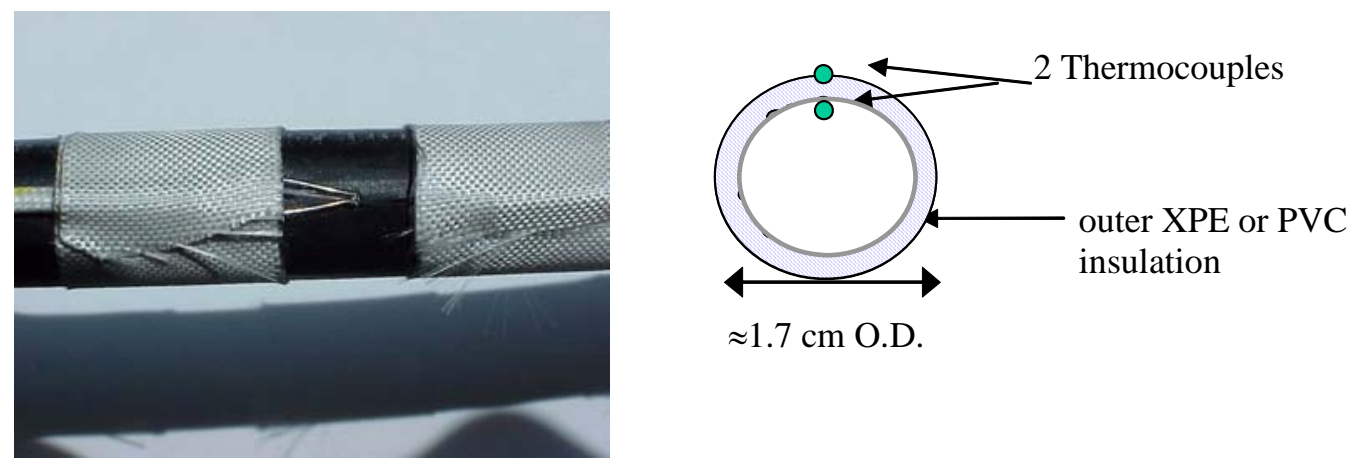

$\approx 1.7 \mathrm{~cm}$ O.D.

\section{Figure 6-3: Photograph and schematic cutaway of a target cable instrumented with bare- bead type $K$ thermocouples on the surface and just under the outer insulation.}

Type K thermocouples were set onto the cable surface and just inside the outer cable jacket material (see Figure 6-3) at various locations as specified in Appendix D. For placement on the cable surface, the insulation was first sliced. The thermocouple was then pushed into the surface at the location of the cut such that the thermocouple bead was partially embedded into the insulation. The same approach was used for mounting the thermocouples on the surface of Target E. 
It should be noted that the cable morphology is complicated and the cables are not symmetrical about the cable center as seen in the detailed schematic diagram in Appendix A. Furthermore, the exact position of the thermocouples relative to various morphological features of the cables was not known. Measurement of temperatures inside and on the cable surface may be affected by the exact thermocouple placement relative to the cable structure. This effect is not quantified and further study may be needed to understand the impact of cable morphology on cable thermal behavior

Two Target E slabs were fabricated using PVC cable jacket material. Target E was located in a high temperature region of the compartment and was initially present during Tests 2 and 10, but was damaged during these tests. Target E was undamaged during Tests 1 and 7 . Target E was not present during Tests 3-6, 8, 9, and 11-18.

For Tests 1-5, 8, 9, 13, 14 and 15, Targets A-D, F, and G were power and control cables constructed of XPE (flame retarded crosslinked polyethylene) insulation and Hypalon jacket material. Hypalon is a registered DuPont trademark for chlorosulfinated polyethylene (CSPE). Table 6-1 lists the designation, measurement location, and orientation of a number of thermocouples. All of the thermocouples on the vertical cable were positioned such that they faced the south wall of the compartment, whereas all of the thermocouples on the horizontal cables were positioned such that they faced downward. The thermocouples were type K and 24 gauge with bead diameters of $1.05 \mathrm{~mm} \pm 0.04 \mathrm{~mm}(0.04 \mathrm{in} \pm 0.002 \mathrm{in})$.

For a variety of reasons (including primarily burning of cables), some of the thermocouple signals did not operate properly during a number of the tests. Appendix E of this report lists the inoperative channels, which are excluded from the companion electronic data set. 
Table 6-1: Thermocouple Physical Location and Orientation on Targets B, E, and G.

\begin{tabular}{|l|c|c|}
\hline Designation & Type & Orientation \\
\hline A-TS-6,18,29 & on cable surface & facing downward \\
A-TC-19 & facing downward \\
\hline B-TS-4,14,27 & on cable surface & facing downward \\
B-TC-15 & under surface & facing downward \\
\hline C-TS-1,8,10,22,24 & on cable surface & facing downward \\
C-TC-2,9,11,23,25 & under surface & facing downward \\
\hline D-TS-3,12,26 & on cable surface & facing downward \\
D-TC-13 & under surface & facing downward \\
\hline E-TS-5, 16 & on top \& bottom & facing upwards \& downwards \\
E-TC 17 & surfaces slab center & in center \\
\hline F-TS-7,20,30 & on cable surface & facing downward \\
F-TC-21 & under surface & facing downward \\
\hline Vertical-TS-31,32,33,35,36 & on cable surface & facing South Wall \\
Vertical-TC-34 & under surface & facing South Wall \\
\hline$* \quad$ the uncertainty is estimated as \pm 0.02 m $(0.06$ ft). & \\
$* *$ Target G: cable in vertical cable tray & \\
\hline
\end{tabular}

\subsection{Results and Discussion}

The transient thermocouple measurements on slab E during Test 2 are shown in Figure 6-4. The expanded instrument uncertainty (with a coverage factor of 2 ) in the thermocouple measurements is estimated as approximately $4{ }^{\circ} \mathrm{C}\left(7^{\circ} \mathrm{F}\right)$ based on manufacturer literature. This does not include uncharacterized uncertainty associated with surface contact, thermocouple placement, etc.

The results show that for the first $400 \mathrm{~s}$ after ignition the top of the slab heated the fastest, followed by the bottom and then the slab center. After $400 \mathrm{~s}$, the thermocouple in the slab center exhibited a higher temperature than the slab surface, which is not expected. The softening temperature of the PVC used here was observed to be approximately $180{ }^{\circ} \mathrm{C}\left(356{ }^{\circ} \mathrm{F}\right.$ ) [Harris, 2003], which may explain the temperature trends after $400 \mathrm{~s}$ when polymer melting may have caused the observed slab temperatures. The results for Tests 3 and 4 were similar to those in Test 2 (see Figure 6-7 for Test 3; Test 4 not shown). The gas temperature near Slab E is discussed in detail in Section 9.4 of this report. 


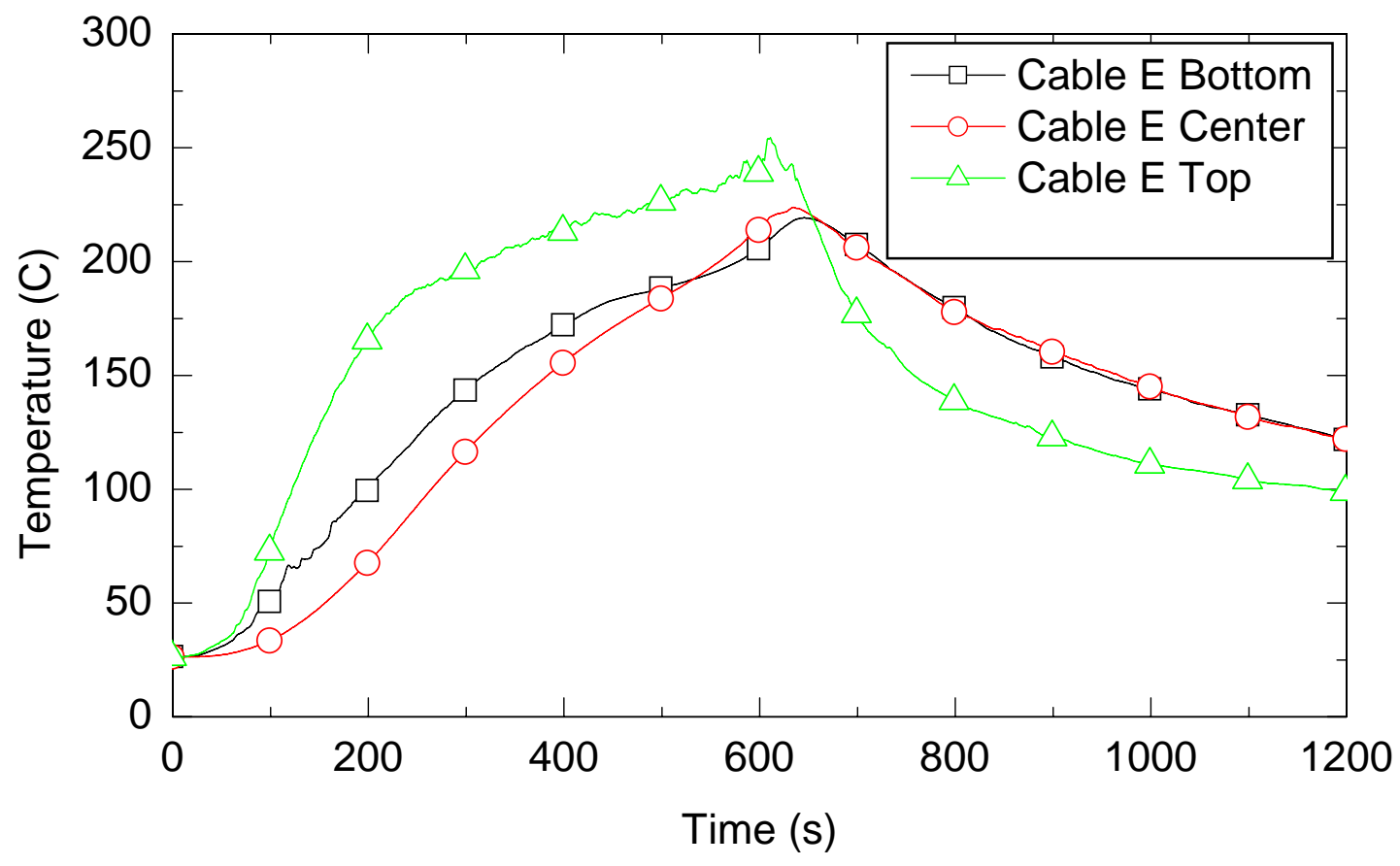

Figure 6-4: The transient temperatures in slab E during Test 2.

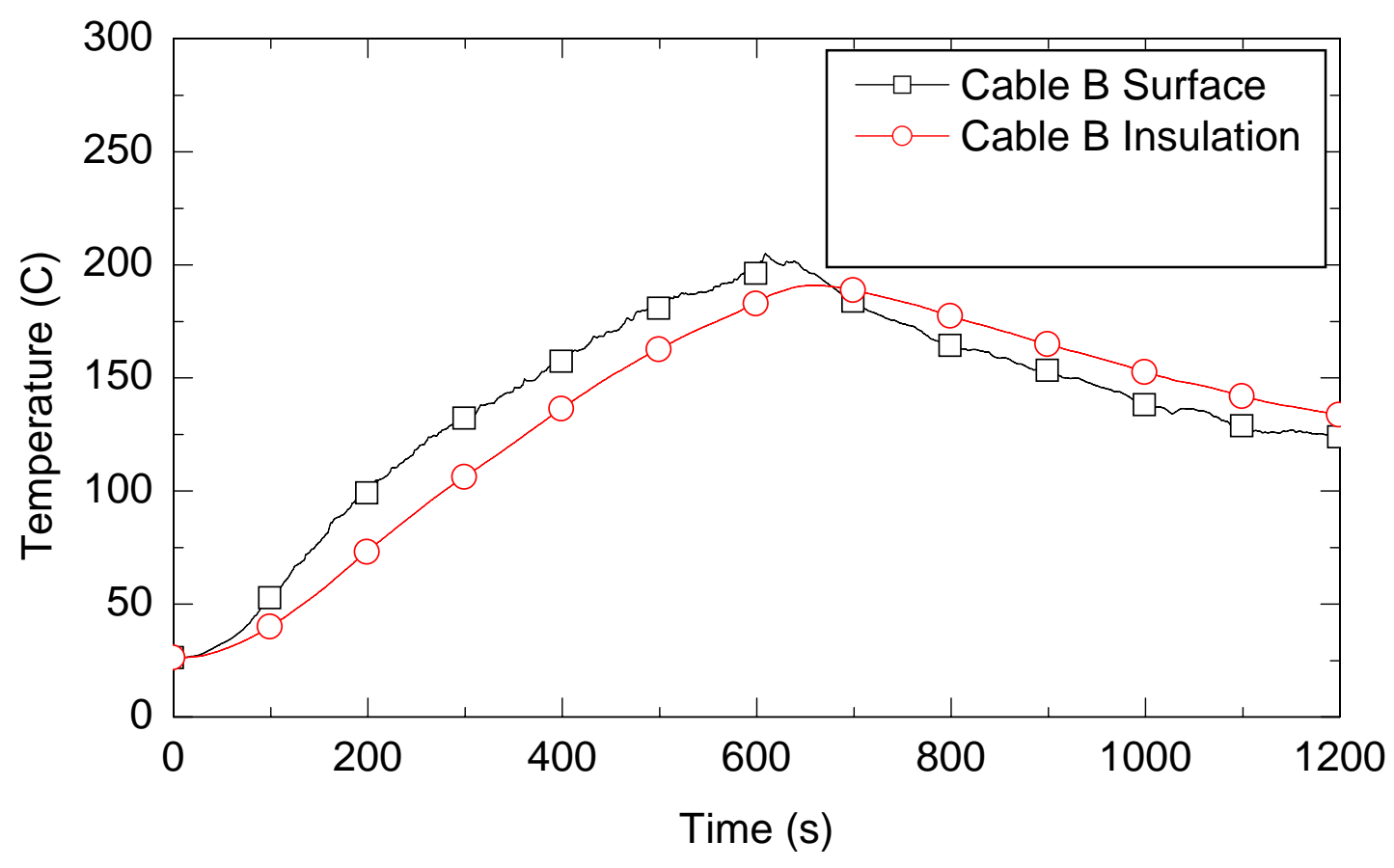

Figure 6-5: The transient temperature on Target B during Test 2. 


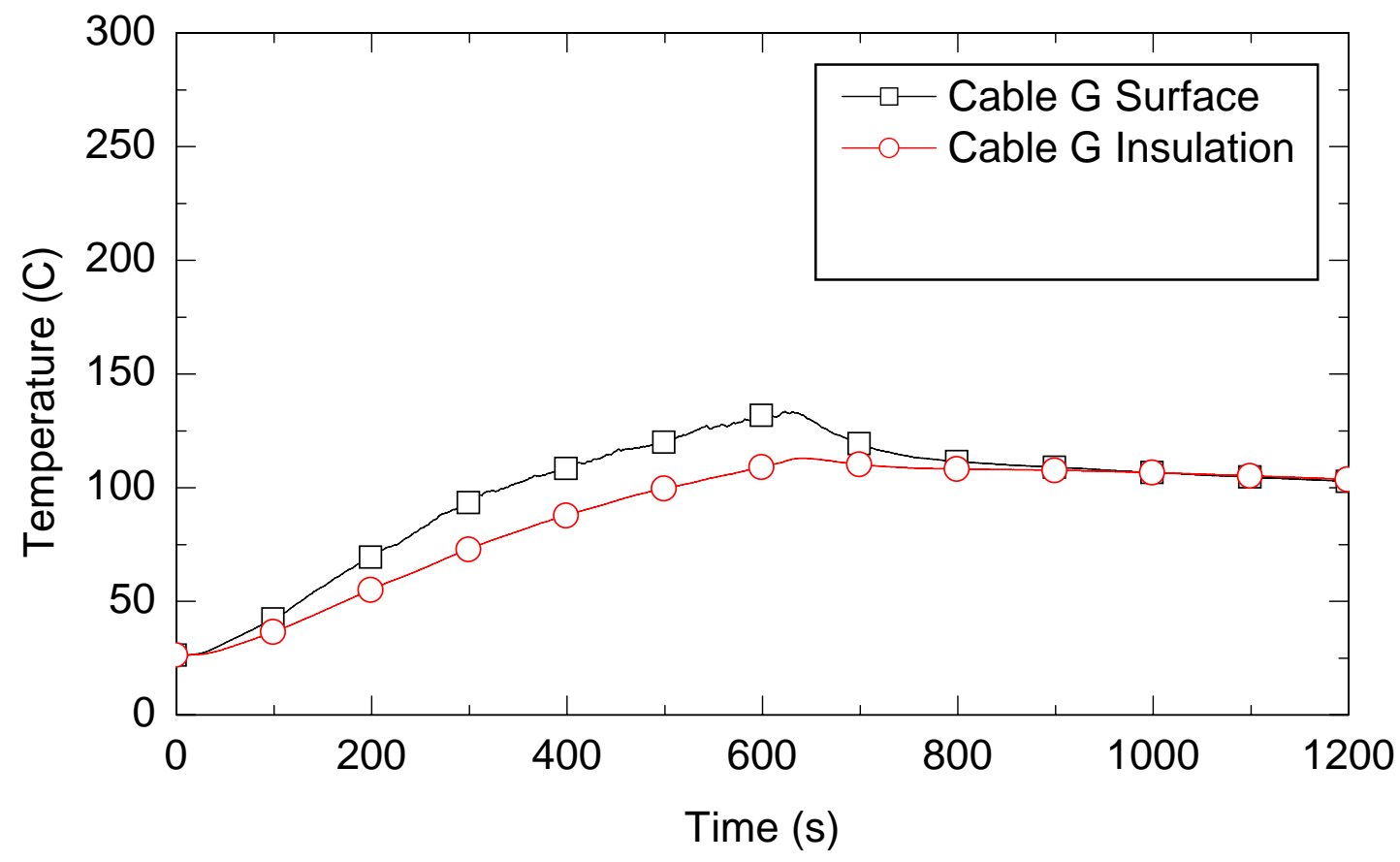

Figure 6-6: The transient temperature on the vertical cable, Target G, during Test 2.

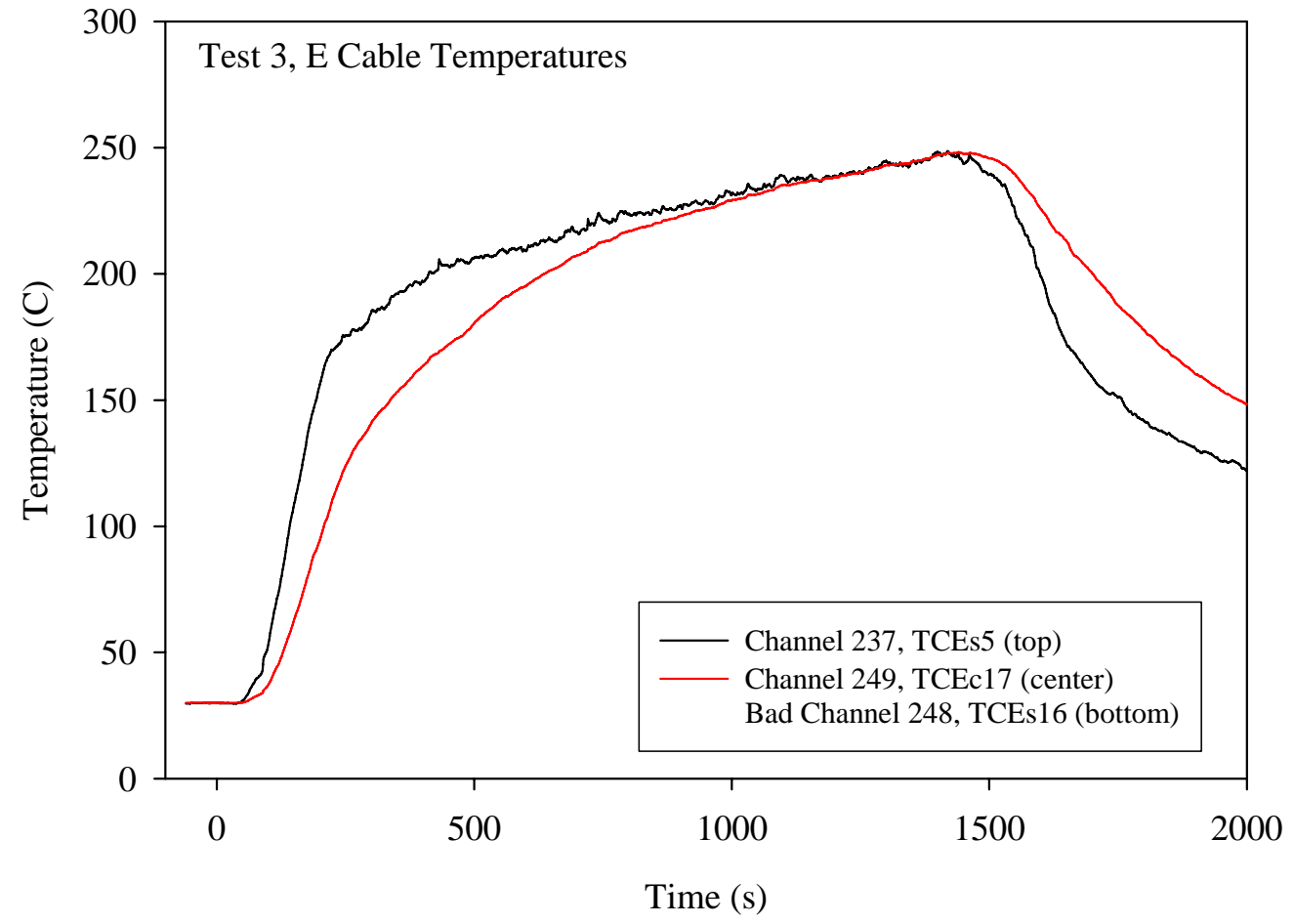

Figure 6-7: The transient temperature at three locations in slab E during Test 3. 
The transient thermocouple measurements on the vertical cable (target $G$ ) during Test 2 are shown in Figure 6-6. The surface temperature steadily rises from ambient at ignition to nearly $130{ }^{\circ} \mathrm{C}\left(266^{\circ} \mathrm{F}\right)$. As expected, the surface temperature was consistently higher than the core temperature. The results for Tests 3 and 4 were qualitatively similar (not shown).

The transient thermocouple measurements on the horizontal cable (target B) during Test 2 are shown in Figure 6-5. The temperatures were somewhat higher than those on the vertical cable, which was considerably further from the fire source. The surface temperature peaked at nearly $200{ }^{\circ} \mathrm{C}\left(392{ }^{\circ} \mathrm{F}\right)$ and the core temperature was nearly $190{ }^{\circ} \mathrm{C}\left(374{ }^{\circ} \mathrm{F}\right)$. The temperature results were qualitatively similar in Tests 3 and 4 (not shown).

The gas temperature near the targets is discussed in Section 9 of this report. 



\section{VENT AND DOORWAY FLOWS}

\subsection{Doorway Flows}

In this section, a description of the measured mass and enthalpy flows through the compartment doorway is given. The doorway was open during Tests 3, 5, 9, 14, 15 and 18. To determine the mass and enthalpy flows into and out of the compartment, measurements of both the temperature field and the gas velocity field were conducted.

To determine the velocity profile in the doorway, 14 bidirectional probes were placed in three vertical arrays in the door opening. The probe locations are indicated by the dark circles in Figure 7-1 as viewed from the outside of the compartment. The instrument locations were essentially symmetric. One probe (PD-12) in the lower north portion of the doorway did not function and is not shown in Figure 7-1.

The gas temperatures in the doorway were measured using type-K bare bead thermocouples. A bare bead thermocouple was positioned $1 \mathrm{~cm}$ above the center of each of the bidirectional probes. To confirm the thermocouple measurements, a limited number of aspirated thermocouples were placed in the doorway. The locations of the three aspirated thermocouples are indicated by the “+” symbols in Figure 7-1. The results of the aspirated thermocouple measurements confirm that radiative flux from the fire was not affecting the bare bead thermocouple readings.

The bidirectional probes were connected to MKS model 220 Baratron differential pressure transducers, each with a maximum differential pressure measurement capability of $133 \mathrm{~Pa}$ (3 $\mathrm{lb} / \mathrm{ft}^{2}$ ). The transducers were calibrated using a Microtector Hook Gauge type manometer. The differential pressure, $\Delta p$, measured by each probe, and the temperature, $T$, at the corresponding probe location were used to compute the gas velocity, $v$, by the equation:

$$
v=\frac{1}{K} \sqrt{\frac{(2 \Delta p)}{\rho}} \text {, where } \rho=\frac{(M) P_{\text {absolute }}}{R T} .
$$

In this computation, the density, $\rho$, was computed as a function of temperature using the ideal gas law. The gas was assumed to be pure air with a molecular weight $(M)$ of $0.029 \mathrm{~kg} / \mathrm{mol}$. Here $P_{\text {absolute }}$ is the absolute barometric pressure and $R$ is the universal gas constant. The $K$ factor was taken as 1.08, as reported by McCaffrey and Heskestad [1976]. The bidirectional probes measure the flow in either direction, into or out of the compartment. A positive value denotes flow into the compartment and a negative value signifies flow out of the compartment. 


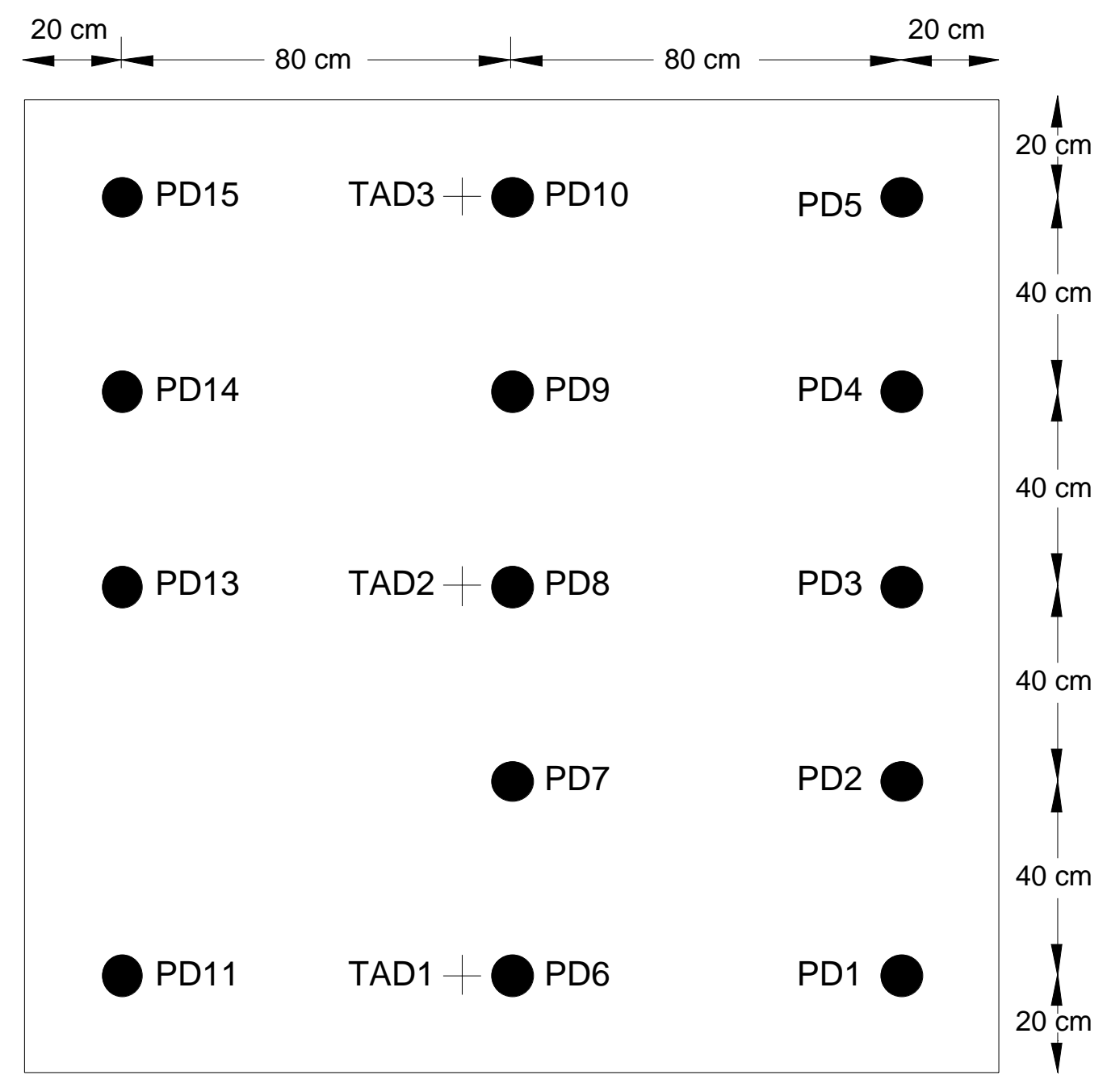

Figure 7-1: Locations of instrumentation in the door opening.

\subsection{Velocities and Mass Flow Through the Doorway}

A plot of the velocity profile measured using the bidirectional probes at the doorway opening for Test 3 is shown in Figure 7-2. The plot shows the probes located along the centerline. The lowest two probes recorded velocities into the compartment equal to approximately $1.0 \mathrm{~m} / \mathrm{s}$ (3.3 $\mathrm{ft} / \mathrm{s})$ during the fire. The uppermost probe measured a velocity equal to nearly $-2.0 \mathrm{~m} / \mathrm{s}(-6.6$ $\mathrm{ft} / \mathrm{s}$ )(out of the compartment), where as the probe second from the top was equal to approximately $1.0 \mathrm{~m} / \mathrm{s}(3.3 \mathrm{ft} / \mathrm{s})$ during the test. The probe located in the center fluctuated slightly above zero indicating a small flow into the compartment at this location. The combined expanded uncertainty of the velocity measurements is $\pm 0.3 \mathrm{~m} / \mathrm{s}( \pm 0.98 \mathrm{ft} / \mathrm{s})$. The uncertainty is due to both scatter in the data and uncertainty in the calibration. 


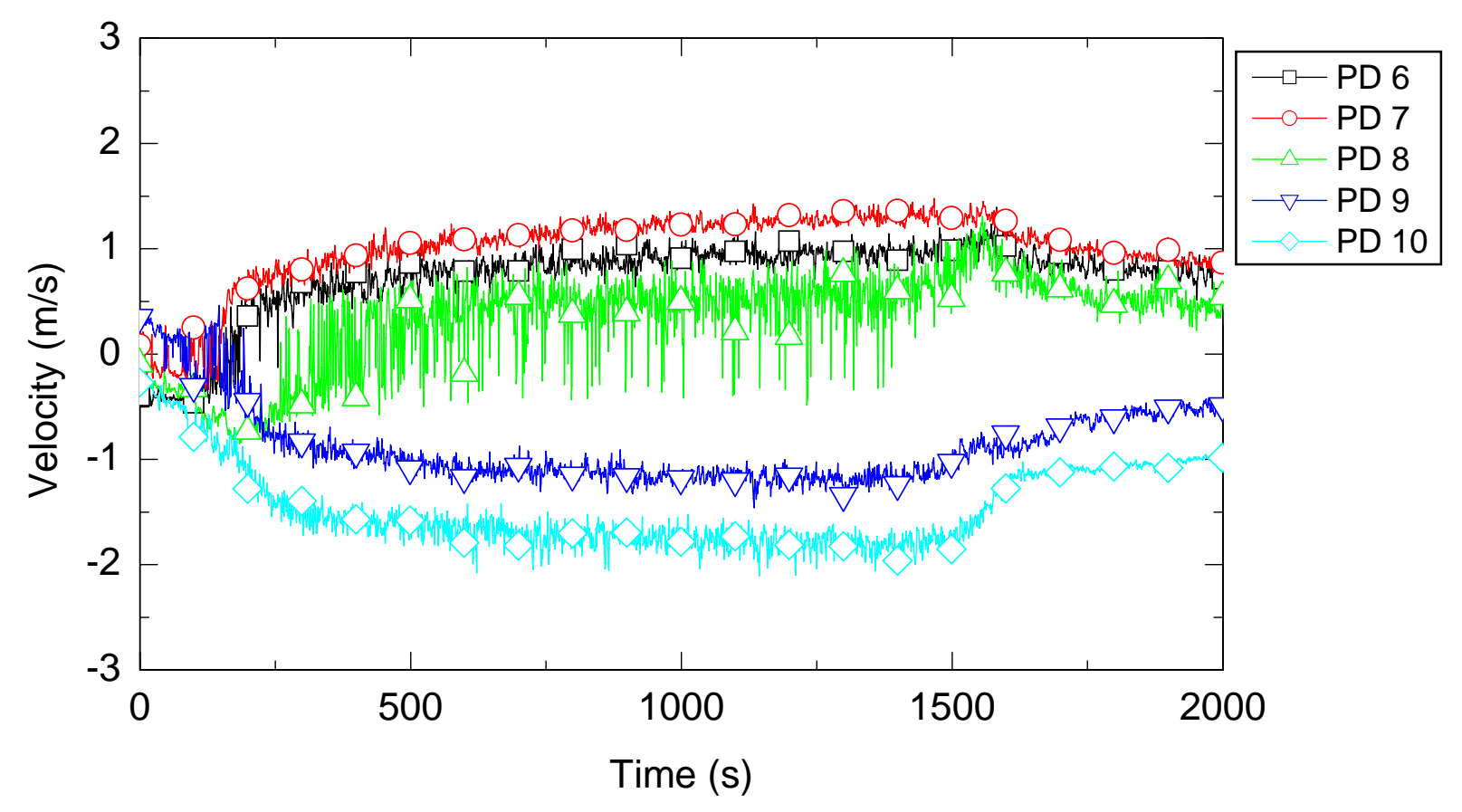

Figure 7-2: Velocities through the doorway measured at the centerline.

Figure 7-3 shows the velocity profile measured on the south side of the doorway for bidirectional probes PD1 through PD5 in Test 3. As with the velocities measured at the centerline, the lower probes measured gas flow into the compartment while the upper probes measured flow out of the compartment. The probe located at the halfway height of the door opening was slightly negative, indicating the flow was going out of the compartment at this location. The velocities measured on the north side were similar to those measured at the south side, as shown in Figure 7-4. For the north side, there were only four bidirectional probes measuring the velocities. There was no probe at the location $60.0 \mathrm{~cm}$ (23.6 in) from the floor (see Figure 7-1). 


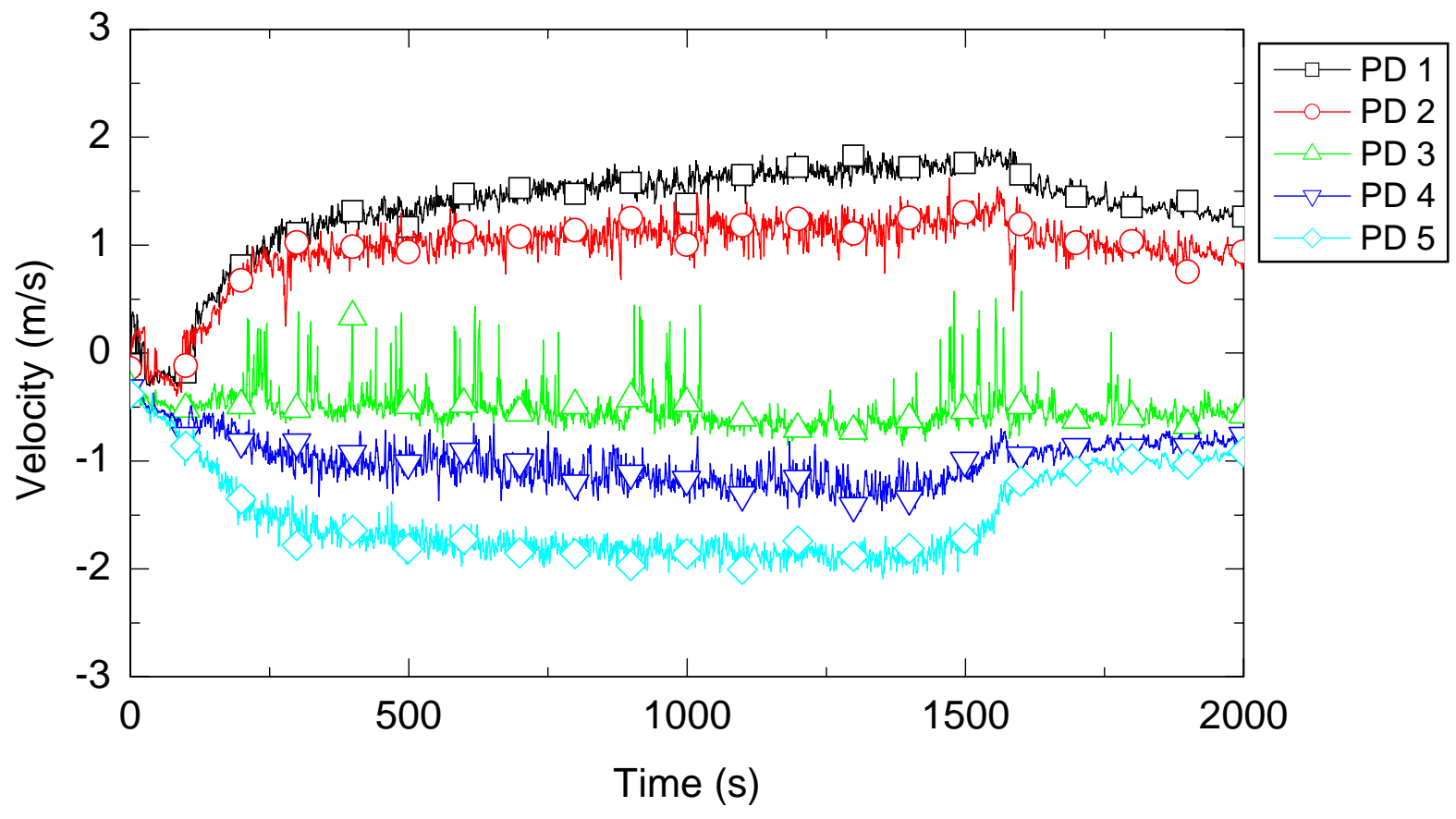

Figure 7-3: Velocities through the doorway measured on the south side.

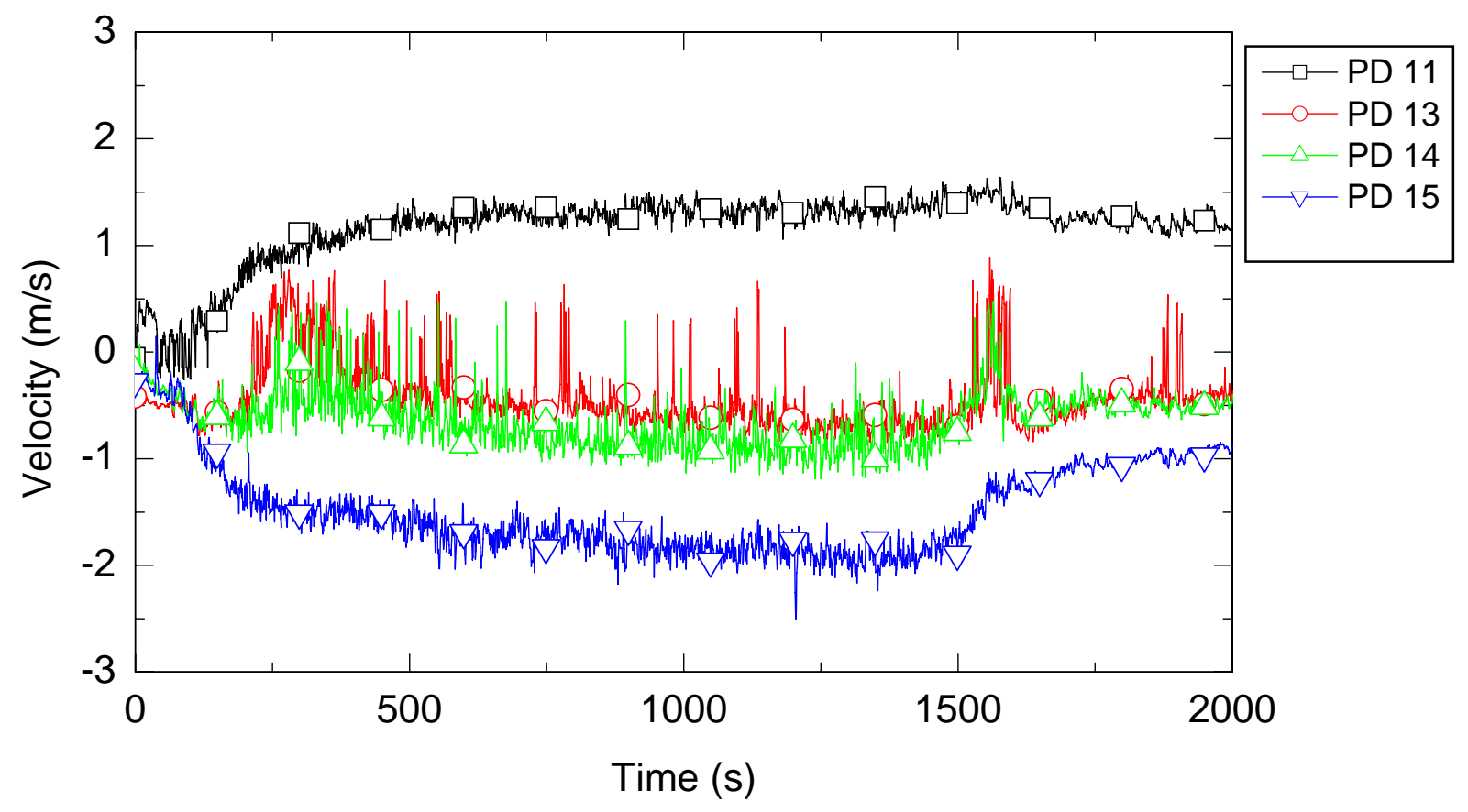

Figure 7-4: Velocities through the doorway measured on the north side. 
The bidirectional probes were used to measure the velocity of the gas flow through the opening, which was then used to compute the mass flow through the doorway. The $4.0 \mathrm{~m}^{2}\left(43 \mathrm{ft}^{2}\right)$ cross-sectional area of the doorway was divided into 14 sections, each containing a bidirectional probe and a thermocouple. The instrument measurements were taken as representative of flow in each section. The net mass flow through the doorway was computed as the summation of the mass flows through each of the sections by using the equation: $\sum \dot{m}=\rho \bar{v} A$, where $A$ is the area of the section corresponding to each velocity measurement. As with the velocity calculations, the density was computed assuming pure air using the ideal gas law.

During the test series, bidirectional probe PD13 experienced a failure and did not record velocity data for Tests 9, 15, or 18. No velocity column data is given for this location in the data files. In order to compute the mass flow through the doorway, the velocity data from Test 3 for PD13 was substituted into the mass calculations as the approximate velocity at this location. For each of the other bidirectional probes, the velocities measured at a particular location were very similar from test to test (excluding Test 5 when the ventilation was operating). Because the results were so repeatable, using the data from Test 3 to replace the missing data in the mass calculations appears to be a good approximation.

Figure 7-5 shows the mass flow into the compartment through the doorway for Test 3 . The flow into the compartment was predominantly through the lower sections of the doorway. The mass flow out of the compartment is shown in Figure 7-6. Figure 7-7 shows the net mass flow through the doorway for Test 3. The combined expanded uncertainty in the mass flow measurements is $\pm 0.60 \mathrm{~kg} / \mathrm{s}( \pm 1.3 \mathrm{lb} / \mathrm{s})$ and is predominantly due to fluctuations in the velocity measurements. Before the fuel was ignited, there was an initial net flow of approximately $0.50 \mathrm{~kg} / \mathrm{s}(1.1 \mathrm{lb} / \mathrm{s})$ out of the compartment through the doorway. This was due to the close proximity of the doorway to the large overhead hood drawing air out of the test facility. The zero differential reading on the compartment pressure transducer during this time indicates that any mass flow out of the doorway was being replenished by flow into the compartment through leakage areas. When the fire was ignited, there was an initial net mass flow out of the compartment as the fire grew and the expanding gases pushed air out of the compartment, as seen in Figure 7-7. The net mass flow out of the compartment reached nearly $2.0 \mathrm{~kg} / \mathrm{s}(4.4 \mathrm{lb} / \mathrm{s})$. About $300 \mathrm{~s}$ into the test, the conditions equilibrated and the mass flow leaving the compartment was approximately equal to the mass flow entering. This equilibrium continued until the fire was extinguished at $1500 \mathrm{~s}$. The cooling of the compartment increased the gas density and drew a burst of cool air into the compartment (further cooling the compartment). 


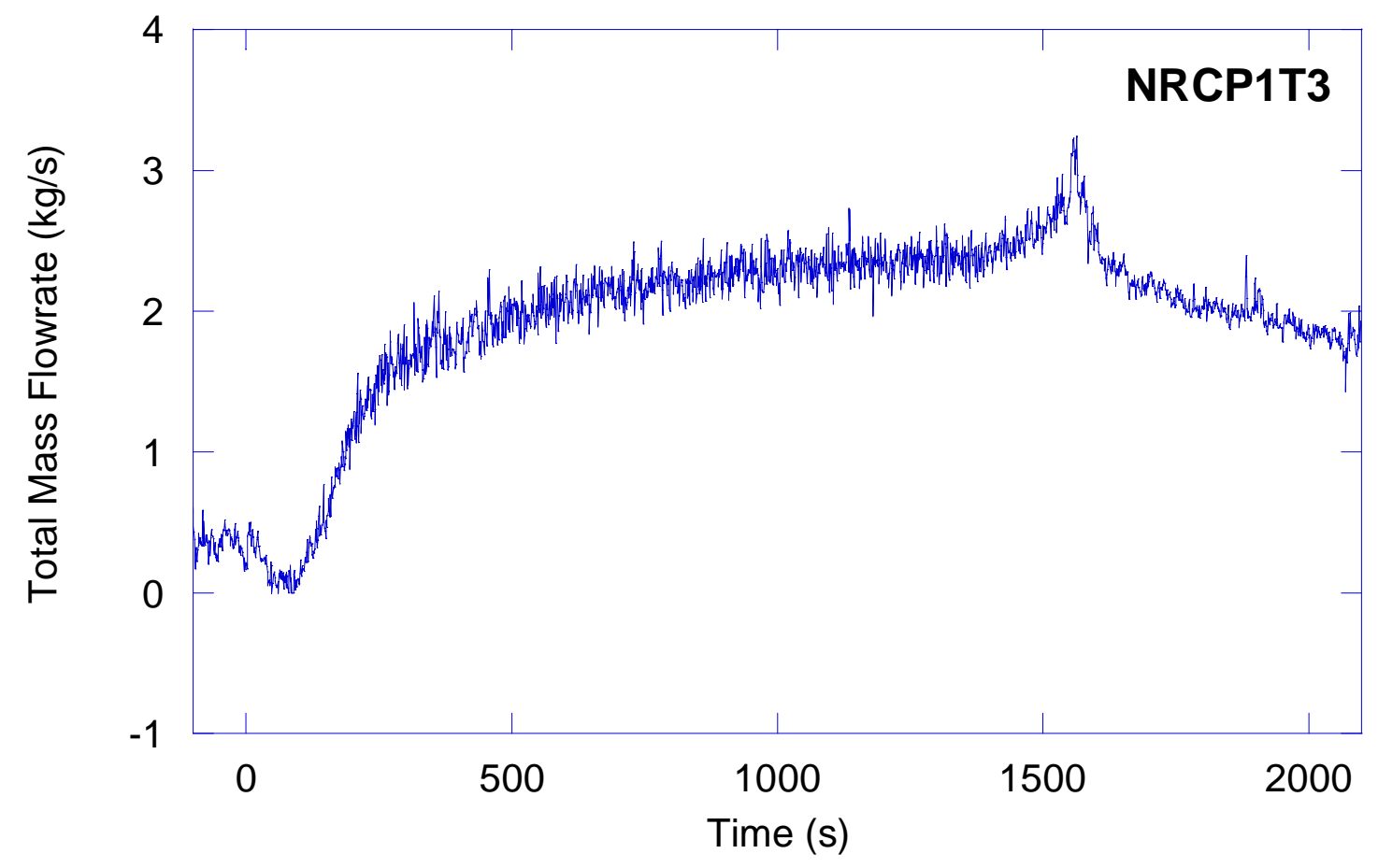

Figure 7-5: Mass flow into the compartment through the open doorway for Test 3.

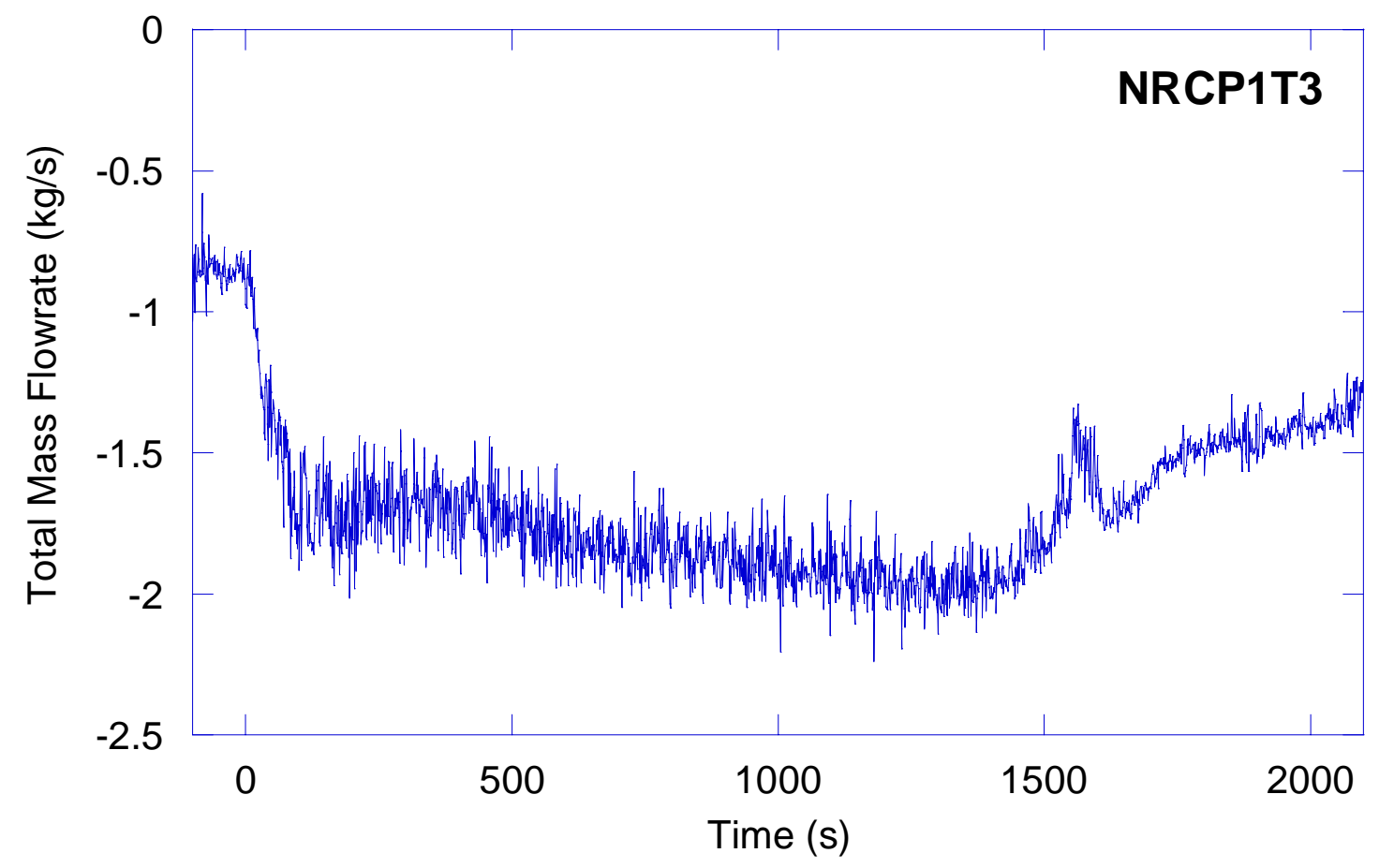

Figure 7-6: Mass flow out of compartment through the upper portion of the doorway for Test 3. 


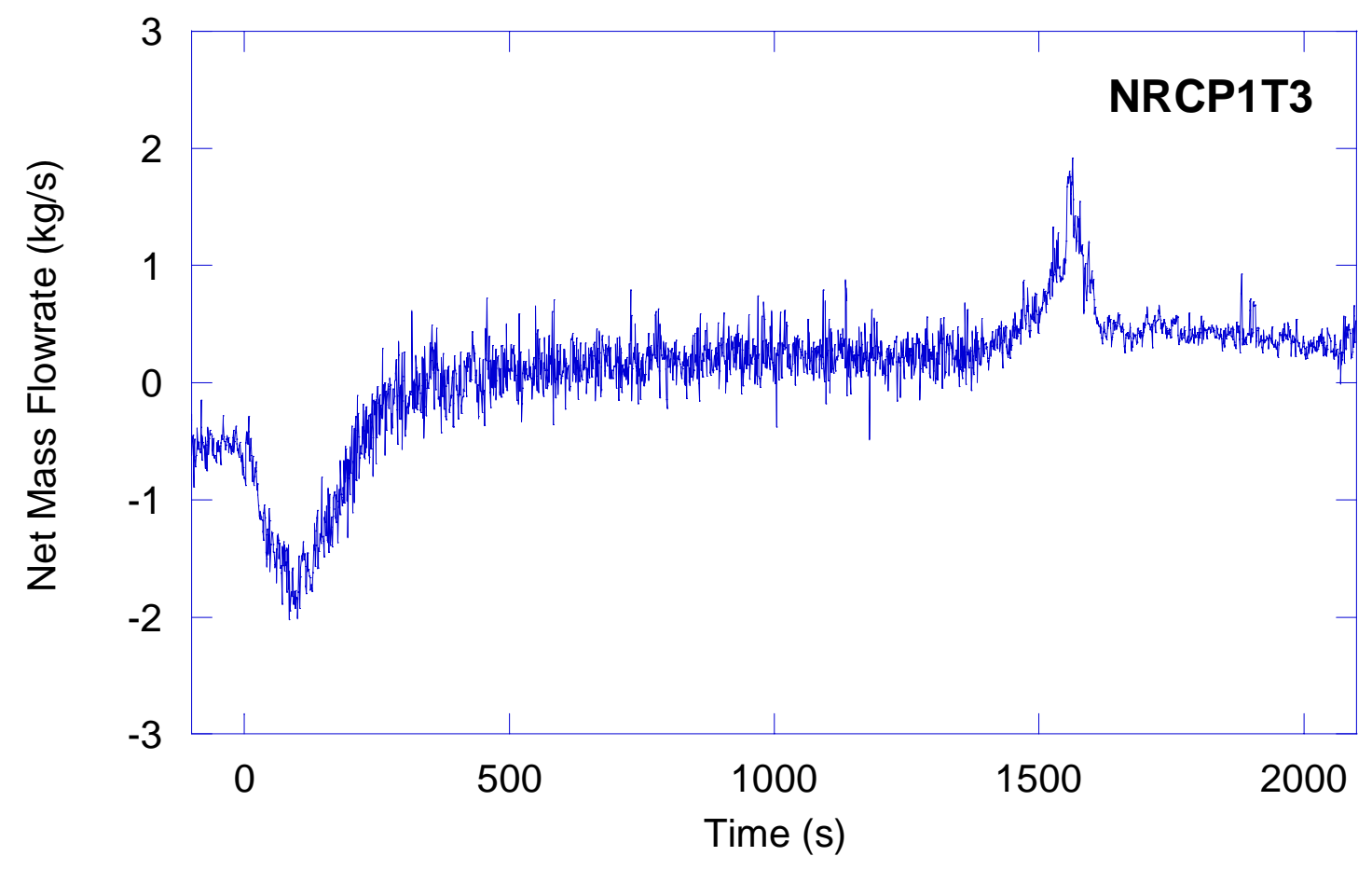

Figure 7-7: Net mass flow through doorway for Test 3.

\subsection{Heat Loss Through the Doorway}

The temperature and velocity measurements acquired at the door opening were used to compute the total heat loss through the doorway $\left(\dot{Q}_{d}\right)$ :

$$
\dot{Q}_{d}=\sum \dot{m} C_{p} \Delta T=\sum \rho \bar{v} A C_{p} \Delta T
$$

The exiting gas was assumed to be pure air, and the density, $\rho$, was computed using the ideal gas law. The heat capacity, $C_{p}$, was likewise computed for pure air as a function of temperature using the DIPPR 85/NIST equation for ideal gas heat capacity. The temperature difference, $\Delta T$, is the difference of temperatures on either side of the doorway. The energy transfer through the doorway was computed for each section about the velocity and temperature measurement location. The summation over the entire doorway opening was computed as the net energy transfer through the doorway. A graph of the resulting thermal energy convected through the doorway for Test 9 is shown in Figure 7-8. The negative total energy indicates a heat flow out of the compartment. The results indicate that as much as one-third of the heat exited through the doorway in the $1 \mathrm{MW}$ fire in Test 9 . The rest of the energy went to heat the walls during the test (see Section 10). The combined expanded uncertainty in the energy flux measurements is $\pm 40 \mathrm{~kW}$. 


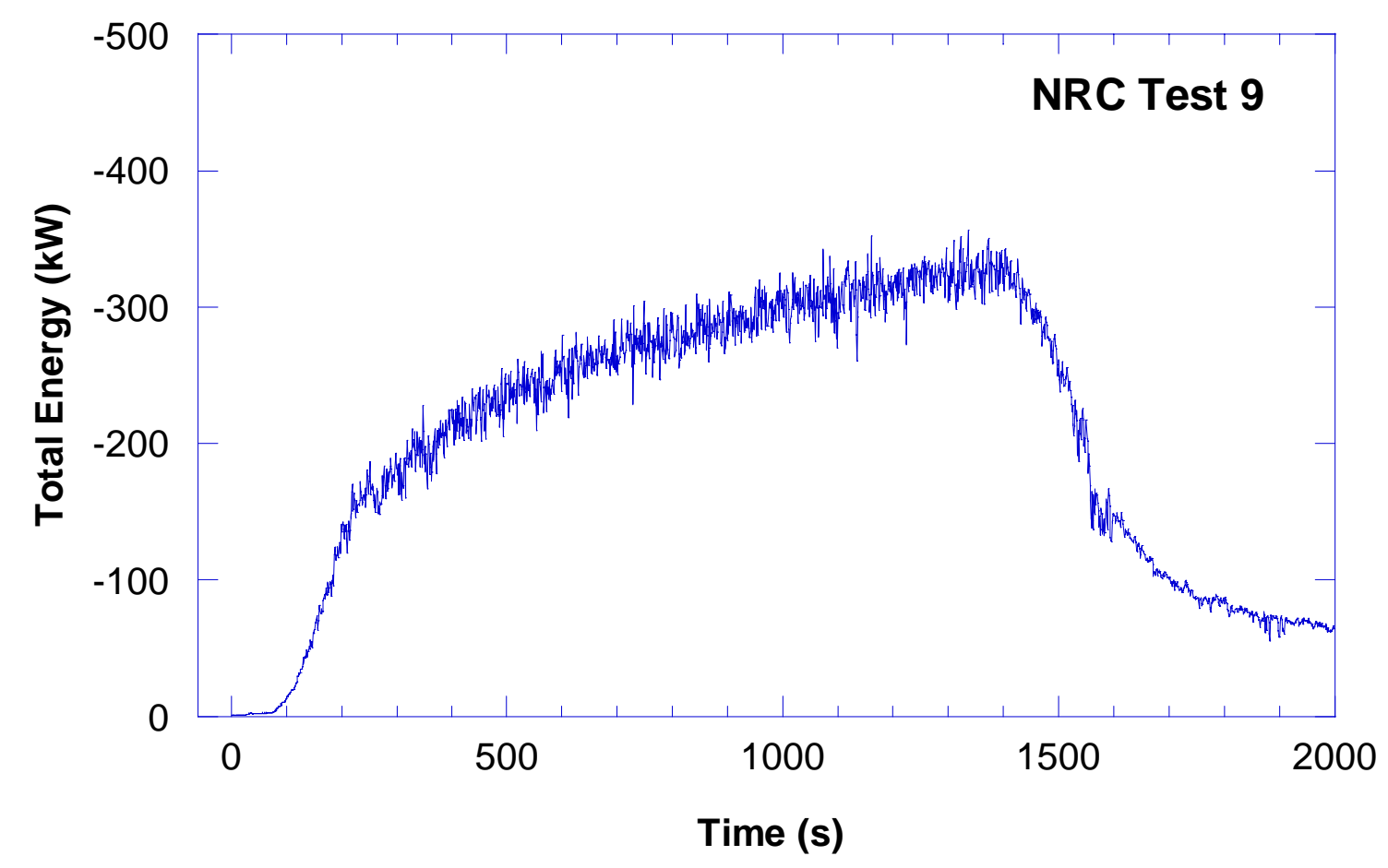

Figure 7-8: The energy loss through the doorway during Test 9.

\subsection{Ventilation Supply and Exhaust}

A forced air ventilation system supplied air to the compartment through one vent and exhausted it through another. The two $0.70 \mathrm{~m}$ by $0.70 \mathrm{~m}$ ( $2.3 \mathrm{ft}$ by $2.3 \mathrm{ft})$ vents were located directly opposite one another on the north and south walls of the compartment. The center of each vent opening was located $2.4 \mathrm{~m}(7.9 \mathrm{ft})$ from the compartment floor at a distance of $11.22 \mathrm{~m}(36.80 \mathrm{ft})$ from the west wall. A blower was attached to the vent on the south wall to feed the supply air to the compartment. The exhaust vent on the north wall led to the building exhaust hood. The ventilations system was operated during Tests 4, 5, 10 and 16.

To determine the air flow into and out of the compartment, bidirectional probes were used to measure the pressure differential in the vents, $\Delta p$, which was then used to compute the velocity. As with the doorway probes, the ventilation probes were connected to MKS model 220 Baratron differential pressure transducers, with a maximum differential of $133 \mathrm{~Pa}\left(3 \mathrm{lb} / \mathrm{ft}^{2}\right)$. The velocity of the air moving through the vents was computed by the equation:

$$
v=\frac{1}{K} \sqrt{\frac{(2 \Delta p)}{\rho}} \text {, where } \rho=\frac{(M) P_{\text {absolute }}}{R T} .
$$

As before, the $K$ factor was taken as 1.08 and the density, $\rho$, was computed as a function of temperature using the ideal gas law. The supply ventilation gas was assumed to be pure air, ( $M=$ $0.029 \mathrm{~kg} / \mathrm{mol})$. The exhaust gas, which actually included a variety of combustion products, was also approximated as pure air for the sake of this calculation. On the supply side, the 
temperature of the air entering the supply fan outside of the compartment was used in the calculation. For the exhaust gas, an aspirated thermocouple at the location of the bidirectional probe was used to measure the temperature of the gas.

The air flow supplied into the compartment by the ventilation system was computed from a 57-point calibration measurement of the inlet velocities. The cross-sectional area of the supply vent was divided into 57 smaller areas, which were selected based on the flow gradient. The velocity in each of the small areas was measured using the bidirectional probe to create a velocity profile across the vent. Figure 7-9 shows the 57 velocity measurement locations on the supply side. More measurement points were concentrated in the lower section of the vent, where the velocity gradient was the greatest, than in the upper section, where the velocity was steady over larger areas. A contour diagram of the measured velocities across the duct is shown in Figure 7-10. The data between the measured points was interpolated to create a continuous plot. The greatest velocities occurred near the outer edges of the lower portion of the duct, between 10 cm (3.9 in) and $30 \mathrm{~cm}$ (11.8 in) high. There were large areas where the velocities were nearly zero.

The volumetric flow rate for each area was computed as the product of the velocity and the area. The total volumetric flow rate through the vent was then found as a summation of the flow measurements. The supply ventilation volumetric flow was computed to be $1.06 \mathrm{~m}^{3} / \mathrm{s}\left(37.4 \mathrm{ft}^{3} / \mathrm{s}\right)$ with a combined expanded uncertainty of $0.22 \mathrm{~m}^{3} / \mathrm{s}\left(7.8 \mathrm{ft}^{3} / \mathrm{s}\right)$. This corresponded to a mass flow rate of $1.3 \mathrm{~kg} / \mathrm{s} \pm 0.2 \mathrm{~kg} / \mathrm{s}(2.9 \mathrm{lb} / \mathrm{s} \pm 0.4 \mathrm{lb} / \mathrm{s})$. The flow calibration measurements were performed both before and after the series of tests, and the results varied by only $3 \%$.

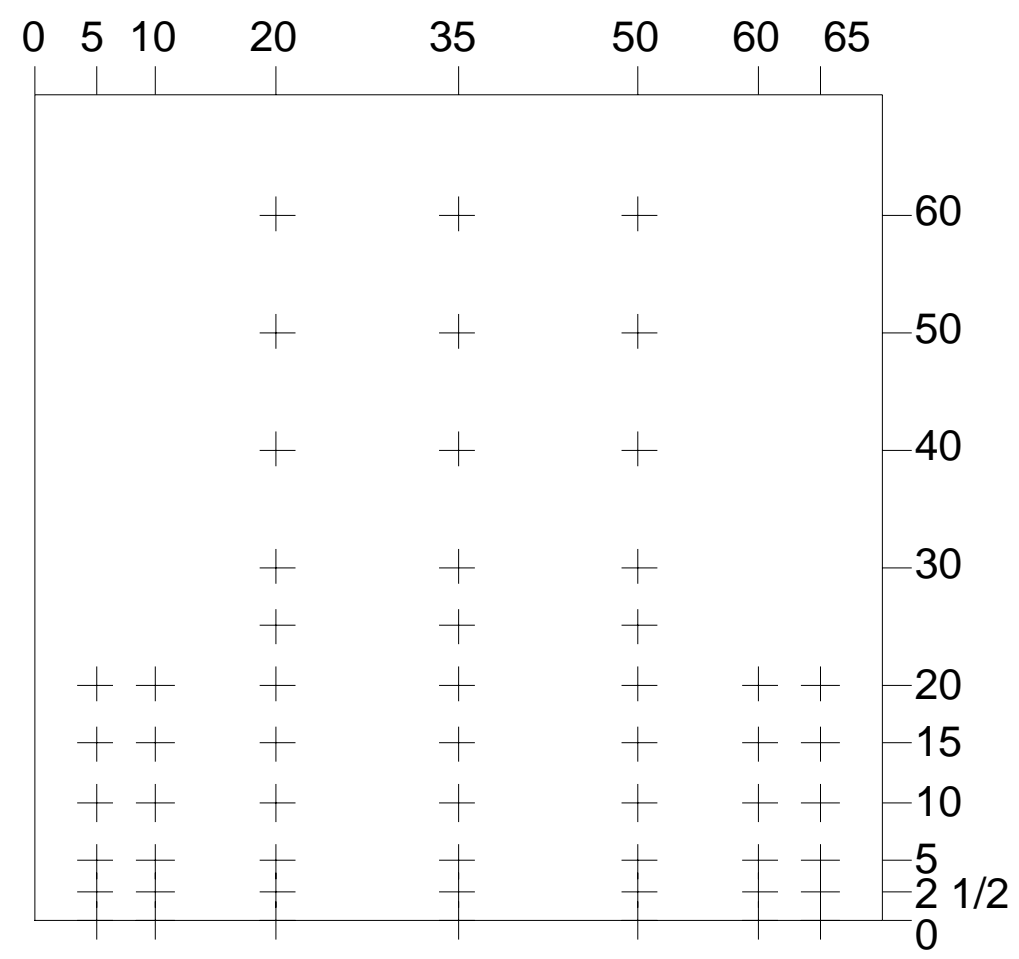

Figure 7-9: Location of velocity measurements in the supply vent during calibration. 
The air supplied by the ventilation system was not uniform when it exited the supply vent, as evidenced by the contour plot of the measured velocities (Figure 7-10). Most of the air was blown out of the bottom third of the supply duct. A visualization of the flow field was performed to determine the path of the air exiting the supply duct. Smoke was added to the supply airflow and the observed results are shown in Figure 7-11(a). Arrows indicating the path of the smoke show that the flow exited the supply vent moving upward at an angle of approximately $35^{\circ}$ to the horizontal plane. The smoke visualization also indicated that the bulk of the flow exited from the mid to lower part of the duct, confirming the velocity measurements, which showed no flow exiting the top of the duct. To confirm that the upward motion of the gas was due to direction from the duct, and not the temperature of the smoke, the flow visualization was performed a second time with room temperature supply air, using string attached to a grid across the duct exit. A photograph of this is shown in Figure 7-11(b). The angle at which the string was deflected from the horizontal was measured. The angle varied between $25^{\circ}$ and $50^{\circ}$ in the areas where the velocity was not near zero.

During the fire tests that had ventilation, the supply velocity was monitored with a single bidirectional probe in the inlet duct. The probe was placed at the center of the duct (left to right), on the plane of the compartment wall. For the first two tests with ventilation, Tests 4 and 5, the probe was positioned $30 \mathrm{~cm}$ (11.8 in) above the bottom edge of the duct. For tests 10 and 16, the probe was moved to $15 \mathrm{~cm}$ (5.9 in) above the bottom edge of the duct. The mean air velocity measured at the probe location prior to the start of the test was set to correspond to the total volumetric flow for the supply duct of $1.06 \mathrm{~m}^{3} / \mathrm{s}\left(37.4 \mathrm{ft}^{3} / \mathrm{s}\right)$. The volumetric flow during the test was computed by scaling the flow to match the change in velocity as measured by the bidirectional probe. Using the volumetric flow and the air density, the mass flow was then computed from the equation $\dot{m}=\rho V$, where $V$ is the volumetric flow of the duct, and $\rho$ the density of the supply air. A graph of the supply vent mass flow for Test 4 is shown in Figure 712. During the fire, the supply mass flow drops from an initial rate of $1.3 \mathrm{~kg} / \mathrm{s} \pm 0.2 \mathrm{~kg} / \mathrm{s}(2.9$ $\mathrm{lb} / \mathrm{s} \pm 0.4 \mathrm{lb} / \mathrm{s})$ to an average mass flow of $1.0 \mathrm{~kg} / \mathrm{s} \pm 0.2 \mathrm{~kg} / \mathrm{s}(2.2 \mathrm{lb} / \mathrm{s} \pm 0.4 \mathrm{lb} / \mathrm{s})$. 


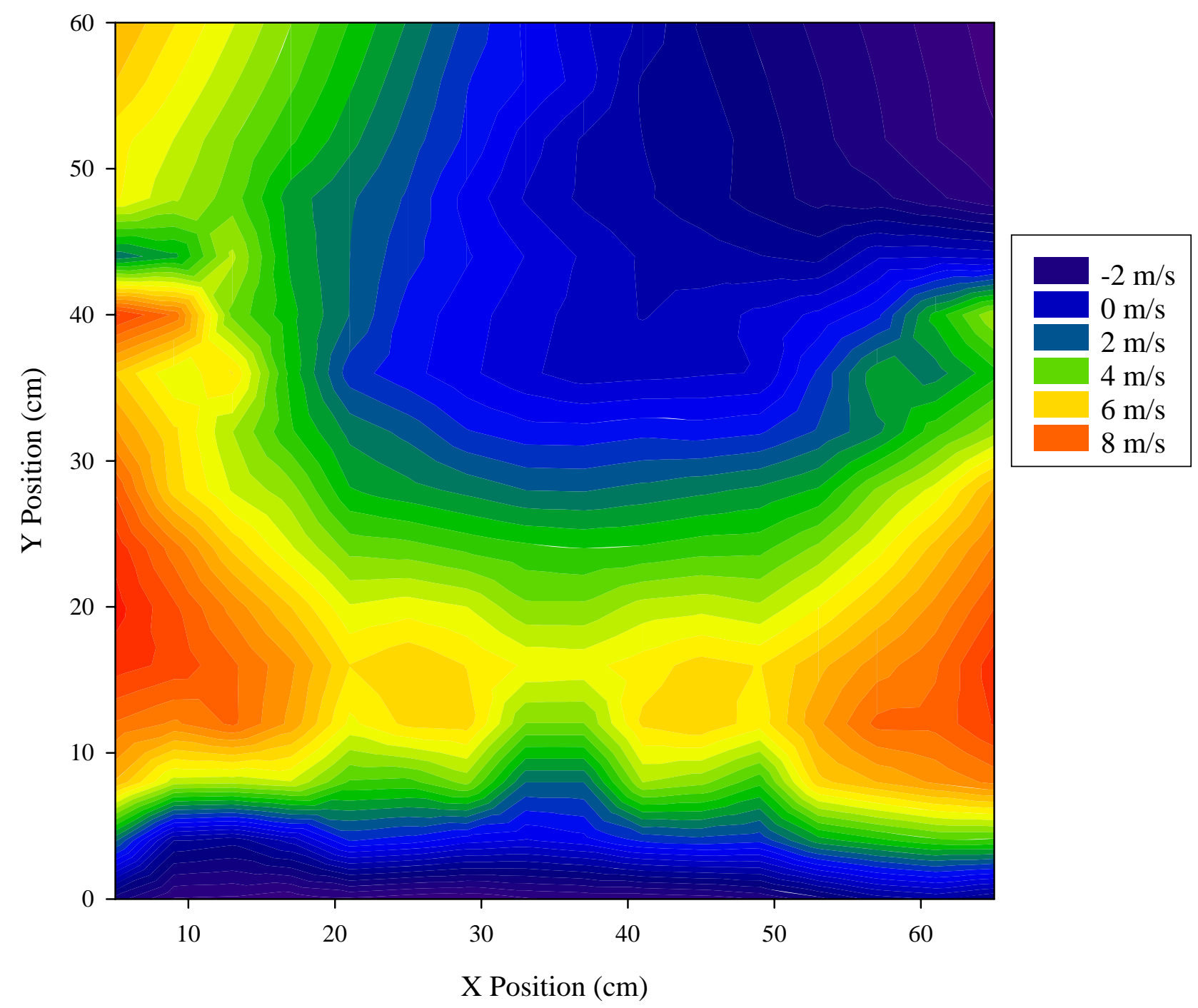

Figure 7-10: Contour plot of supply vent velocities. 

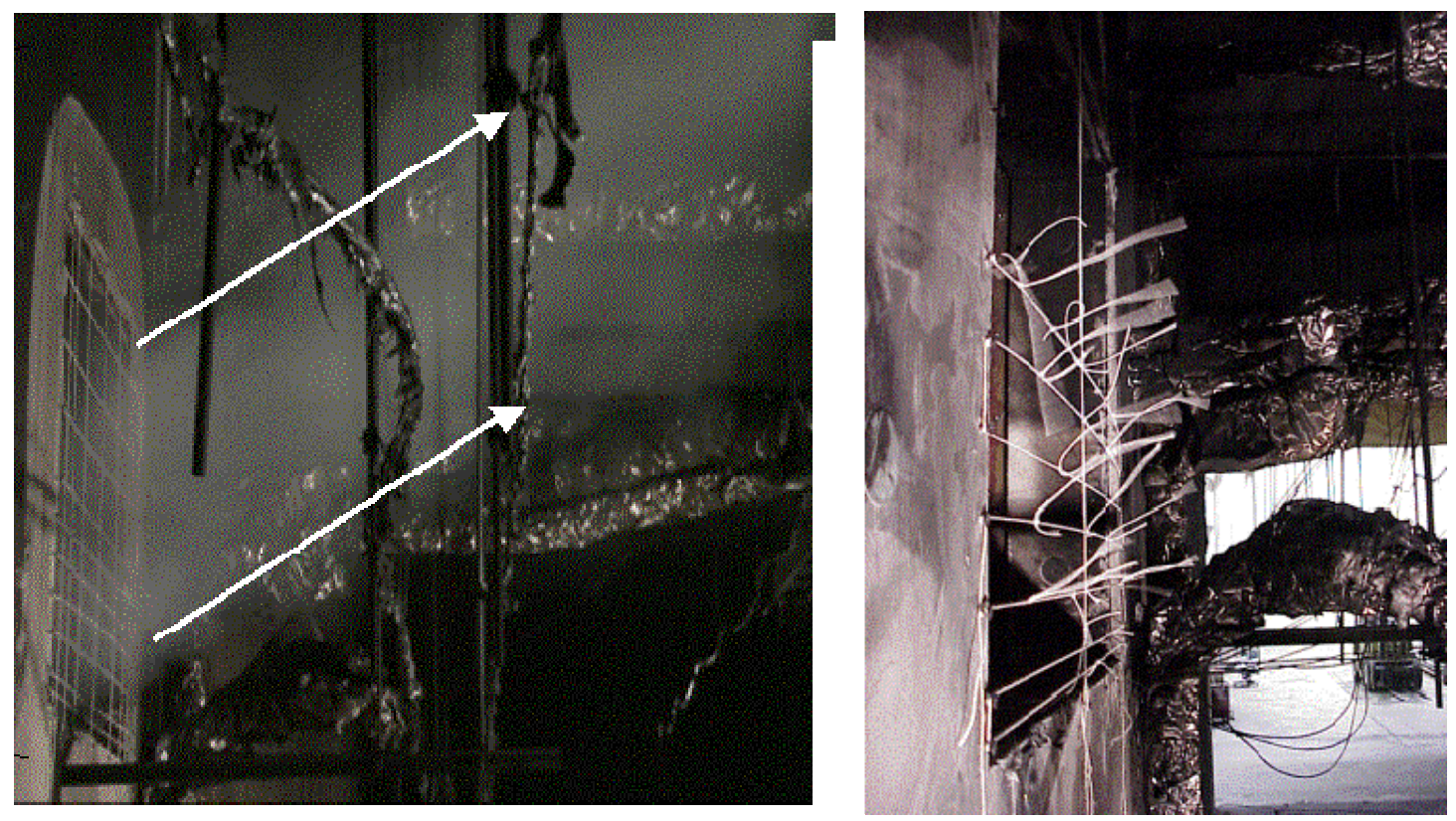

Figure 7-11: Flow visualization of the supply duct flow field using smoke (left), and using string (right).

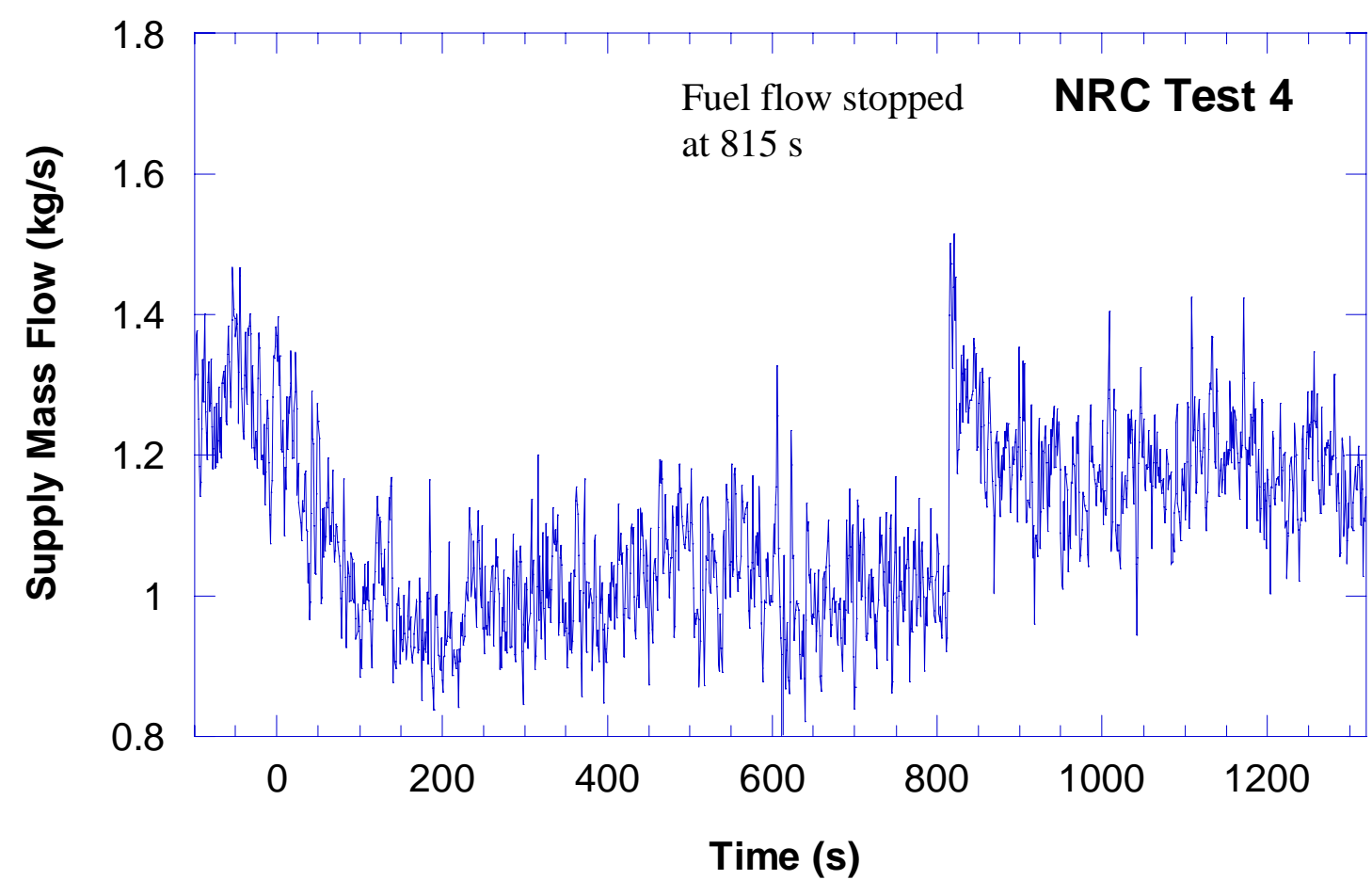

Figure 7-12: Mass flow through supply vent for NRC Test 4, 1 MW, door closed. 
The exhaust flow exiting the compartment when there was no test in progress was determined in a similar way as the supply flow, by using a bidirectional probe to measure the gas exit velocity along the plane compartment wall. The exhaust velocity was fairly uniform across the cross-sectional area of the duct, so the velocity was measured at only nine locations, near the center of the duct. These measurement locations are shown in Figure 7-13. The velocity was slightly higher towards the top of the duct, as seen in the contour plot of the exhaust velocity measurements, Figure 7-14. The contour plot shows only the center of the duct, starting and ending with the measured points and including the interpolated velocities between the measurements. To compute the total volumetric flow rate of the exhaust vent, the cross-sectional area of the duct was divided into nine areas, each containing one of the velocity measurements, and a summation over the areas was computed. The volumetric flow rate through the exhaust vent was measured to be $1.03 \mathrm{~m}^{3} / \mathrm{s}\left(36.4 \mathrm{ft}^{3} / \mathrm{s}\right)$ with a combined expanded uncertainty of $0.20 \mathrm{~m}^{3} / \mathrm{s}\left(7.1 \mathrm{ft}^{3} / \mathrm{s}\right)$.

During the tests, the bidirectional probe was located in the center of the exhaust exit duct, as shown in Figure 7-13. As in the supply duct, the bidirectional probe measured the change in velocity, which was then used to compute the total volumetric flow rate of the gases exiting the duct. The mass flow rate was then computed as the product of the volumetric flow rate and the density. The same density that was computed for the velocity calculation was used in the mass flow calculation. This meant that the combustion products in the exhaust gas were neglected and the density was computed for pure air, as a function of temperature, using the ideal gas law.

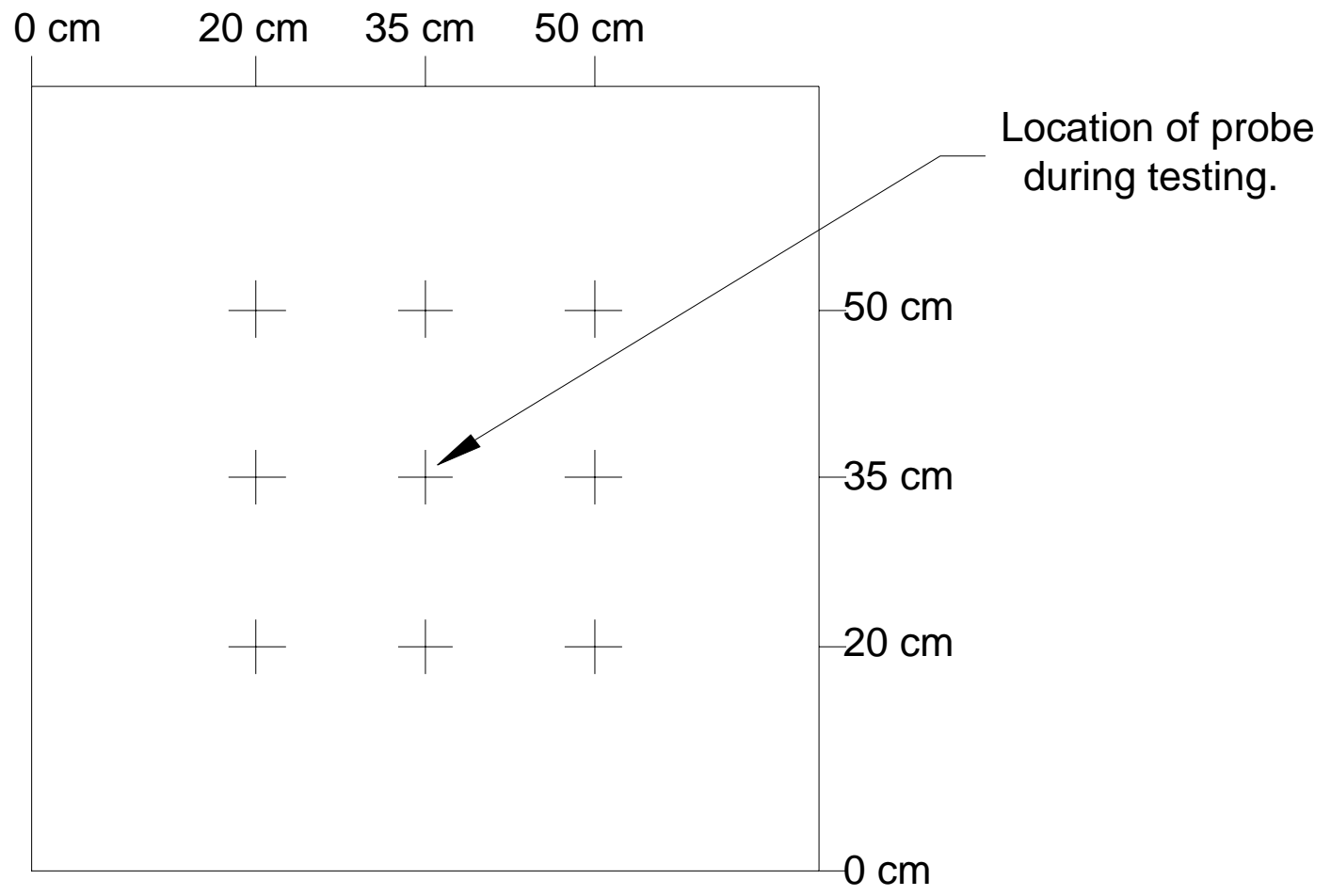

Figure 7-13: Locations where exhaust velocities were measured. 


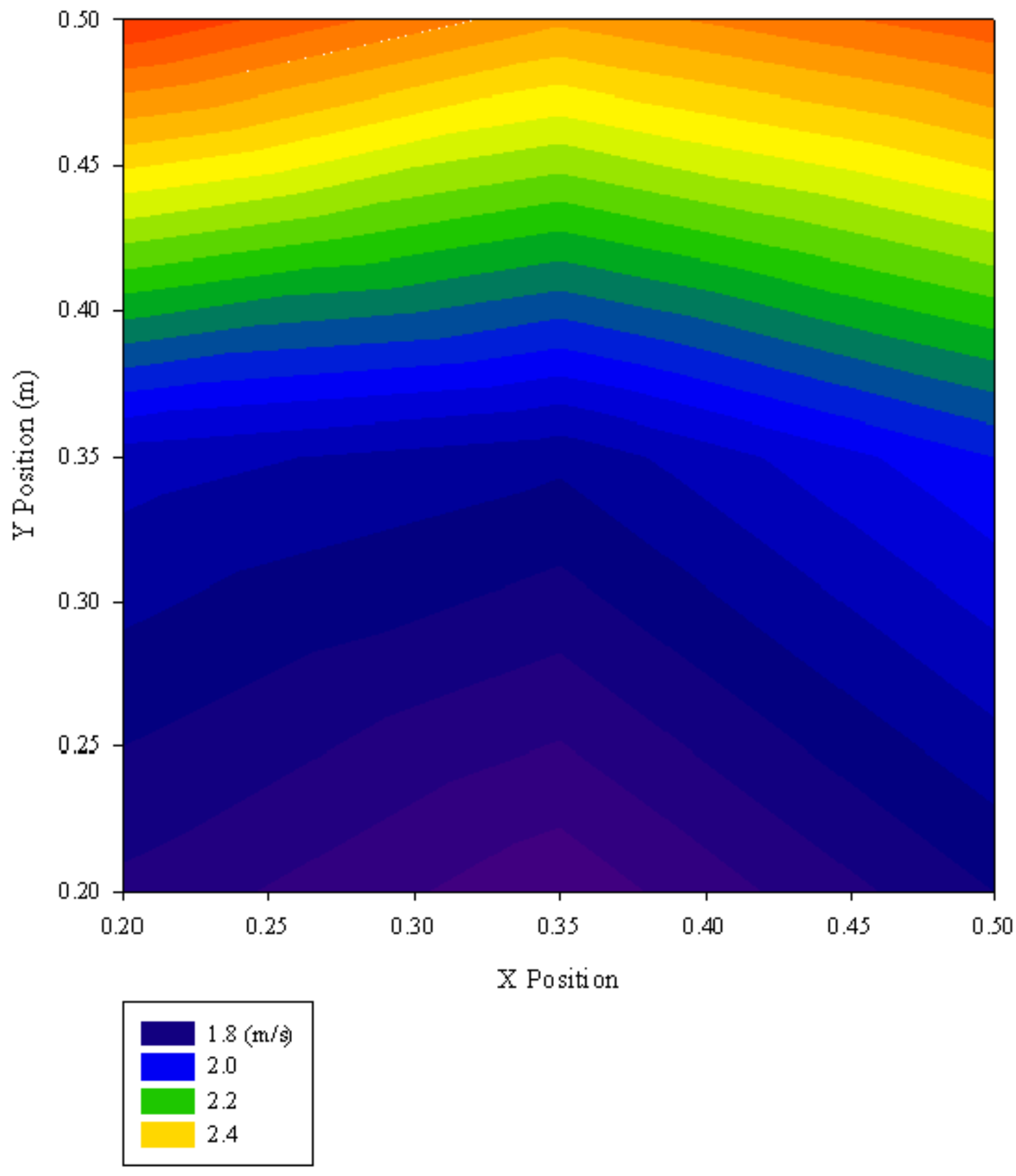

Figure 7-14: Contour plot of the exhaust vent velocities.

The velocity monitored by the bidirectional probe located in the center of the exhaust vent remained fairly constant throughout the testing series when ever there was no fire present. The initial mass flow for all of the tests was $1.2 \mathrm{~kg} / \mathrm{s}(2.7 \mathrm{lb} / \mathrm{s})$ with a combined expanded uncertainty of $0.2 \mathrm{~kg} / \mathrm{s}(0.4 \mathrm{lb} / \mathrm{s})$. In the presence of a fire, the velocity, and thus the mass flow rate, immediately increased by about $50 \%$ and then decreased to a steady state slightly higher than the original flow throughout the remainder of the test. An example of the exhaust mass flow measured during a test is shown for Test 10 in Figure 7-15. When the fire starts, there is a quick 
increase in the mass flow through the exhaust vent. After reaching its peak $120 \mathrm{~s}$ into the test, the mass flow rate decreases to an average flow of $1.4 \mathrm{~kg} / \mathrm{s} \pm 0.2 \mathrm{~kg} / \mathrm{s}(3.1 \mathrm{lb} / \mathrm{s} \pm 0.4 \mathrm{lb} / \mathrm{s})$ for the remainder of the burn time. The fuel flow was shut off in Test 10 after about $830 \mathrm{~s}$. At that time, the pressure in the compartment dropped rapidly, causing a rapid drop in the mass flow through the exhaust duct. Similar results were measured for the other tests with ventilation.

The single point measurements during the fire tests indicated that the flow field changed from its ambient values. The measured supply volume flow rate decreased during testing. For the exhaust, the measured volume flow rate increased during testing. The uncertainties during the fires should be considered substantially higher than the uncertainties in the ambient measurements. The ventilation system affected the compartment pressure, HGL temperature, and the surface temperature of various cable targets. The cable surface TCs were just outside of the direct path of the supply fan. In the absence of a fire, blowing was observed to flow upwards at about a $35^{\circ}$ angle.

The energy flow through the exhaust vent $\left(\dot{Q}_{v}\right)$ was calculated from the equation:

$$
\dot{Q}_{v}=\sum \dot{m} C_{p} \Delta T
$$

where $\dot{m}$ is the exhaust mass flow rate, $C_{p}$ is the heat capacity computed for air using the DIPPR 85/NIST equation for ideal gas heat capacity, and $\Delta T$ is the temperature increase. As with the density calculation, the exhaust gas is approximated as pure air for the purpose of computing the heat capacity. The temperature difference, $\Delta T$, dominates the energy calculation. The temperature of the gas exiting the exhaust duct was measured by four bare-bead thermocouples spaced vertically along the centerline of the duct. Measurements showed a temperature gradient in the duct, with temperatures at the upper location reaching up to $100^{\circ} \mathrm{C}$ more than those measured at the lower location. The aspirated thermocouple located at the center of the duct measured the same temperature as the bare bead thermocouple at the same location, confirming that the thermocouples were not affected by radiation from the fire. The exhaust duct was divided into four area sections, each containing one of the thermocouples. The total energy flow through the exhaust vent was computed as the summation of the energy flow through each area as a function of the temperature. The combined expanded uncertainty in the exhaust vent energy measurements is $\pm 80 \mathrm{~kW}$. The large uncertainty is due to uncertainties in the temperature over the area of the duct, since only four measurements were taken during testing.

An example of the energy flow through the exhaust vent is shown for Test 10 in Figure 7-16. These results are for a nominally $1 \mathrm{MW}$ fire centered in the compartment with the ventilation system operating and the compartment door closed. After an initial rapid increase, the energy flow continues to increase throughout the test. The fuel flow was shut off in Test 10 after about $830 \mathrm{~s}$. At that time, the pressure in the compartment dropped rapidly, causing a rapid drop in the energy flow through the exhaust duct. Test 5 was also a nominally $1 \mathrm{MW}$ fire, but for this test the compartment door was open while the ventilation system was operating and some of the energy exited through the door opening. A plot of this is shown in Figure 7-17. Here, the energy flow through the exhaust vent does not continually increase, but instead it fluctuates as some of the hot gases are diverted to the door opening. 


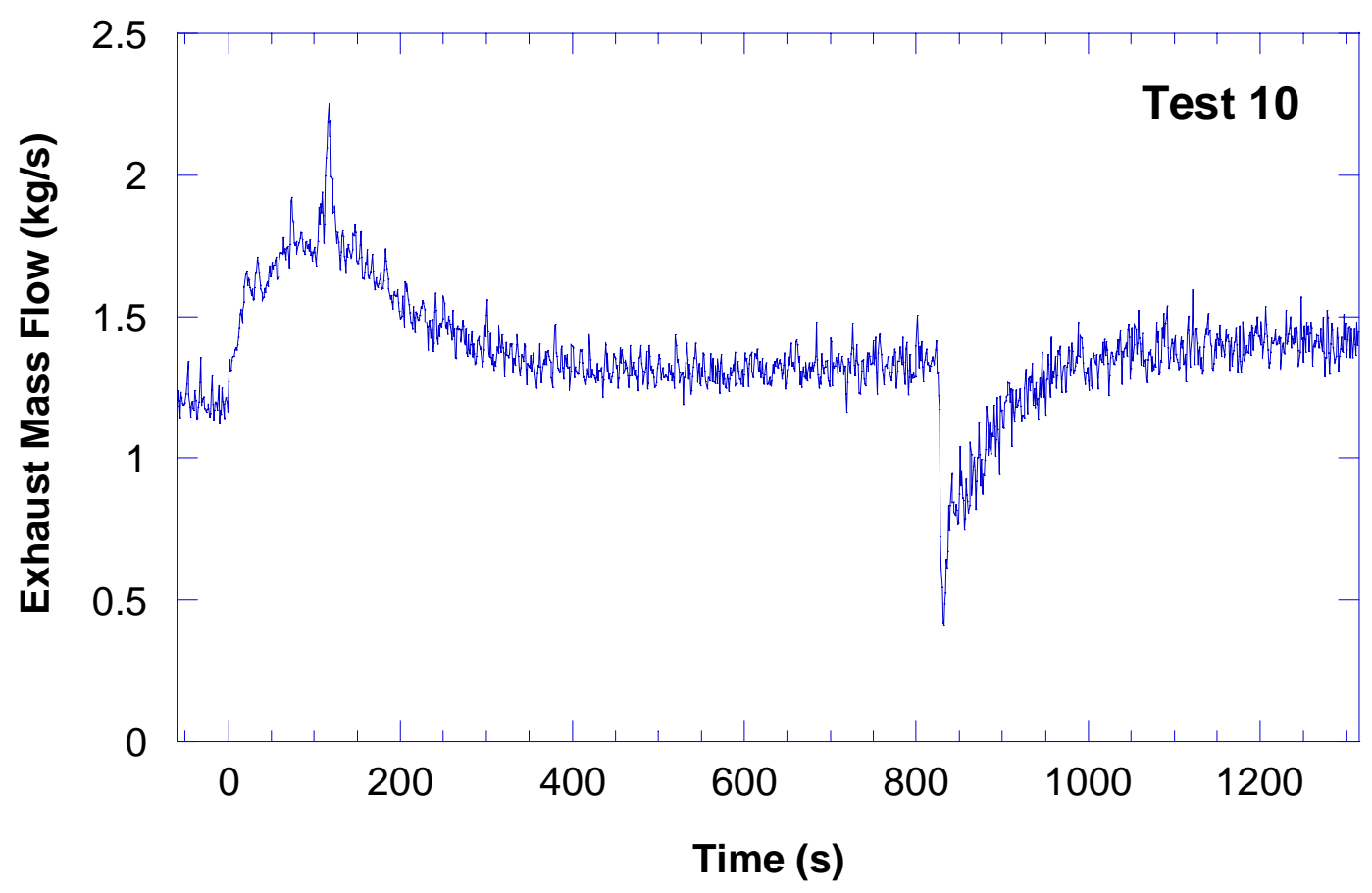

Figure 7-15: Mass flow through exhaust vent for NRC Test 10, $1 \mathrm{MW}$, door closed.

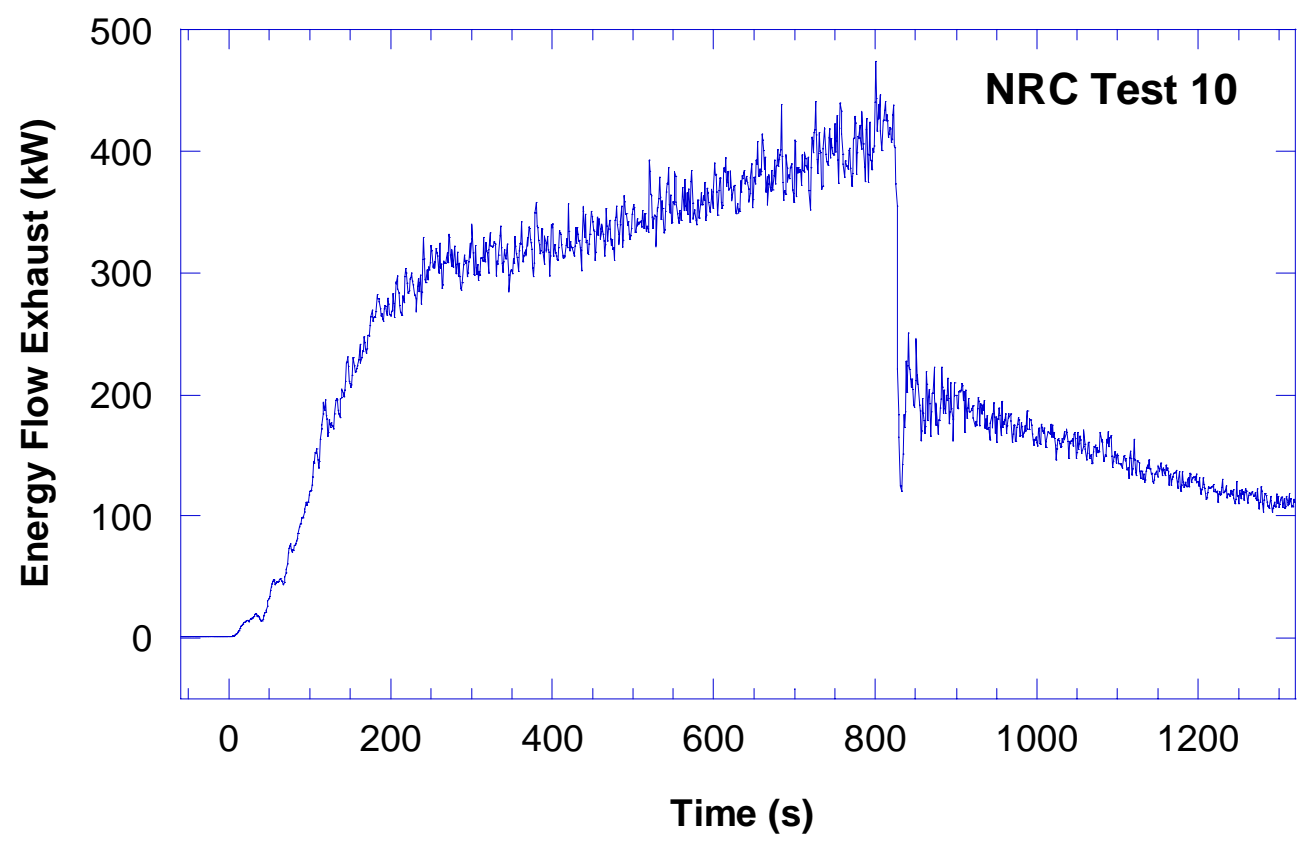

Figure 7-16: Energy flow through exhaust vent for NRC Test 10, $1 \mathrm{MW}$, door closed. 


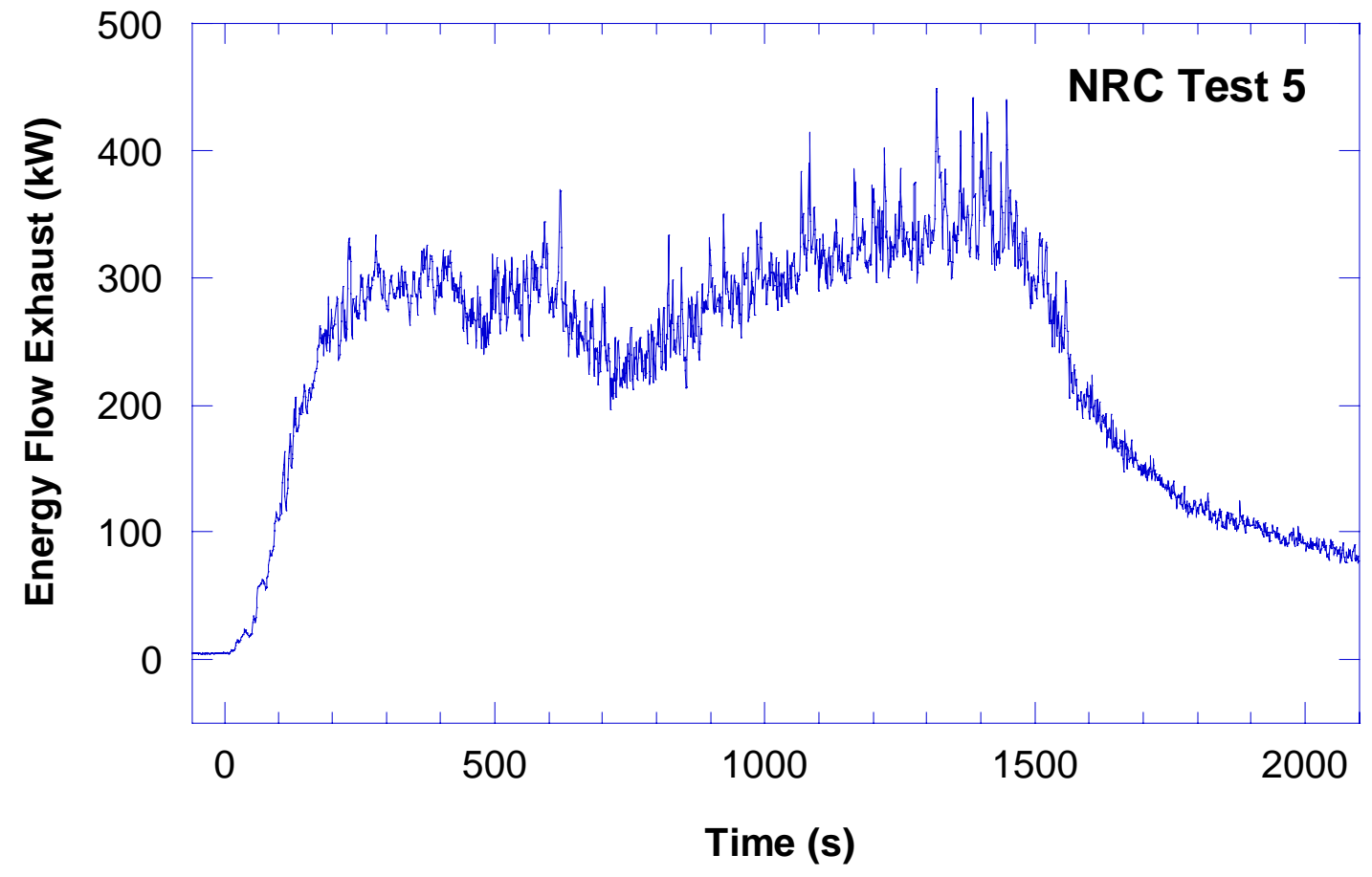

Figure 7-17: Energy flow through the exhaust vent for Test 5, compartment door open. 



\section{GASEOUS SAMPLING}

Extractive gas concentration measurements were made at two locations in the experimental enclosure. Oxygen $\left(\mathrm{O}_{2}\right)$, carbon monoxide $(\mathrm{CO})$ and carbon dioxide $\left(\mathrm{CO}_{2}\right)$ were measured high in the compartment and $\mathrm{O}_{2}$ was also measured low. Both sampling locations are listed in Table 8-1.

Table 8-1: Gaseous sampling locations.

\begin{tabular}{|l|l|l|l|}
\hline Measurement & $\begin{array}{l}\text { Distance from West } \\
\text { wall }(\mathrm{m})\end{array}$ & $\begin{array}{l}\text { Distance from South } \\
\text { Wall }(\mathrm{m})\end{array}$ & $\begin{array}{l}\text { Height from Floor } \\
(\mathrm{m})\end{array}$ \\
\hline $\mathrm{O}_{2}, \mathrm{CO}, \mathrm{CO}_{2}$ & 6.85 & 3.48 & 3.22 \\
\hline $\mathrm{O}_{2}$ & 6.85 & 3.48 & 0.50 \\
\hline
\end{tabular}

\subsection{Apparatus}

The upper level continuous gas sampling system was made of stainless steel tubing in the compartment and copper and plastic tubing outside the enclosure. The gas sample once removed from the compartment went through two moisture and soot traps in series filled with 8 micrometer fiber glass Corning \#3950. A GAST Model DOA-P09-FB pump was used to pull the sample from the compartment and send it to the flow panel. Only a small fraction of the sample was directed to the analyzers, most of the flow being diverted to the excess flow discharge. The lower level $\mathrm{O}_{2}$ sampling was similar; the only difference being that only one analyzer and one trap were employed, see Figure 8-1. The particulars of the analyzers used are listed in Table 8-2. The $\mathrm{CO}$ and $\mathrm{CO}_{2}$ analyzers both have auto-ranging features, allowing the analyzers to switch ranges as the concentration of the measured gas changes. The constants listed in Table 8-2 were used in the data acquisition system because these analyzers were setup in their auto ranging mode. 
Table 8-2: Analyzer Particulars.

\begin{tabular}{|c|c|c|}
\hline \multicolumn{3}{|c|}{$\mathrm{O}_{2}-1$ : SERVOMEX 4100 Gas Purity Analyzer S/N 10410261 (upper level) } \\
\hline Range & $\% \mathrm{O}_{2} \mathrm{v} / \mathrm{v}$ & Constant \\
\hline 1 & $0-25 \%$ & $\mathrm{n} / \mathrm{a}$ \\
\hline \multicolumn{3}{|c|}{$\mathrm{O}_{2}-2$ : SERVOMEX Oxygen Analyzer Model 540A (lower level) } \\
\hline Range & $\% \mathrm{O}_{2} \mathrm{v} / \mathrm{v}$ & Constant \\
\hline 1 & $0-25 \%$ & $\mathrm{n} / \mathrm{a}$ \\
\hline \multicolumn{3}{|c|}{ CO - 3: SIEMENS Ultramat 5E S/N E9-955 } \\
\hline Range & $\% C O v / v$ & Constant \\
\hline 1 & $0-3 \%$ & 0.623 \\
\hline 2 & $0-5 \%$ & 1.033 \\
\hline 3 & $0-10 \%$ & 2.066 \\
\hline 4 & $0-20 \%$ & 4.0 \\
\hline \multicolumn{3}{|c|}{$\mathrm{CO}_{2}-4:$ SIEMENS Ultramat 5E S/N E9-959 } \\
\hline Range & $\% \mathrm{CO}_{2} \mathrm{v} / \mathrm{v}$ & Constant \\
\hline 1 & $0-5 \%$ & 1.036 \\
\hline 2 & $0-10 \%$ & 2.069 \\
\hline 3 & $0-30 \%$ & 6.217 \\
\hline 4 & $0-50 \%$ & 4.0 \\
\hline
\end{tabular}

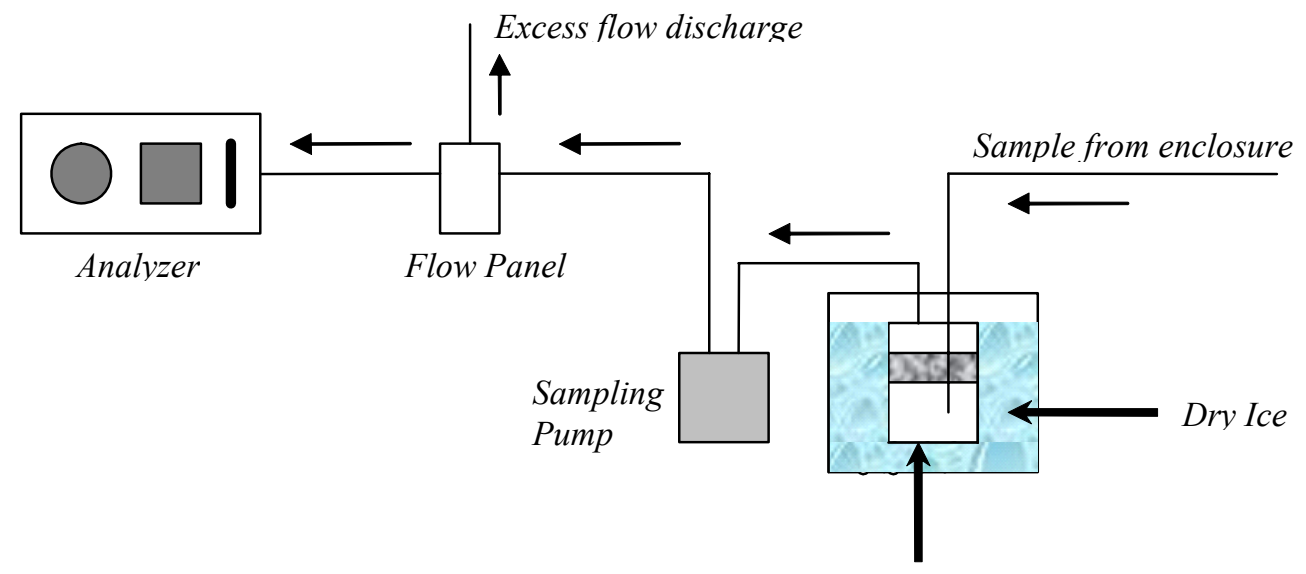

Moisture and Soot Extracting Trap

Figure 8-1: Lower Level Gaseous System components and configuration. 


\subsection{Calibration Procedures}

Every analyzer was calibrated prior to each test. Nitrogen was used to zero all analyzers. A $7.0018 \% \mathrm{CO}, 18.0012 \% \mathrm{CO}_{2}$, Nitrogen balance standard was used to span the $\mathrm{CO}$ and $\mathrm{CO}_{2}$ analyzers. The standard was made by Matheson Gas Products, NIST Traceable Certificate $\# 107304$, Lot \#102-26-02403, expiration date 6/19/05. Ambient air was used to span both oxygen analyzers.

\subsection{Sample Transport Time and Analyzer Response Characterization}

A series of experiments were conducted to determine the sample transport times and analyzer 95 $\%$ response times $\left(\mathrm{T}_{95}\right)$. Nitrogen was used to determine these parameters for the oxygen analyzers. Nitrogen was introduced, not under pressure, at the sampling location and the oxygen analyzer response was recorded. Post test analysis revealed the transport times and $\mathrm{T}_{95}$ values. This experiment was conducted for each oxygen analyzer. A similar experiment was conducted for the $\mathrm{CO}$ and $\mathrm{CO}_{2}$ analyzers. In that case the $\mathrm{CO}$ and $\mathrm{CO}_{2}$ standard was introduced, again not under pressure, at the sampling point and system response documented and characterized. Table 8-3 lists the transport time and $\mathrm{T}_{95}$ values for each analyzer. Uncertainty is estimated as $\pm 1.0 \mathrm{~s}$.

The reporting limit for carbon monoxide was determined by examining baseline $\mathrm{CO}$ data from multiple tests and estimating the signal noise. A noise value of $0.002 \% \mathrm{CO}$ was determined. A value of 5 -times the signal to noise $(\mathrm{S} / \mathrm{N})$, or $0.01 \% \mathrm{CO}$, is used as the reporting limit.

Table 8-3: Sample transport time and analyzer response.

\begin{tabular}{|l|l|l|}
\hline Analyzer & Transport Time (sec)* & $\begin{array}{l}\text { Analyzer 95 \% Response } \\
\text { Time }\left(\mathrm{T}_{95}\right)\end{array}$ \\
\hline $\mathrm{O}_{2}-1$ (upper) & $5.5 \pm 1.0$ & $25.6 \pm 1.0$ \\
\hline $\mathrm{CO}_{2}-4$ & $7.9 \pm 1.0$ & $17.8 \pm 1.0$ \\
\hline $\mathrm{CO}-3$ & $7.8 \pm 1.0$ & $17.3 \pm 1.0$ \\
\hline $\mathrm{O}_{2}-2$ (lower) & $9.3 \pm 1.0$ & $28.7 \pm 1.0$ \\
\hline \multirow{2}{*}{ *The time that the gas was introduced to the sample line is defined as $0 \mathrm{~s}}$. \\
\hline
\end{tabular}

\subsection{Estimated Expanded Uncertainty}

Table 8-4 lists the estimated expanded uncertainties for all four continuous sampling measurements. These uncertainties values were estimated based on calibration, instrument drift, sampling, and analyzer response. Confidence level is approximately $95 \%$. 
Table 8-4: Estimated expanded uncertainty (with an expansion factor of two).

\begin{tabular}{|l|l|}
\hline Analyzer & $\begin{array}{l}\text { Estimated Expanded Uncertainty } \\
\text { (volume fraction) }\end{array}$ \\
\hline $\mathrm{O}_{2}-1$ (upper) & \pm 0.01 \\
\hline $\mathrm{CO}_{2}-2$ & \pm 0.0025 \\
\hline $\mathrm{CO}-3$ & \pm 0.0001 \\
\hline $\mathrm{O}_{2}-4$ (lower) & \pm 0.01 \\
\hline
\end{tabular}

\subsection{Results and Discussion}

During Test 1, a sampling anomaly occurred in both sampling systems. At some point following the fuel off event, flow in both the upper layer and lower layer systems stopped as evidenced by data from the gas analyzers. For this reason, data are not reported for Test 1 after the fuel was secured at the 25 min (1500 s) mark.

During replicate Tests 1 and 7, the upper level oxygen decreased steadily from ambient volume fractions at fire ignition to $14.9 \%$ and $15.0 \%$, respectively, near the end of the fuel ramp down stage. Carbon monoxide in the upper layer remained at or below the $0.01 \%$ reporting limit for both tests. During both tests, the upper layer $\mathrm{CO}_{2}$ volume fractions peaked at approximately $4 \%$.

During Tests 1 and 7, the lower level $\mathrm{O}_{2}$ volume fractions decreased from $20.95 \%$ to a minimum of roughly $16.9 \%$ shortly after fuel shut off. Figures 8-2 - 8-4 are representative of the gas volume fractions during Tests 1 and 7. 


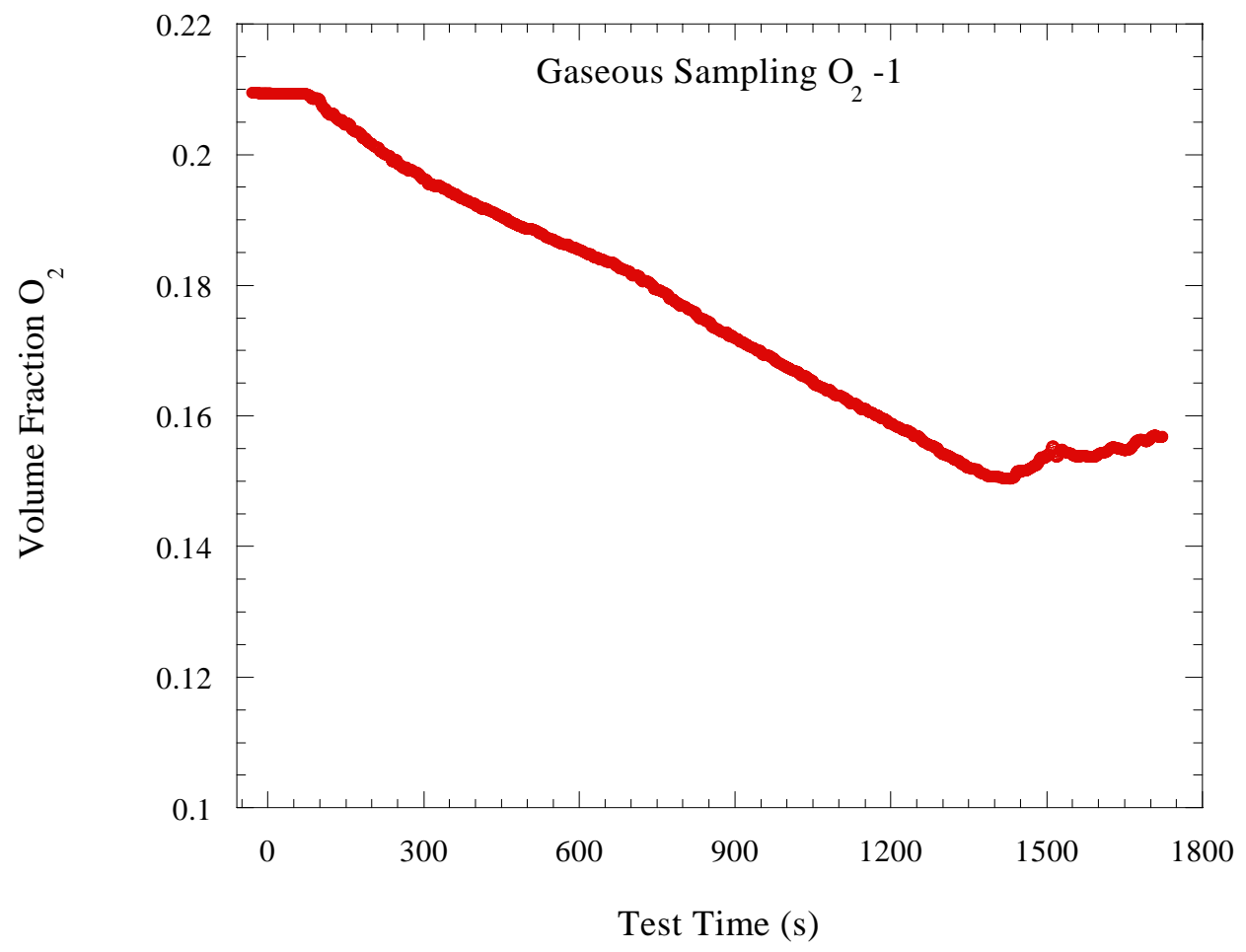

Figure 8-2: Test 7 Upper Layer $\mathbf{O}_{2}$.

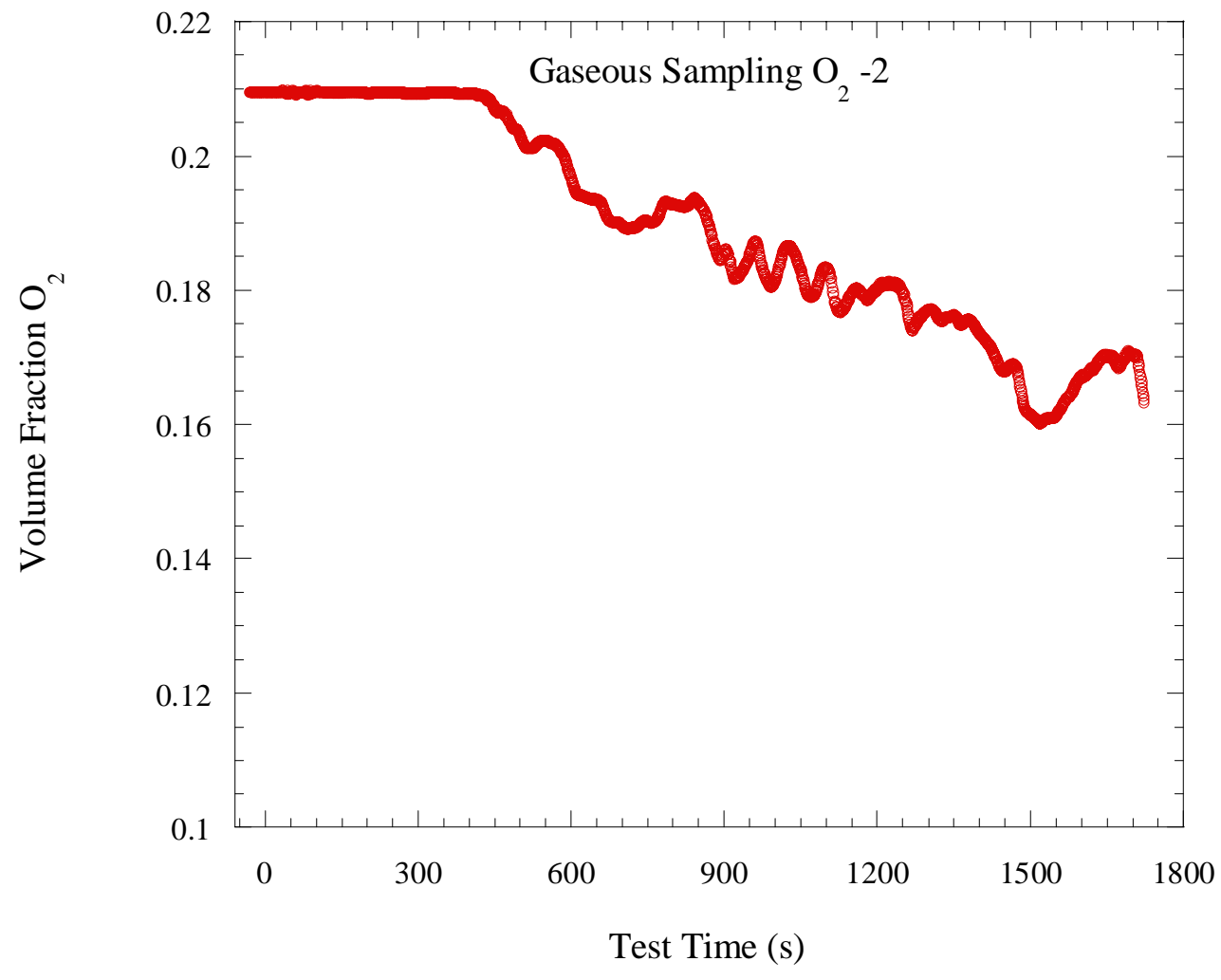

Figure 8-3: Test 7 Lower Layer $\mathbf{O}_{2}$. 


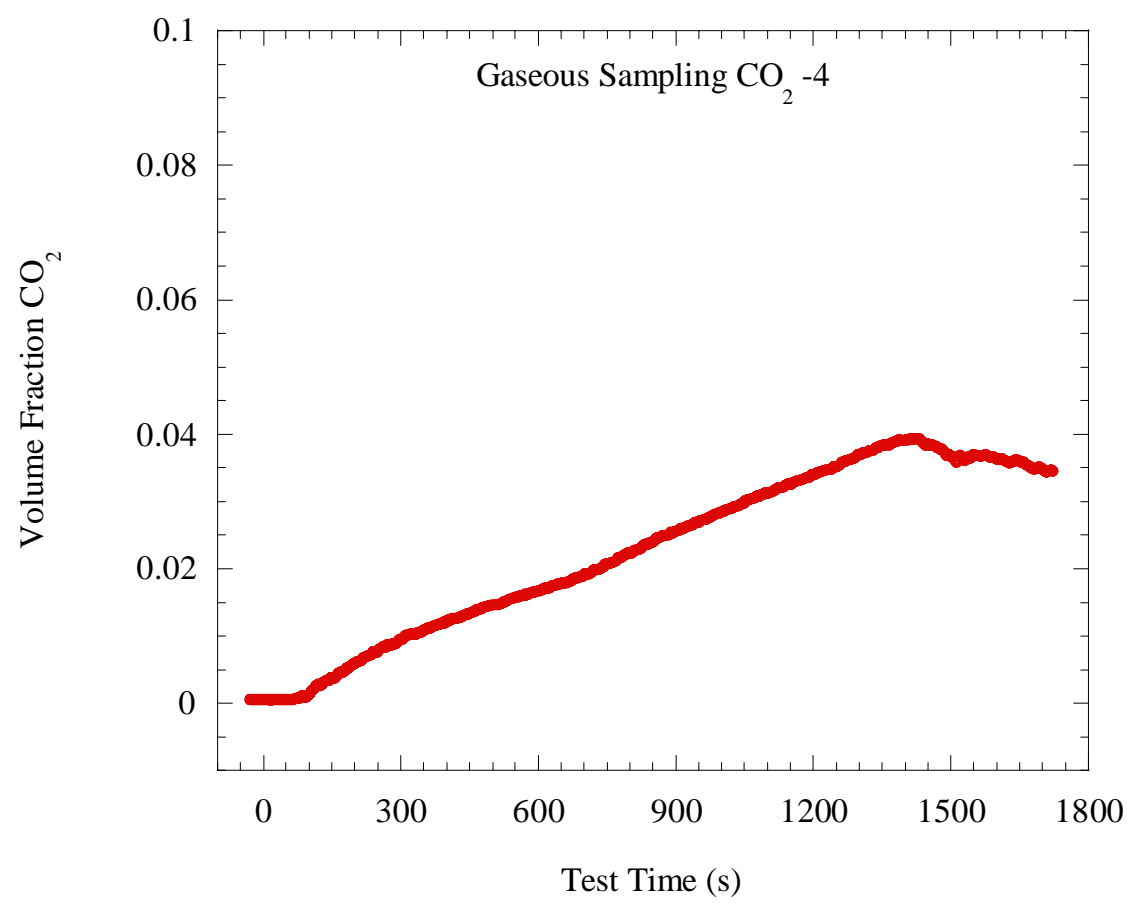

Figure 8-4: Test 7 Upper Layer $\mathrm{CO}_{2}$.

During Test 2, a sampling anomaly occurred in the upper layer gaseous sampling system. Carbon dioxide likely was pulled into the sampling line at the moisture and soot trap. For this reason, data collected from the upper layer sampling system after $640 \mathrm{~s}$ following fire ignition are not reported.

During replicate Tests 2 and 8, the upper layer oxygen volume fraction decreased from ambient values at fire initiation to approximately $12 \%$ shortly after the fuel was secured. Figure 8-5 below is representative of the upper layer $\mathrm{O}_{2}$ volume fraction. The carbon monoxide volume faction in the upper layer peaked at $0.01 \%$ during Test 2 and $0.02 \%$ during Test 8 shortly after fuel was secured as represented in Figure 8-6. Similarly, carbon dioxide during both tests rose steadily from ambient at fire initiation to approximately $6 \%$ shortly after fuel is secured. See Figure 8-7.

Lower layer $\mathrm{O}_{2}$ volume fraction decreased from near ambient at fire initiation to minimum volume fractions near $13.7 \%$ during Tests 2 and 8. Figure 8-8 and Figure 8-9 present the lower level $\mathrm{O}_{2}$ volume fractions during Tests 2 and 8 . 


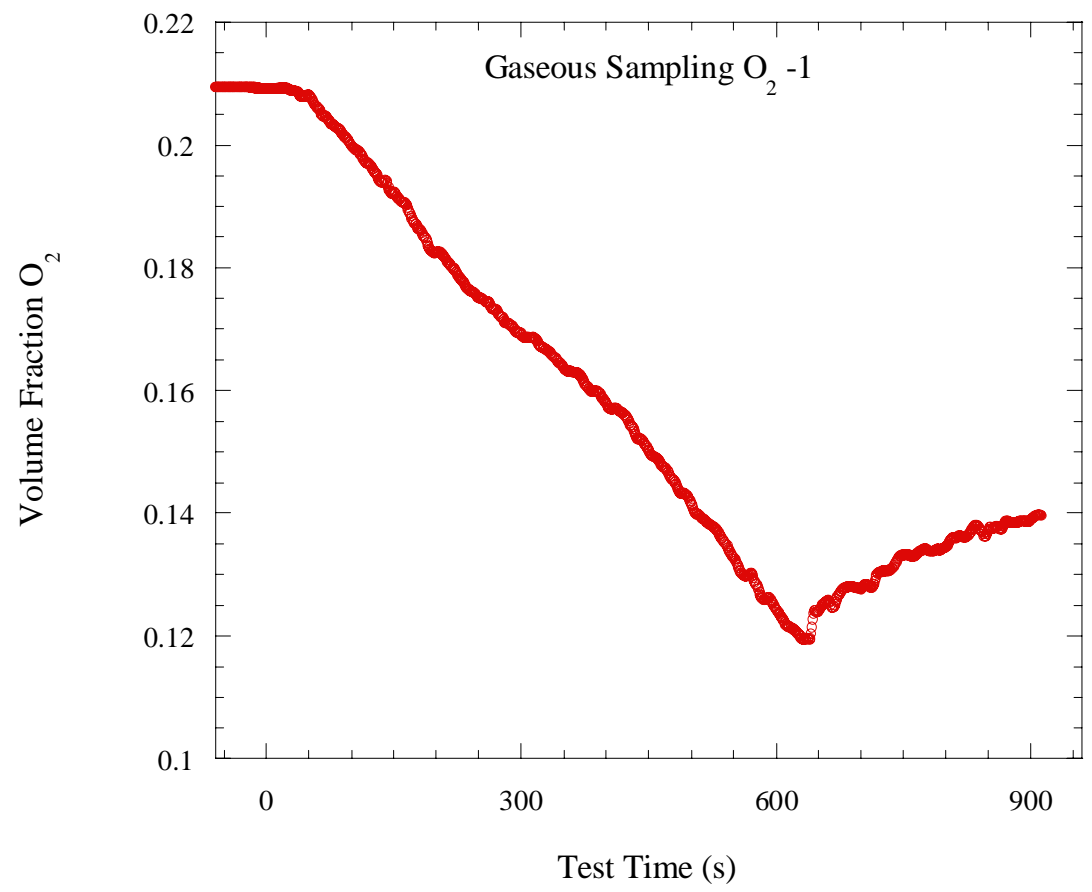

Figure 8-5: Test 8 Upper Layer $\mathrm{O}_{2}$.

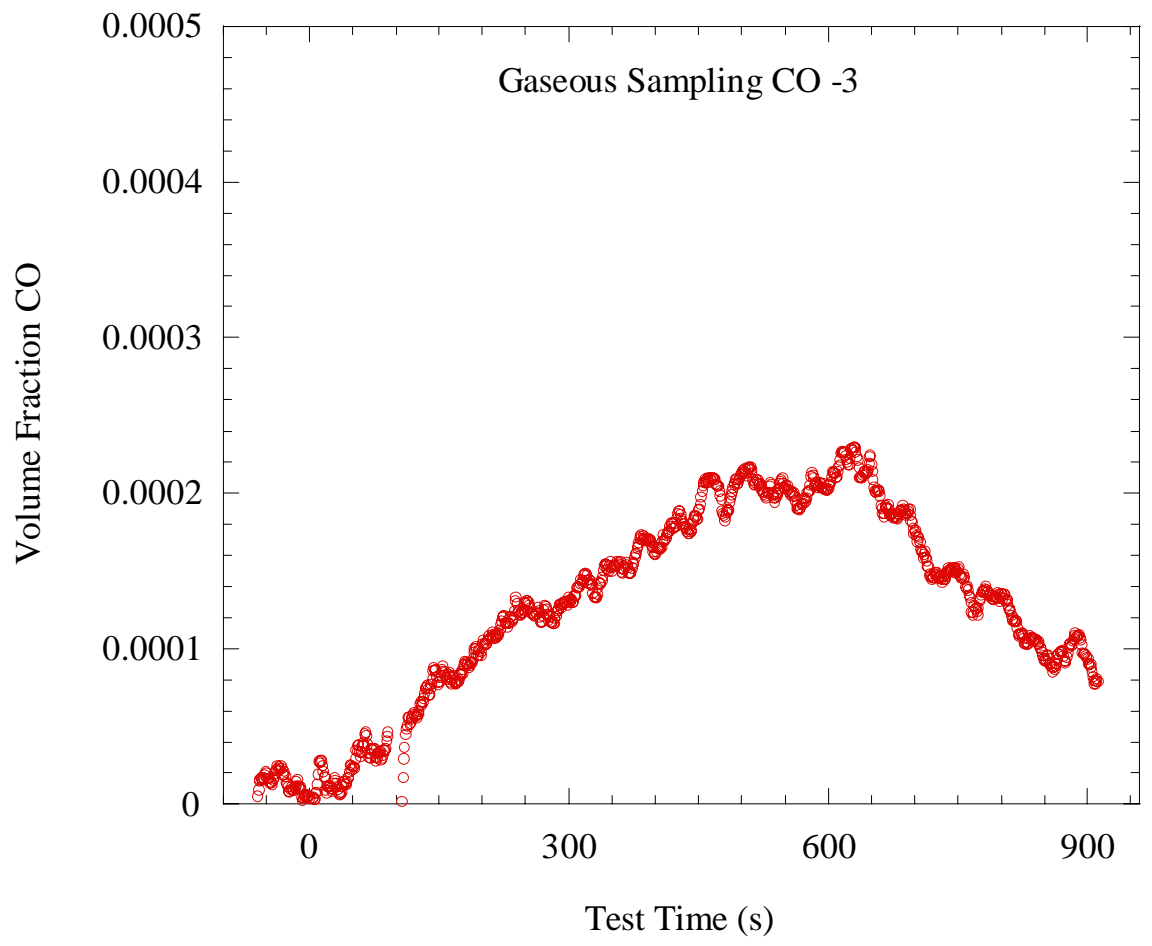

Figure 8-6: Test 8 Upper Layer CO. 


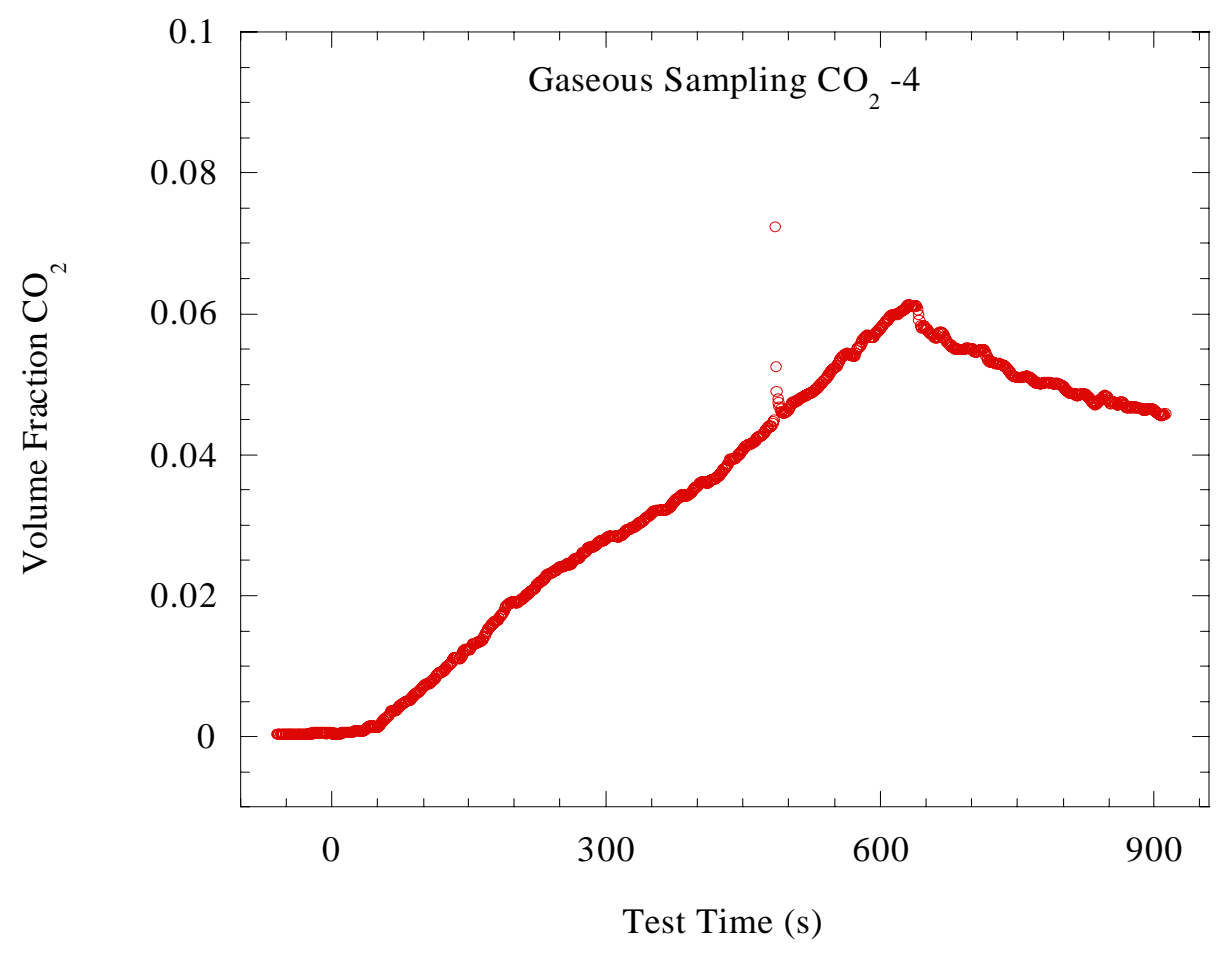

Figure 8-7: Test 8 Upper Layer $\mathrm{CO}_{2}$.

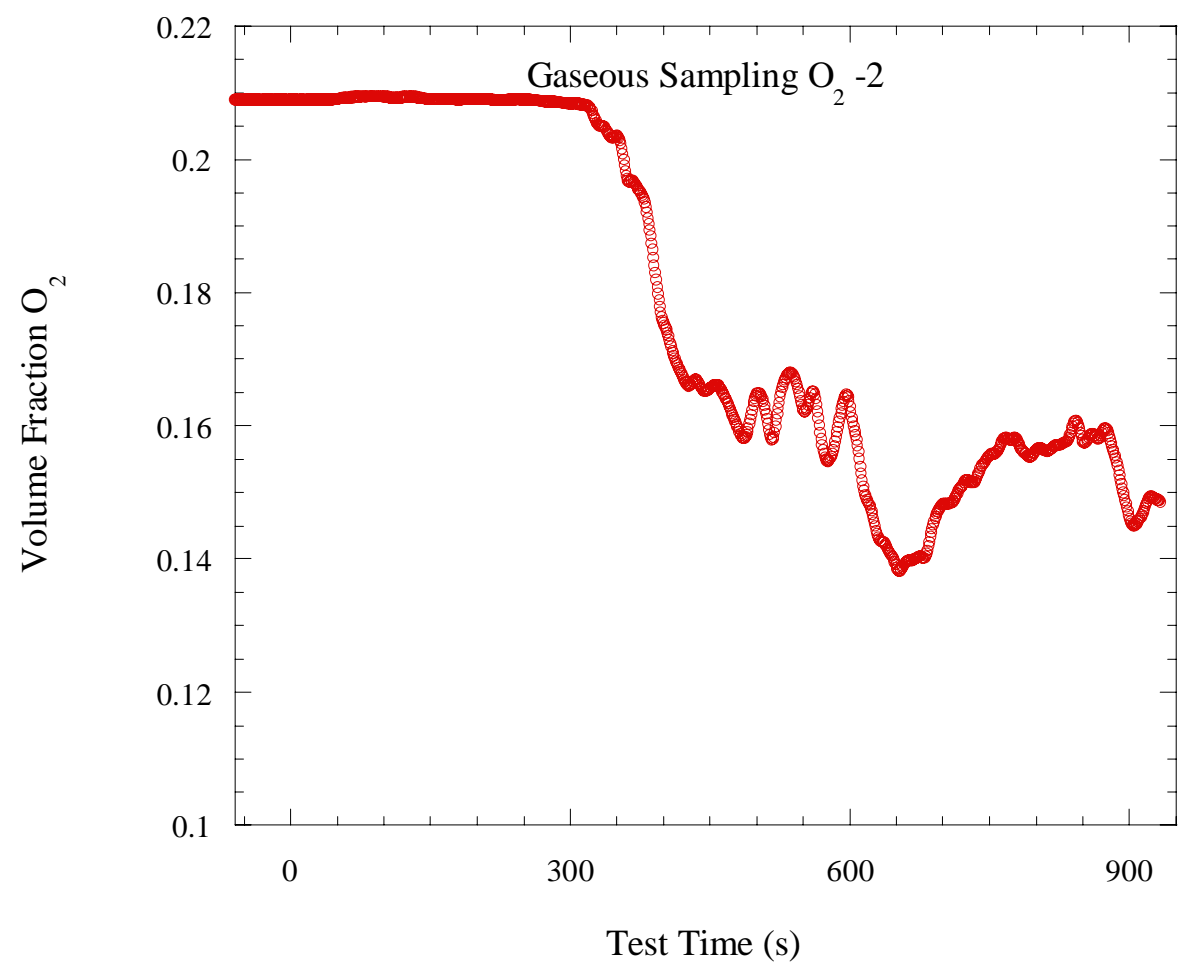

Figure 8-8: Test 2 Lower Layer $\mathrm{O}_{2}$. 


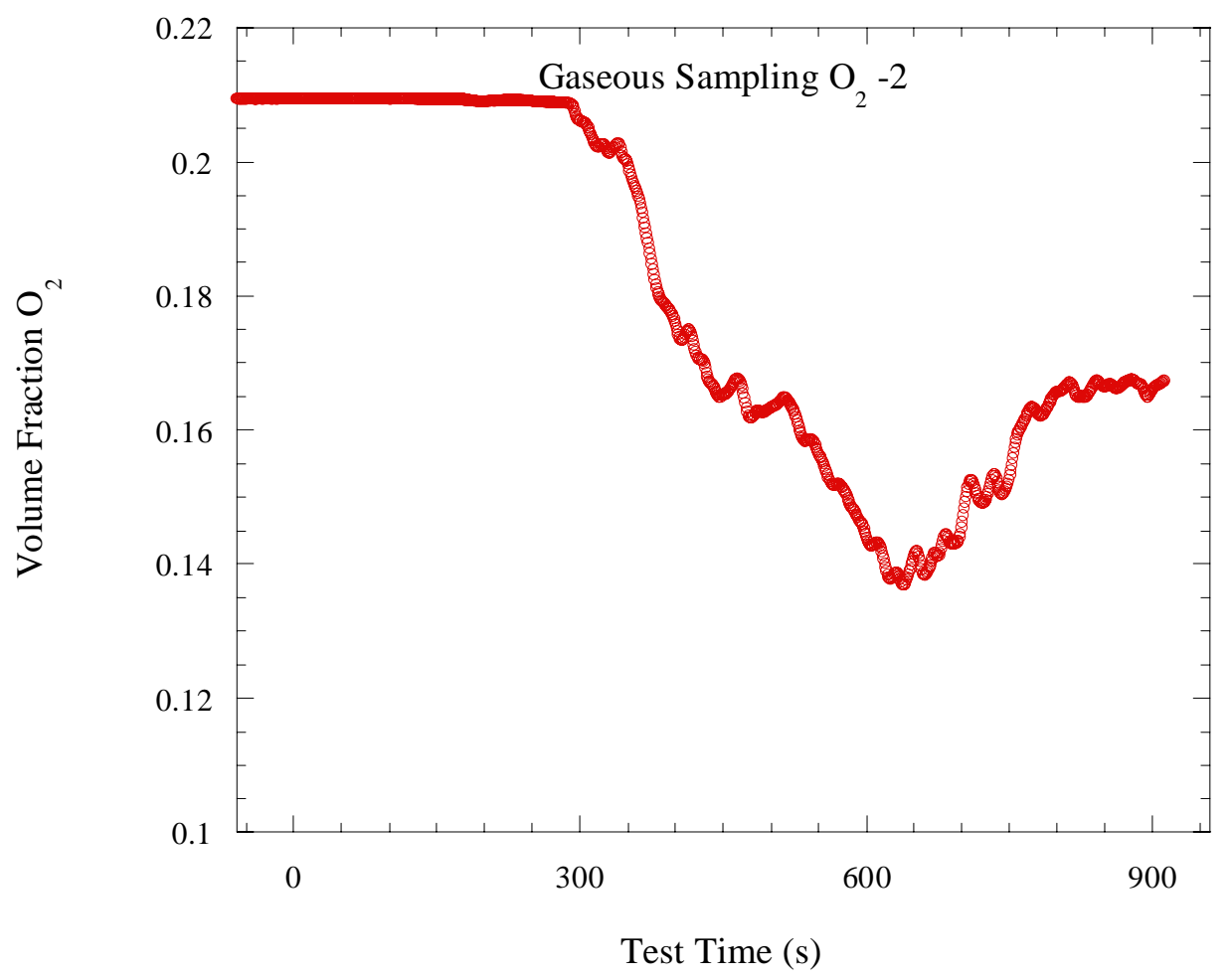

Figure 8-9: Test 8 Lower Layer $\mathrm{O}_{2}$.

Tests 3 and 9 were replicate tests while Test 14 differed only in that it employed an off-center fire location. The oxygen, carbon monoxide and carbon dioxide volume fractions for all three tests were similar.

The upper layer $\mathrm{O}_{2}$ volume fraction, from near ambient at fire initiation, decreased to a volume faction near $16 \%$, as shown in Figure 8-10, when fuel ramp down was initiated. Carbon monoxide volume fraction in the upper layer did not exceed $0.01 \%$ for any of the three tests. The $\mathrm{CO}_{2}$ volume fraction in the upper level rose from ambient at fire initiation to a steady value of approximately $3.1 \%$ during all three tests. The $\mathrm{CO}_{2}$ levels began to decreasing when the fuel ramp down commenced as displayed in Figure 8-11.

The $\mathrm{O}_{2}$ volume fraction in the lower level changed little during the three tests. From near ambient at fire initiation, lower level oxygen measurements decreased to a minimum of approximately $20.9 \%$ within 5 min to 6 min of fire initiation. The lower level $\mathrm{O}_{2}$ volume fraction then gradually returned to near ambient as shown in Figure 8-12. 


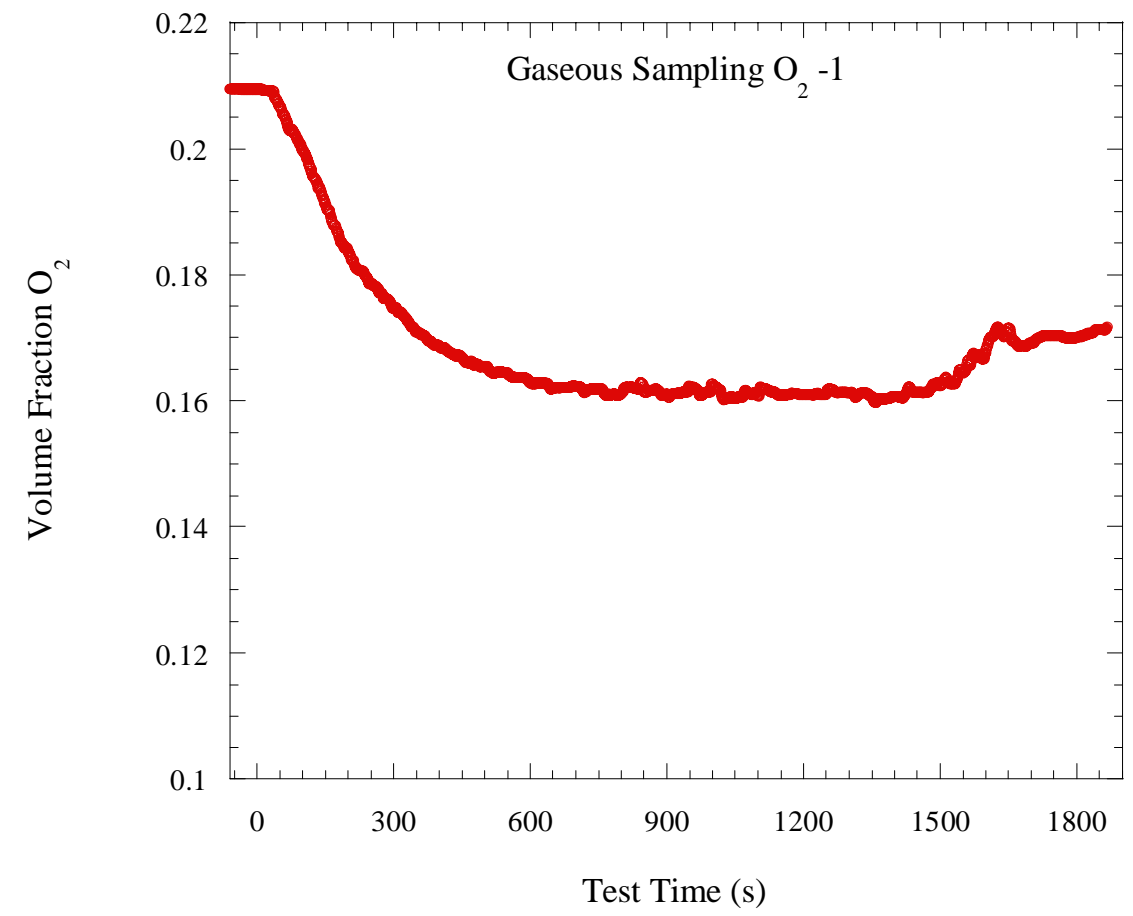

Figure 8-10: Test 9 Upper Layer $O_{2}$.

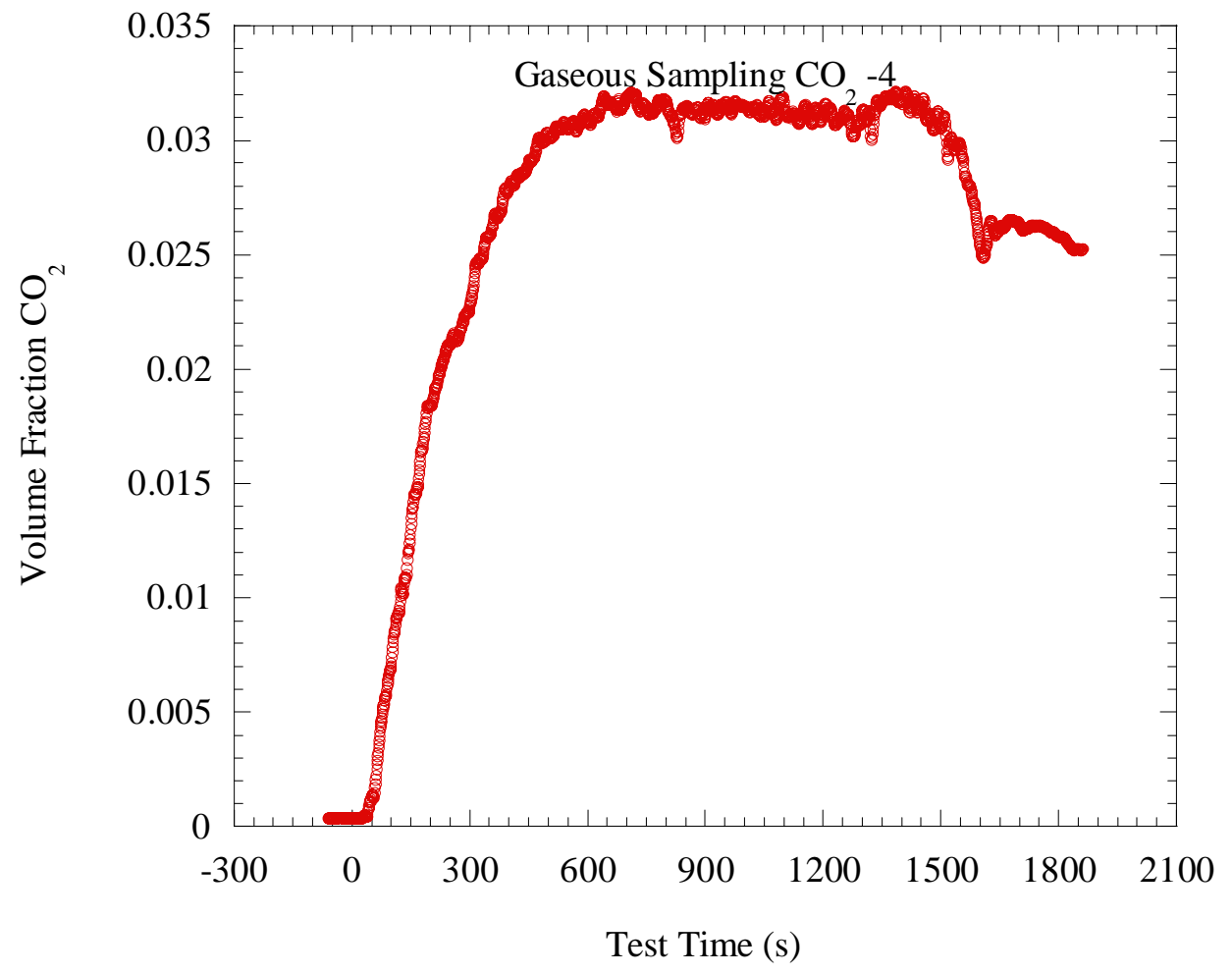

Figure 8-11: Test 3 Upper Layer $\mathrm{CO}_{2}$. 


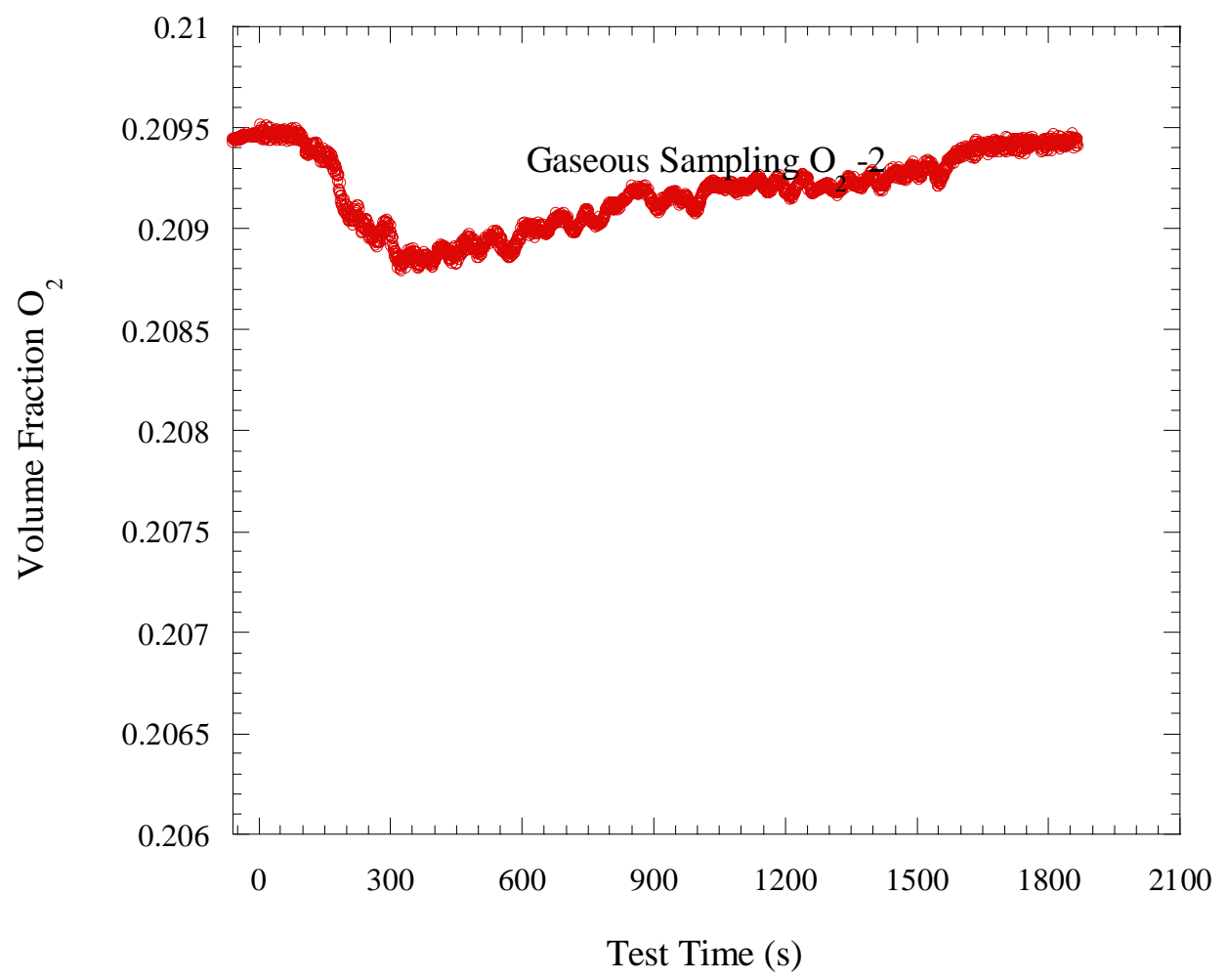

Figure 8-12: Test 14 Lower Layer $\mathrm{O}_{2}$.

Replicate Tests 4 and 10 exhibited upper layer oxygen volume fraction starting near ambient at fire initiation and gradually decreasing to approximately $13.6 \% \mathrm{~s}$ after fuel was secured. The $\mathrm{O}_{2}$ volume fraction then slowly increased for the remainder of each test. Figure 8-13 presents the upper layer $\mathrm{O}_{2}$ volume fraction during Test 10. During both tests, carbon monoxide in the upper layer did not increase by more than $0.01 \%$. Carbon dioxide rose from near ambient to approximately $4.9 \%$ just after fuel was secured. The $\mathrm{CO}_{2}$ levels then declined steadily as shown in Figure 8-14.

In the lower layer, $\mathrm{O}_{2}$ decreased from ambient reaching a minimum volume fraction of approximately $14.7 \%$ roughly 1 min after fuel was secured. As shown in Figure 8-15, the $\mathrm{O}_{2}$ volume fraction in the lower level then gradually increased for the remainder of the test. 


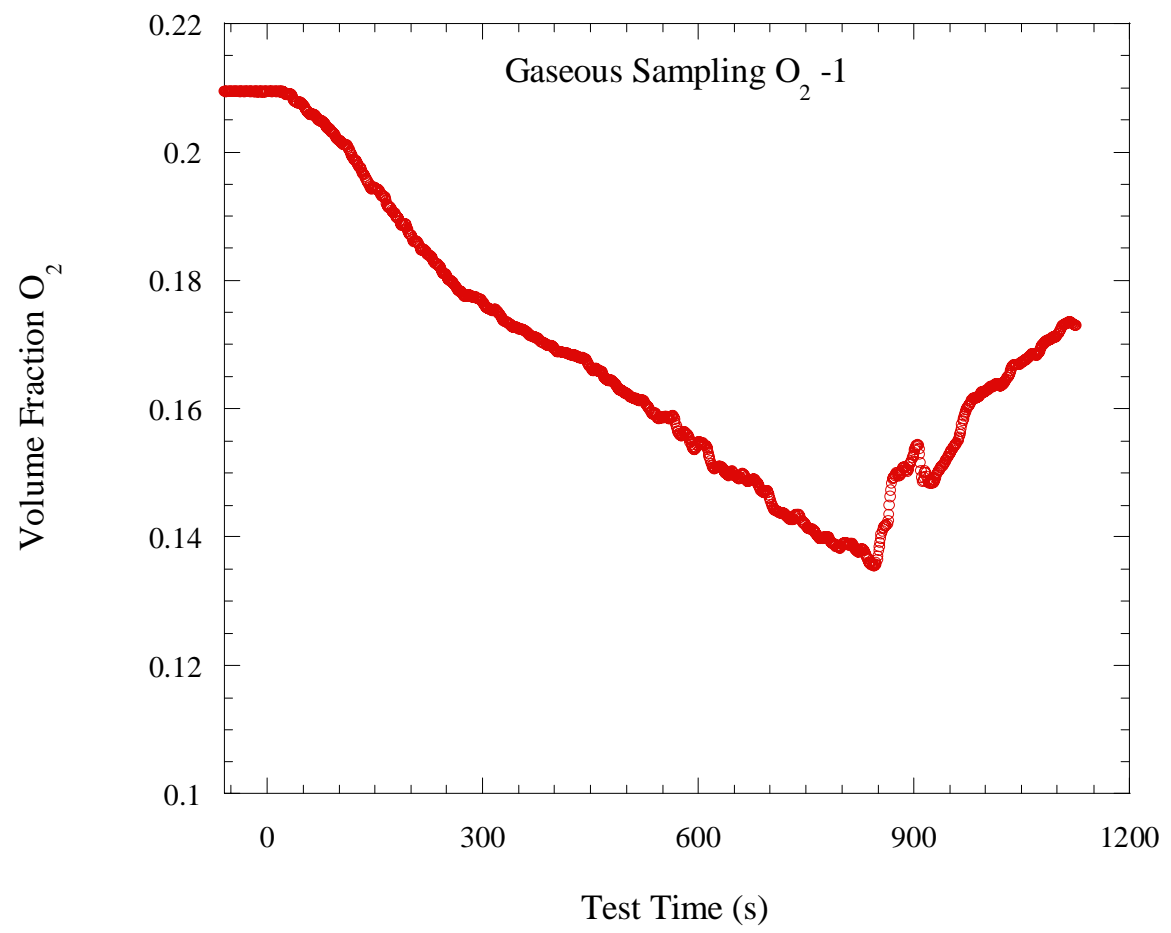

Figure 8-13: Test 10 Upper Layer $\mathrm{O}_{2}$.

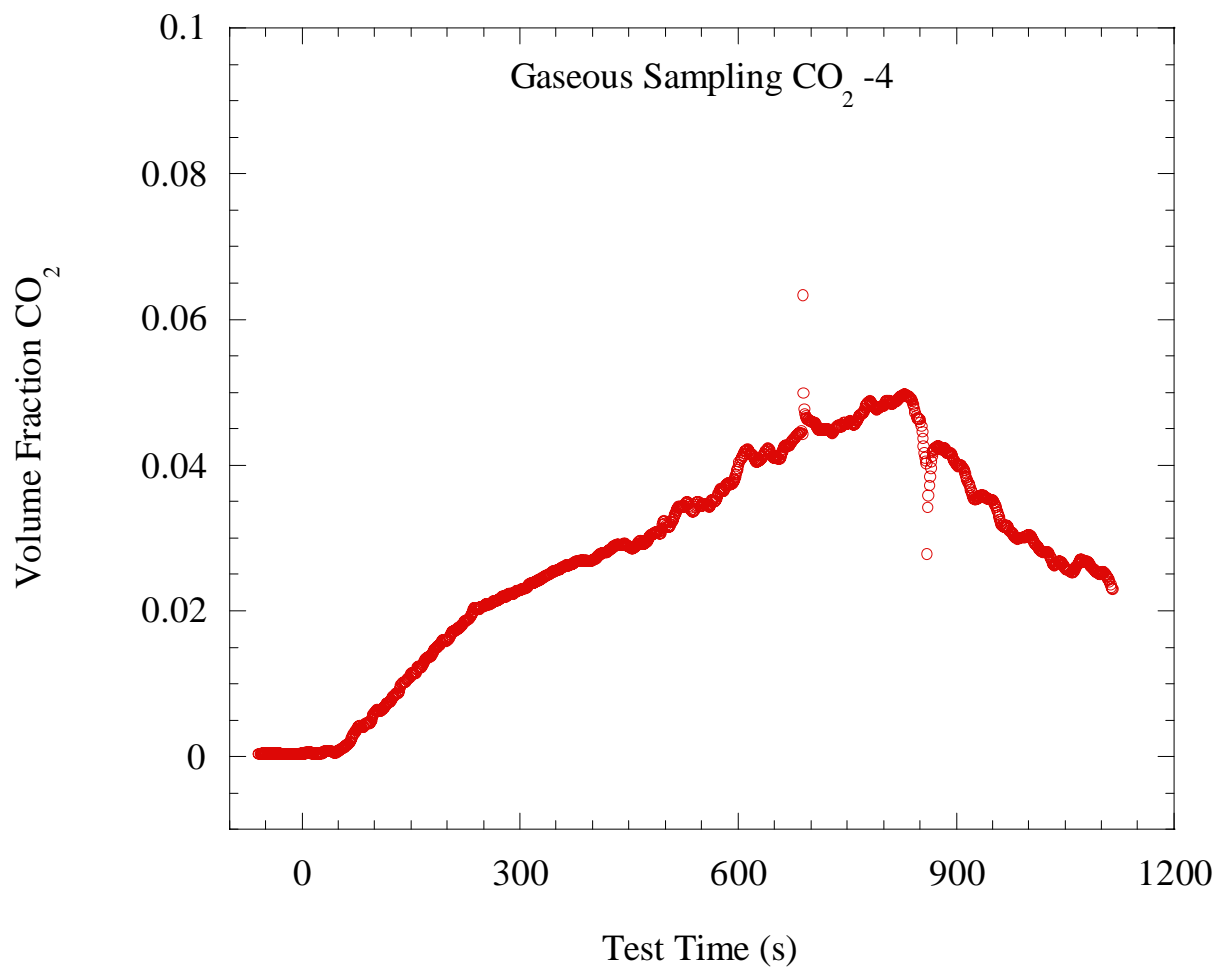

Figure 8-14: Test 4 Upper Layer $\mathrm{CO}_{2}$. 


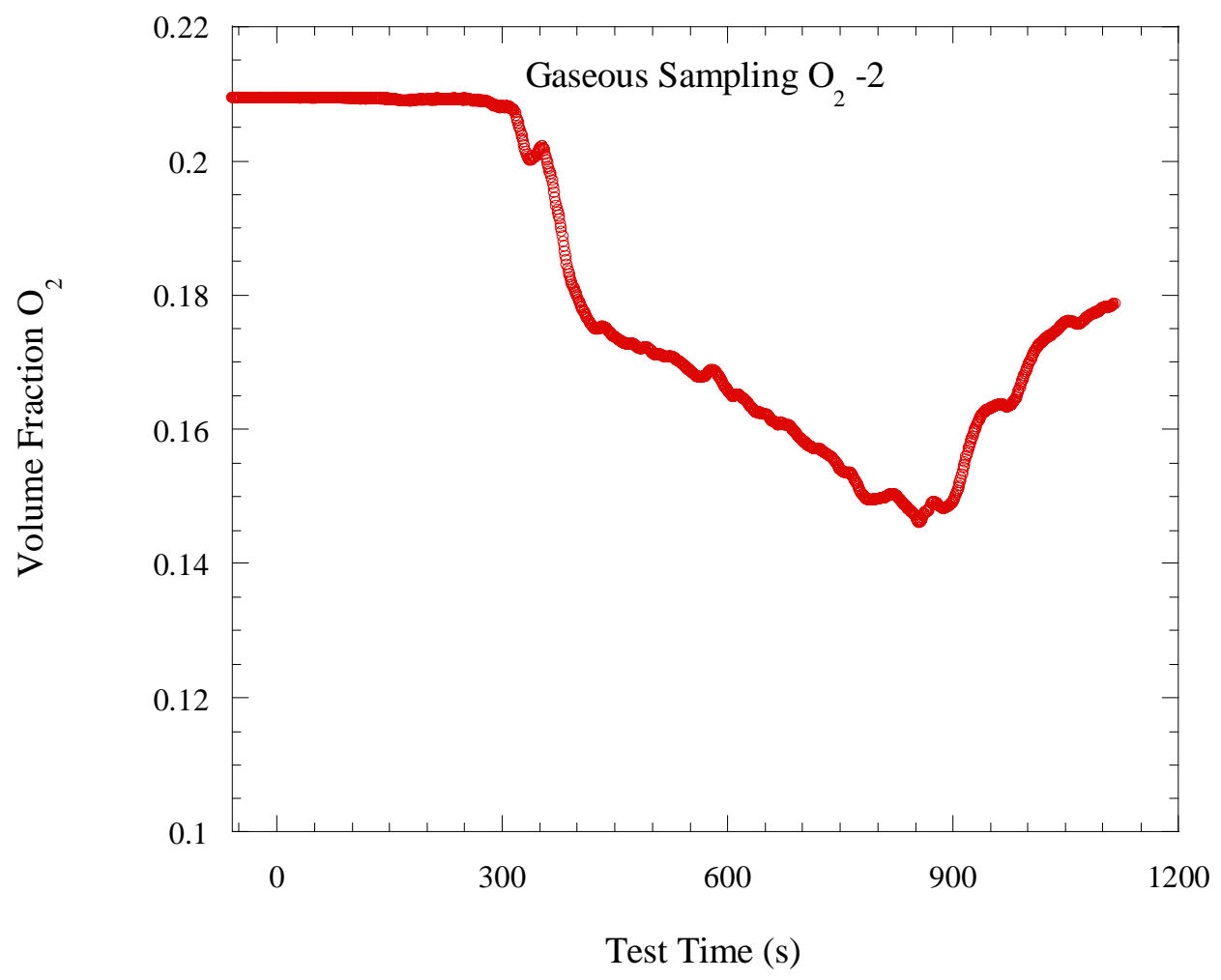

Figure 8-15: Test 4 Lower Layer $\mathrm{O}_{2}$.

During Test 5, the upper layer oxygen volume fraction decreased from ambient at fire initiation to a steady concentration of approximately $18.3 \%$. The $\mathrm{O}_{2}$ levels began to slowly return to ambient during the fuel ramp down. Carbon monoxide in the upper layer was below $0.01 \%$ at all times. Carbon dioxide in the upper layer increased from ambient to a steady concentration near $1.6 \%$. The $\mathrm{CO}_{2}$ volume fraction began returning towards ambient during the fuel ramp down. In the lower layer, the $\mathrm{O}_{2}$ volume fraction did not decrease by more than $0.05 \%$ at any time. The $\mathrm{O}_{2}$ and $\mathrm{CO}_{2}$ volume fractions in the upper layer are shown in Figure 8-16 and Figure 8-17. 


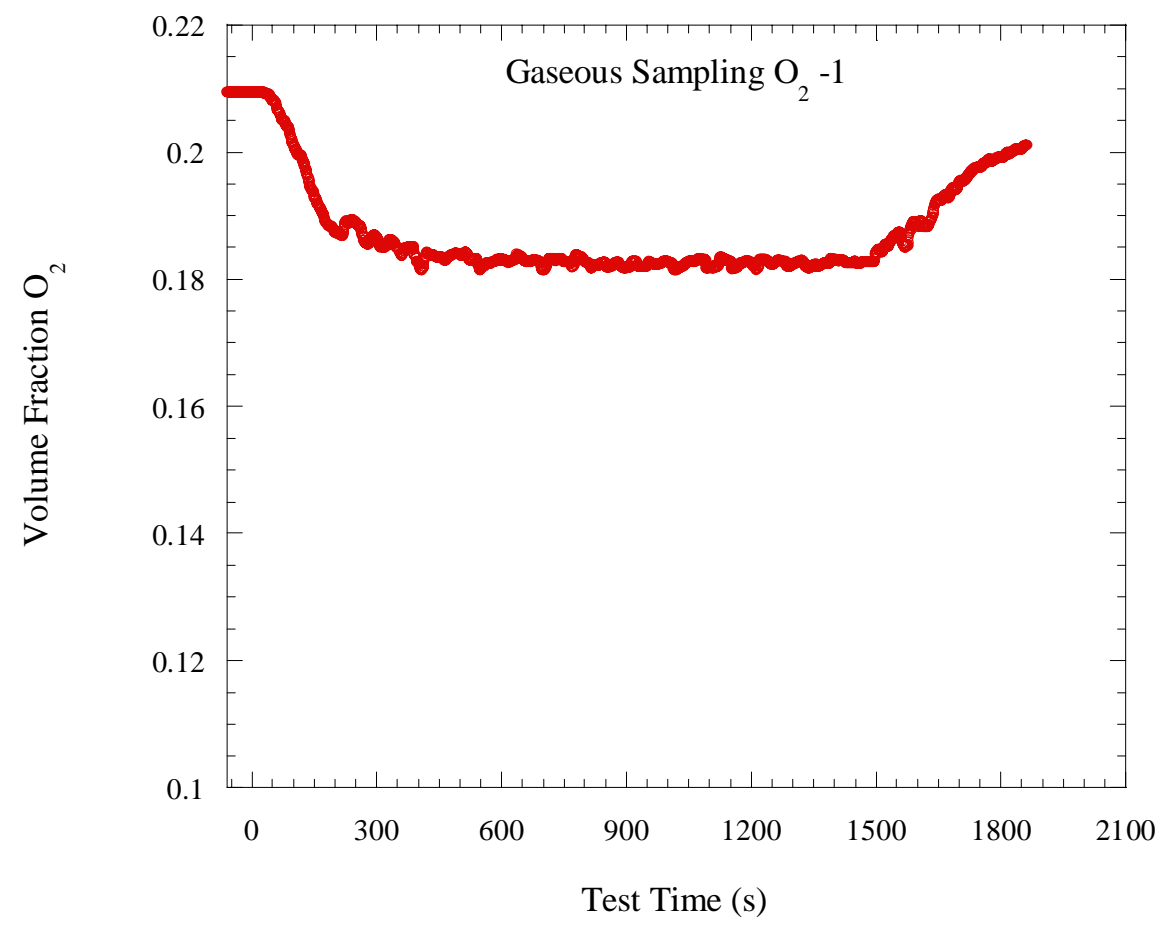

Figure 8-16: Test 5 Upper Layer $O_{2}$.

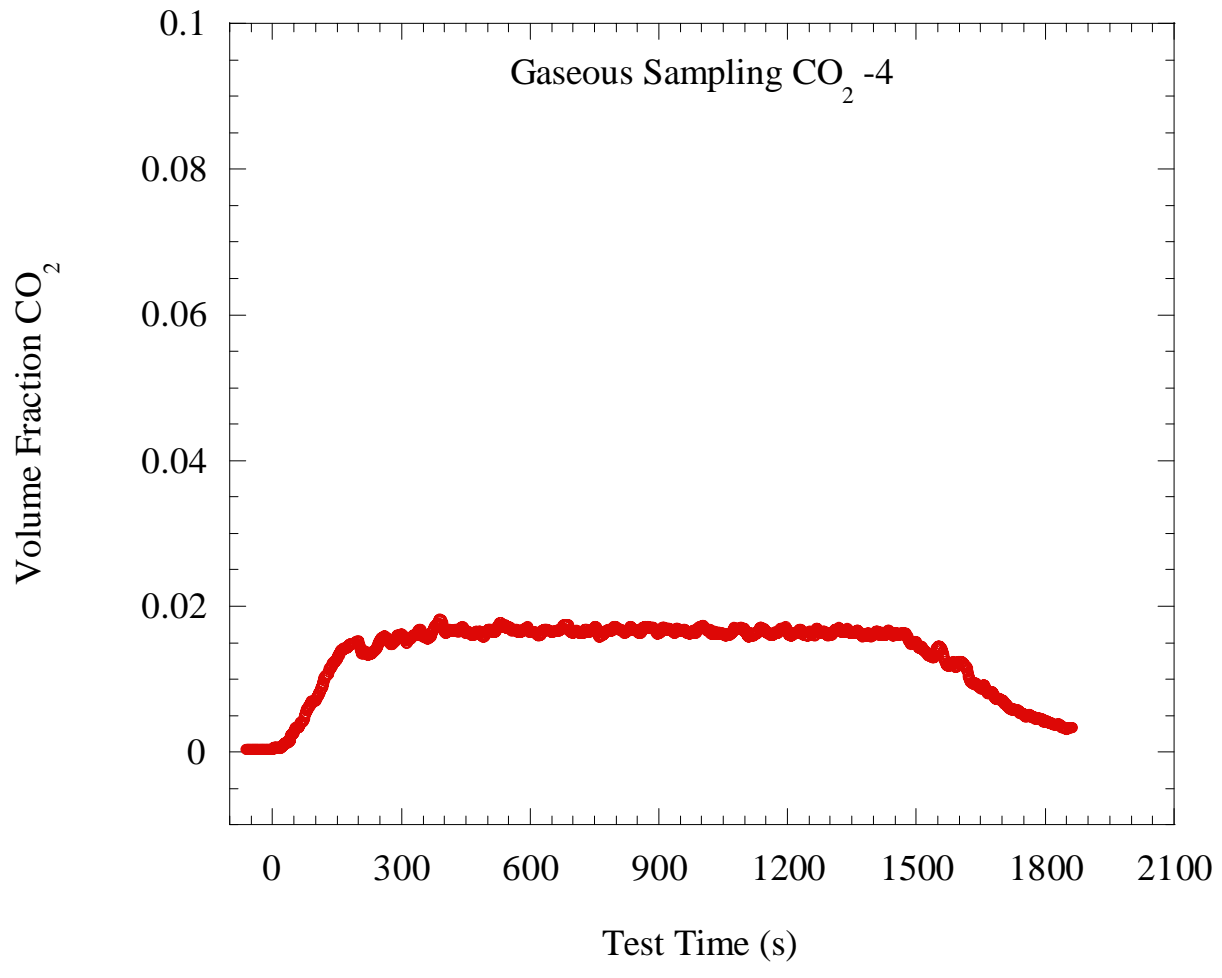

Figure 8-17: Test 5 Upper Layer $\mathrm{CO}_{2}$. 
Replicate Tests 13 and 16 exhibited upper layer oxygen volume fractions that decreased from near ambient at fuel initiation to minimum values of $11.3 \%$ and $12.2 \%$, respectively, after fuel was secured. The upper layer $\mathrm{O}_{2}$ volume fractions during Test 13 are plotted in Figure 8-18 below. Carbon monoxide increased from ambient at fuel initiation to approximately $0.05 \%$ and $0.02 \%$ during Tests 13 and 16, respectively, after fuel was secured. Figure 8-19 below is representative of upper layer CO during both tests. Similarly, carbon dioxide increased from ambient and reached a maximum volume fraction of over $6 \%$ during both tests once fuel flow was stopped. See Figure 8-20.

In the course of both tests, lower level $\mathrm{O}_{2}$ decreased from ambient levels to approximately 13.7 \% shortly after fuel flow was stopped as shown in Figure 8-21. For the remainder of the tests, the lower level $\mathrm{O}_{2}$ volume fraction gradually increased towards ambient levels.

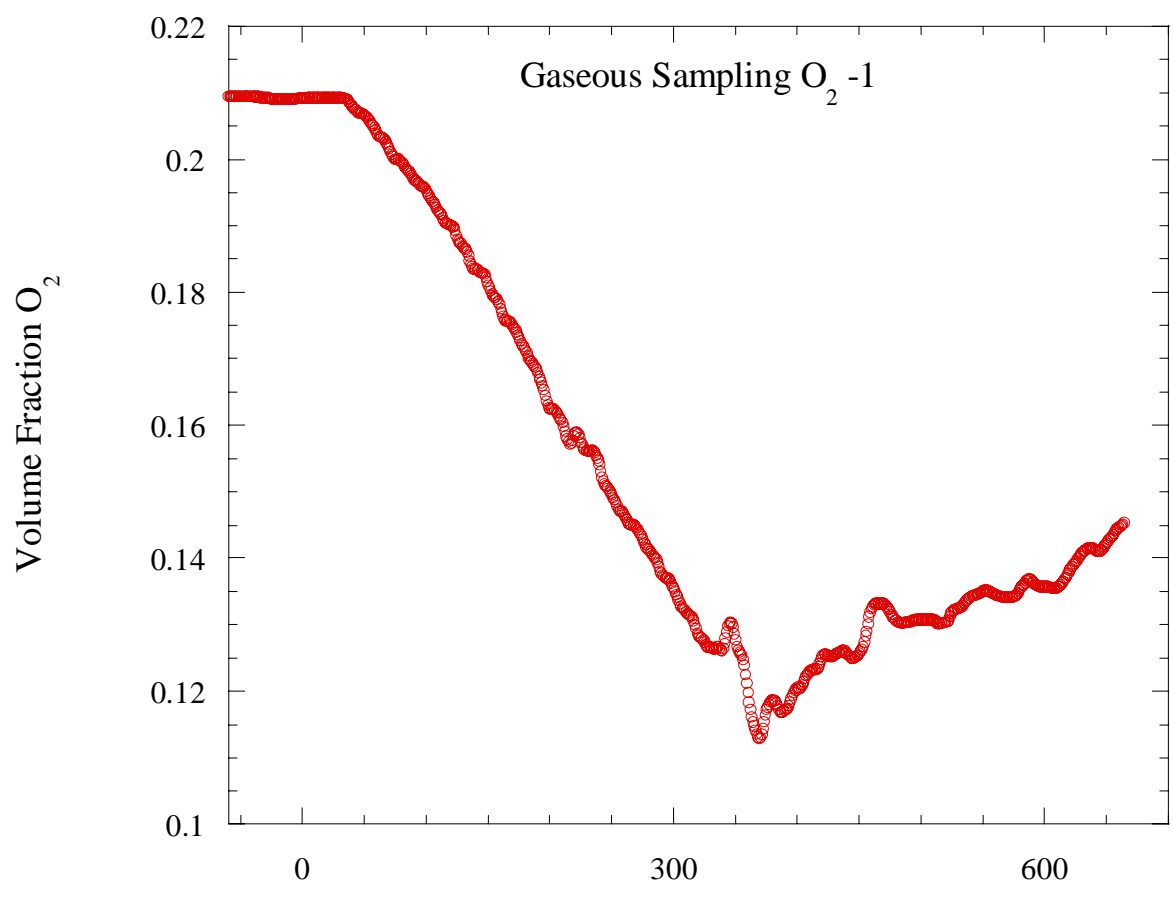

Test Time (s)

Figure 8-18: Test 13 Upper Layer $\mathbf{O}_{2}$. 


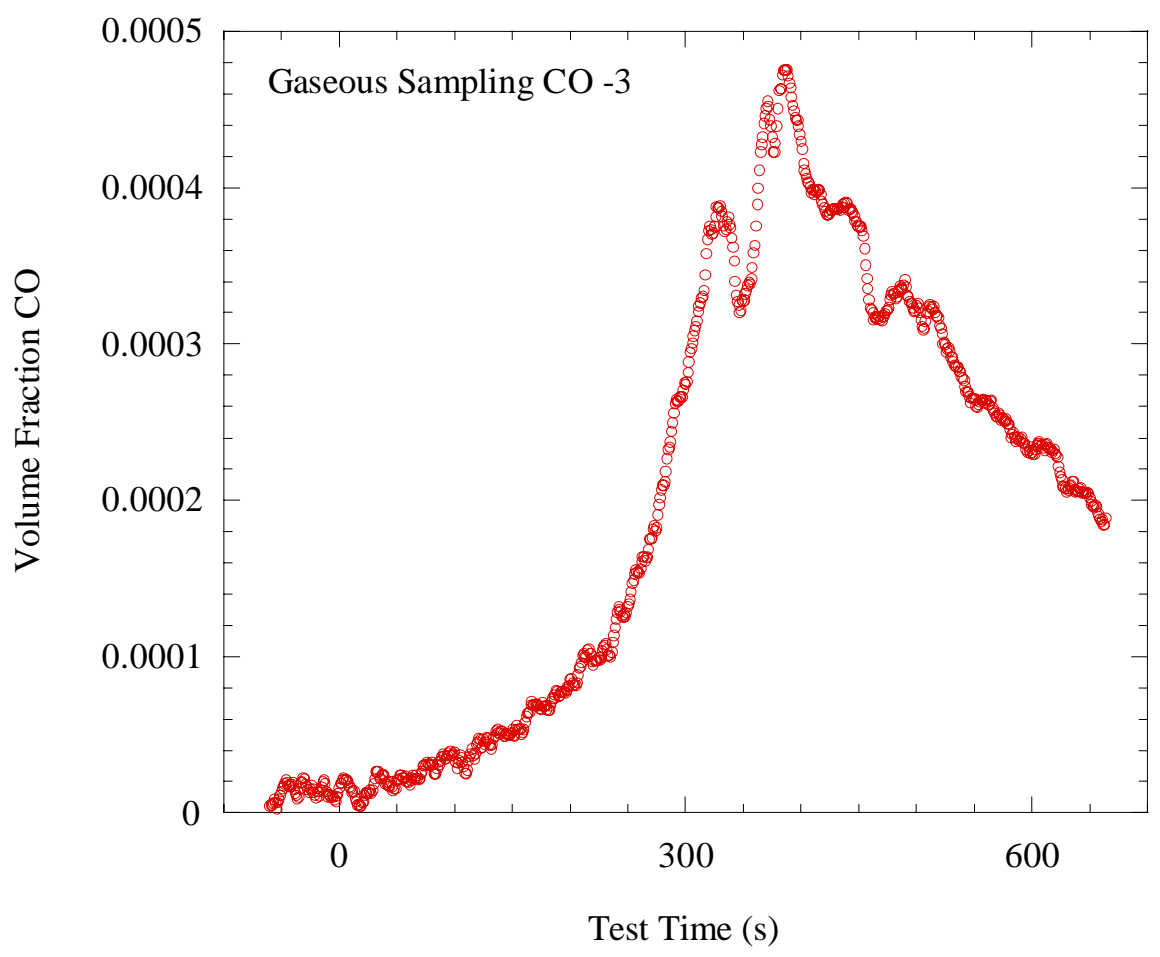

Figure 8-19: Test 13 Upper Layer CO.

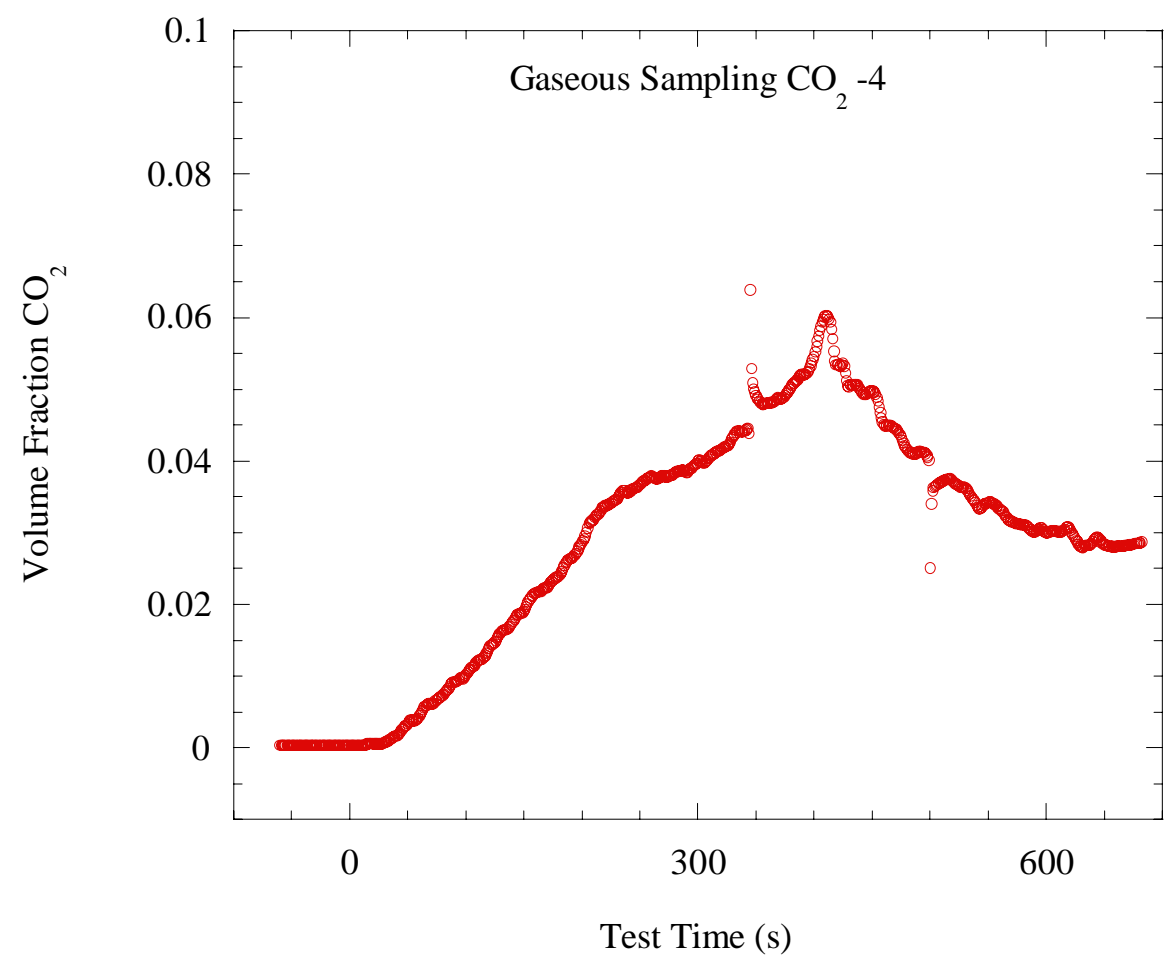

Figure 8-20: Test 16 Upper Layer $\mathrm{CO}_{2}$. 


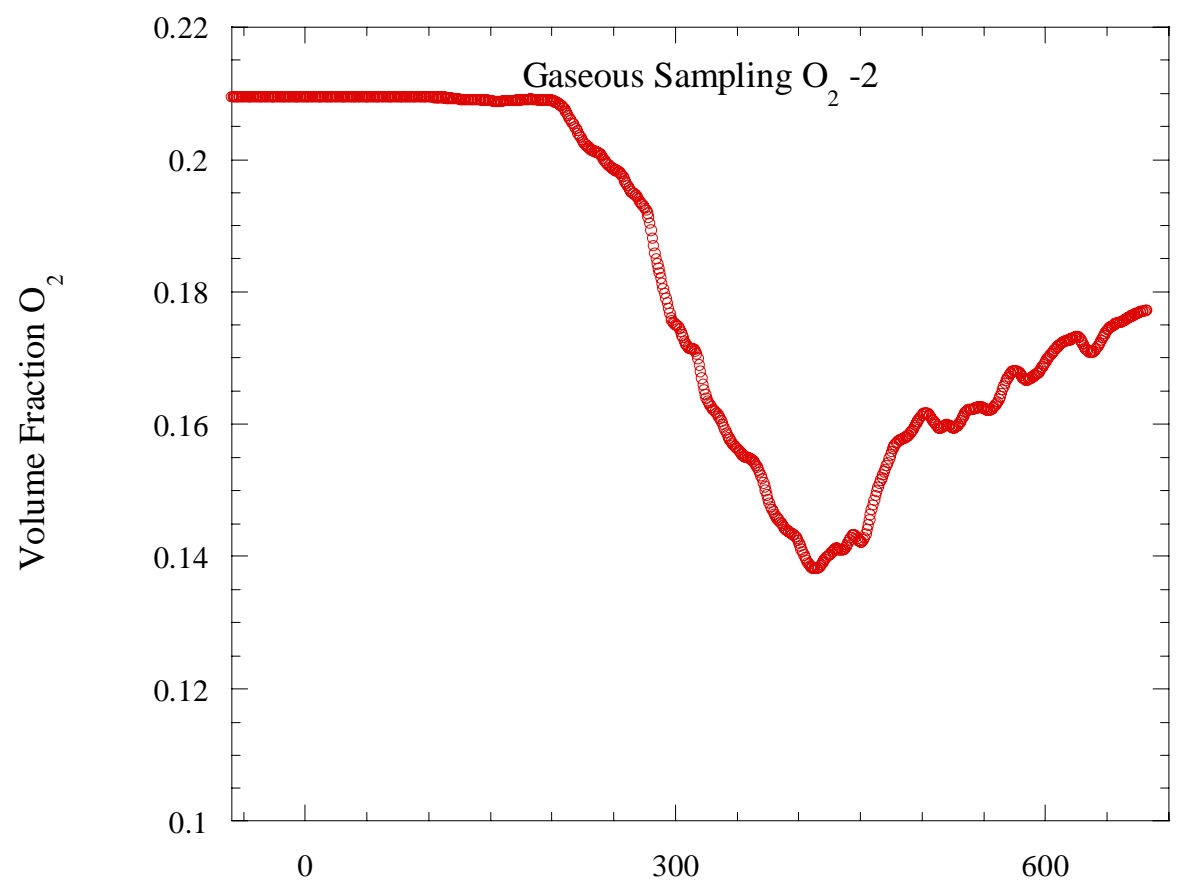

Test Time (s)

Figure 8-21: Test 16 Lower Layer $\mathrm{O}_{2}$.

The upper layer $\mathrm{O}_{2}$ concentrations decreased for Tests 15 and 18 from ambient oxygen volume fraction at fire initiation to near steady state volume fractions of approximately $16.3 \%$ during both tests. Carbon monoxide in the upper layer during both tests reached maximum volume fractions of $0.015 \%$ during fuel ramp down. The maximum volume fraction of carbon dioxide was roughly $3.1 \%$, during the fuel ramp down period. Oxygen, carbon monoxide and carbon dioxide then gradually returned towards ambient values once the fuel was off as shown in Figures 8-22 - 8-24.

The lower layer $\mathrm{O}_{2}$ data from Test 18 suggest that sample flow in the lower layer sampling system stopped approximately 6 min after the fire was initiated. The oxygen had decreased to roughly $20.8 \%$ at that time. Lower level $\mathrm{O}_{2}$ during Test 15 as shown in Figure 8-25, decreased to approximately $20.8 \%$ and began to return to ambient once fuel was secured. 


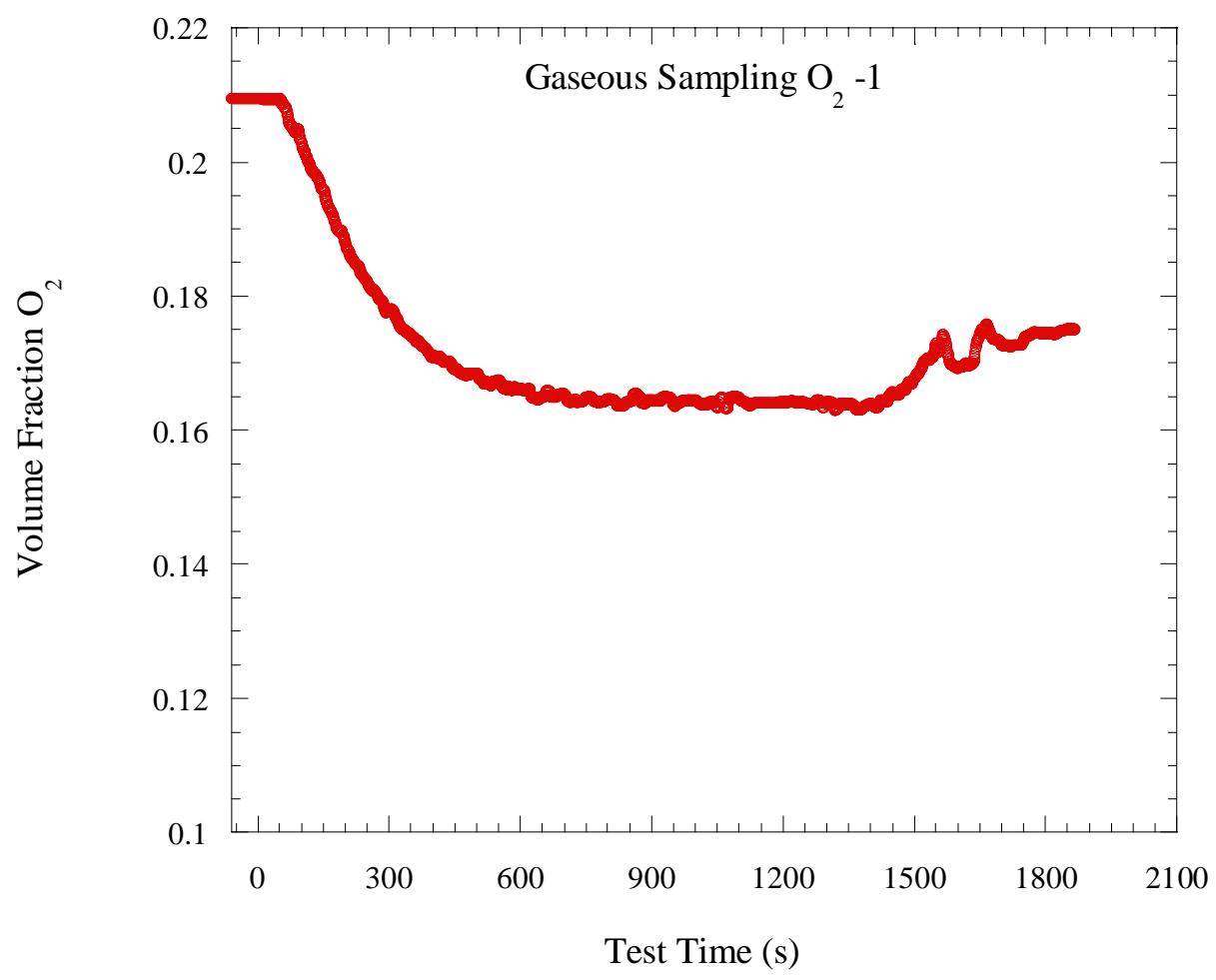

Figure 8-22: Test 18 Upper Layer $\mathrm{O}_{2}$.

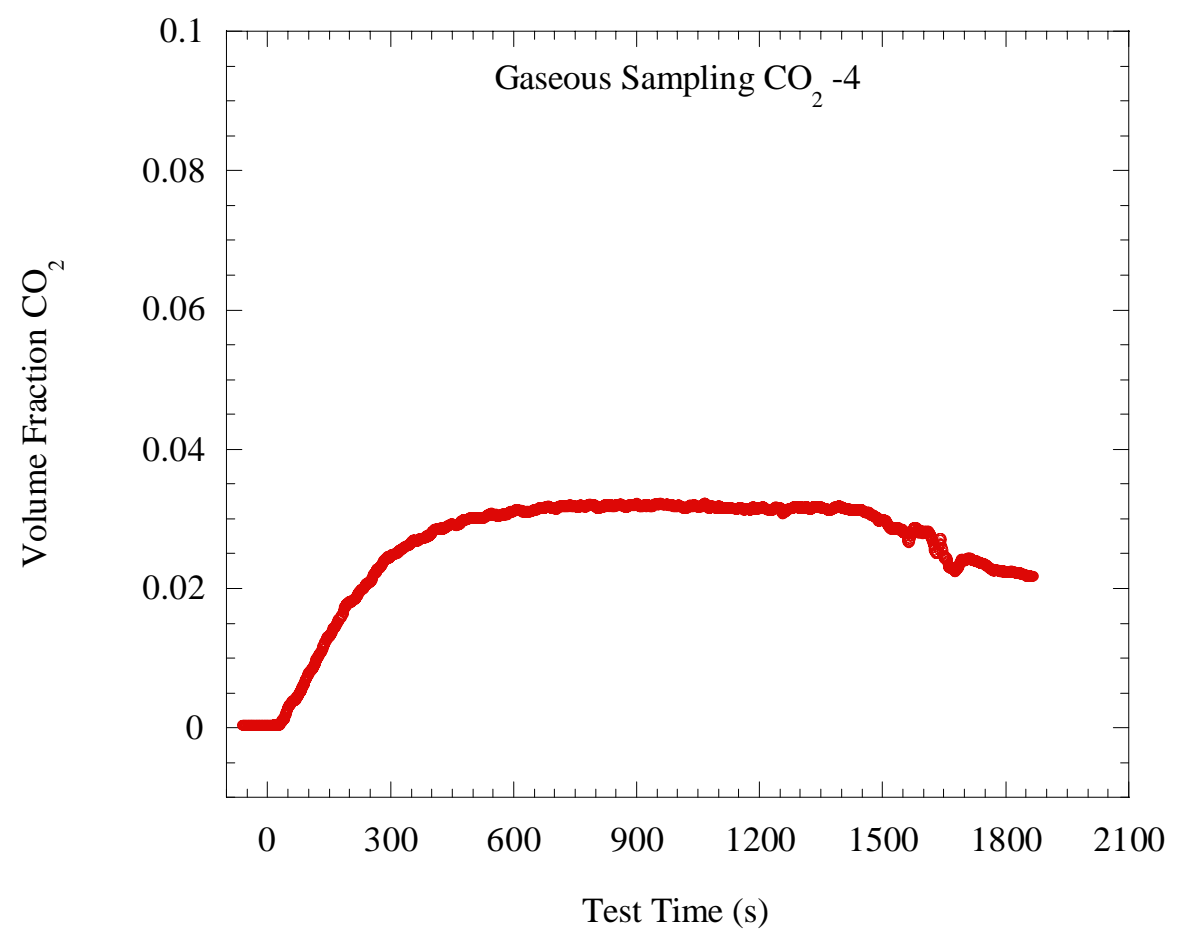

Figure 8-23: Test 15 Upper Layer $\mathrm{CO}_{2}$. 


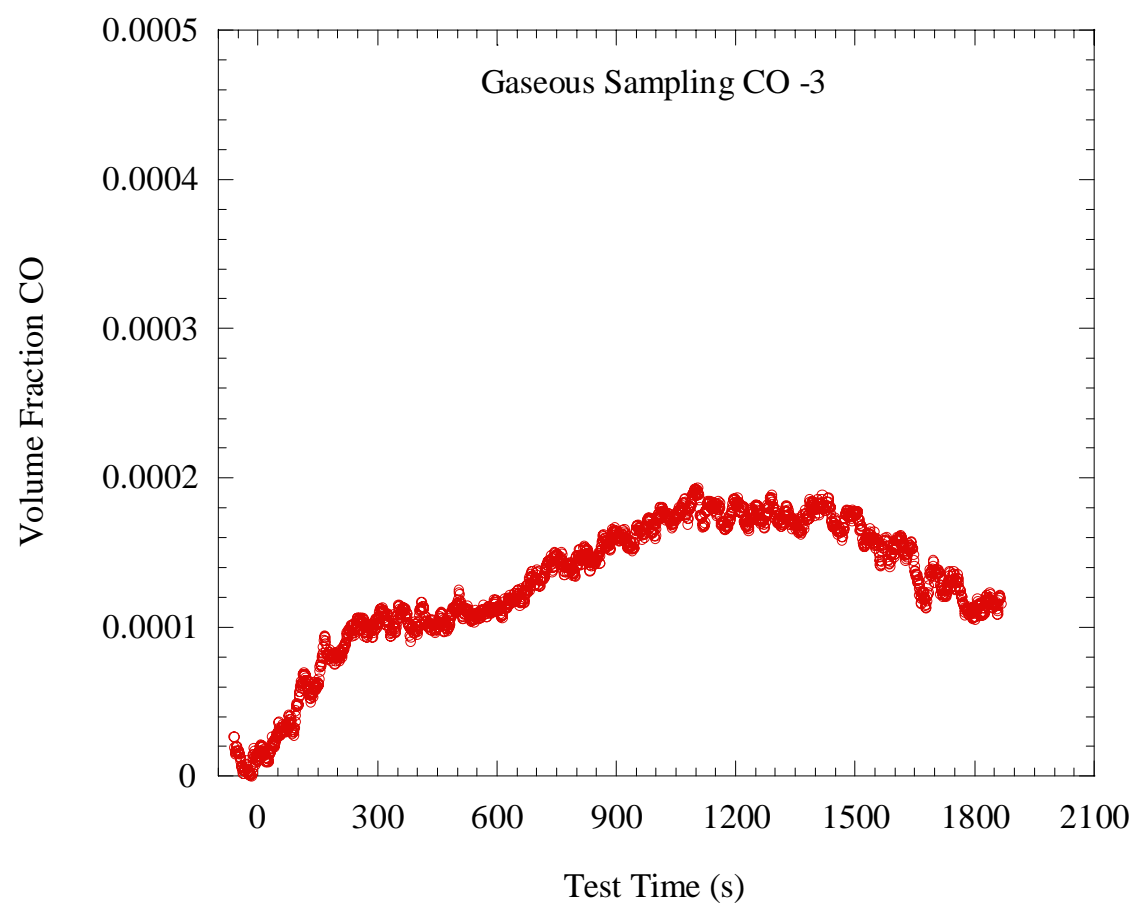

Figure 8-24: Test 15 Upper Layer CO.

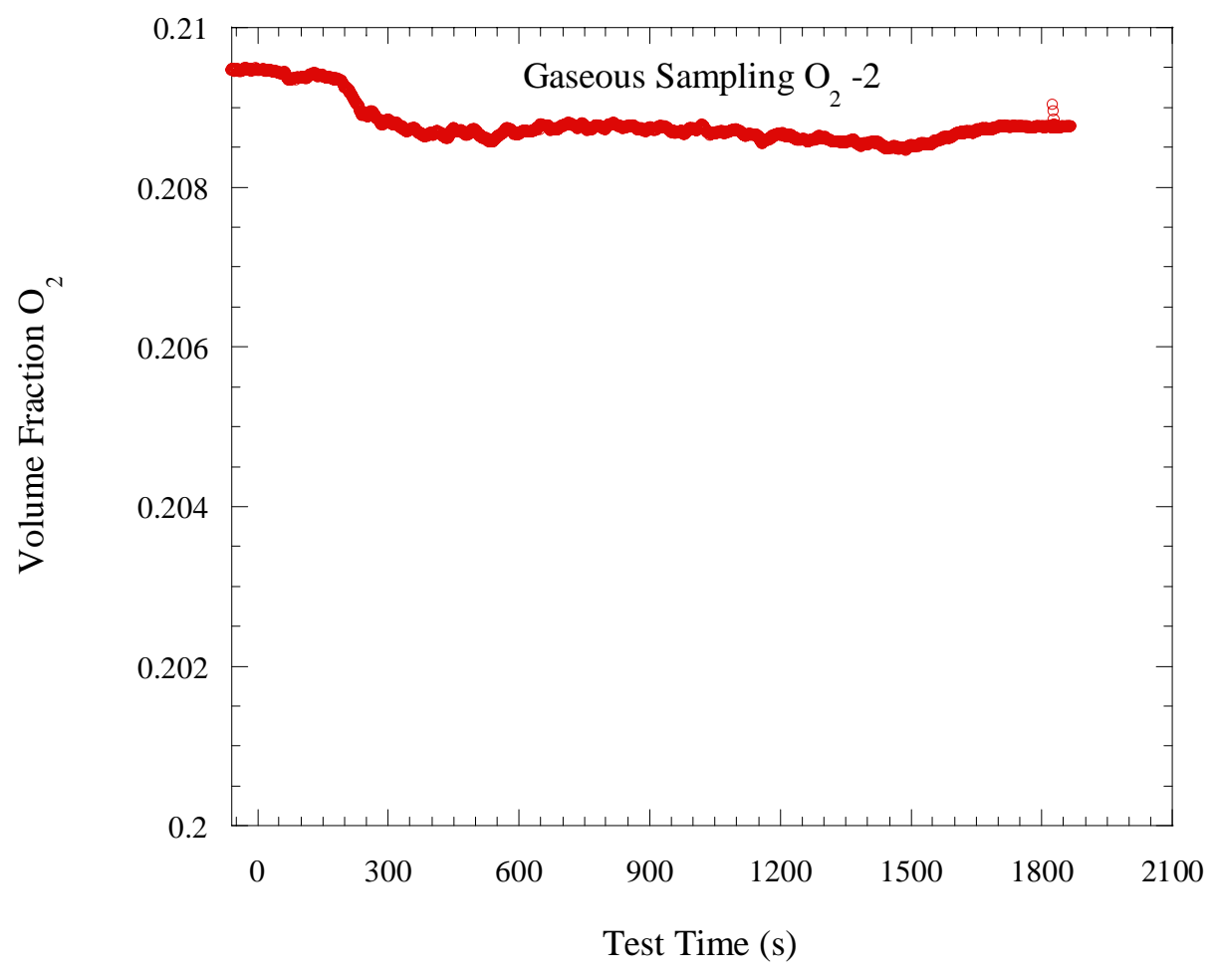

Figure 8-25: Test 15 Lower Level $\mathrm{O}_{2}$. 
During Test 17, oxygen in the upper layer decreased progressively from ambient to approximately $18 \%$ shortly after fuel was secured. Carbon monoxide and carbon dioxide steadily increased from ambient values to maximum values of $0.1 \%$ and $2.3 \%$ respectively. Oxygen, carbon monoxide and carbon dioxide began to return to ambient concentrations once fuel was secured. Oxygen in the lower layer decreased from ambient to about $18.3 \%$ roughly 1.5 mins after fuel flow was stopped. The lower level $\mathrm{O}_{2}$ then gradually increased towards ambient. Gas concentration data from Test 17 are presented in Figures 8-26-8-29.

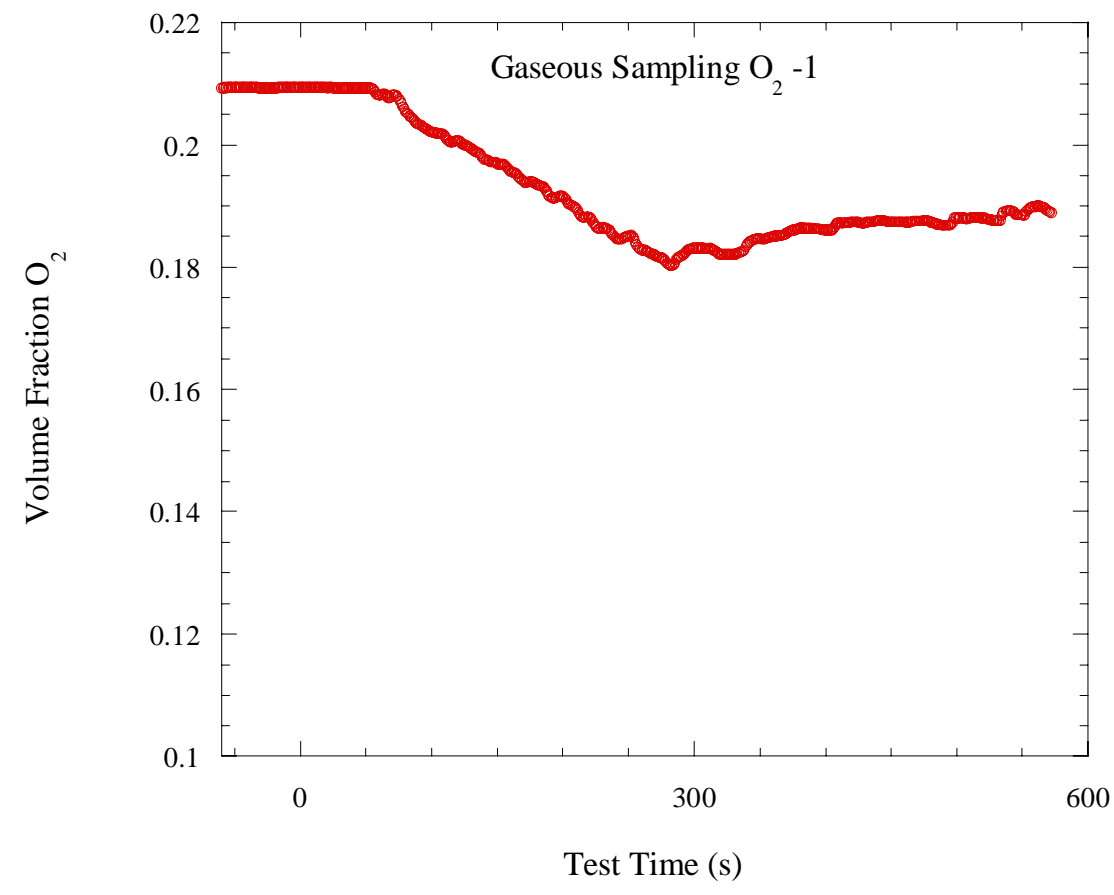

Figure 8-26: Test 17 Upper Layer $\mathrm{O}_{2}$. 


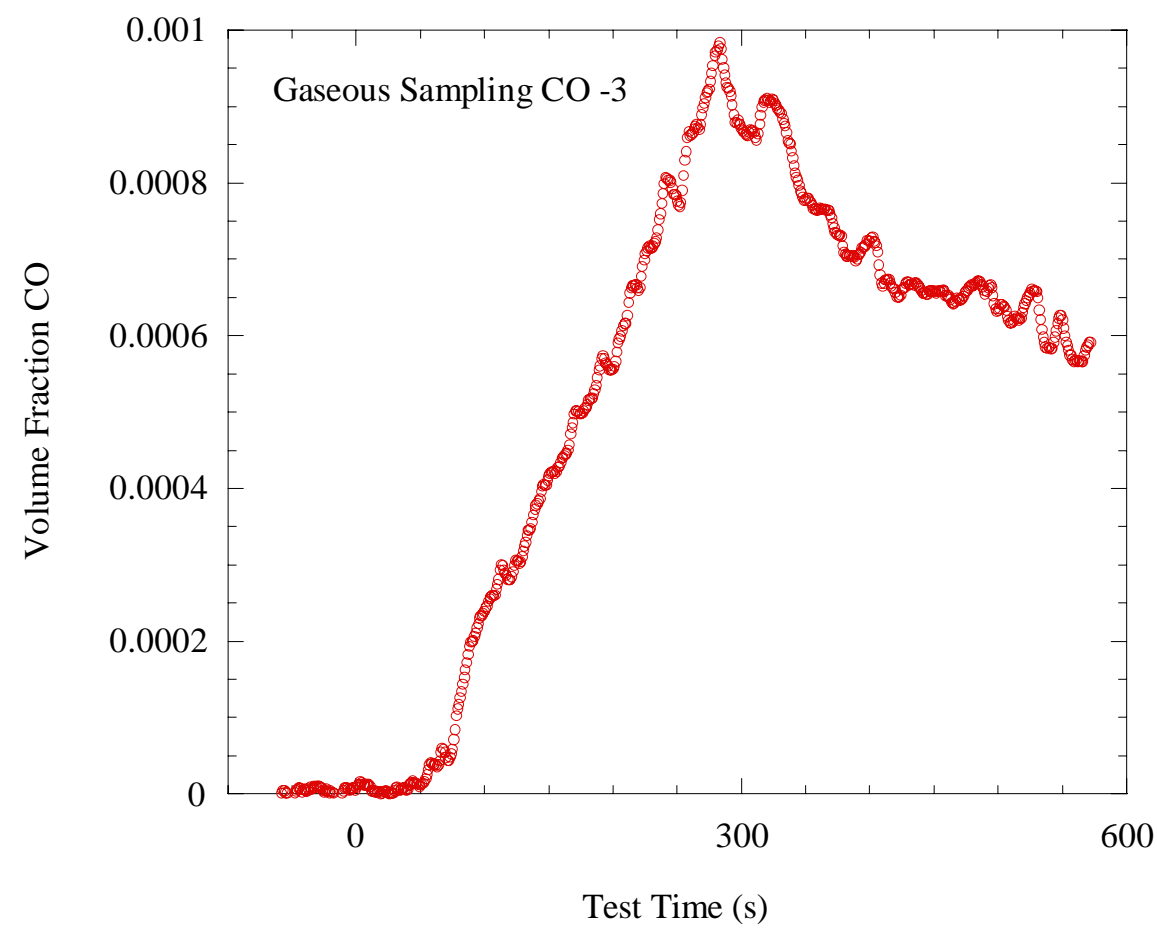

Figure 8-27: Test 17 Upper Layer CO.

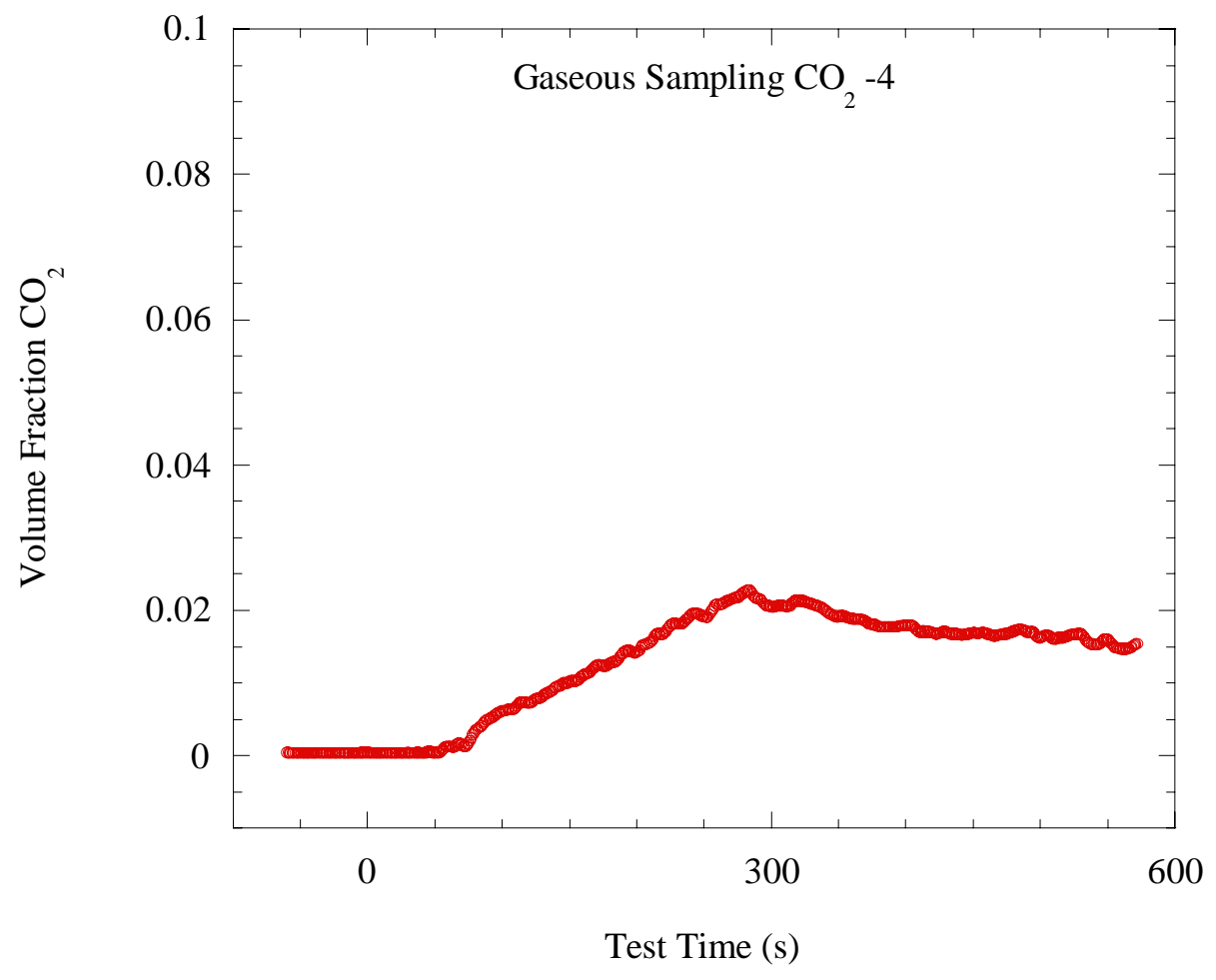

Figure 8-28: Test 17 Upper Layer $\mathrm{CO}_{2}$. 


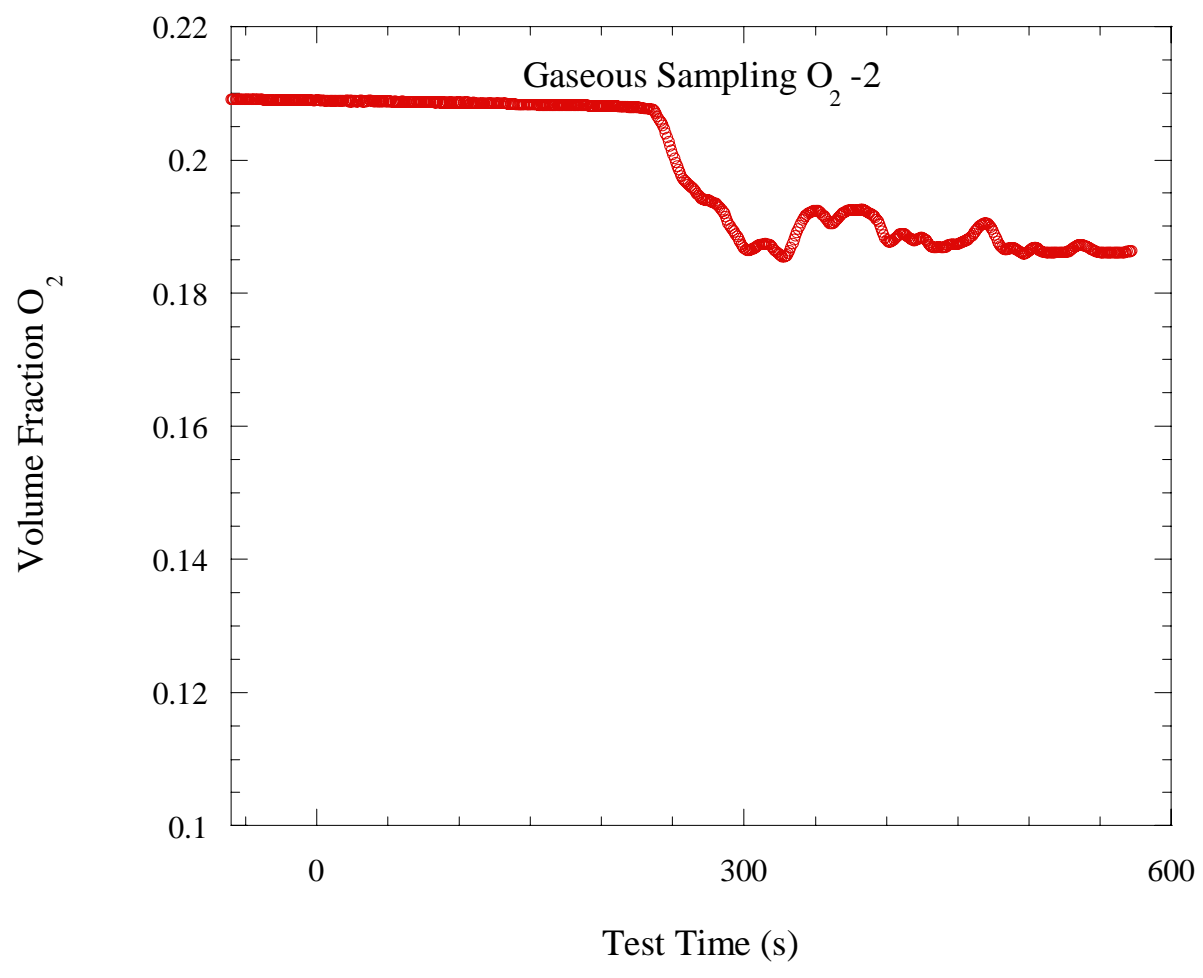

Figure 8-29: Test 17 Lower Layer $O_{2}$. 


\section{GAS TEMPERATURES}

Gas temperatures were measured using seven thermocouple trees, with each tree holding ten type $\mathrm{K}$ thermocouples. The thermocouple locations are denoted in Appendix D.

\subsection{Measurement Uncertainties}

A discussion of uncertainties is necessary before describing the results of the gas temperature measurements and their derived results. The uncertainties in measured temperature are primarily due to radiative heating and cooling of the thermocouple bead that causes it to respond to phenomena other than the surrounding gas temperature. Since the thermal environment surrounding a given thermocouple was very difficult to characterize, aspirated thermocouples, which do not suffer radiative exchange problems [McCaffrey and Heskestad, 1976], were used to check the magnitude of the needed temperature correction at a limited number of locations.

The aspirated probes used a double-shielded design, which overcomes radiation effects on the bead much more effectively than a single-shielded model [Pitts et al., 1998]. The materials were either 304 SS or Inconel. The outer diameter of the outer shield is $0.95 \mathrm{~cm}(0.375 \mathrm{in})$. The probes available extended either $1.8 \mathrm{~m}(5.9 \mathrm{ft}), 1.2 \mathrm{~m}(3.9 \mathrm{ft})$, or $7.0 \mathrm{~m}(23 \mathrm{ft})$ into the enclosure. To generate sufficient velocity (approximately $1.0 \mathrm{~m} / \mathrm{s}(3.3 \mathrm{ft} / \mathrm{s})$ ) and convective heat transfer over the bead, gases were pulled through the probes at a minimum of $24 \mathrm{~L} / \mathrm{min}\left(0.85 \mathrm{ft}^{3} / \mathrm{min}\right)$.

The results for two bare-bead and aspirated thermocouple pairs (T5-3, TA5; T5-8, TA6) are considered here. Thermocouples T5-3 and T5-8 were part of Thermocouple Tree 5, which was located approximately $3.0 \mathrm{~m}(9.8 \mathrm{ft})$ from the center of the fire pan for Tests 1 to 13, 16, and 17, approximately $4.80 \mathrm{~m}(15.7 \mathrm{ft})$ from the pan center for Test 14, $1.0 \mathrm{~m}(3.3 \mathrm{ft})$ from the pan center for Test 18, and $0.7 \mathrm{~m}$ (2.3 ft) from the pan center for Test 15. The Appendix lists the exact locations for Thermocouple Tree 5 and the aspirated thermocouples (TA5 and TA8). Each pair of the two types of thermocouples was positioned within $4 \mathrm{~cm}$ (1.6 in) of each other. The differences between bare bead and aspirated thermocouple temperatures varied during each test, and from test to test. Table 9-1 summarizes these variations as represented by the mean and standard deviation of the differences that occurred during each of the tests. The magnitudes of the differences at these locations show that the difference between the bare-bead thermocouple temperature measurements and the aspirated temperature measurements were generally less than $10^{\circ} \mathrm{C}\left(18^{\circ} \mathrm{F}\right)$ for the lower layer and less than $5{ }^{\circ} \mathrm{C}\left(9^{\circ} \mathrm{F}\right)$ in the hot gas layer, with the exception of Tests 15 and 18 where the burner was closer to the thermocouple tree resulting in much larger radiative effects.

Also included in Table 9-1 are the resulting expanded temperature uncertainty limits for the upper and lower compartment layers. The uncertainty limits are asymmetric and consider radiation effects as well as the inherent uncertainty associated with thermocouple calibration. 
The uncertainties are considered conservative for thermocouple measurements more than $3.0 \mathrm{~m}$ $(9.8 \mathrm{ft})$ from the fire since the comparisons were made at locations near the fire plume where radiative effects are greatest. For thermocouples further away from the fire plume, radiation effects would be less significant. The results suggest that the thermocouple measurements were accurate within $10^{\circ} \mathrm{C}\left(18^{\circ} \mathrm{F}\right)$, except when the fire was within $1.0 \mathrm{~m}$ (3.3 ft) of the thermocouples as occurred in Tests 15 and 18, where radiation effects are significant.

Figures 9-1 to 9-6 are pairs of plots showing the absolute and relative differences between the

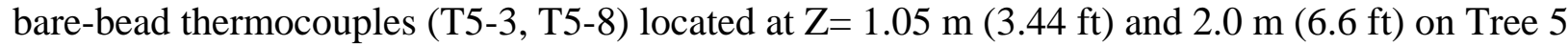
and the nearby aspirated thermocouples (TA5, TA6) for tests 2, 3, and 4. The results of analysis of all the tests are contained in Table 9-1.

Table 9-1: Calculated differences between aspirated and bare bead thermocouple temperature measurements and expanded temperature uncertainties.

\begin{tabular}{|c|c|c|c|c|c|c|c|c|}
\hline \multirow{2}{*}{ Test No. } & \multicolumn{4}{|c|}{ Differences $\left({ }^{\circ} \mathrm{C}\right)$} & \multicolumn{3}{c|}{ Expanded Uncertainty Limits $\left({ }^{\circ} \mathrm{C}\right)$} \\
\cline { 2 - 9 } & \multicolumn{2}{|c|}{ T5-3 - TA5 } & \multicolumn{2}{|c|}{ T5-8 - TA6 } & \multicolumn{2}{c|}{ Lower Layer } & \multicolumn{2}{c|}{ Hot Gas Layer } \\
\cline { 2 - 9 } & Mean & S.D. & Mean & S.D. & Low & High & Low & High \\
\hline 1 & -3.1 & 1.8 & -3.5 & 0.8 & -2 & 8 & 0 & 7 \\
\hline 2 & 1 & 6 & -0.4 & 2.6 & -14 & 12 & -6 & 7 \\
\hline 3 & 14.9 & 5.2 & 1 & 3.1 & -27 & -3 & -9 & 7 \\
\hline 4 & 0 & 4.8 & 1.5 & 2.9 & -11 & 11 & -9 & 6 \\
\hline 5 & 0.7 & 5.9 & -1.6 & 2 & -14 & 13 & -4 & 7 \\
\hline 7 & -2.3 & 0.9 & -2.9 & 1.6 & -1 & 6 & -2 & 8 \\
\hline 8 & -2.2 & 3.2 & -2.2 & 2 & -6 & 10 & -3 & 8 \\
\hline 9 & 4.9 & 10.5 & -1 & 2.4 & -27 & 18 & -5 & 7 \\
\hline 10 & 0.5 & 4.3 & 6.2 & 3.1 & -11 & 10 & -14 & 1 \\
\hline 13 & -1.5 & 5.2 & -1.5 & 3.5 & -10 & 13 & -7 & 10 \\
\hline 14 & -1.1 & 2.4 & -5.3 & 5.3 & -5 & 7 & -7 & 17 \\
\hline 15 & 75.3 & 98.5 & -0.5 & 6.6 & -274 & 123 & -14 & 15 \\
\hline 16 & -1.6 & 3.7 & -1.5 & 3 & -7 & 10 & -6 & 9 \\
\hline 17 & -2.5 & 2.8 & -2.1 & 2.4 & -5 & 10 & -4 & 8 \\
\hline 18 & 18.5 & 28.5 & -2.6 & 2.4 & -77 & 40 & -4 & 9 \\
\hline
\end{tabular}




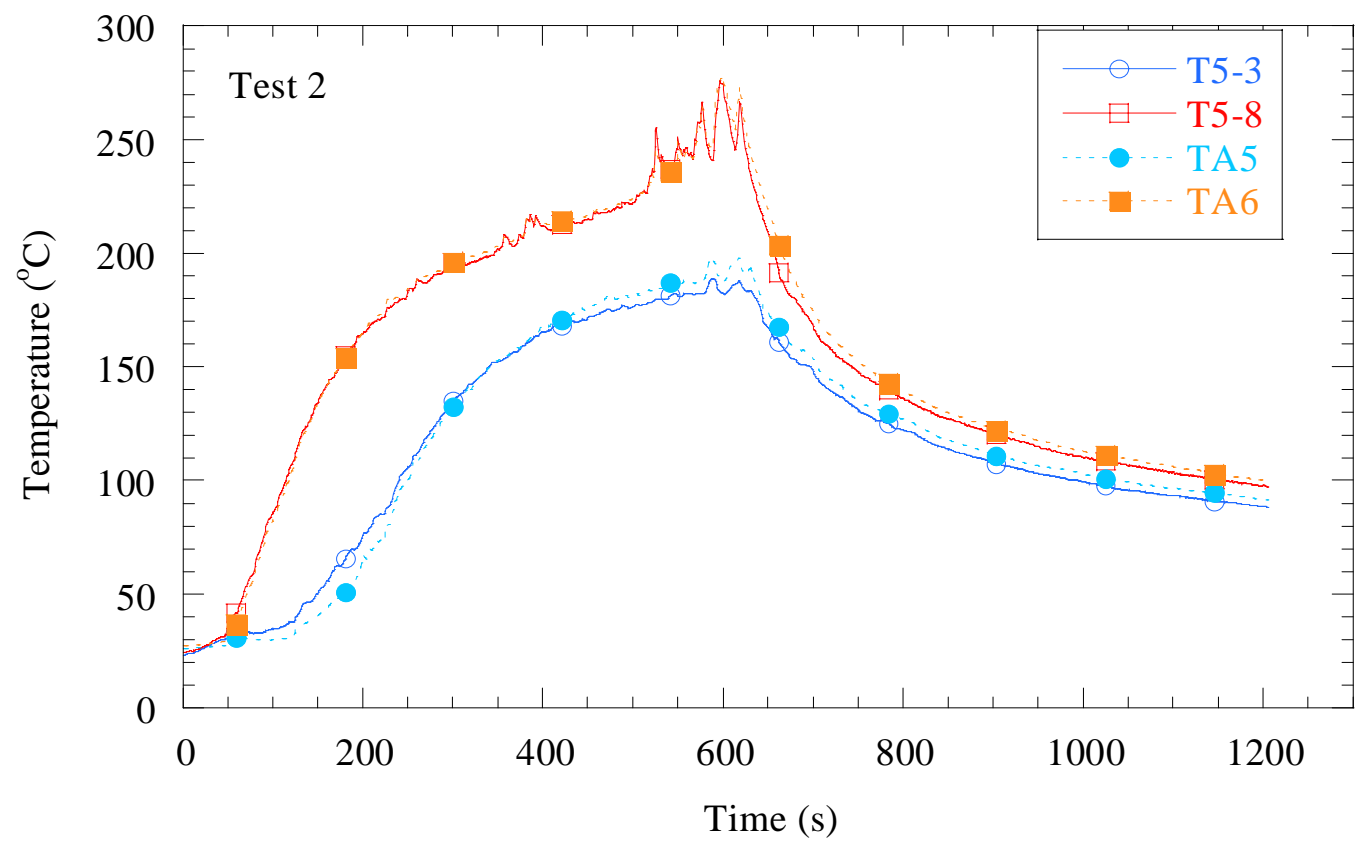

Figure 9-1: Temperature comparison as a function of time for aspirated (TA5, TA6) and bare-bead thermocouples (T5-3, T5-8) located at $Z=1.05 \mathrm{~m}$ and $2.0 \mathrm{~m}$ on Tree 5 during Test 2.

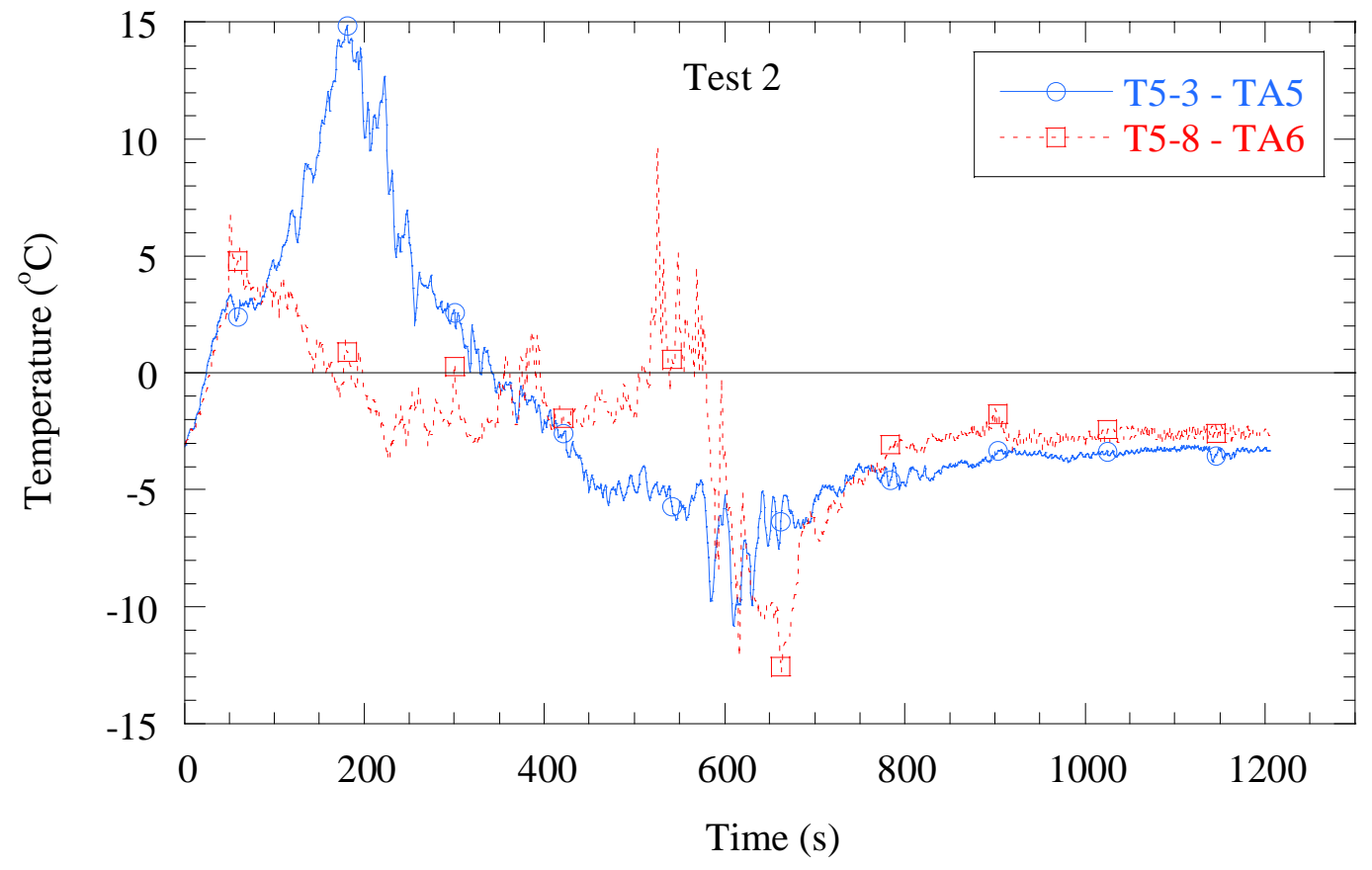

Figure 9-2: Temperature differences as a function of time for aspirated (TA5, TA6) and bare-bead thermocouples (T5-3, T5-8) located at $Z=1.05 \mathrm{~m}$ and $2.0 \mathrm{~m}$ on Tree 5 during Test 2. 


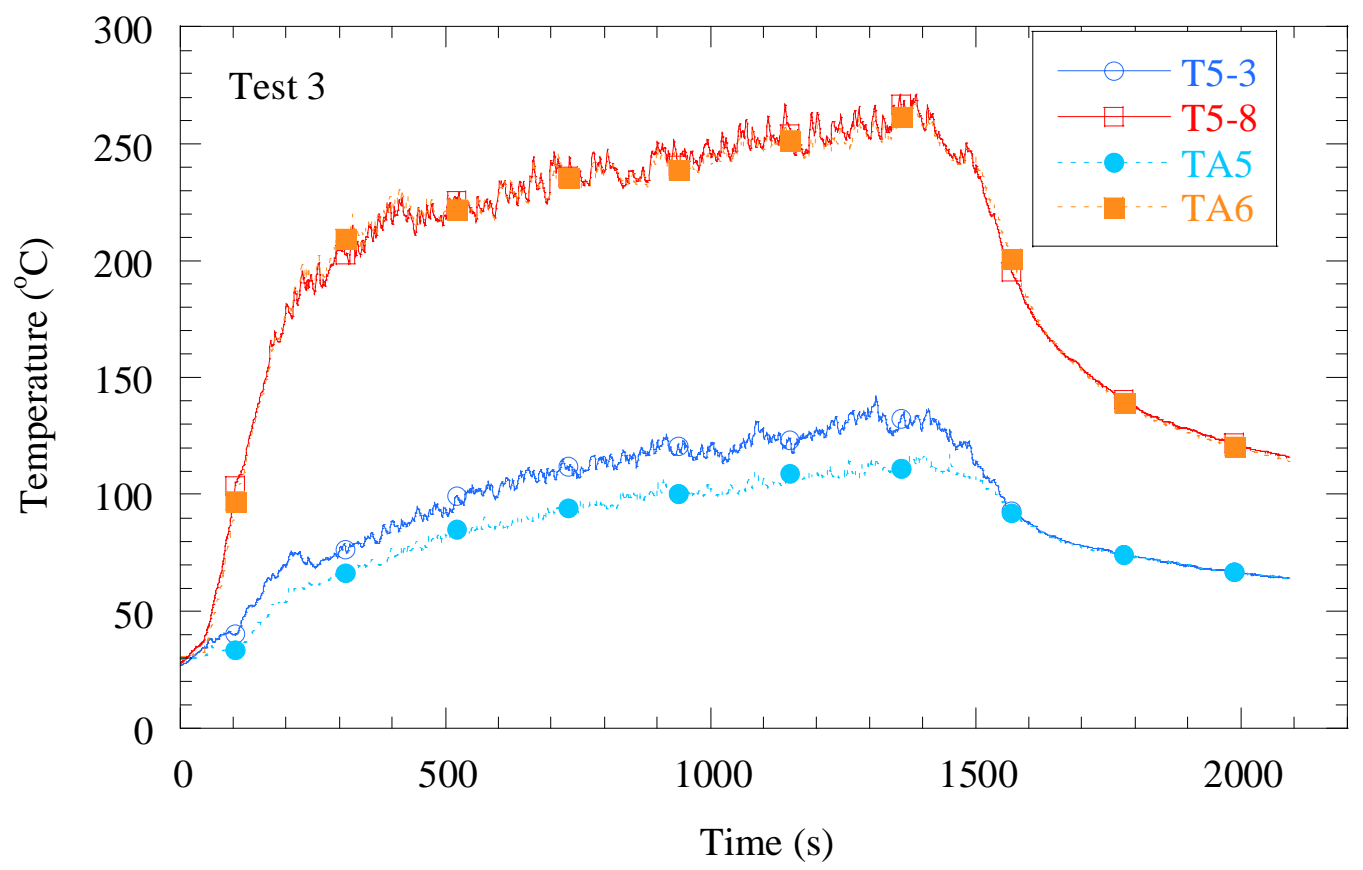

Figure 9-3: Temperature comparison as a function of time for aspirated (TA5, TA6) and bare-bead thermocouples (T5-3, T5-8) located at $\mathrm{Z}=1.05 \mathrm{~m}$ and $2.0 \mathrm{~m}$ on Tree 5 during Test 3.

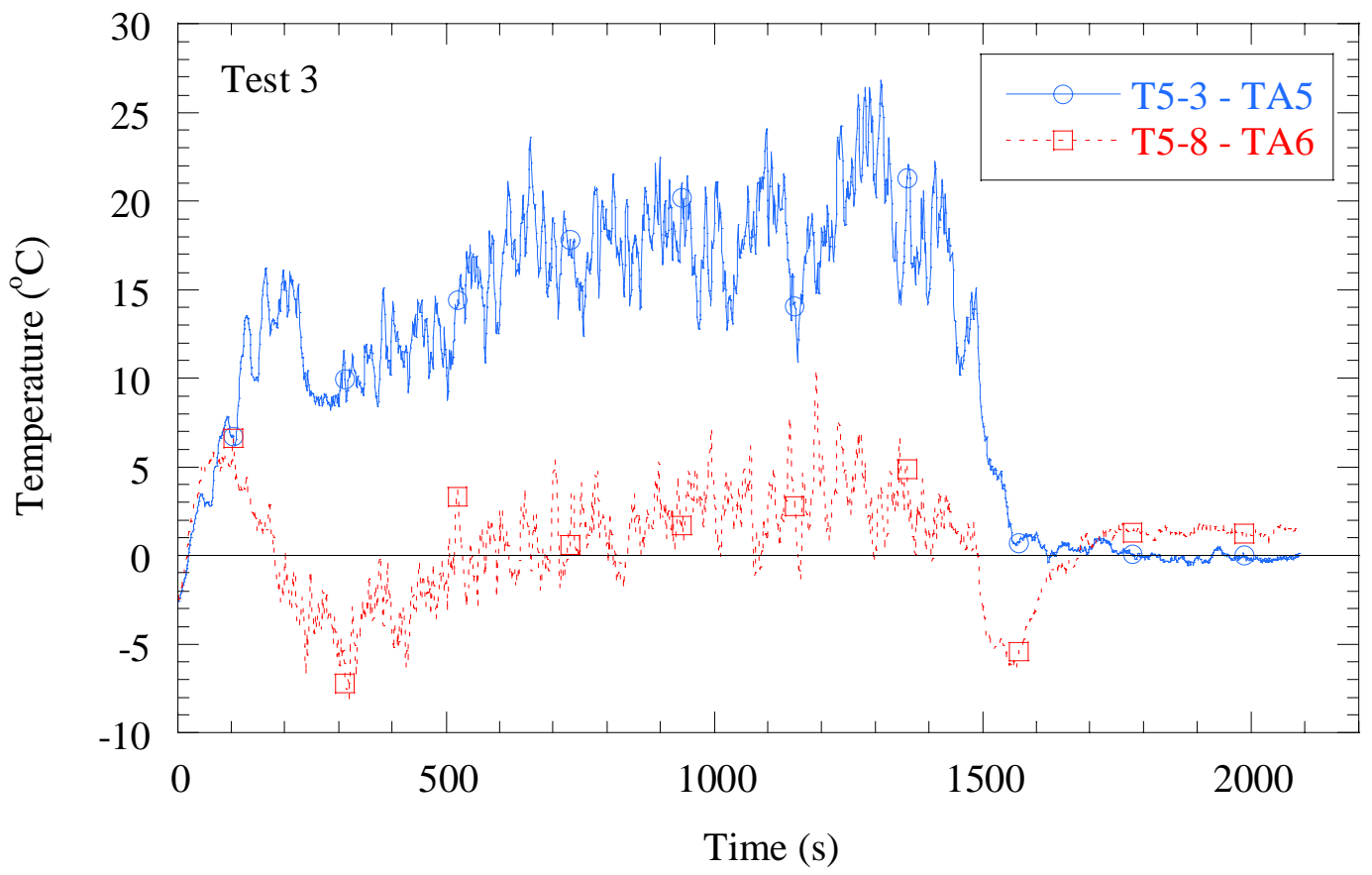

Figure 9-4: Temperature differences as a function of time for aspirated (TA5, TA6) and bare-bead thermocouples (T5-3, T5-8) located at $\mathrm{Z}=\mathbf{1 . 0 5} \mathrm{m}$ and $2.0 \mathrm{~m}$ on tree 5 during Test 3. 


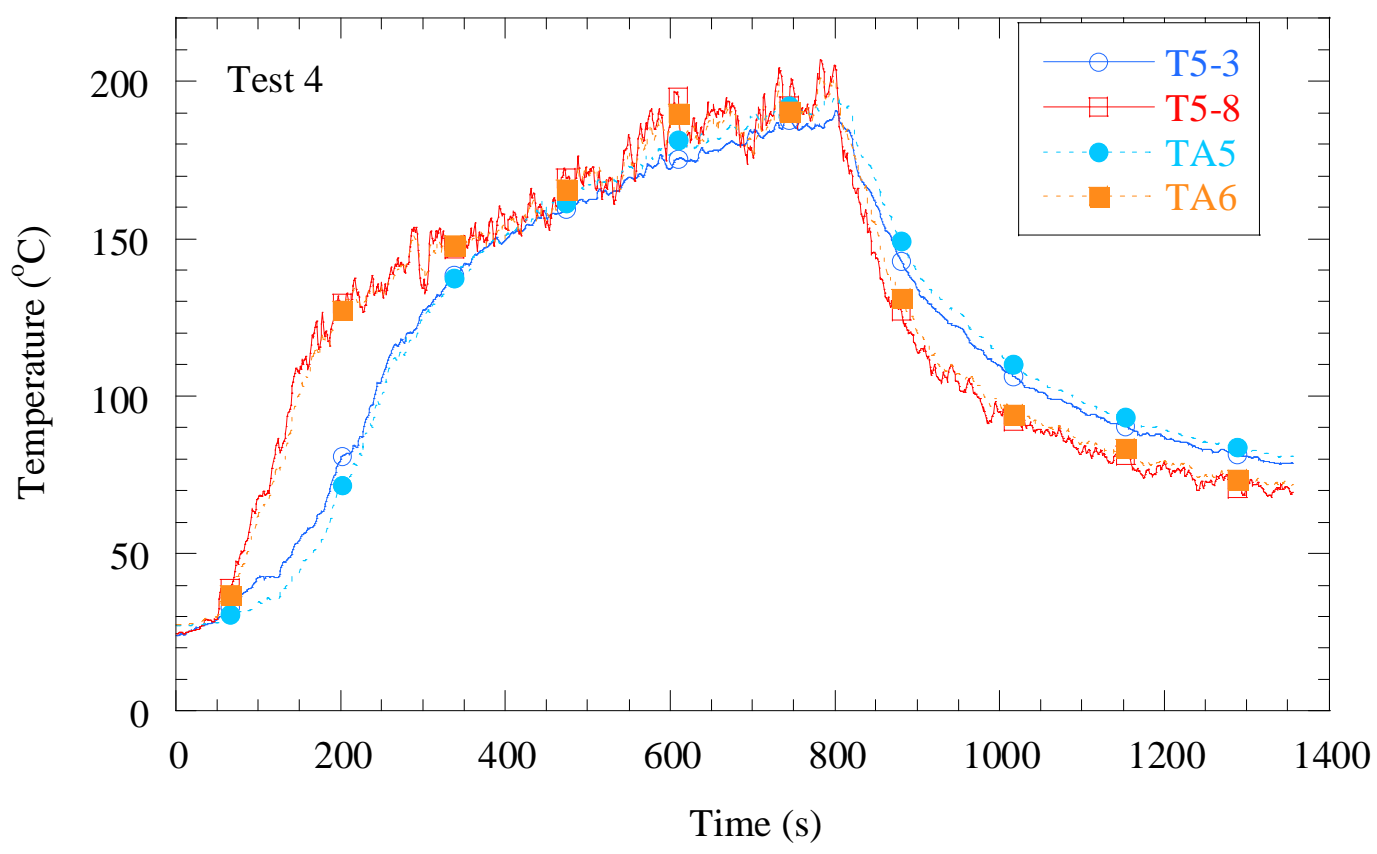

Figure 9-5: Temperature comparison as a function of time for aspirated (TA5, TA6) and bare-bead thermocouples (T5-3, T5-8) located at $\mathrm{Z}=\mathbf{1 . 0 5} \mathrm{m}$ and $2.0 \mathrm{~m}$ on Tree 5 during Test 4.

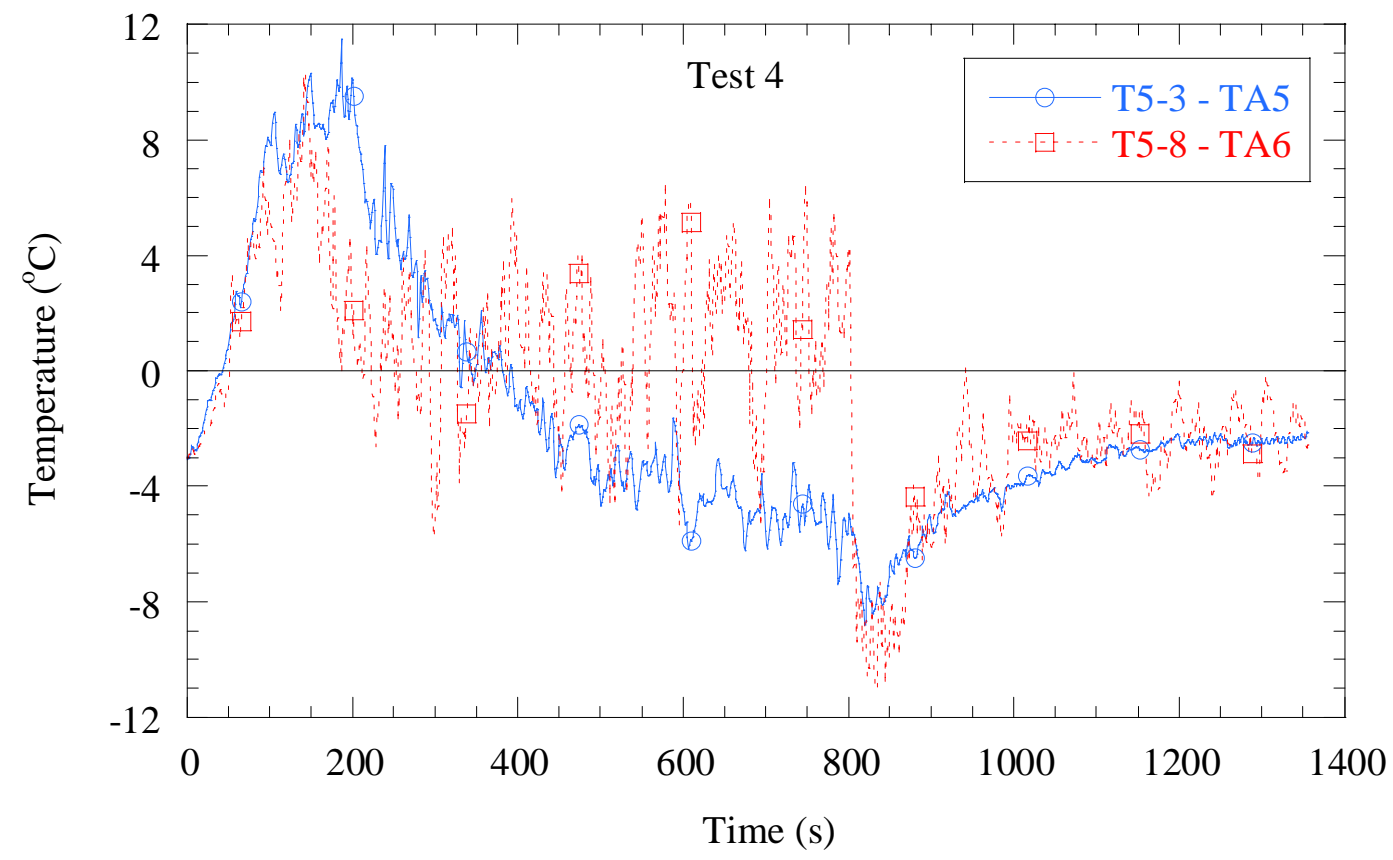

Figure 9-6: Temperature differences as a function of time for aspirated (TA5, TA6) and bare-bead thermocouples (T5-3, T5-8) located at $Z=1.05 \mathrm{~m}$ and $2.0 \mathrm{~m}$ on Tree 5 during Test 4. 


\subsection{Hot Gas Layer Temperature}

Estimates of the mean temperature of the hot upper gas layer and the lower layer are reported here, based on the temperature measurements made at Tree 7 . Tree 7 consisted of 10 thermocouples spaced $35 \mathrm{~cm}$ (13.8 in) apart starting $35 \mathrm{~cm}$ (13.8 in) from the floor and ending near the ceiling. The type $\mathrm{K}$ thermocouples used were constructed of 24 gauge wires. The beads were located on individual horizontal "branches" approximately $6.0 \mathrm{~cm}$ (2.4 in) from the vertical centerline of the tree. The tree was suspended from the ceiling and attached to the floor with a screw to provide tension for maintaining vertical alignment. Tree 7 was approximately $6.0 \mathrm{~m}$ $(19.7 \mathrm{ft})$ from the fire, so uncertainties due to radiation effects can be expected to be significantly smaller than those for Tree 5 (located about $3.0 \mathrm{~m}$, or $9.8 \mathrm{ft}$, from the fire) discussed above.

The estimated expanded uncertainties for the hot gas layer temperatures are contained in Table 92. The uncertainties were calculated by the following procedure. Times were chosen for each test when the fire was most steady or nearing the time of extinguishment. Those times were: $1300 \mathrm{~s}$ for tests $1,3,5,7,9,14,15$, and 18; $600 \mathrm{~s}$ for tests 2 and 8; $800 \mathrm{~s}$ for tests 4 and 10; $300 \mathrm{~s}$ for tests 13 and 16; and $250 \mathrm{~s}$ for test 17. At those times, the appropriate expanded temperature uncertainties listed in Table 9-1 were added to the Tree 7 temperatures to obtain the 2 standard deviation limits around the nominal measurement. The layer interfaces were determined from the layer height calculations described in the next section. Four combinations of variations were then used: lowest limit for both lower and hot gas layers, lowest limit for lower layer and highest limit for hot gas layer, highest limit for lower layer and lowest limit for hot gas layer, and highest limit for both layers. The layer interface heights and temperatures were recalculated for these modified temperature profiles. The spread of the four new heights and temperatures about the nominal, unmodified values determined typical lower and upper expanded uncertainty bounds to be used for the hot gas layer temperatures and layer heights. A plot of the nominal and modified results for layer temperature is shown in Figure 9-7.

Table 9-2: Hot gas layer temperature expanded uncertainty limits.

\begin{tabular}{|c|c|c|c|c|c|}
\hline \multirow{2}{*}{ Test No. } & \multicolumn{2}{|c|}{ Uncertainty Limits $\left({ }^{\circ} \mathrm{C}\right)$} & \multirow{2}{*}{ Test No. } & \multicolumn{2}{|c|}{ Uncertainty Limits $\left({ }^{\circ} \mathrm{C}\right)$} \\
\cline { 2 - 3 } & Lower & Upper & & Lower & Upper \\
\hline 1 & -0.2 & 7 & 10 & -14 & 2 \\
\hline 2 & -7 & 8 & 13 & -7 & 10 \\
\hline 3 & -9 & 7 & 14 & -7 & 17 \\
\hline 4 & -9 & 7 & 15 & -6 & 10 \\
\hline 5 & -4 & 7 & 16 & -6 & 9 \\
\hline 7 & -2 & 8 & 17 & -4 & 8 \\
\hline 8 & -3 & 8 & 18 & -7 & 6 \\
\hline 9 & -6 & 8 & - & - & - \\
\hline
\end{tabular}




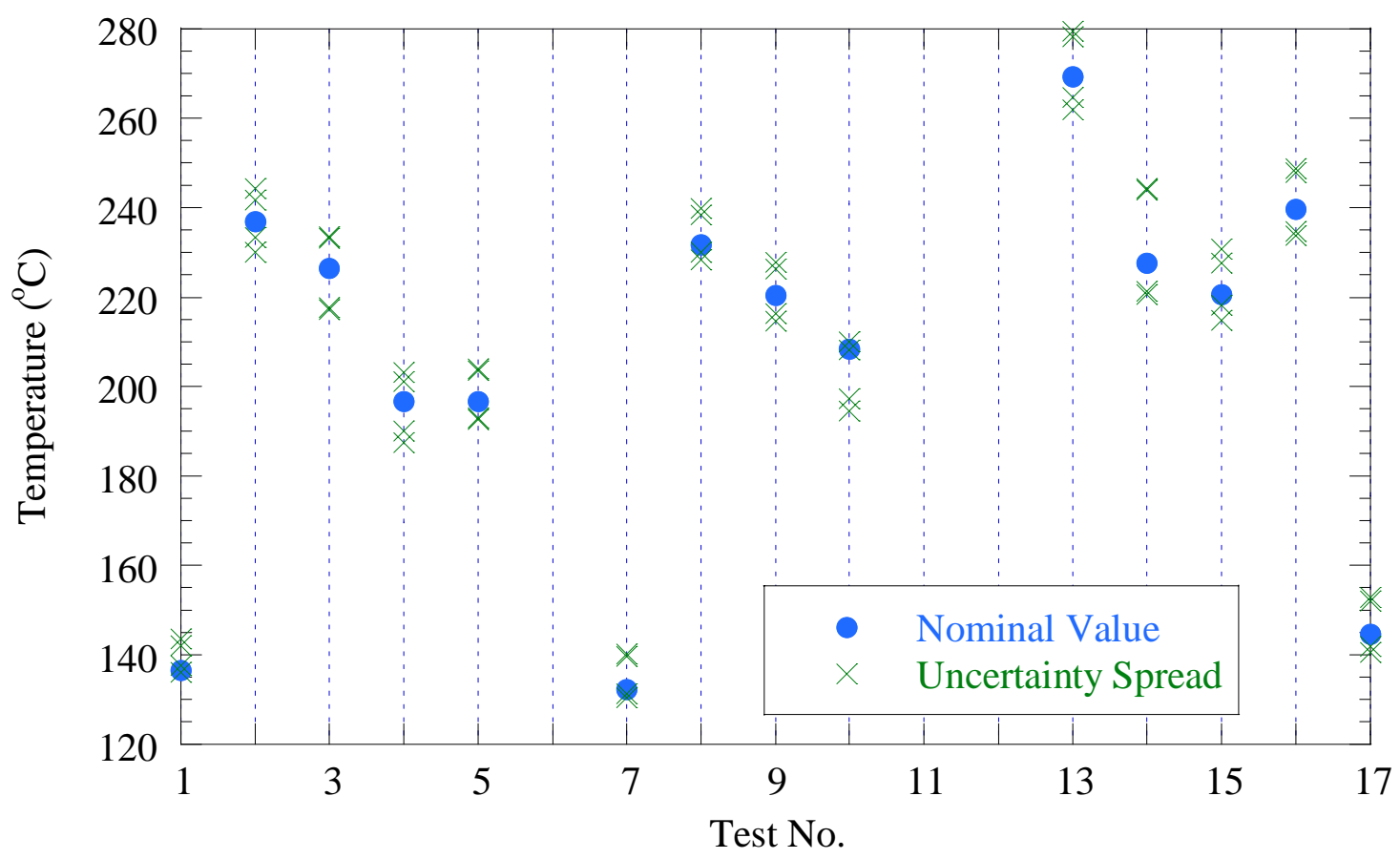

Figure 9-7: The expanded uncertainty spread around nominal values of hot gas layer temperature for all tests except Test 18.

Figures 9-8 to 9-11 show the temperature versus time traces of all 10 thermocouples on Tree 7 for Tests 2 - 5. Figures 9-12 to 9-15 show the average hot gas layer temperatures for all of the tests versus time calculated using the two-layer reduction method. Figure 9-12 compares the first and repeat tests of center burner $1 \mathrm{MW}$ fires under the four combinations of door open/closed and ventilation on/off. The repeatability of the layer temperature for these tests is excellent. The door closed with the ventilation off condition produced the highest temperatures $\left.\left(240{ }^{\circ} \mathrm{C} ; 460^{\circ} \mathrm{F}\right)\right)$ and at the fastest rate. The door closed with the ventilation on condition produced temperatures typical of the door open tests with the ventilation off $\left.\left(210^{\circ} \mathrm{C} ; 410^{\circ} \mathrm{F}\right)\right)$, although less than the door closed/ventilation off condition. The door open conditions produced parallel layer temperatures with the ventilation off condition higher by about $40^{\circ} \mathrm{C}\left(70{ }^{\circ} \mathrm{F}\right)$ by the end of the tests.

Figure 9-13 compares the hot gas layer temperature for the three fire sizes ( $350 \mathrm{~kW}, 1 \mathrm{MW}$, and $2 \mathrm{MW}$ ) for the condition of the door closed and the ventilation off. The temperatures and rate of increase of temperature are highest for the largest fire and lowest for the smallest fire. The repeatability of the layer temperature for these tests is also excellent.

Figure 9-14 compares the hot gas layer temperature for two 2 MW heptane blend fires with the door closed and with the ventilation on and off and for two $1 \mathrm{MW}$ fires with the door closed and ventilation off for the heptane blend and toluene. The $2 \mathrm{MW}$ fire with the ventilation on had about $\left.40{ }^{\circ} \mathrm{C}\left(70^{\circ} \mathrm{F}\right)\right)$ lower temperatures, but it paralleled the ventilation off curve. The $1 \mathrm{MW}$ 
toluene fire had about $30^{\circ} \mathrm{C}\left(50^{\circ} \mathrm{F}\right)$ lower temperatures, but it paralleled the heptane blend fire curve.

Figure 9-15 compares the hot gas layer temperatures for four tests with the door open and ventilation off for $1 \mathrm{MW}$ heptane blend fires with the centered burner and three alternate burner positions described in the test descriptions. All of the temperature-time curves were very similar with continued increases for the duration, and there was no significant effect of burner position.

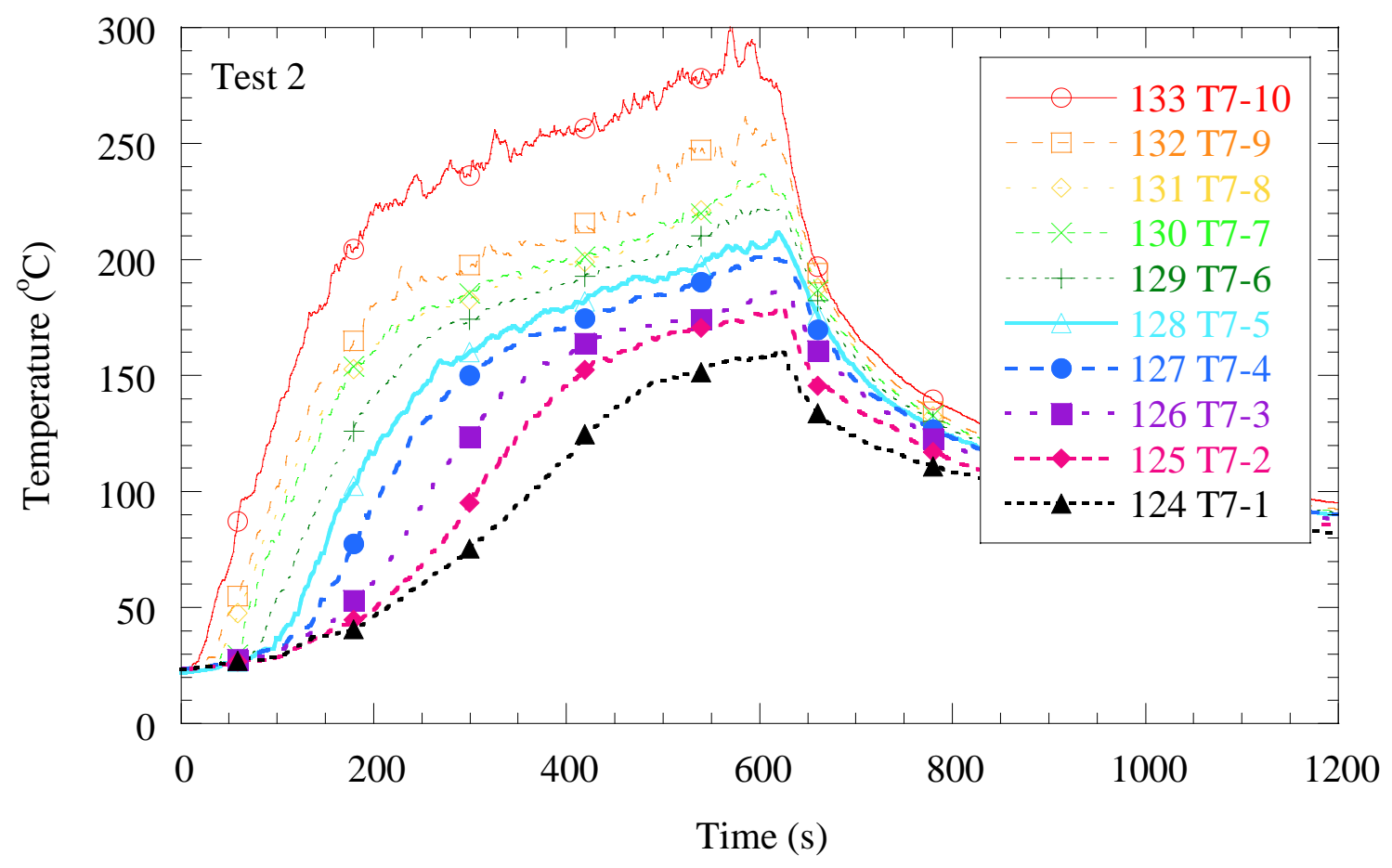

Figure 9-8: Bare bead thermocouple temperatures as a function of time for Tree 7 during Test 2. 


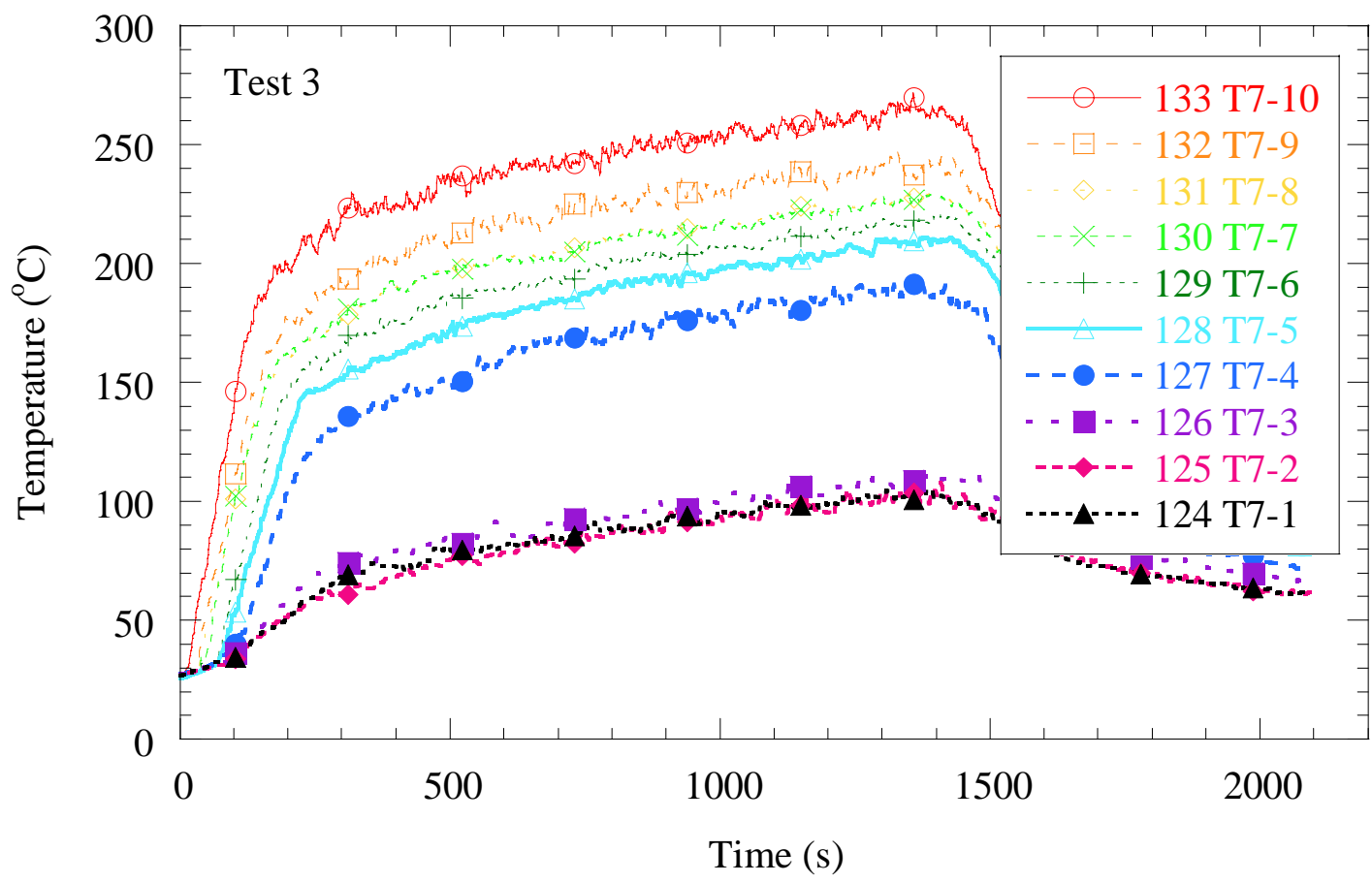

Figure 9-9: Bare bead thermocouple temperatures as a function of time for Tree 7 during Test 3.

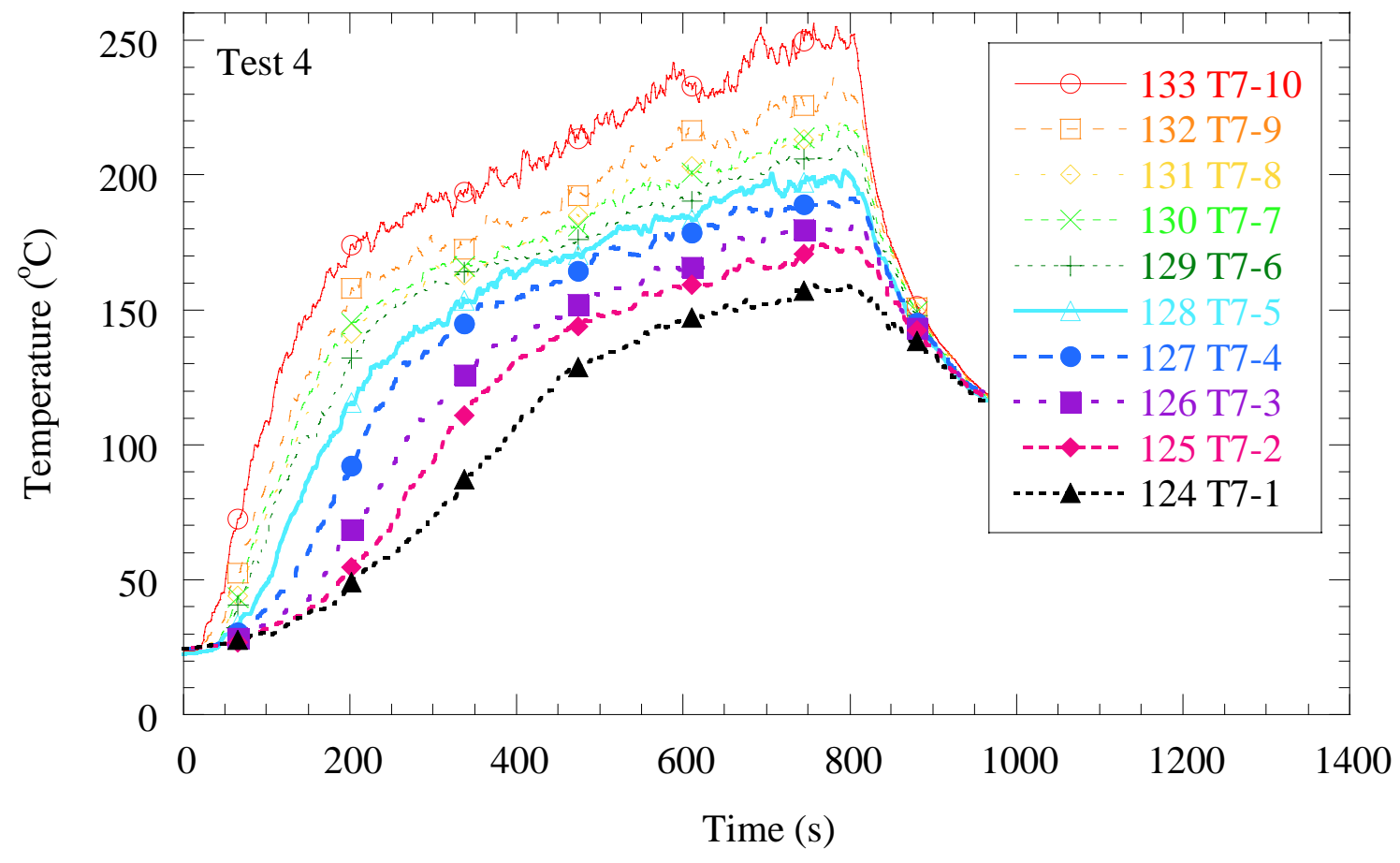

Figure 9-10: Bare bead thermocouple temperatures as a function of time for Tree 7 during Test 4. 


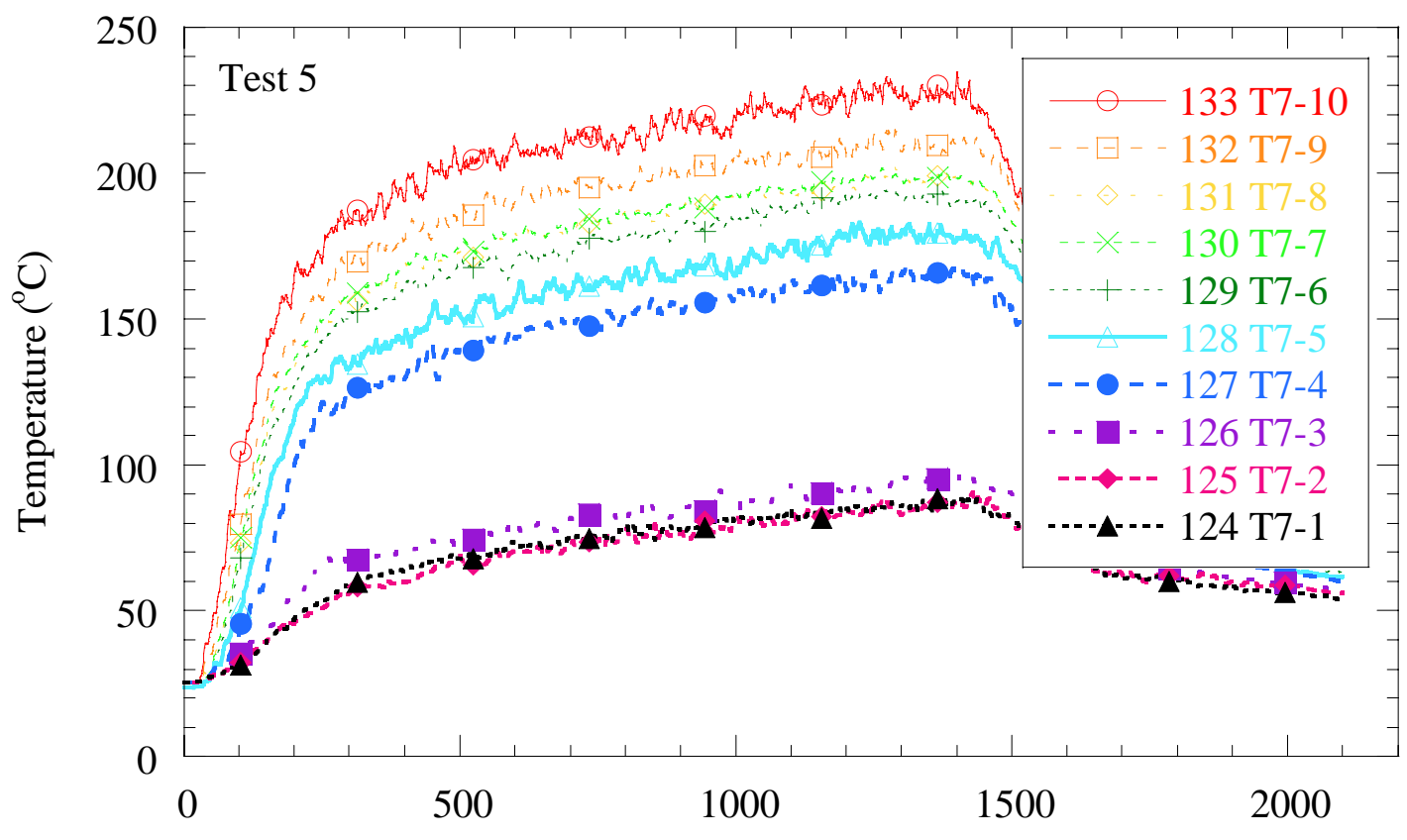

Time (s)

Figure 9-11: Bare bead thermocouple temperatures as a function of time for Tree 7 during Test 5.

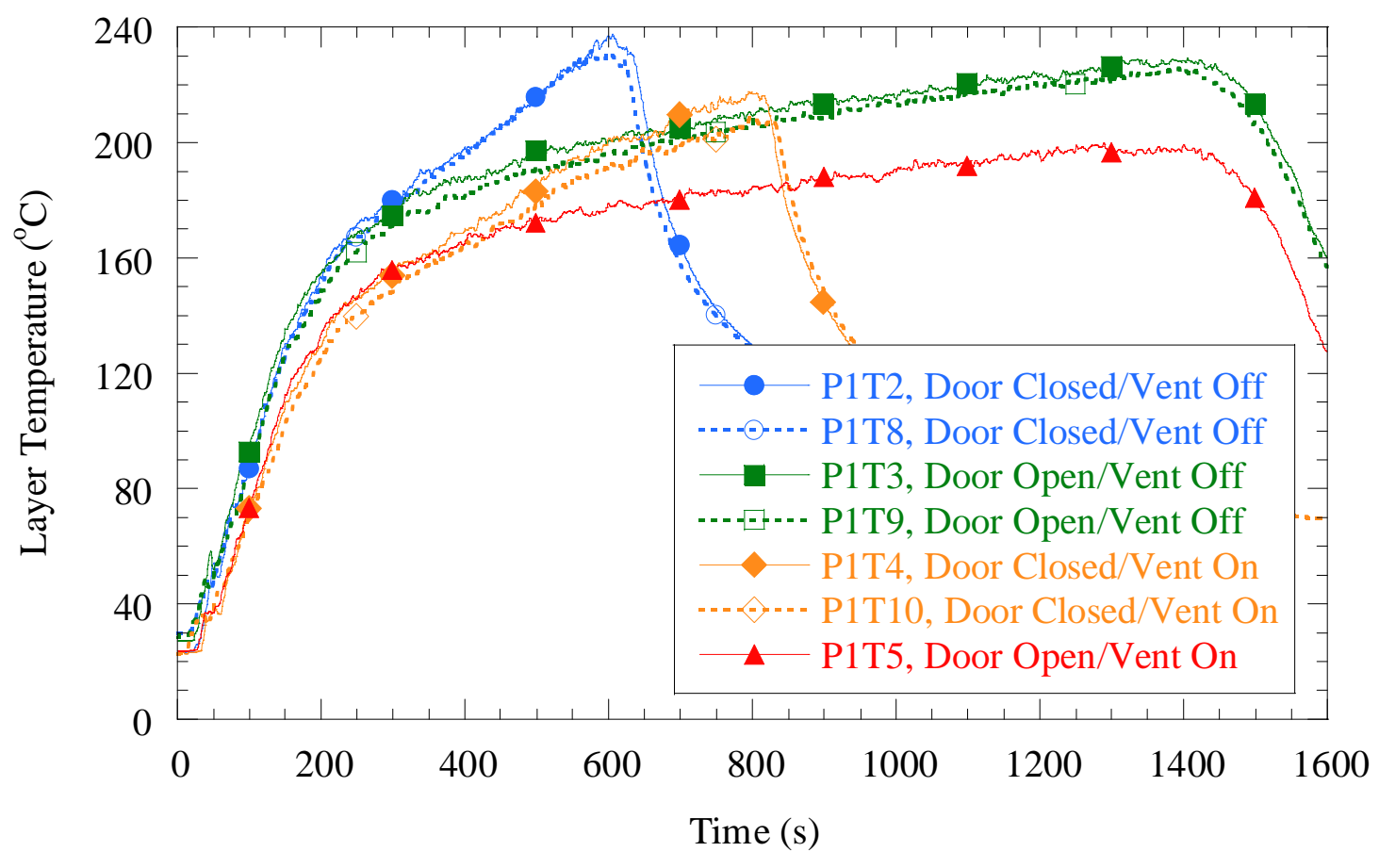

Figure 9-12: Hot gas layer temperature as a function of time for Tree 7 during Tests 2, 8, 3, $9,4,10$, and 5 calculated using the two-layer reduction method. 


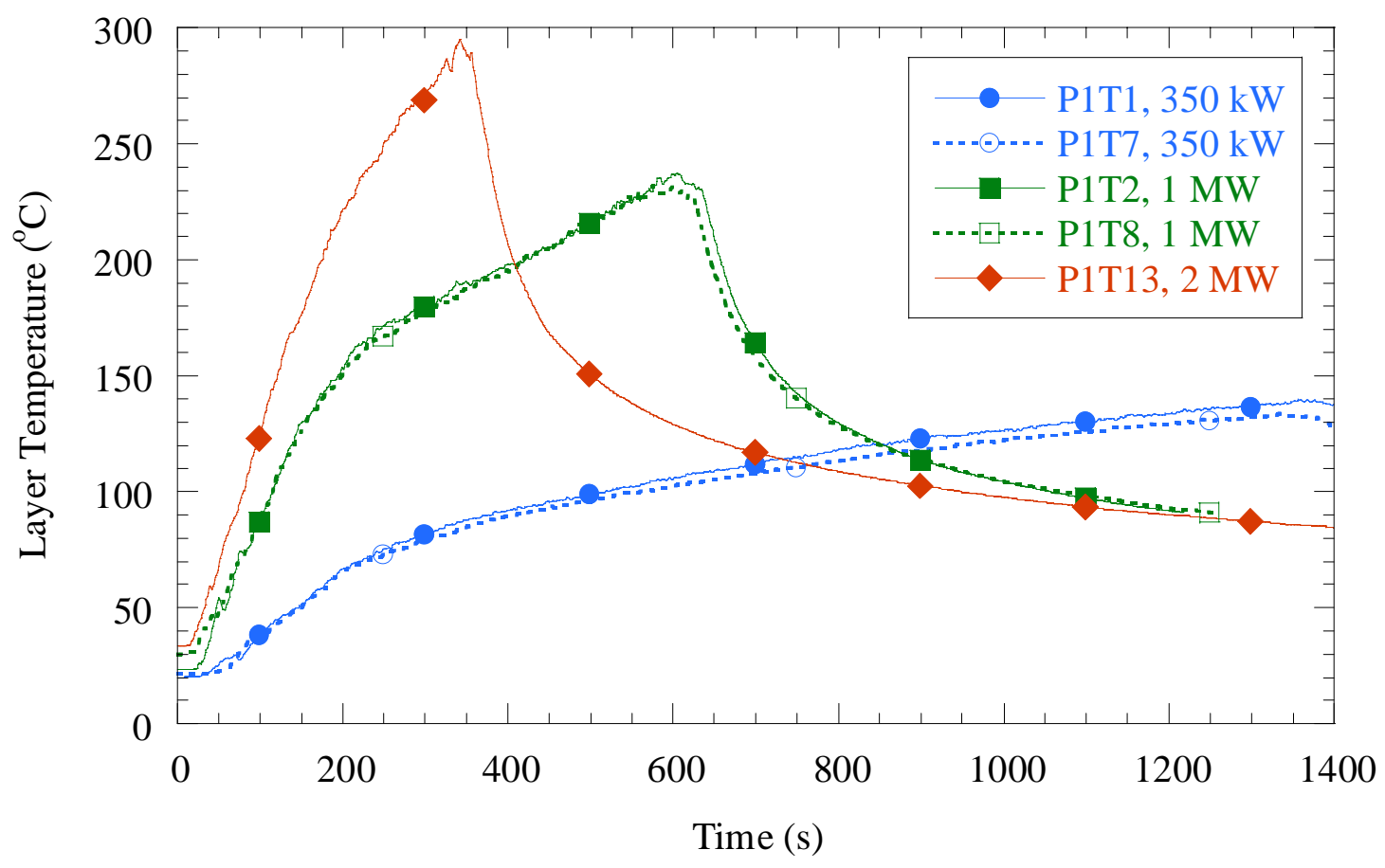

Figure 9-13: Hot gas layer temperature as a function of time for Tree 7 during Tests 1, 7, 2, 8,13 calculated using the two-layer reduction method.

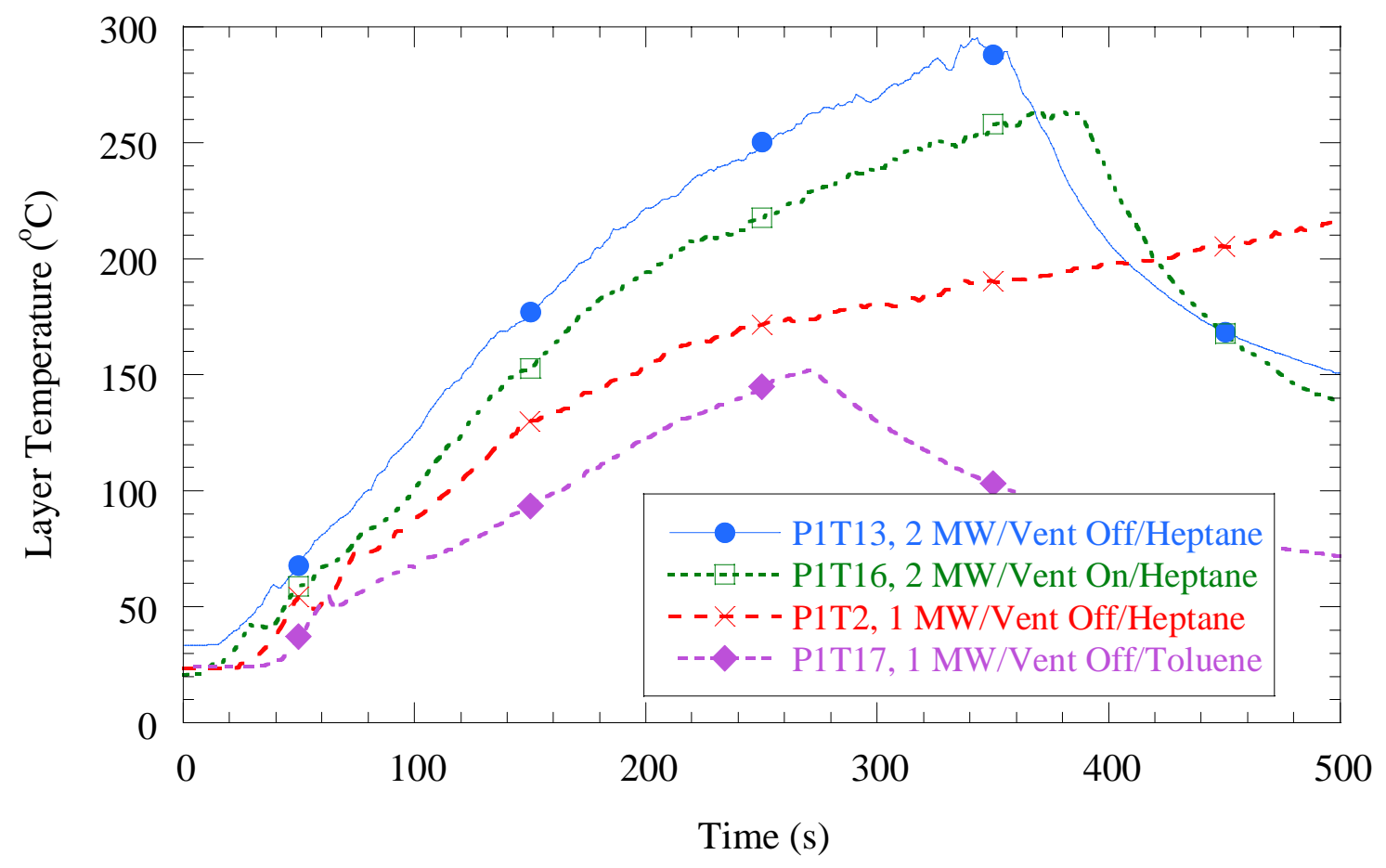

Figure 9-14: Hot gas layer temperature as a function of time for Tree 7 during Tests 13, 16, 2, and 17 calculated using the two-layer reduction method. 


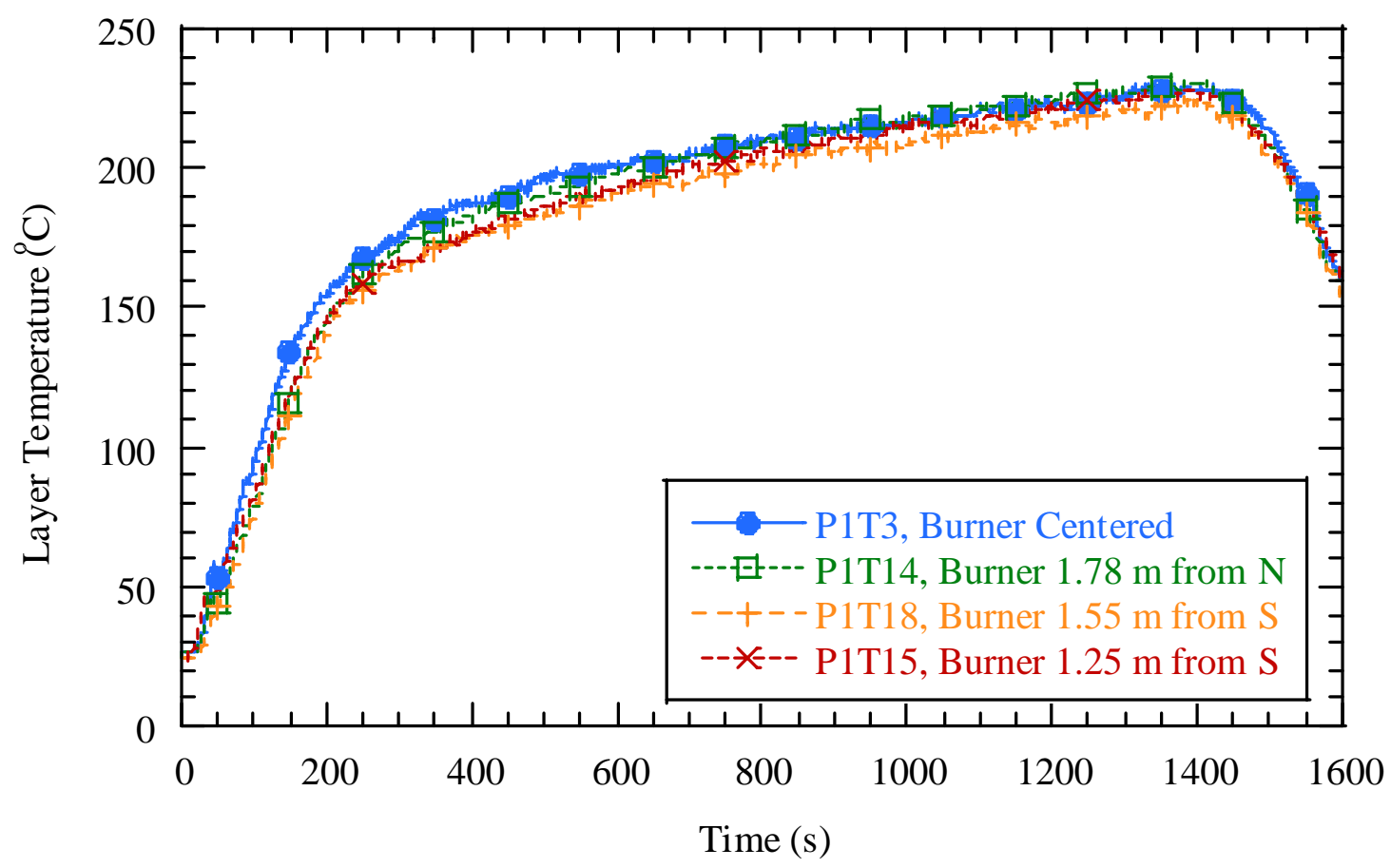

Figure 9-15: Hot gas layer temperature as a function of time for Tree 7 during Tests 3, 14, 18, and 15 calculated using the two-layer reduction method.

\subsection{Hot Gas Layer Depth}

The results reported here for the hot gas layer depth are from an analysis of the temperature profile of thermocouple Tree 7 using the two-layer reduction method. The two-layer reduction model is a one-dimensional analytical method based on the zone model concept. It uses conservation of mass and energy and temperature profiles to define the height at which the upper and lower masses are equal. The equations used were:

$$
\begin{aligned}
& (H-z \text { int }) T_{u p}+z \text { int } T_{\text {low }}=\int_{0}^{H} T(z) d z=I_{1} \\
& (H-z \text { int }) \frac{1}{T_{u p}}+z \text { int } \frac{1}{T_{\text {low }}}=\int_{0}^{H} \frac{1}{T(z)} d z=I_{2} \\
& z \text { int }=\frac{T_{\text {low }}\left(I_{1} I_{2}-H^{2}\right)}{I_{1}+I_{2} T_{\text {low }}{ }^{2}-2 T_{\text {low }} H}
\end{aligned}
$$

where $H$ is the ceiling height (m), $Z_{\text {int }}$ is the layer interface height (m), $T_{u p}$ is the hot layer average temperature $(\mathrm{K}), T_{\text {low }}$ is the lower layer average temperature $(\mathrm{K}), T(z)$ is the temperature as a function of height $(\mathrm{K}), z$ is the height $(\mathrm{m}), I_{1}$ is the term 1 , and $I_{2}$ is the term 2 . This method defines the lower layer temperature by the temperature of the lowest thermocouple. 
The uncertainties in the calculation are based on the uncertainties in the bare-bead thermocouples. The method of estimating the uncertainties is explained in the previous section on the layer temperature. Table 9-3 lists the estimated expanded uncertainty limits for each test. Figure 9-16 shows a plot of the spread of the modified profile interface heights about the unmodified heights for each test except 15.

Table 9-3: Hot gas layer interface height expanded uncertainty limits.

\begin{tabular}{|l|l|l|l|l|l|}
\hline \multirow{2}{*}{ Test No. } & \multicolumn{2}{|l|}{ Uncertainty Limits $(\mathrm{m})$} & \multirow{2}{*}{ Test No. } & \multicolumn{2}{|l|}{ Uncertainty Limits (m) } \\
\cline { 2 - 3 } \cline { 5 - 6 } & Lower & Upper & & Lower & Upper \\
\hline 1 & -0.01 & 0.03 & 10 & -0.03 & 0.27 \\
\hline 2 & -0.08 & 0.15 & 13 & -0.07 & 0.16 \\
\hline 3 & -0.02 & 0.01 & 14 & -0.03 & 0.04 \\
\hline 4 & 0 & 0.08 & 15 & -0.02 & 0.07 \\
\hline 5 & -0.01 & 0.02 & 16 & -0.03 & 0.07 \\
\hline 7 & -0.07 & 0.10 & 17 & -0.05 & 0.10 \\
\hline 8 & -0.02 & 0.04 & 18 & N/A & N/A \\
\hline 9 & -0.01 & 0.03 & & & \\
\hline
\end{tabular}

Figure 9-17 compares the first and repeat tests of the centered burner $1 \mathrm{MW}$ fires for the four combinations of door open/closed and ventilation on/off. The repeatability of the layer height for the three pairs of similar tests is excellent. The results for the condition of the door closed with the ventilation on and off produced similar curves and had deeper layers than those with the door open. The door closed tests experienced oscillating layer heights. The algorithm used to estimate layer height from thermocouple measurements was developed for scenarios in which two distinct layers were present, and has not been validated for cases when there is no ventilation and/or the doors are closed. The assumption that there is a cooler lower layer may not hold for the tests with the door closed (Tests $1,2,4,7,8,10,13,16$, and 17). In tests 4 and 10, the fire was turned off for safety reasons after about $800 \mathrm{~s}$, with the ventilation staying on, resulting in severe oscillations shown in Figure 9-17. The door open tests (Tests 3, 5, 9, 14, 15, 18) showed no significant differences in location of the interface height or temporal behavior, even between ventilation on and off. For the door open tests, the height was very steady after the first few minutes.

Figure 9-18 compares the hot/cold gas interface height for the three fire sizes (350 kW, $1 \mathrm{MW}$, and $2 \mathrm{MW}$ ) for the condition of the door closed and the ventilation off. The two-layer reduction calculation yields results that are not physical for these closed-door tests, with the layer height about $1 \mathrm{~m}$ off the floor. The $350 \mathrm{~kW}$ fires were extinguished at about $1400 \mathrm{~s}$, the $1 \mathrm{MW}$ fires at about $600 \mathrm{~s}$ and the $2 \mathrm{MW}$ fire at about $350 \mathrm{~s}$. It is interesting to note that the larger fires' interface heights dropped at faster rates than the smaller fires. 
Figure 9-19 compares the hot/cold gas interface height for two 2 MW heptane blend fires with the door closed and with the ventilation on and off and for two $1 \mathrm{MW}$ fires with the door closed and ventilation off for the heptane blend and for toluene. Again, as seen in Figure 9-18, the twolayer reduction calculation yields results that are not physical for these closed-door tests, with the layer height about $1.0 \mathrm{~m}$ (3.3 ft) off the floor.

Figure 9-20 compares the hot/cold gas interface heights for four tests with the door open and ventilation off for $1 \mathrm{MW}$ heptane blend fires with the centered burner and three alternate burner positions described in the test description. All of the temperature-time curves were very similar

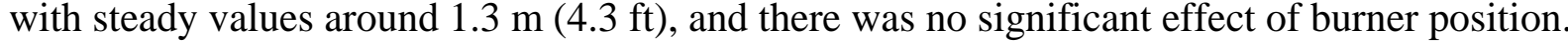

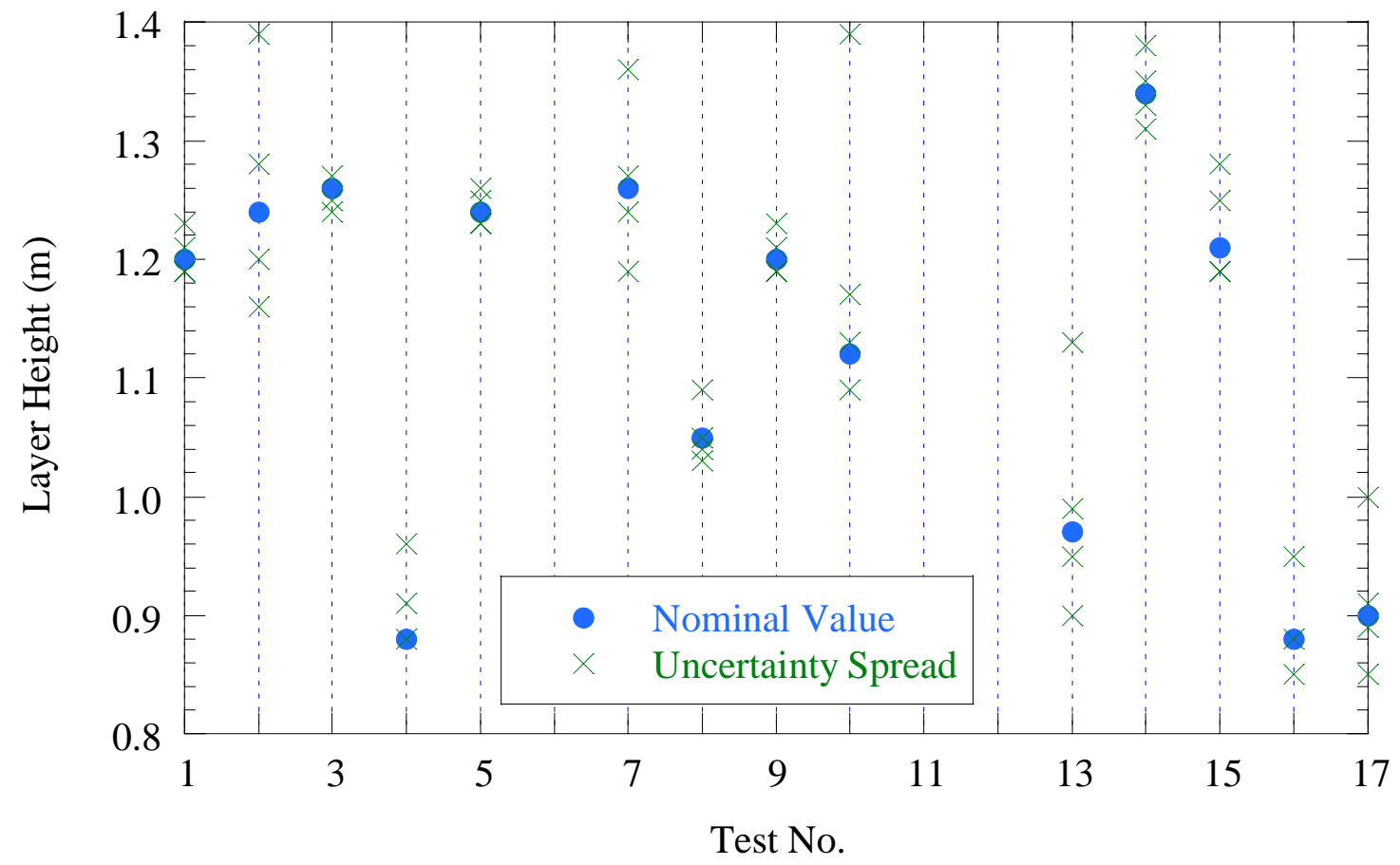

Figure 9-16: The expanded uncertainty spread around nominal values of the hot/cold gas layer interface height for all tests except Test 18. 


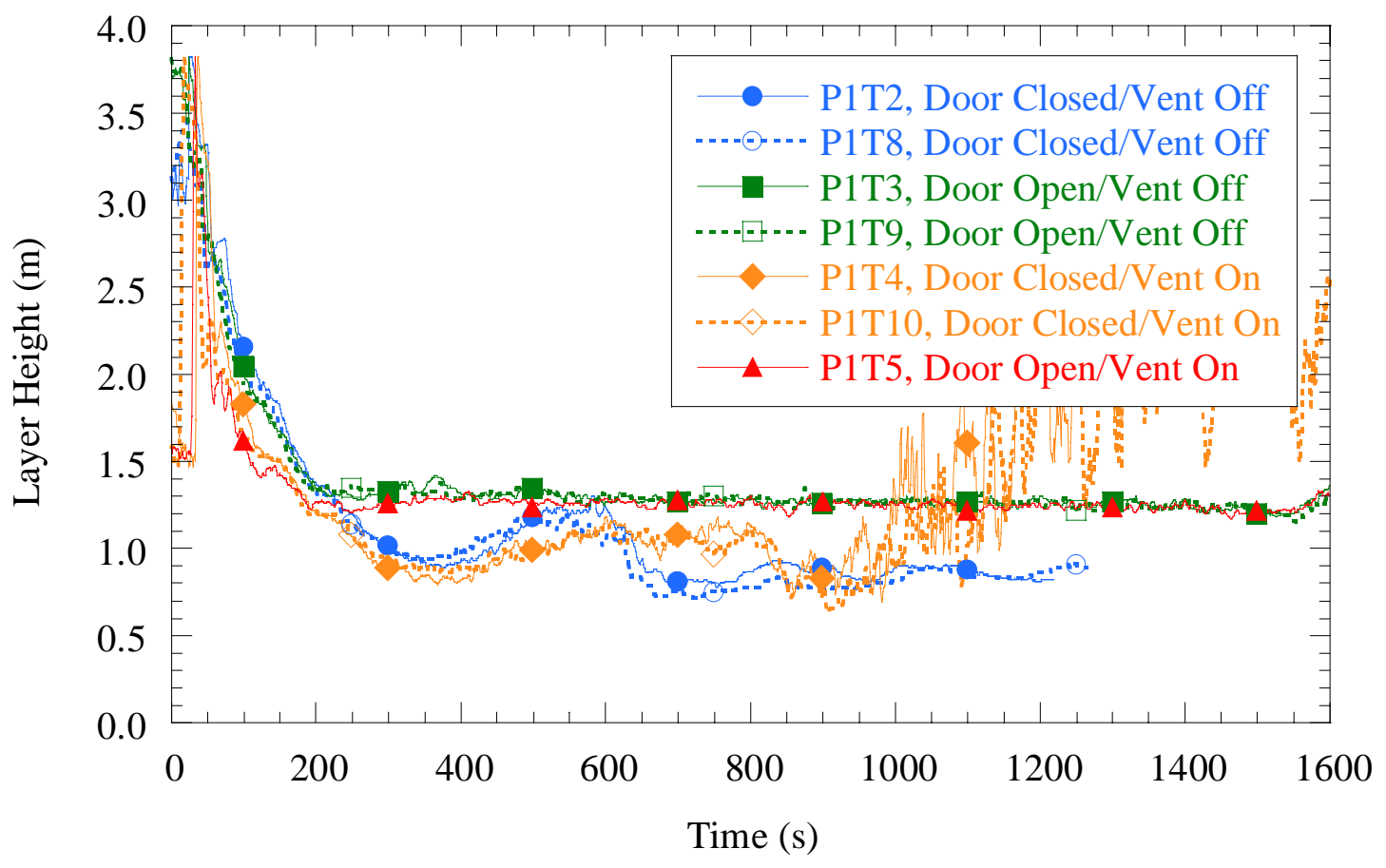

Figure 9-17: Layer interface height as a function of time for Tree 7 during Tests 2, 8, 3, 9, 4,10 , and 5 calculated using the two-layer reduction method.

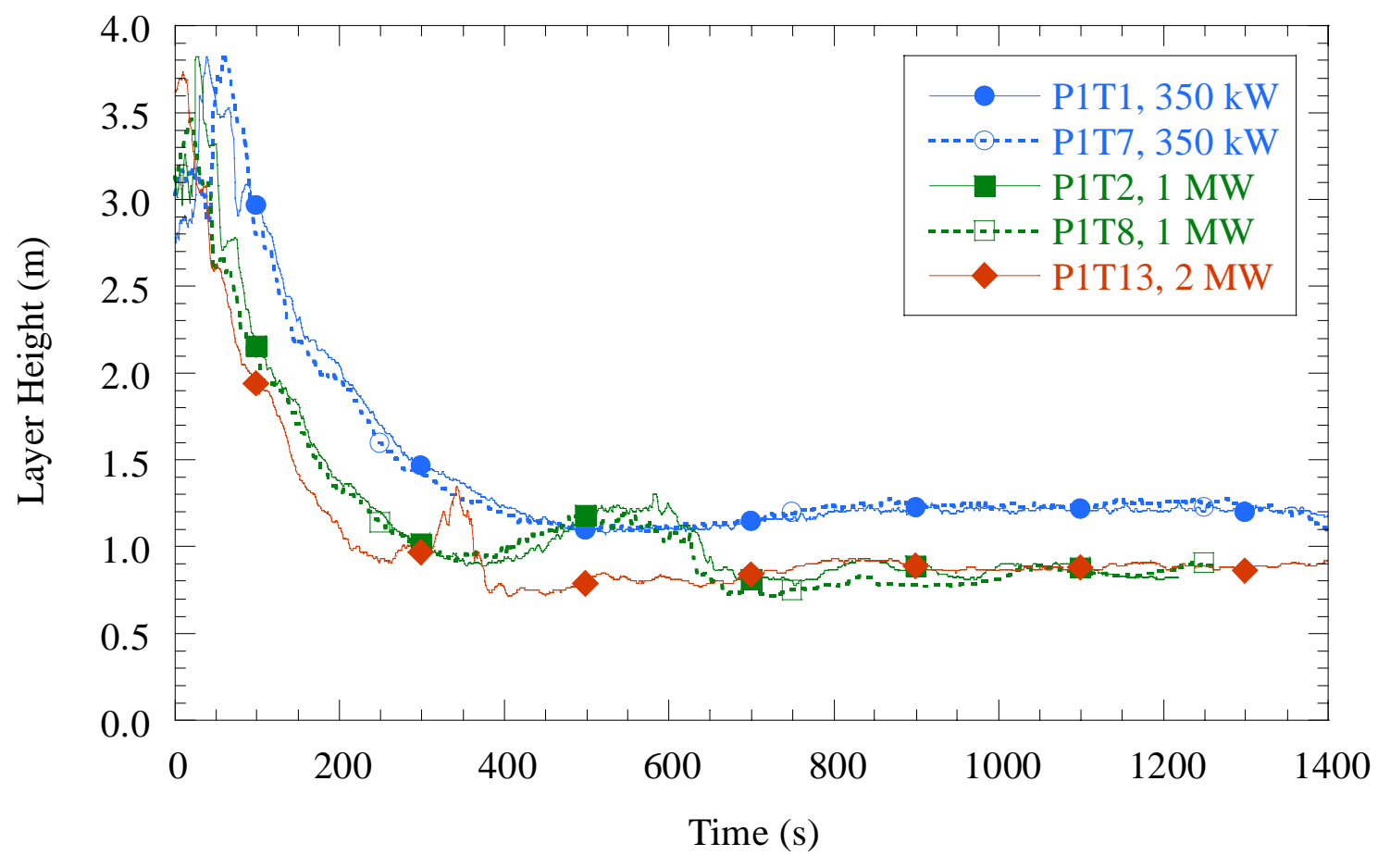

Figure 9-18: Layer interface height as a function of time for Tree 7 during Tests 1, 7, 2, 8, and 13 calculated using the two-layer reduction method. 


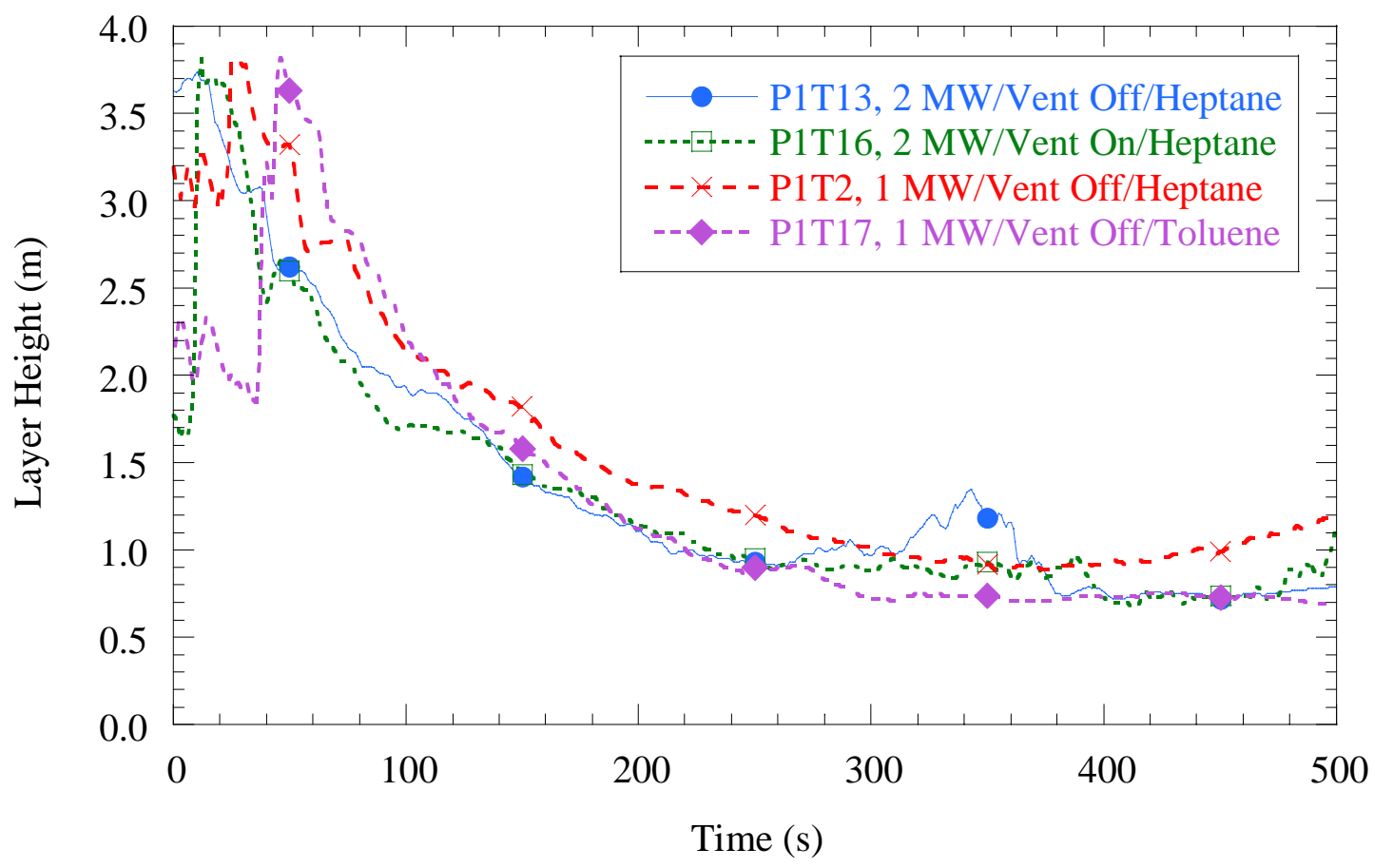

Figure 9-19: Layer interface height as a function of time for Tree 7 during Tests 13, 16, 2, and 17 calculated using the two-layer reduction method.

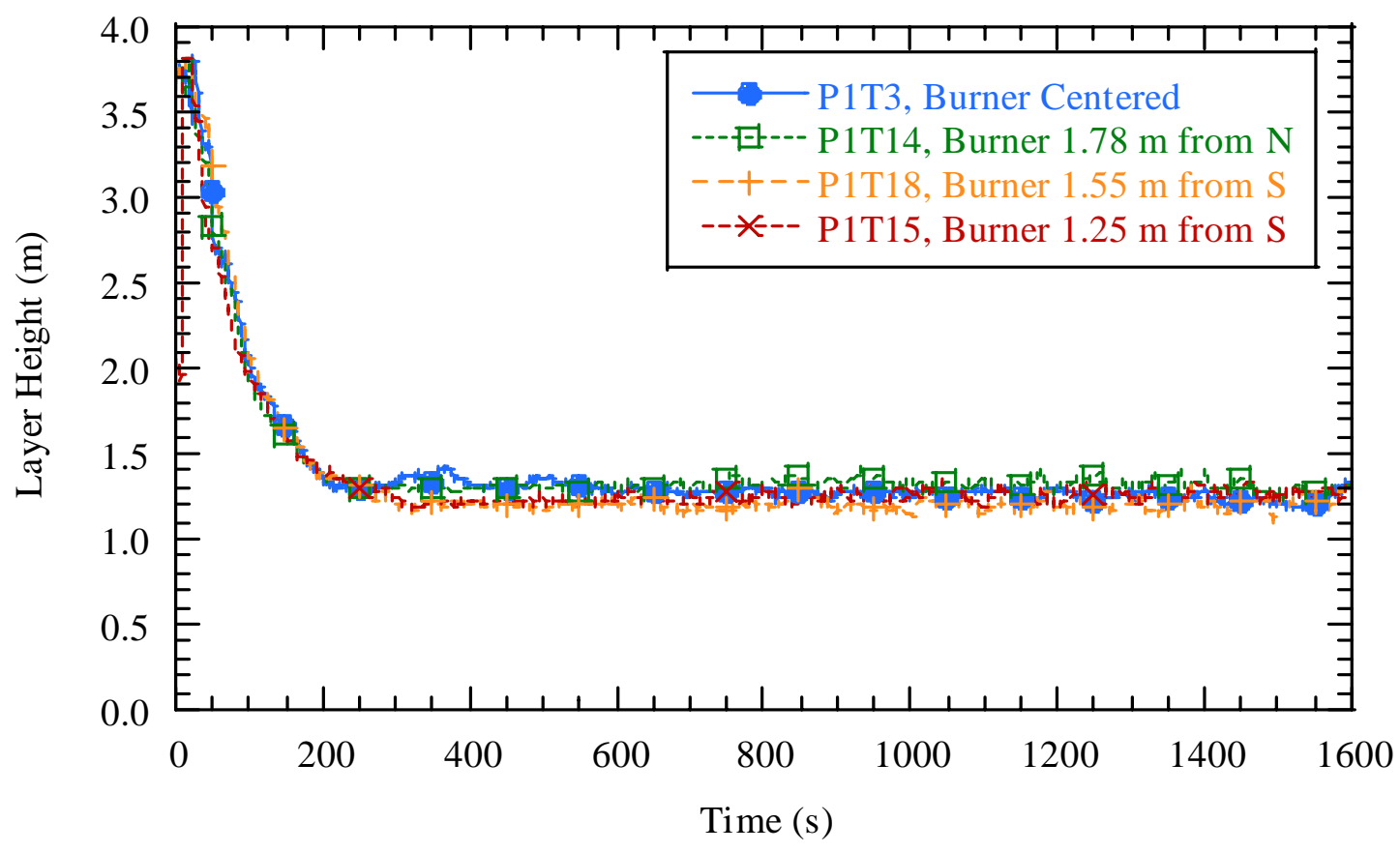

Figure 9-20: Layer interface height as a function of time for Tree 7 during Tests 3, 14, 18, and 15 calculated using the two-layer reduction method. 


\subsection{Gas Temperature at Targets $B$ \& $E$}

The gas temperature nearest Targets $\mathrm{B} \& \mathrm{E}$ is best represented by the thermocouple at position 8 on thermocouple Tree 4 . Tree 4 was very close to the supply vent. Position 8 was located $2.8 \mathrm{~m}$ $(9.2 \mathrm{ft})$ above the floor. In Table 9-1, the expanded uncertainties for the hot gas layer temperature are associated with this temperature measurement.

Figure 9-21 compares the first and repeat tests of the centered burner $1 \mathrm{MW}$ fires for the four combinations of door open/closed and ventilation on/off. The repeatability of the temperature for these tests is generally less than $5^{\circ} \mathrm{C}$ to $10^{\circ} \mathrm{C}\left(9^{\circ} \mathrm{F}\right.$ to $\left.18{ }^{\circ} \mathrm{F}\right)$. Unlike the layer behavior where the door had the strongest effect, the ventilation condition seems to be more important for these results. The highest temperatures were with the ventilation off and the door closed, which also produced a much faster rate of increase. The tests with the ventilation on were very similar in both the open and closed door tests, with the closed door condition producing a slightly higher temperature $\left(+20^{\circ} \mathrm{C}\right.$, or $\left.+36{ }^{\circ} \mathrm{F}\right)$ by the end of the experiments. Figure 9-22 compares the hot gas layer temperature for the three fire sizes ( $350 \mathrm{~kW}, 1 \mathrm{MW}$, and $2 \mathrm{MW}$ ) for the condition of the door closed and the ventilation off. The temperatures and rate of increase of temperature are highest for the largest fire and lowest for the smallest fire. The repeatability of the layer temperature for these tests was generally less than $10^{\circ} \mathrm{C}\left(18^{\circ} \mathrm{F}\right)$.

Figure 9-23 compares the hot gas layer temperature for two $2 \mathrm{MW}$ heptane blend fires with the door closed and with the ventilation on and off and for two $1 \mathrm{MW}$ fires with the door closed and ventilation off for heptane blend and toluene. The $2 \mathrm{MW}$ fire with the ventilation on had about $90^{\circ} \mathrm{C}\left(160^{\circ} \mathrm{F}\right)$ lower temperatures by the end of the experiments. At $250 \mathrm{~s}$ in the $1 \mathrm{MW}$ toluene fire, the temperature of Tree $4-8$ was about $75^{\circ} \mathrm{C}\left(167^{\circ} \mathrm{F}\right)$, while the temperature in the heptane blend fire was about $160^{\circ} \mathrm{C}\left(320^{\circ} \mathrm{F}\right)$.

Figure 9-24 compares the hot gas layer temperatures for four tests with the door open and ventilation off for $1 \mathrm{MW}$ heptane blend fires with the centered burner and three alternate burner positions described in the test description. Tests 3, 14, and 15 had very similar temperature-time curves with continued increases for the duration of the experiments. There was no significant effect of burner position. Test 15 had a much higher temperature, which may be accounted for by the close proximity of the burner to the thermocouple tree.

Figure 9-25 compares the thermocouple Tree 2-5 during the first test and the repeat tests with a 1 MW fire burning in the center of the compartment for the four combinations of door open/closed and ventilation on/off. The repeatability of the temperature for these tests was generally less than $5{ }^{\circ} \mathrm{C}\left(9^{\circ} \mathrm{F}\right)$. The behavior of the Tree 2-5 thermocouple is different than that of Tree 4-8 and is very similar to the results for the hot gas layer average temperatures. Like the layer temperatures, but unlike TC4-8, the door condition is more important than the ventilation condition. The door closed with the ventilation off condition produced the highest temperatures $\left(230{ }^{\circ} \mathrm{C} ; 446{ }^{\circ} \mathrm{F}\right)$ and at the fastest rate. The door closed with the ventilation on condition produced temperatures typical of the door open tests with the ventilation off $\left(215^{\circ} \mathrm{C} ; 419^{\circ} \mathrm{F}\right)$, although less than the door closed/ventilation off condition. The door open conditions produced 
parallel temperatures with the ventilation off condition, higher by about $25^{\circ} \mathrm{C}\left(45^{\circ} \mathrm{F}\right)$ by the ends of the tests.

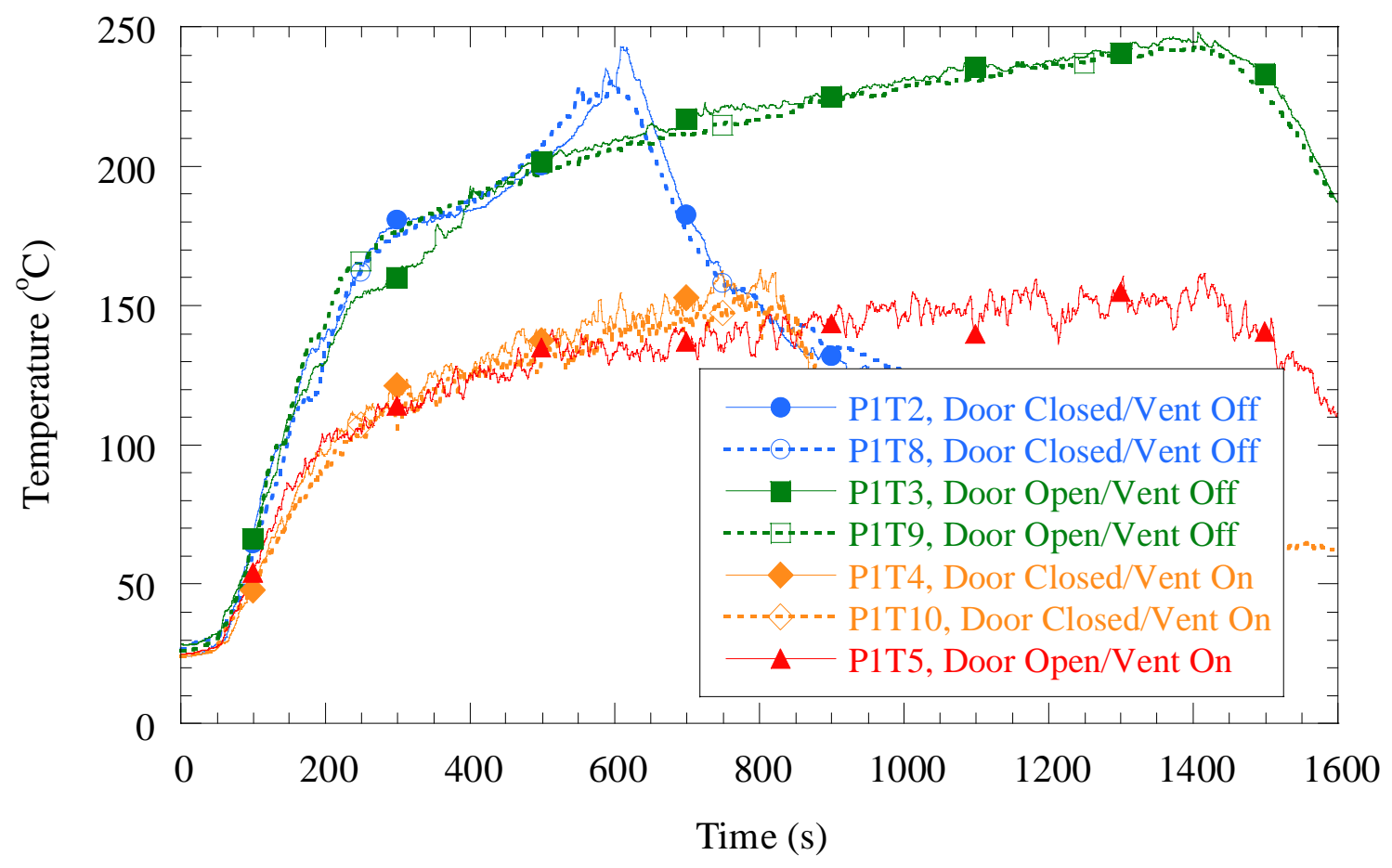

Figure 9-21: Temperature versus time for the thermocouple located at position 8 on Tree 4 and also near Targets $B$ and $E$ for Tests $2,8,3,9,4,10$, and 5. 


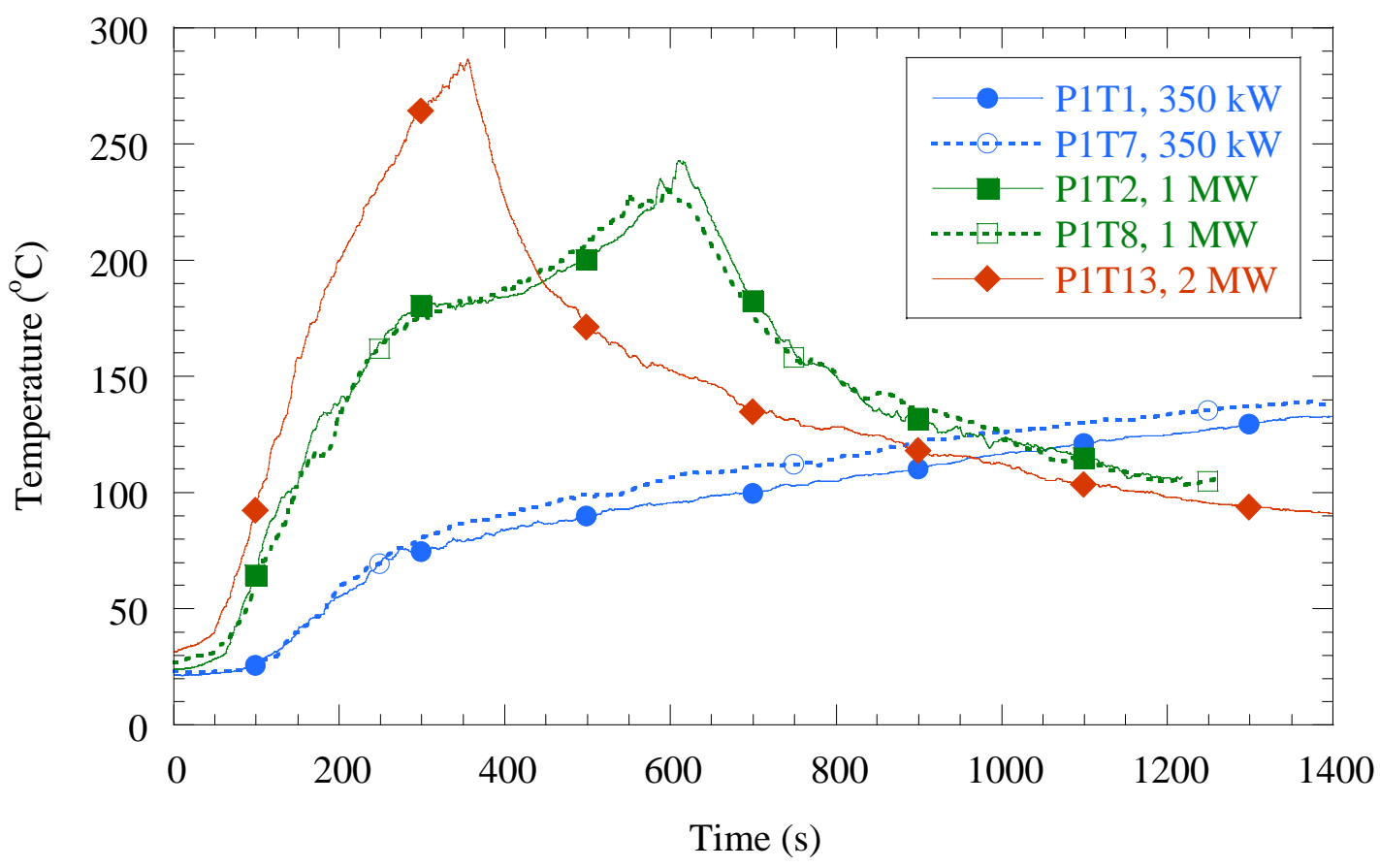

Figure 9-22: Temperature versus time for the thermocouple located at position 8 on Tree 4 and also near Targets $B$ and $E$ for Tests 1, 7, 2, 8, and 13.

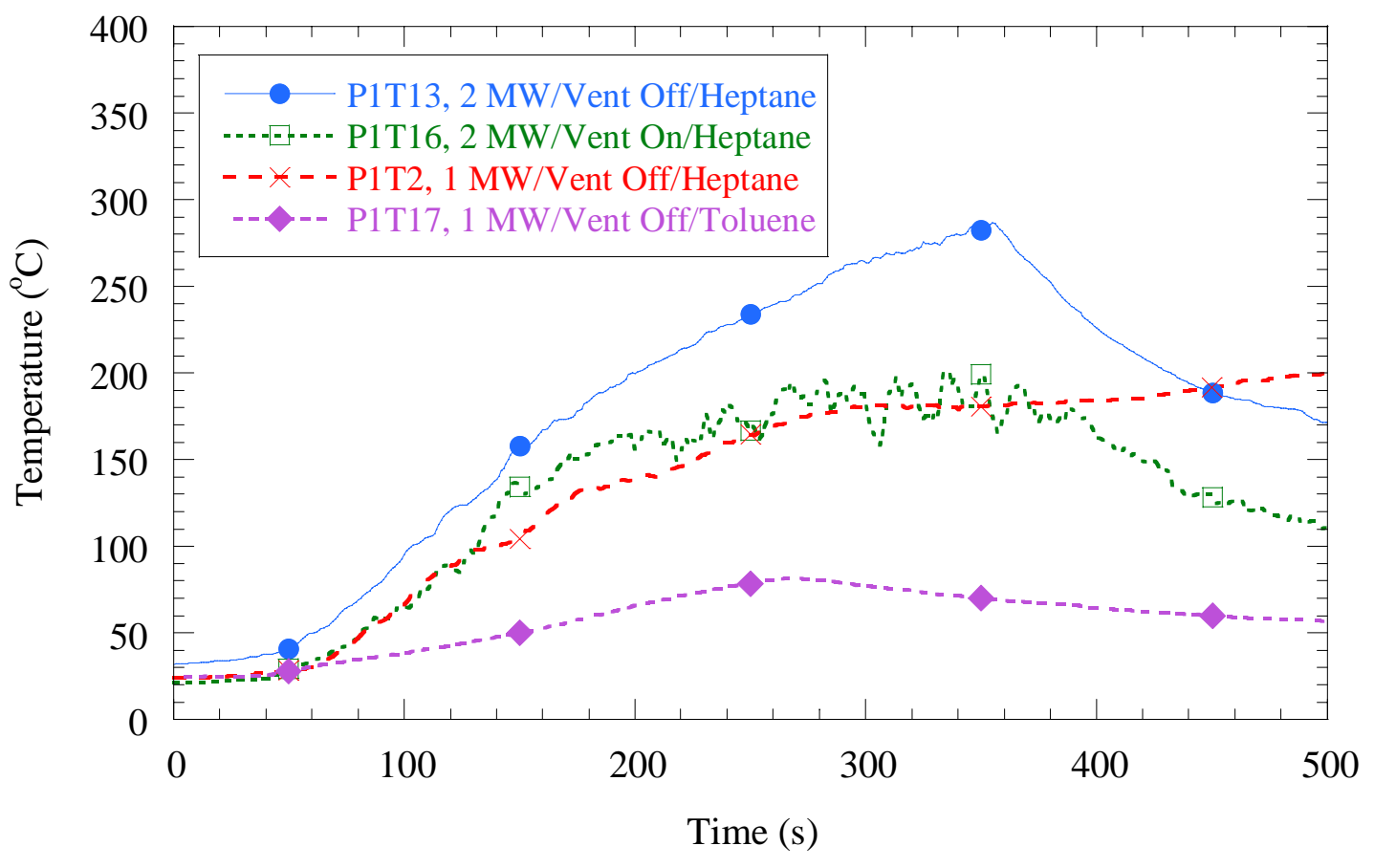

Figure 9-23: Temperature versus time for the thermocouple located at position 8 on Tree 4 and also near Targets $B$ and $E$ for Tests 13, 16, 2, and 17 (labeled P1T13, P1T16, P1T2, and P1T17, respectively). 


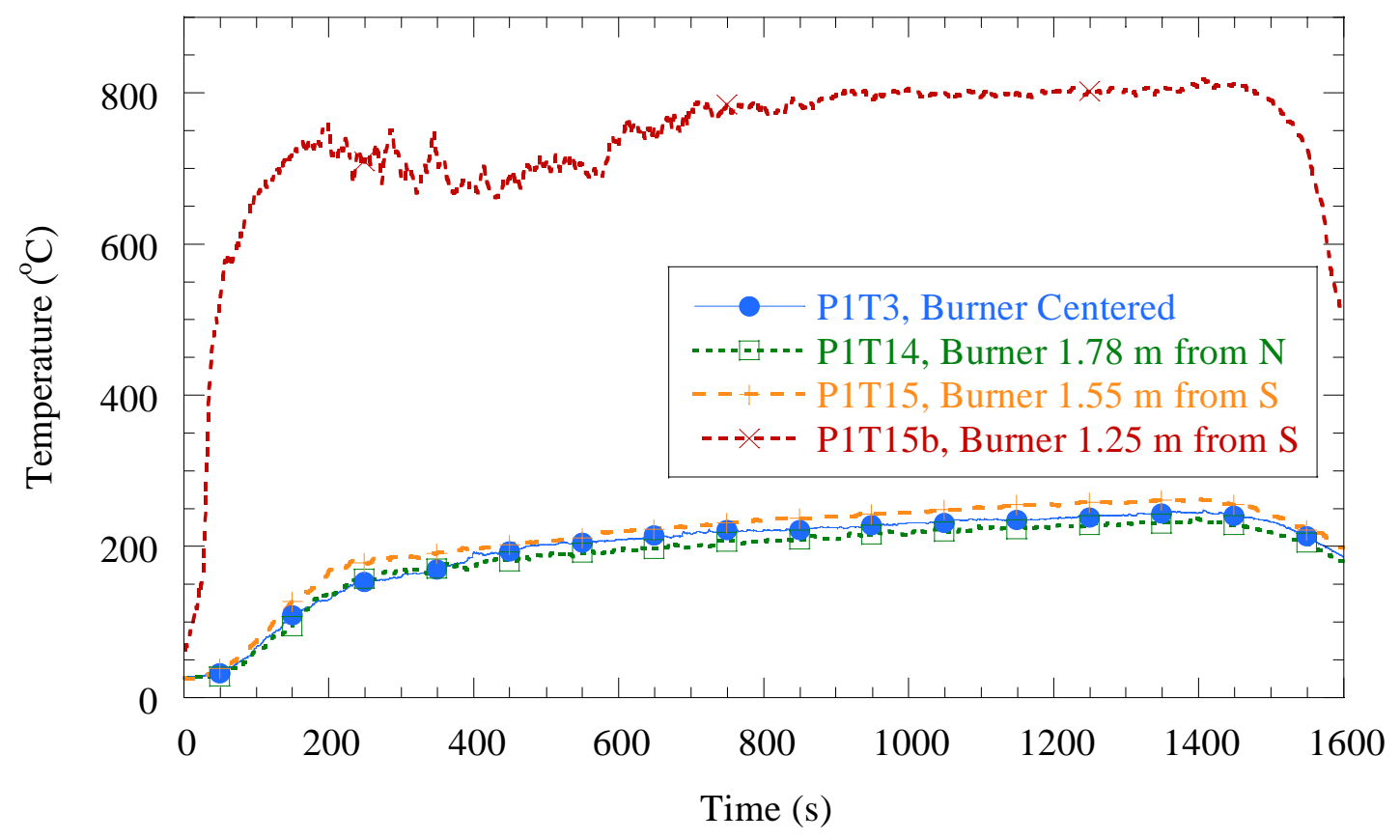

Figure 9-24: Temperature versus time for the thermocouple located at position 8 on Tree 4 and also near Targets B and E for Tests 3, 14, 15, and 18 (labeled P1T3, P1T14, P1T15, and P1T15b, respectively).

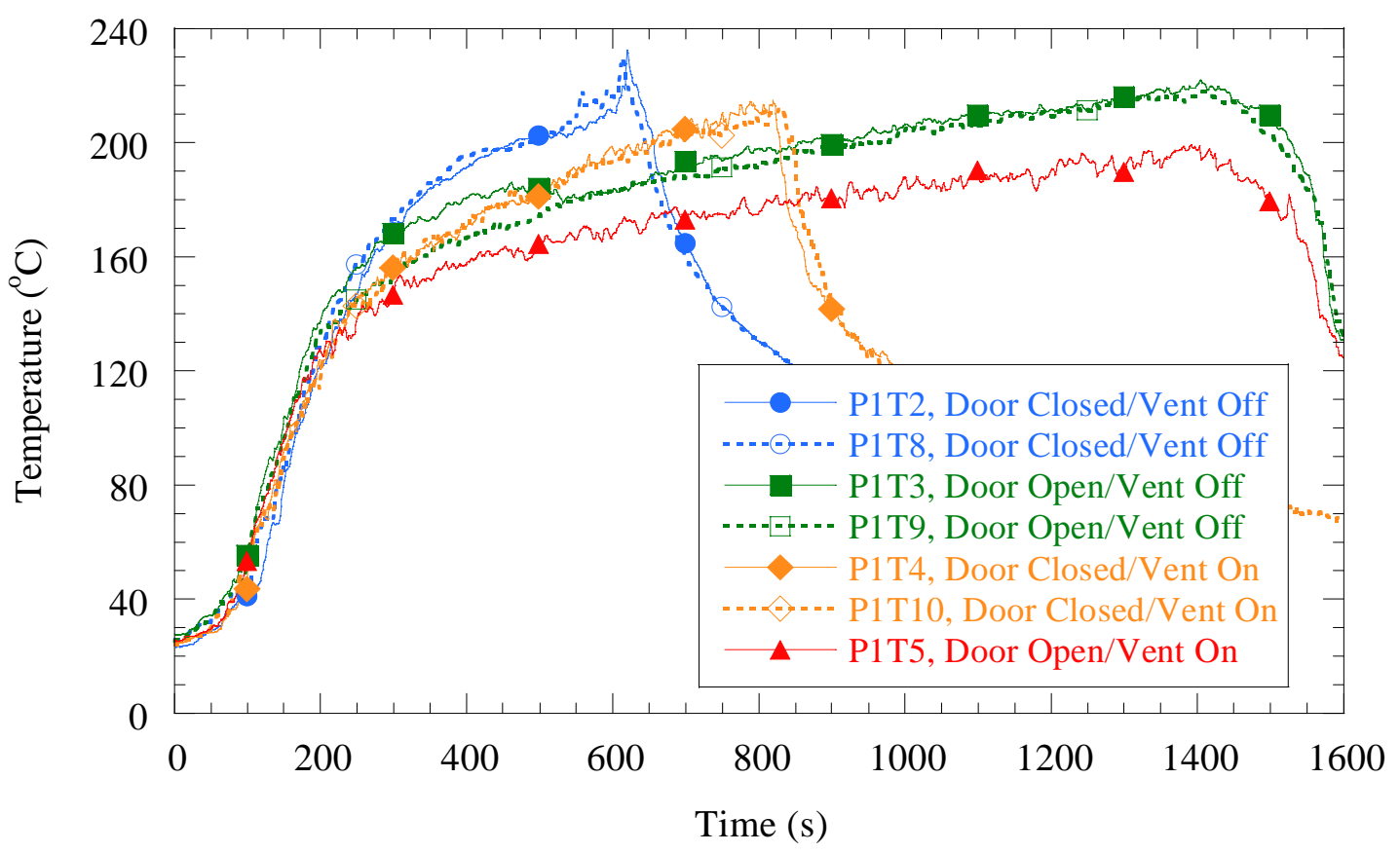

Figure 9-25: Temperature versus time for the thermocouple located at position 5 on Tree 2 and also near Target $G$ for Tests 2, 8, 3, 9, 4, 10, and 5 (labeled P1T2, P1T8, P1T3, P1T9, P1T4, P1T10, and P1T5, respectively). 


\subsection{Gas Temperature at Target $\mathrm{G}$}

The gas temperature nearest Target $\mathrm{G}$ is best represented by the thermocouple at position 5 on thermocouple Tree 2. Position 5 was located $1.75 \mathrm{~m}$ (5.74 ft) above the floor. In Table 9-1, the expanded uncertainties for the hot gas layer temperature are associated with this temperature measurement.

Figure 9-26 compares the Tree 2-5 temperature for the three fire sizes (350 kW, $1 \mathrm{MW}$, and 2 MW) for the condition of the door closed and the ventilation off. The temperatures and rate of increase of temperature are highest for the largest fire and lowest for the smallest fire. The repeatability of the temperature for the two pairs of similar tests is also excellent.

Figure 9-27 compares the hot gas layer temperature for two $2 \mathrm{MW}$ heptane blend fires with the door closed and with the ventilation on and off and for two $1 \mathrm{MW}$ fires with the door closed and ventilation off for heptane blend and toluene. The $2 \mathrm{MW}$ fire time-temperature curves were very similar with no significant effect of ventilation condition. The $1 \mathrm{MW}$ toluene fire and $1 \mathrm{MW}$ heptane blend fire time-temperature curves were also very similar with no significant effect of fuel type.

Figure 9-28 compares the hot gas layer temperatures for four tests with the door open and ventilation off for $1 \mathrm{MW}$ heptane blend fires with the centered burner and three alternate burner positions described in the test descriptions. All of the temperature-time curves were parallel with some differences related to location. The maximum temperatures reached were $265^{\circ} \mathrm{C}\left(509^{\circ} \mathrm{F}\right)$ for Test $14,220^{\circ} \mathrm{C}\left(428{ }^{\circ} \mathrm{F}\right)$ for Test $3,210^{\circ} \mathrm{C}\left(410^{\circ} \mathrm{F}\right)$ for Test 18 , and $200^{\circ} \mathrm{C}\left(392^{\circ} \mathrm{F}\right)$ for Test 15.

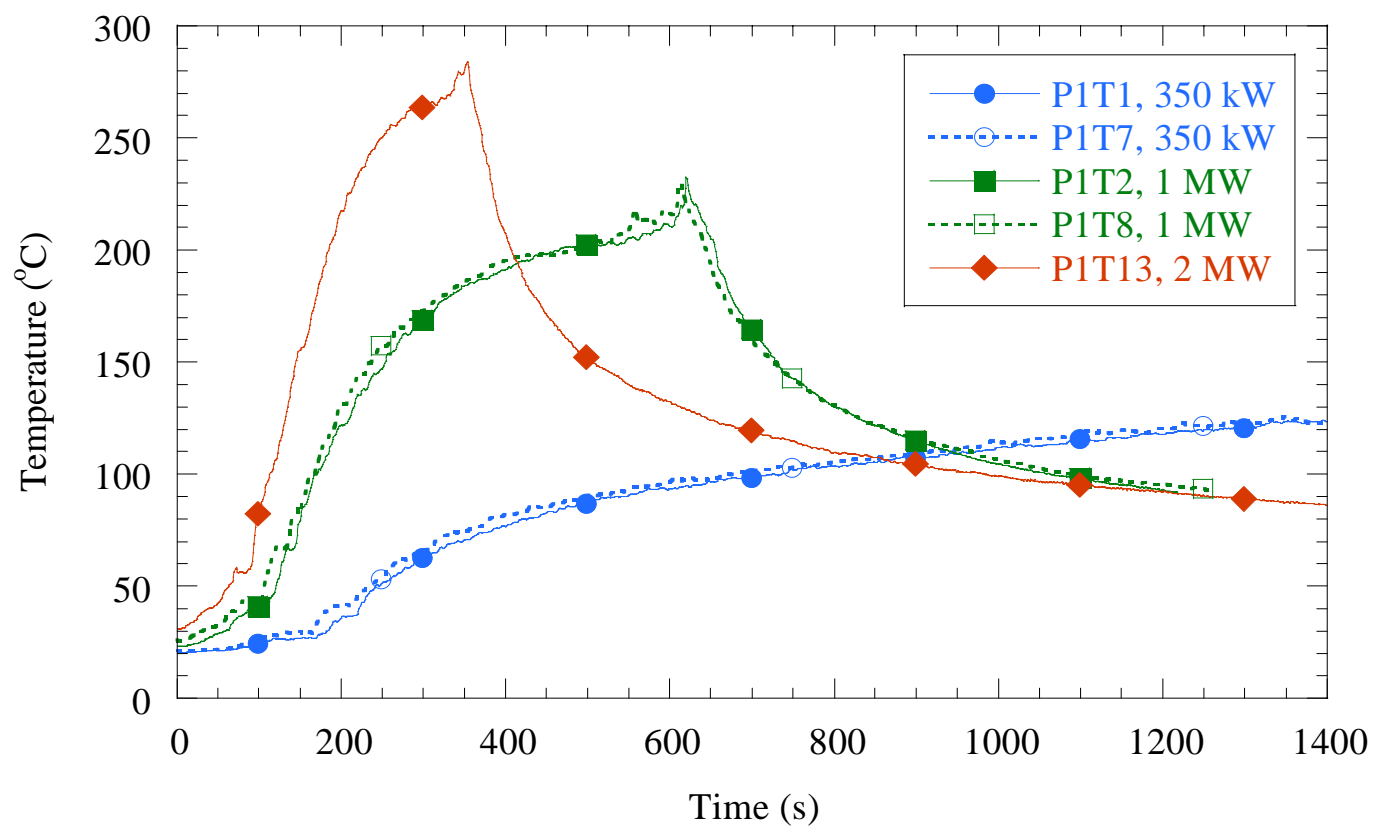

Figure 9-26: Temperature versus time for the thermocouple located at position 5 on Tree 2 and also near Target $G$ for Tests 1, 7, 2, 8, 13 (labeled P1T1, P1T7, P1T2, P1T8, and P1T13, respectively). 


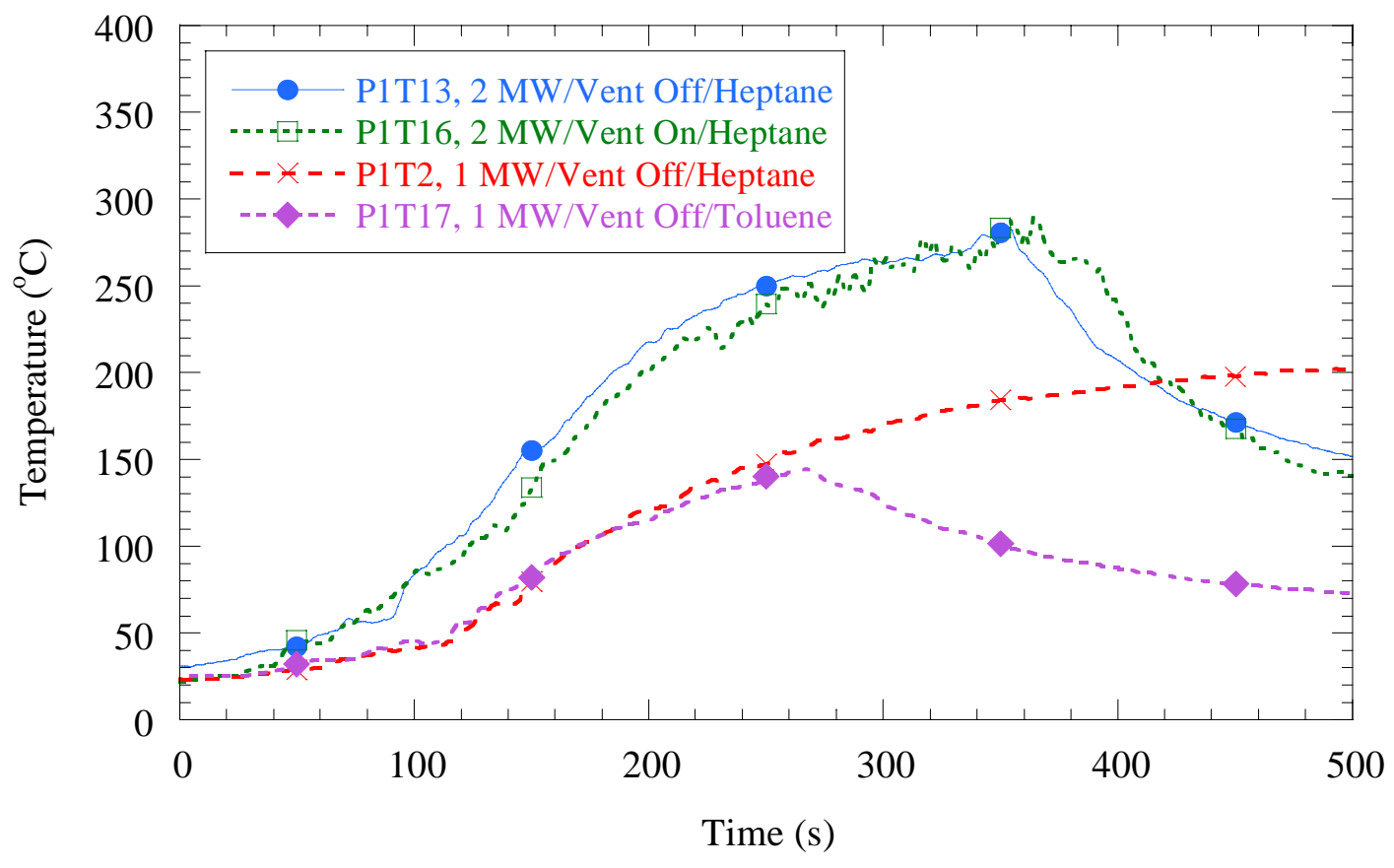

Figure 9-27: Temperature versus time for the thermocouple located at position 5 on Tree 2 and also near Target $G$ for Tests 13, 16, 2, and 17 (labeled P1T13, P1T16, P1T2, and P1T17, respectively).

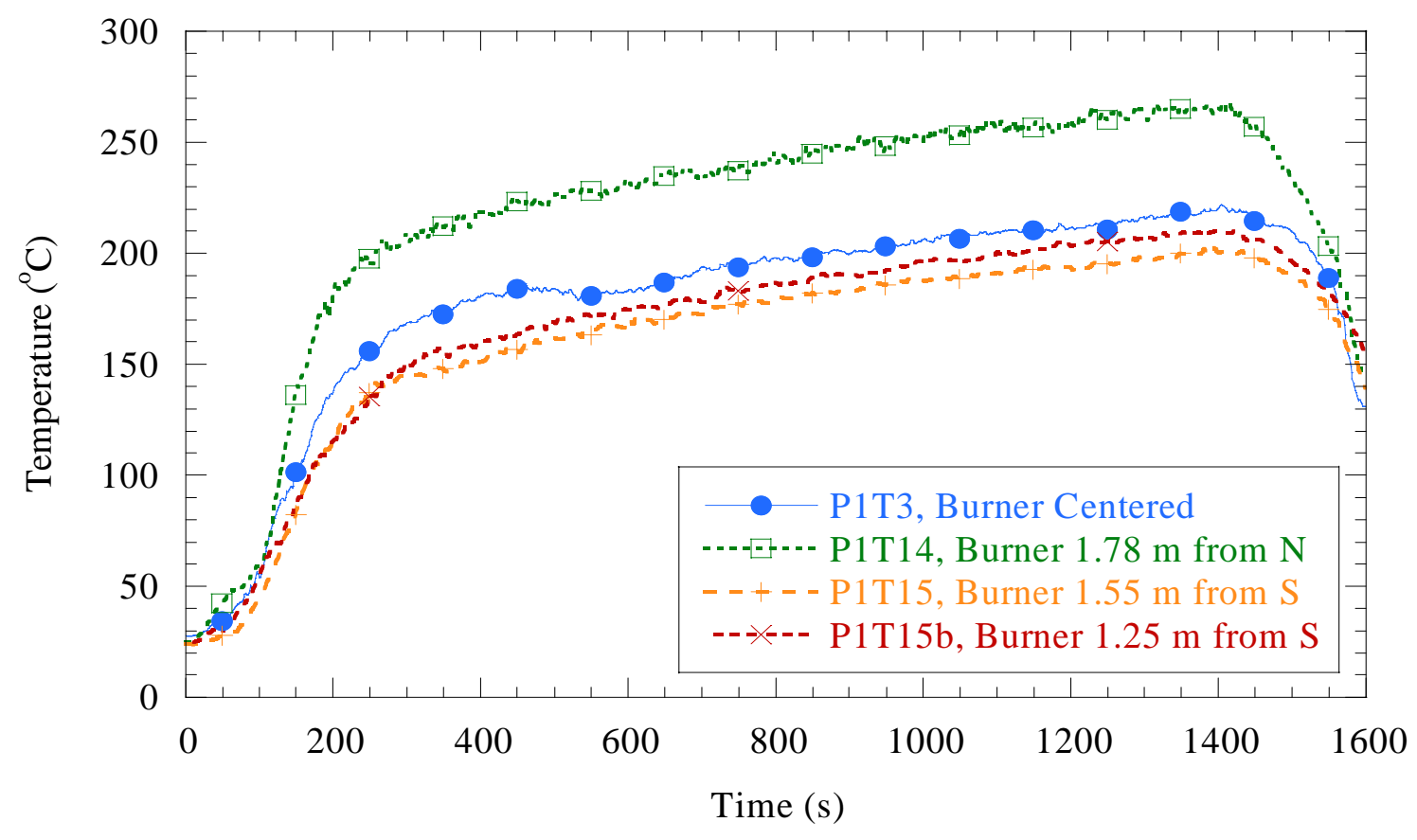

Figure 9-28: Temperature versus time for the thermocouple located at position 5 on Tree 2 and also near Target $G$ for Tests 3, 14, 15, and 18 (labeled P1T3, P1T14, P1T15, and P1T15b, respectively). 


\section{0 heat Loss to the enclosure}

\subsection{Introduction}

In order to evaluate the fire models, it is important to have measurements with estimated uncertainties of the heat lost to the walls, ceiling, and floor of the enclosure as well as through the vents. The resulting energy balance is important when evaluating how the models handle energy transport. Measurements and analysis were performed to generate this energy balance for the test scenarios that incorporated a $1 \mathrm{MW}$ fire in the center burner location with and without door vents, but without the mechanical vents. The result of this testing and analysis are a valuable, previously unavailable validation tool.

\subsection{Measurement Design}

In order to estimate the total heat loss in the test enclosure, measurements of heat flux to the interior surfaces were required at numerous locations. The primary design choices to accomplish this were the kind of measurements to make, the sensors to use, the number of sensors necessary, and their location.

The number of heat flux measurement locations was limited by resource availability. The measurement approach was to optimize the placement and sensor type through analysis using computational modeling.

To determine how many measurements were necessary, an evaluation of sensor density versus uncertainty level was conducted. The NIST Fire Dynamics Simulator (FDS) was used to model the enclosure with a $1 \mathrm{MW}$ fire located in the center with the door open [McGrattan et al., 2001]. Among many outputs, the model predicted the temperature and radiation fields on the interior surfaces of the enclosure. The sensor placement was analyzed by testing the effect of the number and placement of nodes used in the calculation relative to the calculated value using all of the nodes. The accuracy of the calculation was sensitive to the distribution pattern as well as the number of nodes used. A non-uniform approach worked best with more nodes used in regions of high flux gradients and fewer nodes used where fluxes were more uniform. This finding was translated from the model prediction to physical test design by generating patterns of sensor locations that provided greater concentrations of measurements to characterize small areas of high flux and more sparse measurements far from the burner to characterize larger areas of more uniform, lower fluxes.

The uncooled gauges used here measured the net heat flux. The gauges were sensitive to total heat flux including both radiation and convection. The net heat flux takes into account the incident total heat flux less re-radiation to the environment from the gauge and is a function of the temperature and emissivity of the gauge. The net radiation to the wall (not the sensor) is 
equal to the net flux to the gauge adjusted by the difference between the net flux to the gauge and to the adjacent wall material. This depends on the differences between their temperatures and emissivities. The emissivities of the gauges and wall materials were measured or provided by the manufacturers. For the two types of gauges used here, the emissivities averaged about 0.94 over the infrared spectrum. The temperatures of the gauges and surfaces near the gauges were measured to estimate the net flux to the compartment walls.

To estimate the net flux to the compartment walls, the temperatures of the gauge as well as the compartment surface near the gauge were measured in case their temperatures differed. The gauge temperature was generally lower than the adjacent surface temperature by a few degrees to tens of degrees. There are a few possible explanations for this. While the emissivities of the gauge and wall were approximately the same at ambient temperature, they may have varied as the temperature increased in the compartment. The gauge also has a finite mass with the thermocouple actually embedded within the gauge. This causes an additional heat capacity and time lag not experienced on a bare surface. While the heat flux gauges were attached with a conductive paste, the contact and level of conduction may not have allowed sufficient thermal communication between the gauge and wall. The quality of the surface thermocouple installation may have also affected the surface temperature measurement. Finally, near the fire and especially in the lower layer, the surface temperatures could have been overestimated by thermocouples by some amount due to radiative heating of the thermocouple bead.

For the calculations of heat loss to the enclosure, (which were performed for Tests $2-5$ ), the gauge net heat flux data was transformed to compartment surface net heat fluxes by correcting for the temperature difference between the compartment surface and the gauge according to the following equation:

$$
\dot{q}_{\text {wall }}^{\prime \prime}=\dot{q}_{\text {gauge }}^{\prime \prime}-\sigma\left(\varepsilon_{\text {wall }} \mathrm{T}_{\text {wall }}{ }^{4}-\varepsilon_{\text {gauge }} \mathrm{T}_{\text {gauge }}{ }^{4}\right)
$$

where $\dot{q}_{\text {wall }}^{\prime \prime}$ is the net heat flux to the compartment surface, $\dot{q}_{\text {gauge }}^{\prime \prime}$ is the net heat flux to the gauge, $\sigma$ is the Stefan- Boltzmann constant and $\varepsilon$ is the emissivity (of the marinite and the gauge). For all tests, the data in the associated data files represents the net heat flux to the gauge with no temperature adjustment.

\subsection{Instrumentation}

Preliminary modeling of the test fires predicted heat fluxes to average about $2 \mathrm{~kW} / \mathrm{m}^{2}$ on the compartment walls with some regions reaching several times that and much of the enclosure receiving less than $1 \mathrm{~kW} / \mathrm{m}^{2}$. Modeling also predicted surface temperatures greater than $150{ }^{\circ} \mathrm{C}$ $\left(302^{\circ} \mathrm{F}\right.$ ) on relatively small areas near the burner, while the remaining surface temperatures were predicted to be less than $150{ }^{\circ} \mathrm{C}\left(302^{\circ} \mathrm{F}\right)$. Because of the temperature variations, different types of sensors were selected for the high and low temperature regions. Low cost, uncooled heat flux sensors were used in regions expected to remain below $150{ }^{\circ} \mathrm{C}\left(302^{\circ} \mathrm{F}\right)$. More expensive, hightemperature heat flux gauges were used in the higher flux regions near the fire. 
The lower temperature gauge was a Vatell model BF-04 with an embedded K-type thermocouple and utility up to $150{ }^{\circ} \mathrm{C}\left(302^{\circ} \mathrm{F}\right)$. The higher temperature gauge was ITI Model C Polyamide Heat Flux Transducer with an embedded type-K thermocouple usable to $300{ }^{\circ} \mathrm{C}\left(572{ }^{\circ} \mathrm{F}\right)$. The gauges were mounted with Omega Engineering's Omegatherm thermally conductive high temperature grease, model number OT-201. Four 6-32 screws and washers $(0.79 \mathrm{~cm}$ OD, 0.37 in ID) were used to hold the corners against the grease and prevent slipping from vertical surfaces or motion due to temperature cycling. Each heat flux gauge had an associated, embedded thermocouple to determine the surface temperature of the gauge and also one located approximately $5 \mathrm{~cm}$ (2 in) away on the enclosure surface for comparison.

The following tables, 10-1 to 10-3, describe the type and location, and area represented by the sensor groups. Figures 10-2 to 10-4 show schematics of the approximate sensor locations and coverage areas on component surfaces. Sensor Package L consisted of a lower temperature Vatell gauge and two type-K thermocouples. Sensor Package H consisted of a higher temperature ITI gauge and two type-K thermocouples. Both large side walls had the same sensor distribution pattern, both smaller end walls also had matching patterns, and the ceiling and floor had matching patterns. The total number of sensor packages was 36 of which 8 were for higher temperature.

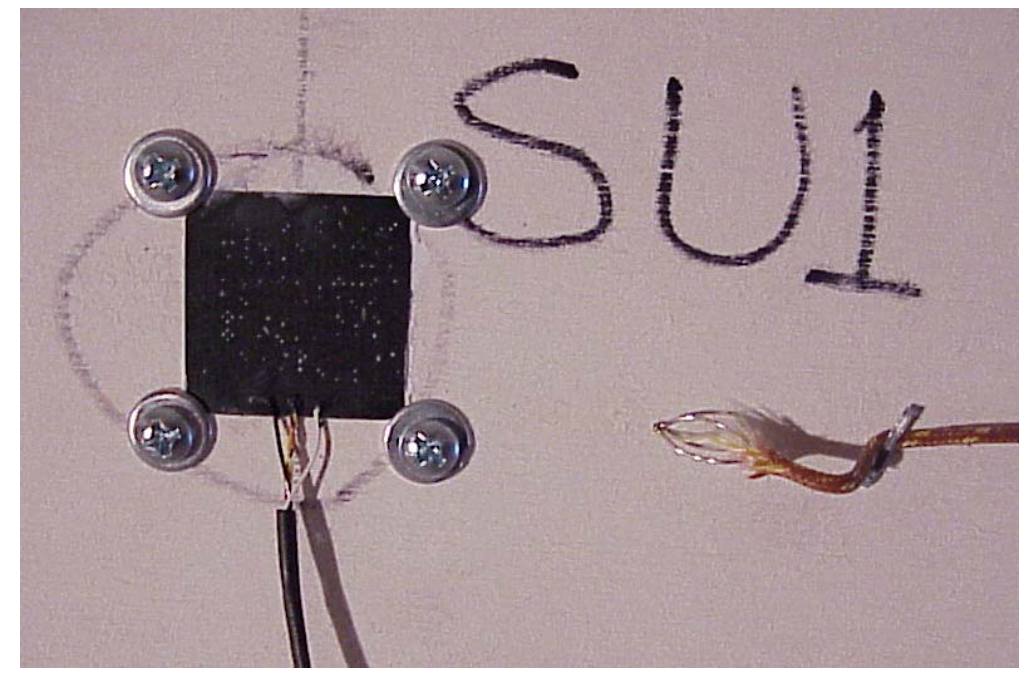

Figure 10-1: A Vatell model BF-04 heat flux gauge installed on the South wall along with a wall thermocouple. 
Table 10-1: North and south wall sensor locations.

\begin{tabular}{|c|c|c|c|c|}
\hline \multirow{2}{*}{ Number } & \multicolumn{2}{|c|}{ Sensor Package } & Location (X m,Z m) & $\begin{array}{c}\text { Area Represented } \\
\left(\% \text { of surface, } \mathrm{m}^{2}\right)\end{array}$ \\
\cline { 2 - 3 } & North & South & & $19.5,15.7$ \\
\hline 1 & L & L & $3.91,1.49$ & $16.8,13.5$ \\
\hline 2 & L & L & $3.91,3.72$ & $13.7,11.1$ \\
\hline 3 & L & L & $9.73,1.86$ & $13.7,11.1$ \\
\hline 4 & H & L & $12.15,1.86$ & $19.5,15.7$ \\
\hline 5 & L & L & $17.79,1.49$ & $16.8,13.5$ \\
\hline 6 & L & L & $17.79,3.72$ & $100.0,80.7$ (per wall) \\
\hline Totals & 5 L, $1 \mathrm{H}$ & 6 L, 0 H & & \multicolumn{2}{c}{} \\
\hline
\end{tabular}

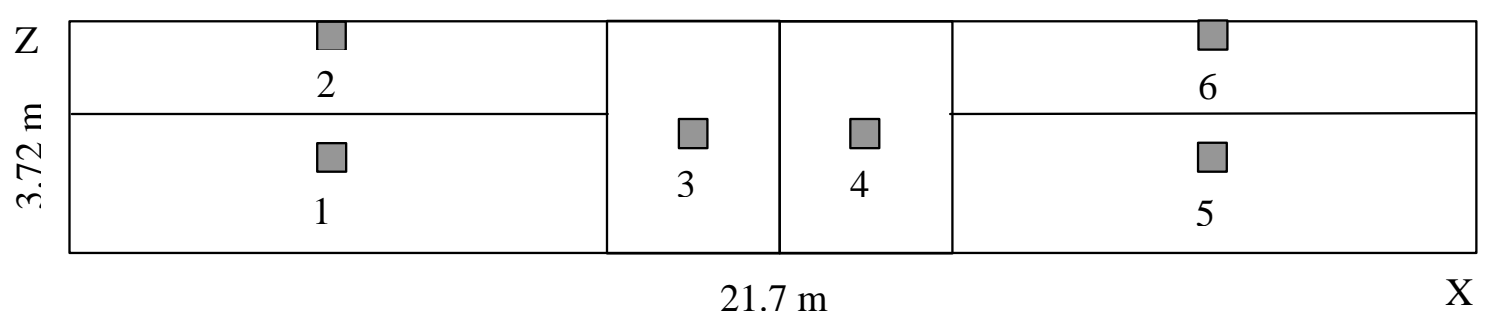

Figure 10-2: North and south Wall Sensor Locations.

Table 10-2: Ceiling and floor sensor locations.

\begin{tabular}{|c|l|c|c|c|}
\hline \multirow{2}{*}{ Number } & Sensor & Package & Location (X m,Y m) & $\begin{array}{c}\text { Area Represented } \\
\left.(\%) \text { of surface, } \mathrm{m}^{2}\right)\end{array}$ \\
\cline { 2 - 3 } & Floor & Ceiling & & $35.0,54.3$ \\
\hline 1 & $\mathrm{~L}$ & $\mathrm{~L}$ & $3.04,3.58$ & $5.0,7.8$ \\
\hline 2 & $\mathrm{~L}$ & $\mathrm{H}$ & $9.11,1.99$ & $5.0,7.8$ \\
\hline 3 & $\mathrm{~L}$ & $\mathrm{H}$ & $9.11,5.96$ & $5.0,7.8$ \\
\hline 4 & $\mathrm{~L}$ & $\mathrm{H}$ & $10.85,2.38$ & $5.0,7.8$ \\
\hline 5 & $\mathrm{H}$ & $\mathrm{H}$ & $10.85,5.16$ & $5.0,7.8$ \\
\hline 6 & $\mathrm{~L}$ & $\mathrm{H}$ & $13.02,1.99$ & $5.0,7.8$ \\
\hline 7 & $\mathrm{~L}$ & $\mathrm{H}$ & $13.02,5.96$ & $35.0,54.3$ \\
\hline 8 & $\mathrm{~L}$ & $\mathrm{~L}$ & $18.66,3.58$ & $100.0,155.2$ (per surface) \\
\hline Totals & 7 L, $1 \mathrm{H}$ & $2 \mathrm{~L}, 6 \mathrm{H}$ & & \\
\hline
\end{tabular}




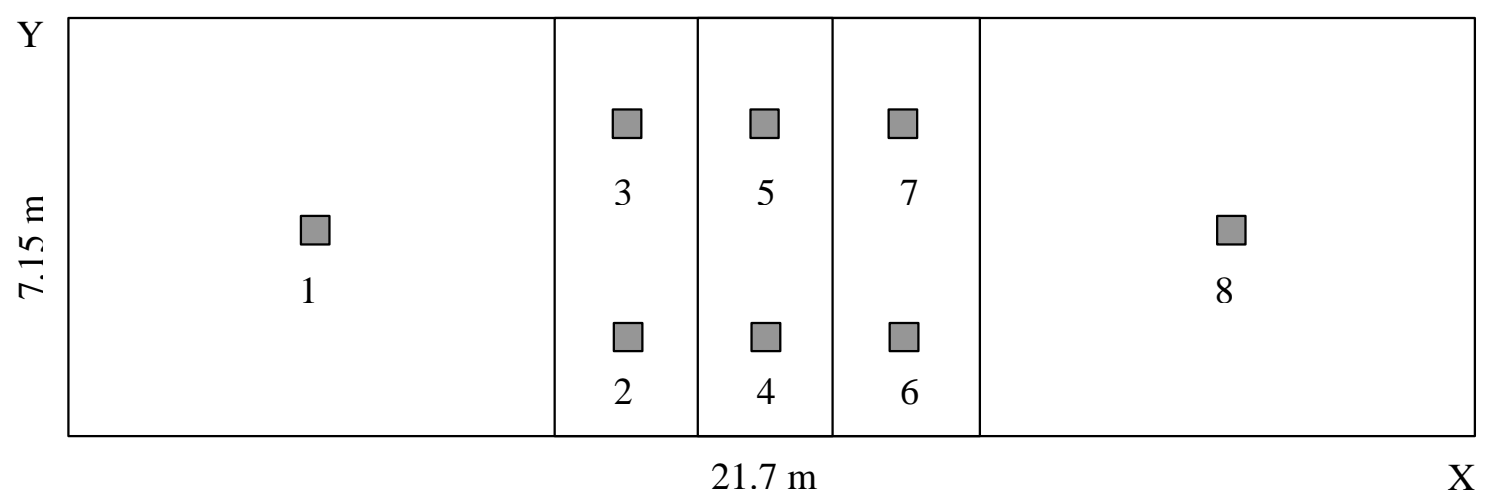

Figure 10-3: Ceiling and floor Sensor Locations.

Table 10-3: East and west wall sensor locations.

\begin{tabular}{|c|c|c|c|}
\hline Number & Sensor Package & Location (Y m,Z m) & $\begin{array}{c}\text { Area Represented } \\
\text { (\% of surface, } \mathrm{m}^{2} \text { ) }\end{array}$ \\
\hline 1 & $\mathrm{~L}$ & $1.59,1.12$ & $25.0,6.7$ \\
\hline 2 & $\mathrm{~L}$ & $1.59,2.42$ & $25.0,6.7$ \\
\hline 3 & $\mathrm{~L}$ & $5.76,1.12$ & $25.0,6.7$ \\
\hline 4 & $\mathrm{~L}$ & $5.76,2.42$ & $25.0,6.7$ \\
\hline & 4 L, 0 H (each wall) & & $100.0,26.6$ (per wall) \\
\hline
\end{tabular}

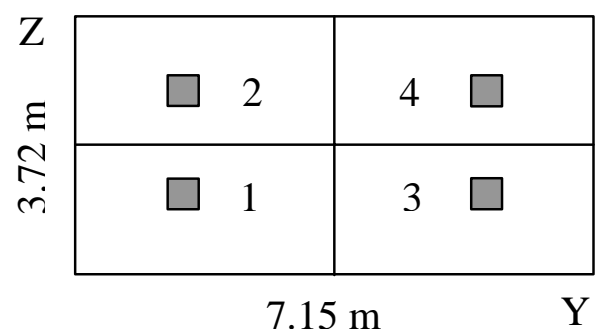

Figure 10-4: East and west wall sensor locations.

\subsection{Measurement Uncertainties}

The number of sensors used and their location pattern contributed to the uncertainty estimate for the flux to the compartment surfaces. The model predictions were used to estimate uncertainty levels produced by the particular sensor pattern used. Also, uncertainties associated with emissivities and temperature measurements were included.

All of the heat flux gauges were provided with factory calibrations with uncertainties of $\pm 3 \%$. The calibration of one of each model was checked at NIST to determine if there was a significant difference between the factory and NIST calibrations. To check the calibration, each gauge was mounted on a $30 \mathrm{~cm}$ (11.8 in) square piece of the enclosure wall material, Marinite, and placed at predetermined positions in front of a radiant panel. The heat fluxes at the positions in front of 
the panel were previously measured with a cooled reference gauge. Since the gauges' output changed during heating, the gauge temperature as well as the flux output was measured.

Table 10-4 lists the sources of uncertainty in the heat loss measurements. The first source, factory calibration of the gauges, is the uncertainty reported by the manufacturers. The "additional calibration" uncertainty in Table 10-4 resulted from the differences experienced during the check, described above, of the factory calibration with the gauges mounted in a configuration similar to the actual test situation. The surface temperature uncertainty arises because the gauge flux output is corrected to account for the difference between the gauge temperature and the wall temperature. This has some uncertainty due to radiation effects and uncertainty inherent to both thermocouples. The active area uncertainty is related to the fact that the screws and washers used to mount the gauges covered up small portions of the corners of each gauge which could lead to more or less flux depending on how much the metal conducted heat to a gauge. This blockage varied slightly with each installation so a maximum uncertainty based on the relative geometry of the gauge and washers was assigned to it. The emissivity uncertainty was determined from the manufacturer's measurement for the lower temperature gauge and from a NIST measurement for the higher temperature gauge. Finally, the table shows the typical uncertainty due to the difference from the model average flux per region and the average flux using the model values at only the actual sensor locations.

The total uncertainty resulting from adding these component uncertainties in quadrature is $11 \%$. The difference between the factory calibration and the calibration for a gauge mounted on Marinite (per radiant panel experiments) is the driving uncertainty source. The uncertainty components such as the surface temperature are generally much less than $\pm 8 \%$. The uncertainty due to using the model to design the sensor layout is unknown. Because a simulation of Test 3 , with the open door and no ventilation, was used to determine the locations of the sensors, the heat loss results for Tests 2, 4, and 5, which had closed doors and/or the ventilation on, may be less robust than those for Test 3. The uncertainty for gauge data during Tests 7, 10, 13, 14, 15, 17 and 18 was greater than for the other tests (and is difficult to quantify) since most of the gauges experienced higher than their stated temperature limits during the 2 MW tests (Tests 13 and 16), although they were protected by a cover.

Table 10-4: Overview uncertainties of net heat flux.

\begin{tabular}{|l|l|}
\hline \multicolumn{1}{|c|}{ Source of Uncertainty } & \multicolumn{1}{|c|}{$\begin{array}{c}\text { Expanded Relative Uncertainty } \\
\text { (2 standard deviations) }\end{array}$} \\
\hline Factory Calibration & $\pm 3 \%$ \\
\hline Additional Calibration & $\pm 8 \%$ \\
\hline Surface Temperature Uncertainty & typically $\pm 5 \%$ \\
\hline Active Area & $\pm 2 \%$ \\
\hline Emissivity & $\pm 4 \%$ \\
\hline Sensor Average Difference from Model & Varied per sensor location, averaged $\pm 2 \%$ \\
\hline Total Uncertainty & $\mathbf{1 1} \%$ \\
\hline
\end{tabular}




\subsection{Results}

The only tests for which heat losses to the enclosure are reported are Tests 2, 3, 4, and 5. For other tests, the instrumentation was inoperative, which was likely due to overheating of the gauges. After $1150 \mathrm{~s}$ in Test 3, some adjustment to the data was required. From $1150 \mathrm{~s}$ to 1300 s, symmetric sensor (S3, N4) data were substituted for the failed sensor (N3, S4) data. After $1300 \mathrm{~s}$, both of a pair (S3, N3) of symmetric sensors failed so the values were retained constant at their last operating values until the time of extinguishment. Therefore, for Test 3 , the heat fluxes for the north and south walls and the total heat loss were less accurate after $t=1150 \mathrm{~s}$. As was described in the uncertainty section, the most confidence in the sensor layout resides with Test 3 which had the door open, but the ventilation off.

Figure 10-5 is a comparison of net heat fluxes to the wall (see Eq. 10.1) near sensors N1 and N3 on the North wall for Tests 2 to 5. Sensor N1 was located in a low flux region and sensor N3 was in a high flux region. The high flux region sensor, N3, experienced very similar fluxes in Tests 2 and 4 and in Tests 3 and 5. Each of those test pairs had the same doorway condition. The low flux region sensor, N1, experienced different fluxes for each test condition. In general for all of the tests, the N3 sensor experienced about two times the flux as the N1 sensor.

Figure 10-6 shows the net heat fluxes on each surface as well as their sum. The symmetric walls (north \& south, east \& west) experienced nearly identical fluxes as would be expected. The ceiling flux was not significantly different than the flux to the floor. As the upper layer heated, the temperature difference with the plume decreased and the reradiation from the ceiling was larger so the net flux decreased. The floor flux increased during the fire, probably because the whole upper layer grew hotter causing more radiative heating to the relatively cool floor. Test 5 is the test most similar to Test 3 in that the door was open, although the ventilation was on. Figure 10-7 shows the plot of the component and total net heat fluxes. Test 5 shows very similar behavior to Test 3 with similar symmetry and trends.

Test 2 had the door closed and the ventilation off. Figure 10-8 shows the corresponding net heat flux plot for Test 2. Test 4 had the door closed and the ventilation on. Figure 10-9 shows its net heat flux plot. For both Tests 2 and 4, the symmetry between north and south and east and west is still apparent. The net heat flux trends with time are similar between Tests 2 and 4, but somewhat different from those in tests 3 and 5. In Tests 2 and 4, the ceiling flux is always higher than the floor flux and both ceiling and floor fluxes tend to increase throughout.

Figure 10-10 represents an accounting of the energy balance in the compartment. The figure shows the total energy loss to compartment surfaces, through the doorway, and accumulated in the upper layer, the sum of these three terms, and the calorimetric HRR (see Section 3). The term accounting for heating of gases in the compartment represented less than $4 \%$ of the total enthalpy [Hamins et al., 2005] - a relatively small fraction. For early times $(t<250 \mathrm{~s})$, the calorimetry results lag behind the heat loss to the walls as the compartment volume fills before combustion products are transported to the exhaust hood where the calorimetry measurements are made. The total heat loss rate and the calorimetry HRR should, in theory, be equal, apart from the time lag. The uncertainty in the total heat loss is estimated to be $12 \%$, while the uncertainty in the calorimetry is $15 \%$. The agreement between the two curves is within the 
overlapping uncertainty limits. For other tests, the agreement is also within the overlapping uncertainties.

Two of the uncooled heat flux gauges, N3 and N4, were in the vicinity of two cooled gauges, FG9 and RG10. The uncooled gauges were physically separated from the cooled gauges by about $1.1 \mathrm{~m}$ (3.6 ft), which is not insignificant near the fire plume in terms of heat flux. Figures 10-11 and 10-12 compare the heat fluxes to these different types of sensors for Tests 2 and 3. A flux adjustment was applied to the uncooled gauges' output to account for the $75^{\circ} \mathrm{C}\left(167{ }^{\circ} \mathrm{F}\right)$ temperature of the cooled gauges. The differences are greater than can be accounted for by the uncertainties and are probably due to the different environments at the three locations.

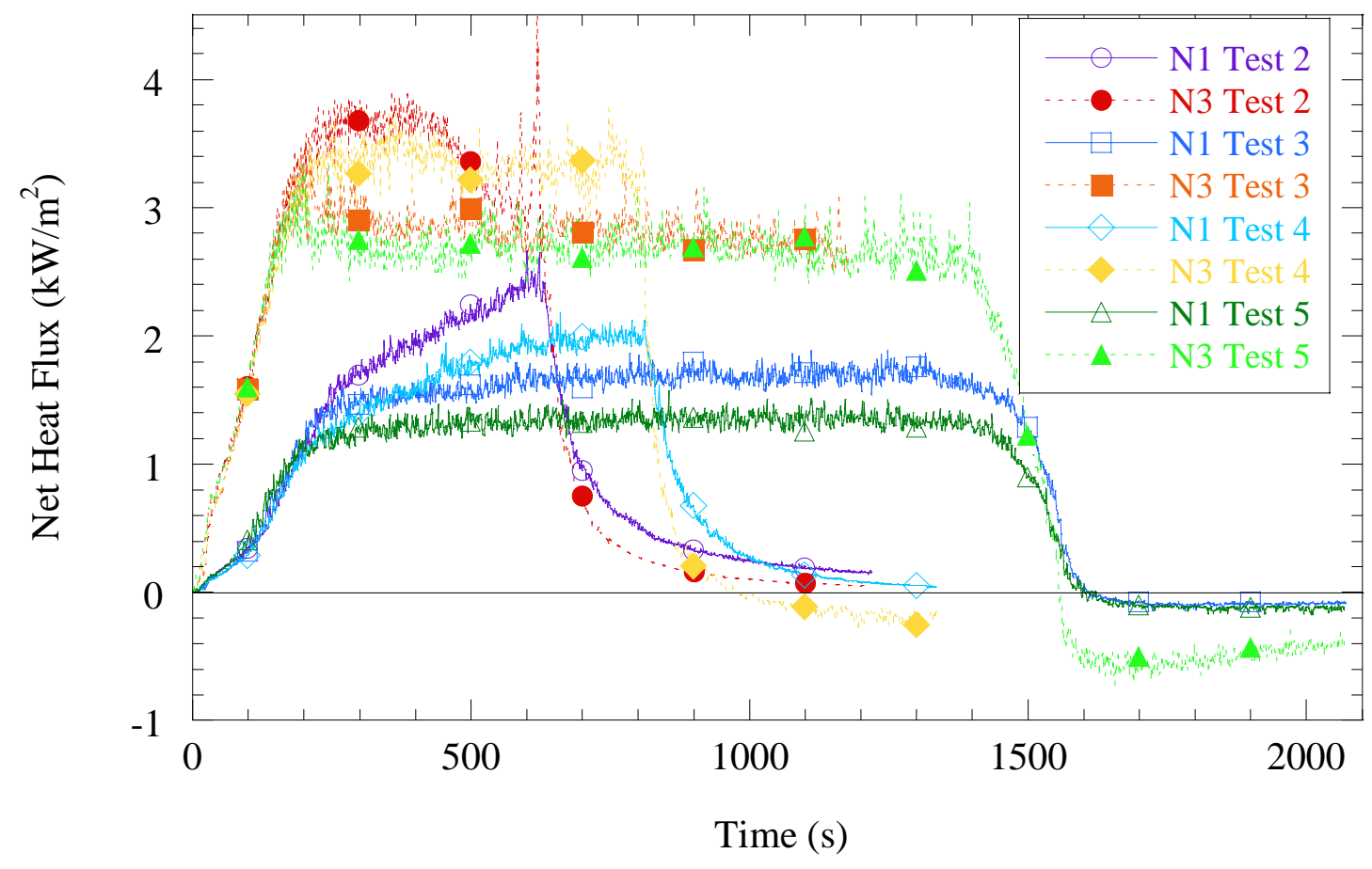

Figure 10-5: Net heat flux to the wall near N1 and N3 gauges versus time for Tests 2 to 5. 


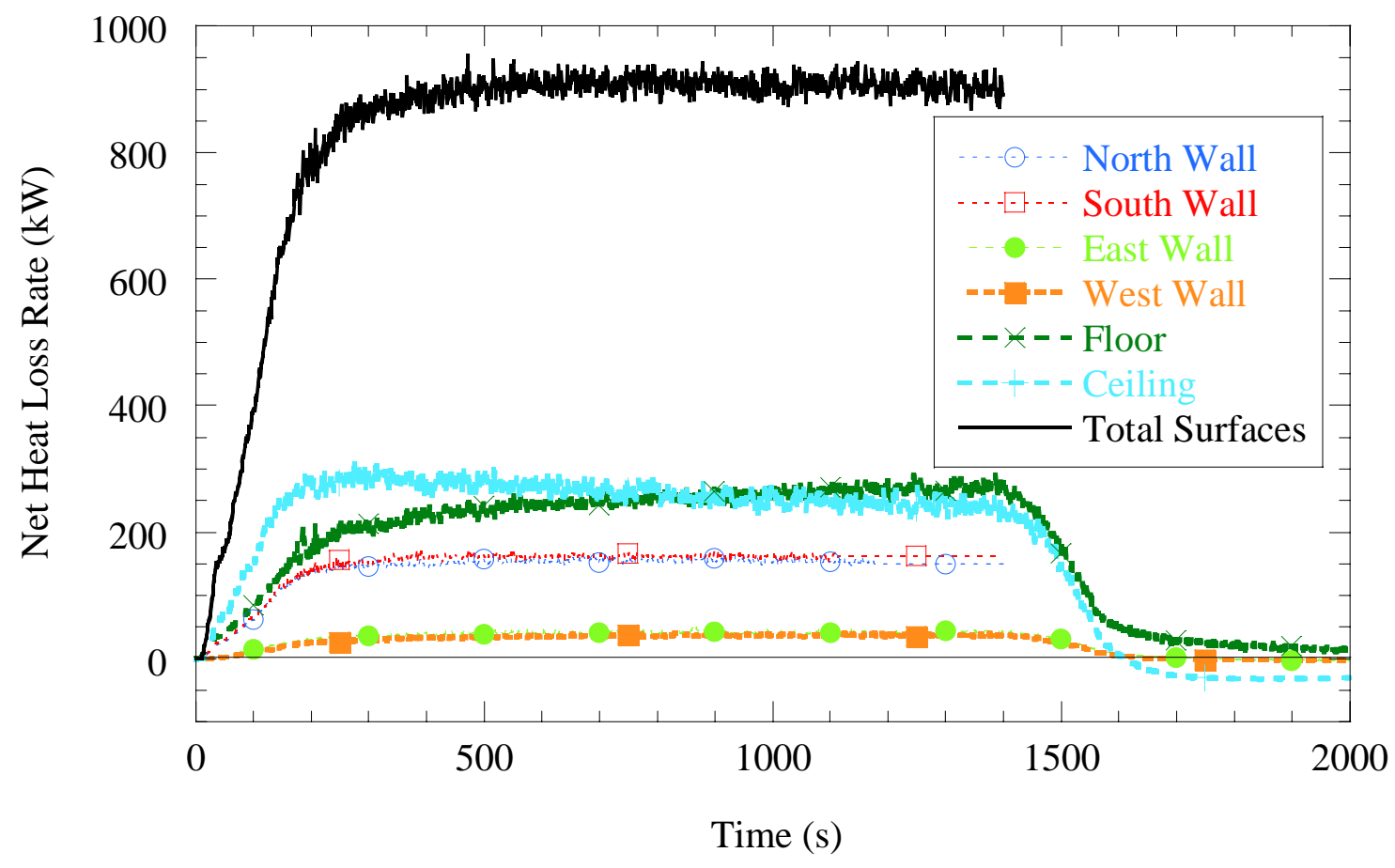

Figure 10-6: Net heat loss rate to individual surfaces and the total sum for all surfaces versus time for Test 3 .

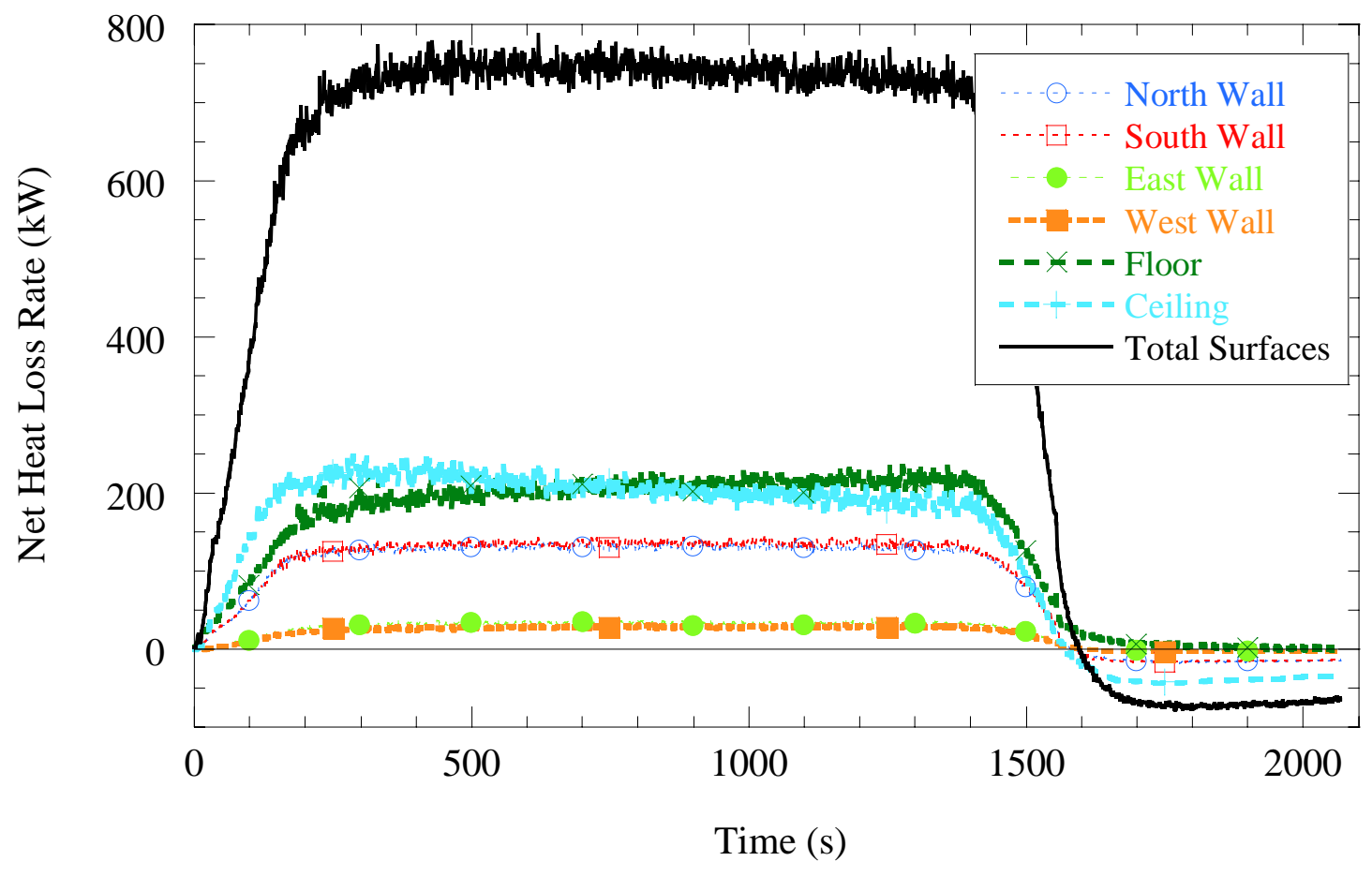

Figure 10-7: Net heat loss rate to individual surfaces and the total sum for all surfaces versus time for Test 5 . 


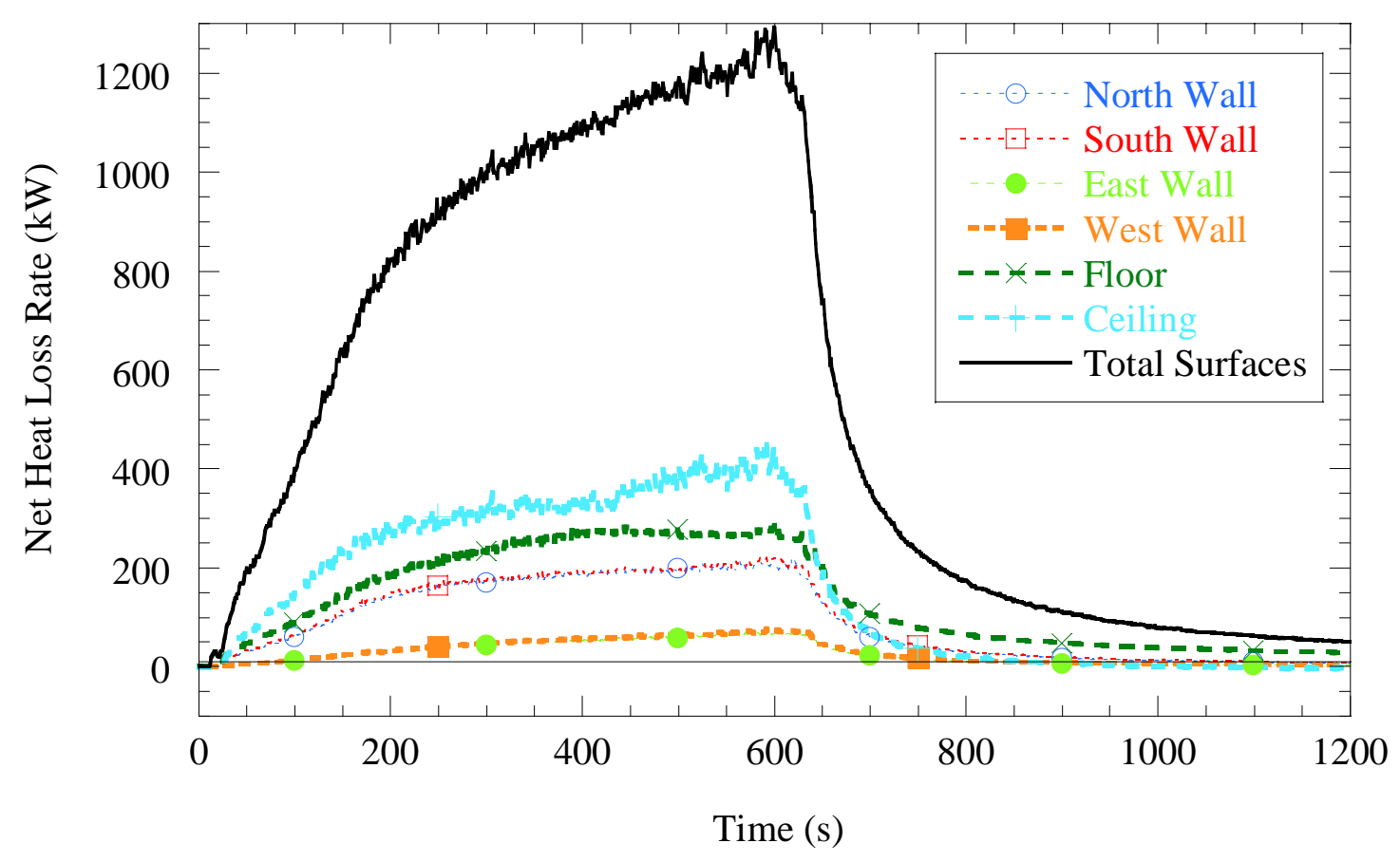

Figure 10-8: Net heat loss rate to individual surfaces and the total sum for all surfaces versus time for Test 2 .

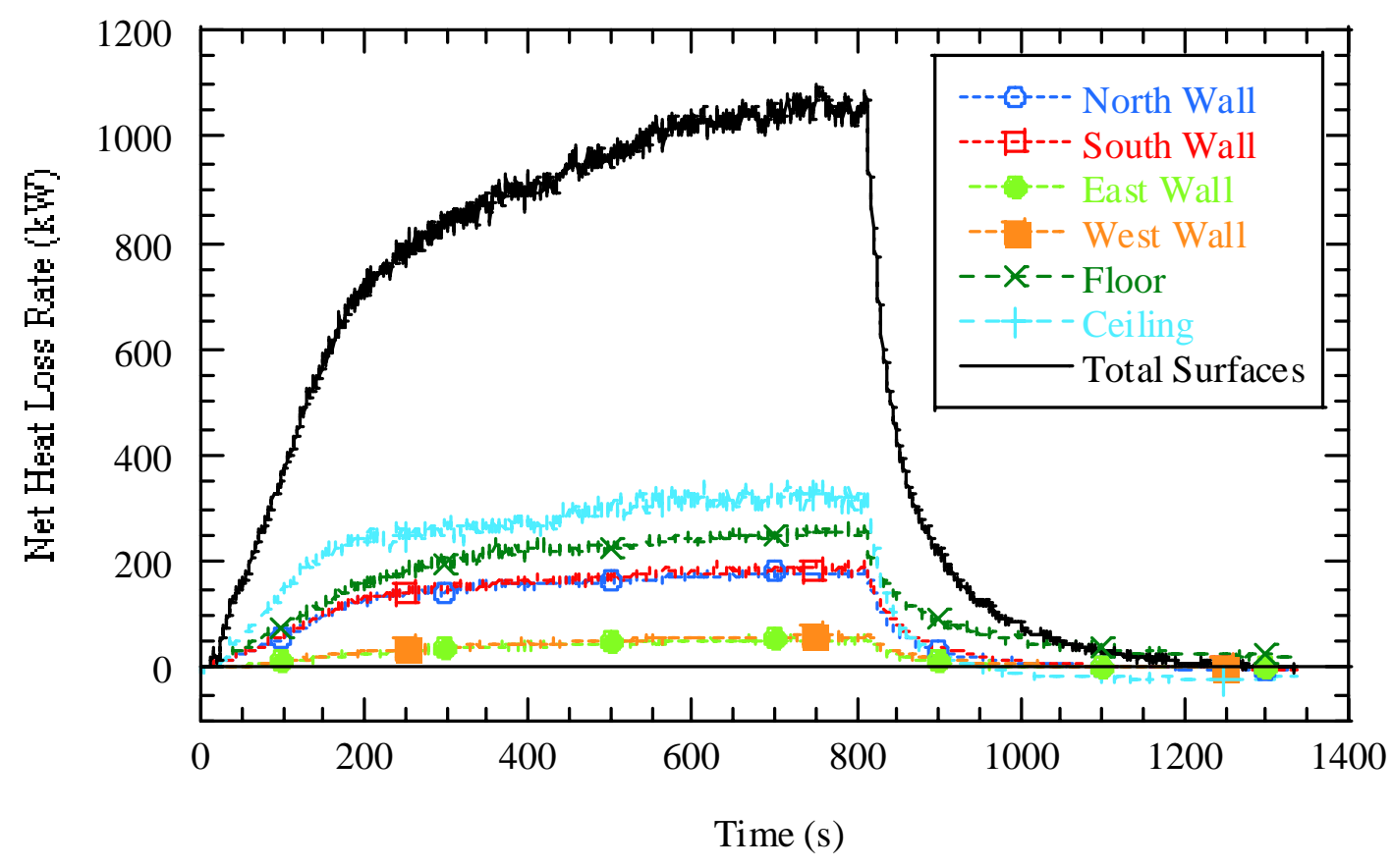

Figure 10-9: Net heat loss rate to individual surfaces and the total sum for all surfaces versus time for Test 4 . 


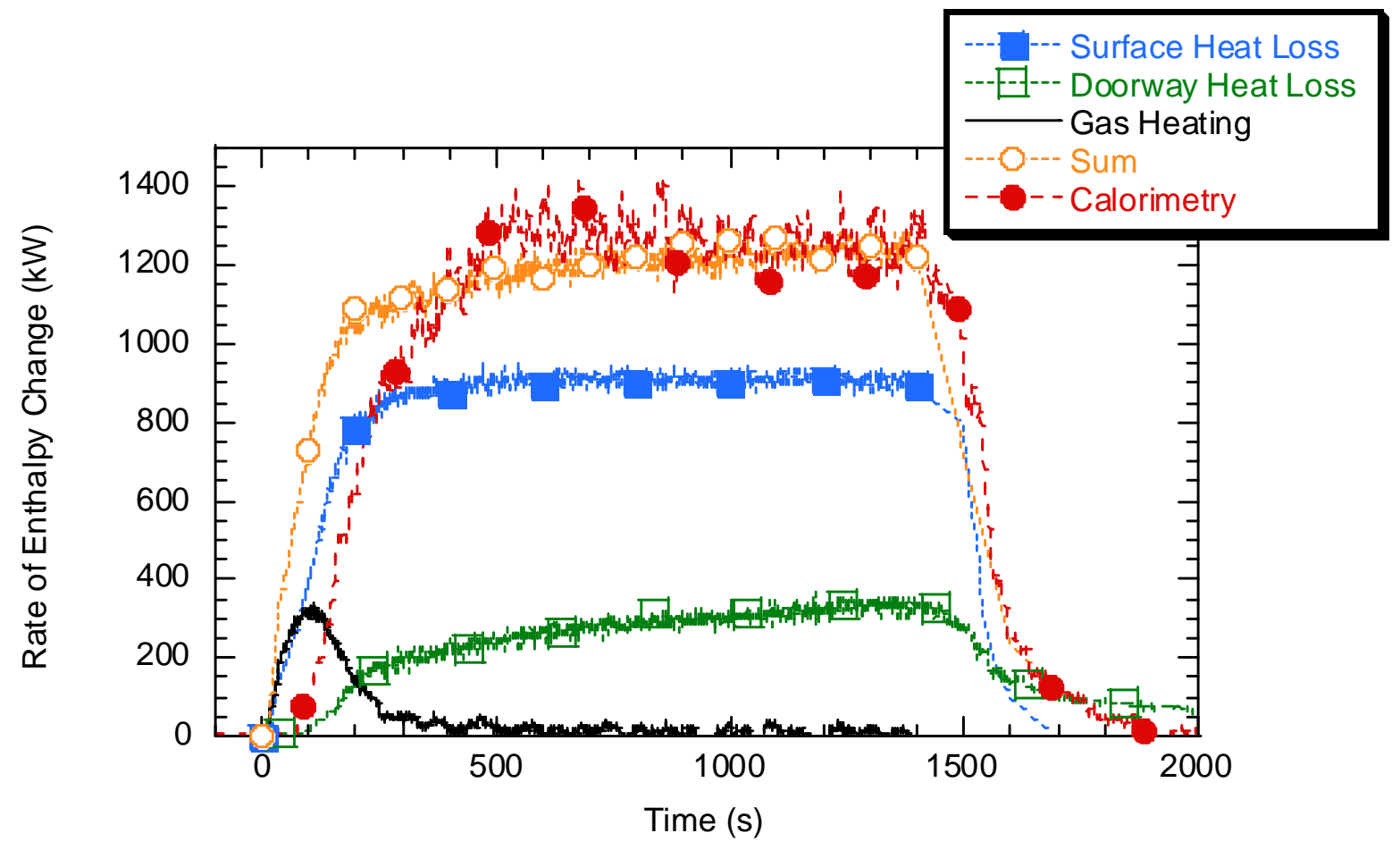

Figure 10-10: Rate of heat loss to the enclosure surfaces, through the doorway, and their sum as a function of time for Test 3.

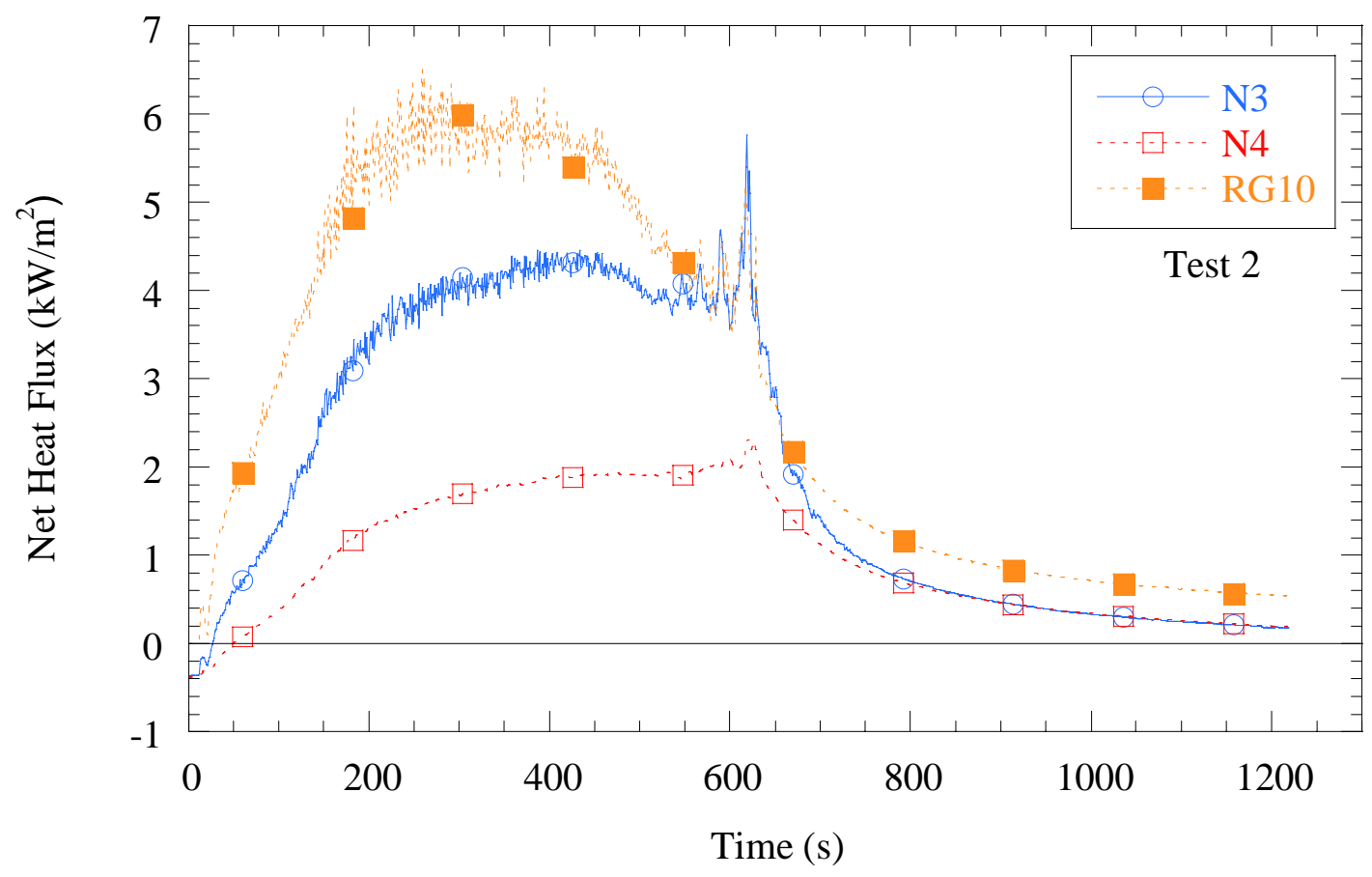

Figure 10-11: Net heat flux comparison of uncooled gauges N3 and N4 with cooled gauge RG10 for Test 2 as a function of time. 


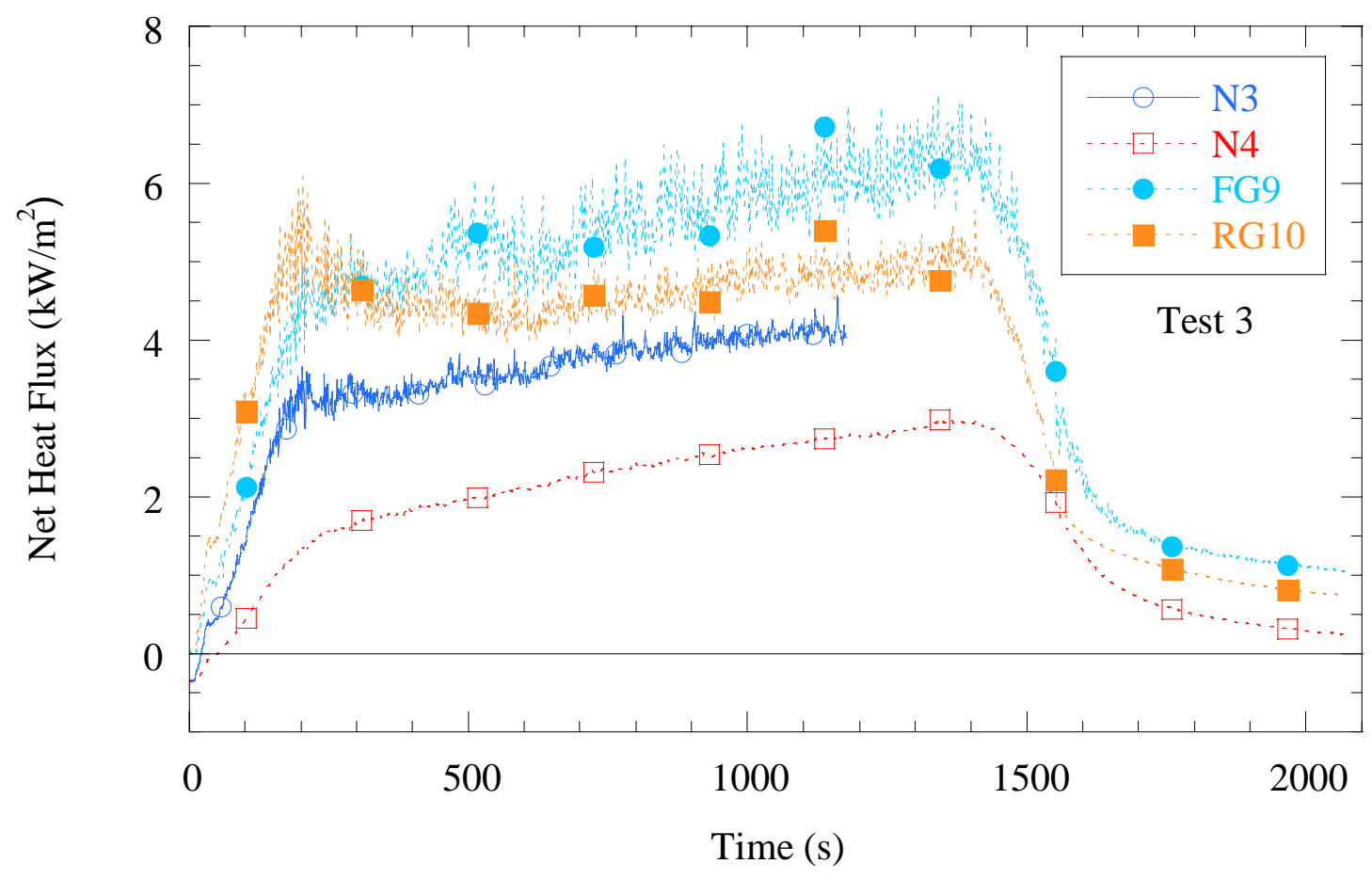

Figure 10-12: Net heat flux comparison of uncooled gauges N3 and N4 with cooled gauges FG9 and RG10 for Test 3 as a function of time.

\subsection{Contact Resistance Between Marinite Boards}

As part of the evaluation of the heat loss to the enclosure boundaries, a study was conducted of the contact resistance between the two $12.7 \mathrm{~mm}$ (0.500 in) marinite boards constituting the walls and ceiling. One purpose for this study was to determine the feasibility of using a simple conduction model for the heat transfer through the walls based on the properties of the marinite and measured temperatures on the inside and outside surfaces. A second objective was to determine the importance of the contact resistance and how much it varied at different locations.

Five locations were selected for making these measurements. The locations were near the heat loss flux gauges designated N4, S3, W3, C1, and C5. Three of these are wall positions and two are ceiling positions. Adjacent to the gauge locations, single layers of doubly thick marinite board were inserted in holes cut in the 2-layer surfaces. These square sections were outfitted with thermocouples on the inside and outside at the centers. Also, thermocouples were installed on the outside of the surfaces in the 2-layer regions near the gauges and opposite the near-gauge inside temperature measurement locations. With these measurements, the conduction of heat through single and 2-layer boards of the same material and local conditions could be compared.

The following are the details of the implementation of these measurements. The square marinite board inserts were $30 \mathrm{~cm}$ (11.8 in) on a side and $25.4 \mathrm{~mm}$ (1.00 in) thick. They replaced two marinite layers of $12.7 \mathrm{~mm}$ (0.500 in) thickness. The outer $12.7 \mathrm{~mm}$ (0.500 in) of the perimeter 
of the inserts was milled down to $12.7 \mathrm{~mm}$ ( 0.500 in) thick and the outer board hole was 25.4 $\mathrm{mm}$ (1.00 in) smaller on each side to create an inset arrangement and flange-like attachment area for screws which also provided a much tighter seal than an insert cut straight through. The edges of the square inserts were located between $10 \mathrm{~cm}$ (3.9 in) and $15 \mathrm{~cm}$ (5.9 in) from the gauge location and also within about $10 \mathrm{~cm}$ (3.9 in) of the interior surface temperature measurement. Variations in these relative locations were necessary in order to accommodate the structural members of the enclosure. The exact $\mathrm{x}, \mathrm{y}$, and $\mathrm{z}$ positions of all the thermocouples are detailed in the list of instrumentation (see Appendix D). The thermocouples were type $\mathrm{K}$ and 24 gauge. Some thermocouple leads were equipped with high temperature insulation while others were not. The insulation characteristics are described elsewhere. Each thermocouple was attached by spring-loading it (bending it near the end so the bead pushed against the surface) and also by lightly peening the bead (tapping it into the surface). Figures 10-13 and 10-14 are photos of an interior and exterior installation, respectively.

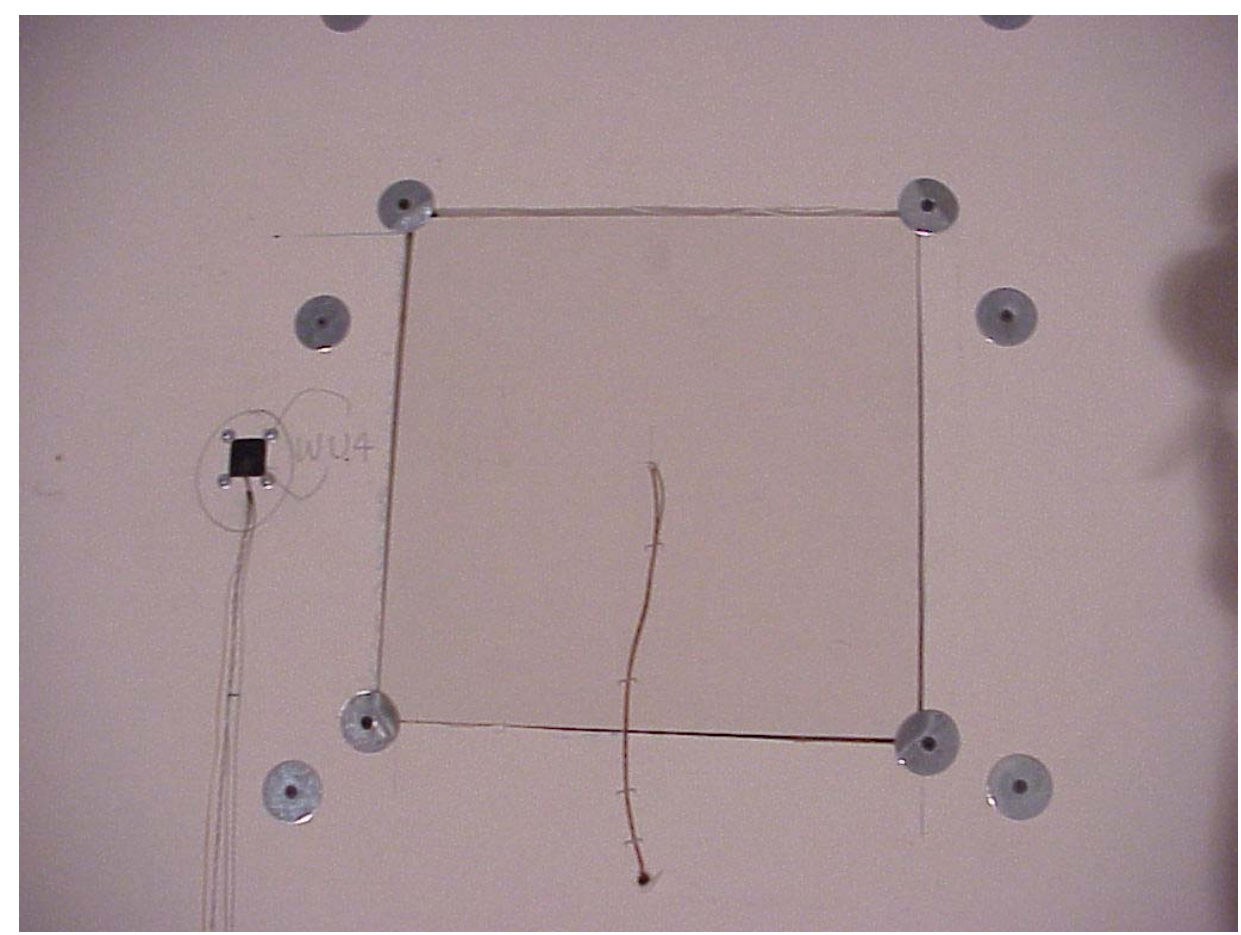

Figure 10-13: Interior installation of marinite thermocouples. 


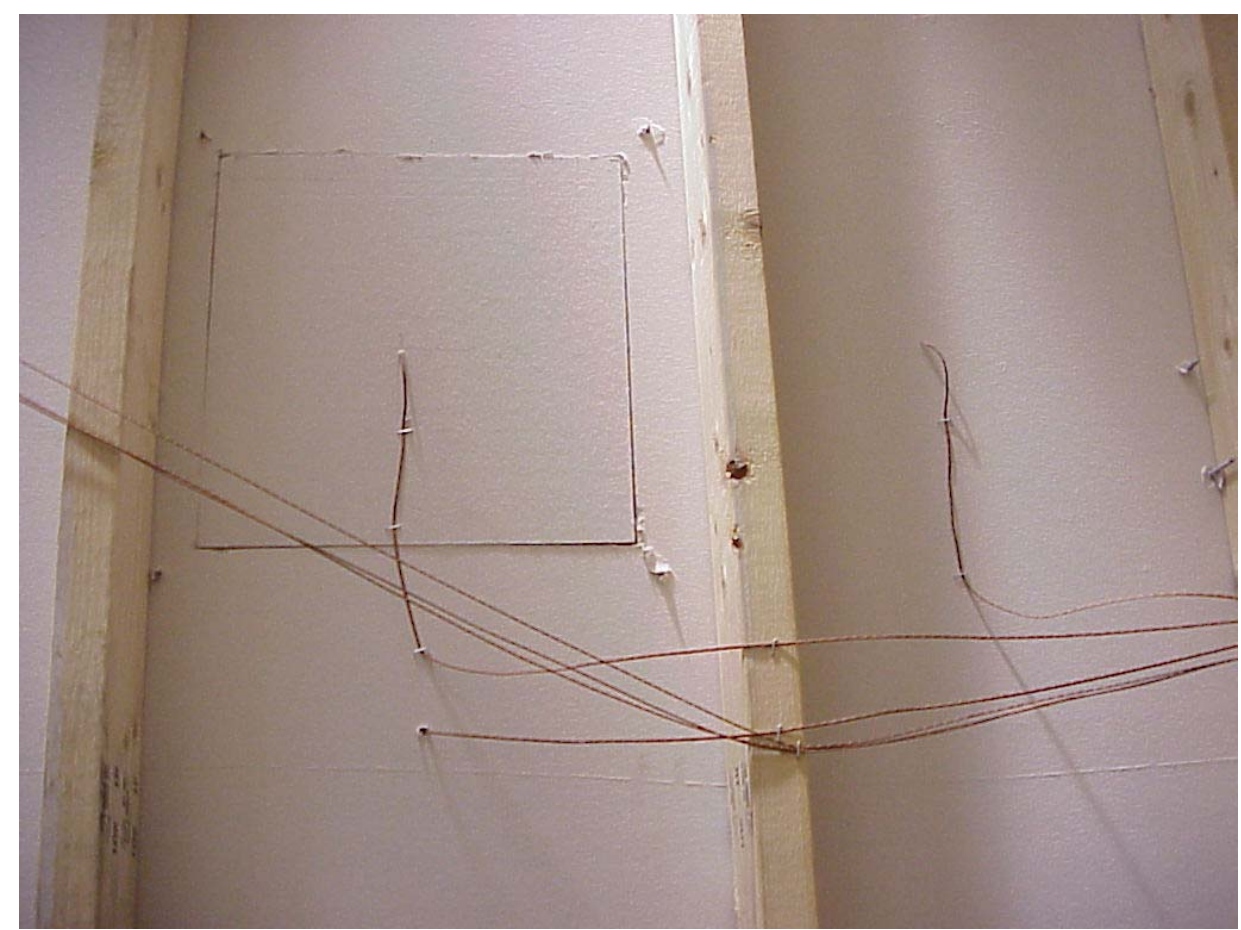

Figure 10-14: Exterior installation of marinite thermocouples.

The uncertainty in the thermocouple measurements was approximately $2{ }^{\circ} \mathrm{C}\left(4^{\circ} \mathrm{F}\right)$ for the manufacturer's calibration. The uncertainty could also have been affected by radiative heating (or cooling), surface contact quality, or other installation and environmental parameters. A conservative uncertainty estimate would use the values used in Table 9-1 for gas temperature measurements.

Figure 10-15 shows the peak temperatures inside and outside the two thicknesses of marinite board at five measurement stations (N3, S3, W3, C1 and C2) for Tests 2 - 4. The data show that significant differences were sometimes present between the interior temperatures. The reasons for the differences may be due to loss of contact between thermocouple bead and compartment surface. For the C-5 installation, however, the differences were probably due to actual temperature gradients associated with non-uniform heating of the ceiling by the fire plume. The exterior temperatures in Figure $10-15$ were often within $5^{\circ} \mathrm{C}$ to $10^{\circ} \mathrm{C}\left(9^{\circ} \mathrm{F}\right.$ to $18^{\circ} \mathrm{F}$ ) which is near the uncertainty limits of the measurements and make differentiating the results for the two thicknesses unreasonable. This type of data could be used in an analysis of heat loss to the compartment surfaces, although the uncertainty in such an analysis would be large due to inconsistencies in the data. 


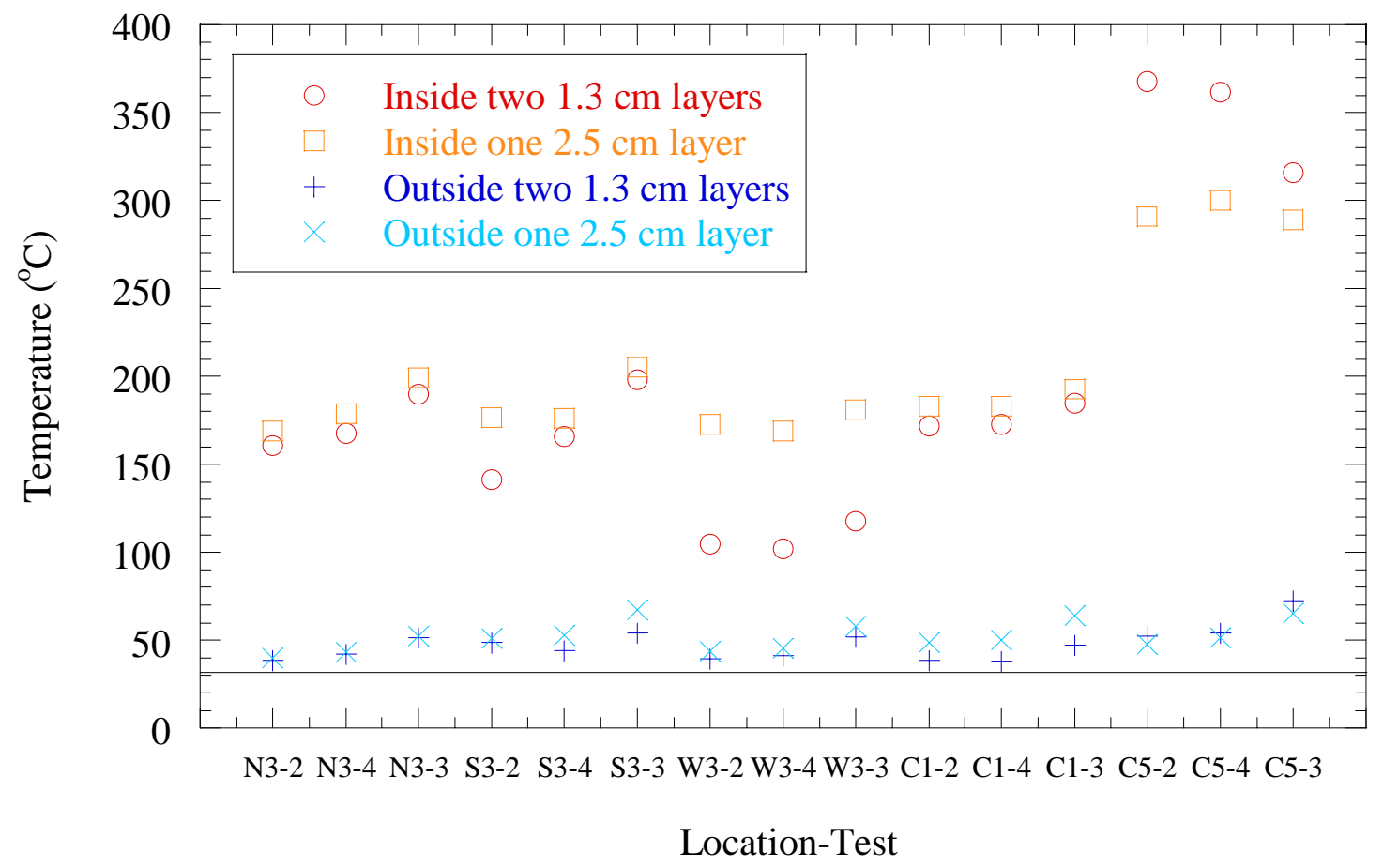

Figure 10-15: Peak marinite temperatures for Tests 2 to 4 at five measurement stations (N3, S3, W3, C1 and C2). 



\section{COMPARTMENT PRESSURE}

The compartment pressure was determined by measuring the differential pressure between the compartment and the ambient environment outside the experimental enclosure. A temperature controlled pressure transducer with a maximum reading of $1.3 \mathrm{kPa}\left(27.2 \mathrm{lb} / \mathrm{ft}^{2}\right)$ was used to measure the differential. The high side of the pressure transducer was located inside the compartment, $10.85 \mathrm{~m}(35.59 \mathrm{ft})$ from the west wall, $0.1 \mathrm{~m}(0.3 \mathrm{ft})$ from the south wall and $0.1 \mathrm{~m}$ $(0.3 \mathrm{ft})$ from the floor, as specified in the test plan. The low pressure side was open to the high bay area. A positive value indicated that the pressure was higher inside the compartment than in the high bay area. The pressure transducer was calibrated using a Microtector Hook Gage type manometer. The combined expanded uncertainty in the compartment pressure measurements was $\pm 40 \mathrm{~Pa}\left( \pm 0.8 \mathrm{lb} / \mathrm{ft}^{2}\right)$.

Table 11-1 summarizes the maximum increase in compartment pressure measured during tests when the door was closed. As expected, the smaller fires resulted in smaller pressure differentials than the larger fires. Operating the ventilation system also resulted in lower pressure differentials compared to similar tests in which the ventilation was off. For tests in which the doorway was open (Tests $3,5,9,14,15,18$; see Table 2-1), the measured pressure difference between the compartment and the test area was much smaller than the uncertainty.

Figure 11-1 shows the increase in compartment pressure for Test 2, in which the door was closed and the ventilation system was not operating. These results are typical for all of the tests conducted with the compartment door closed and no ventilation operating. The pressure inside the compartment increased immediately after the fire began, reaching a peak pressure differential within the first $200 \mathrm{~s}$ of the test and then decreased over the test duration. Figure 11-2 shows a plot of the pressure differential for Test 4, which represents typical results for tests when the doors were closed but the ventilation system was operating. For tests when the ventilation system was on, the pressure inside the compartment increased for approximately $100 \mathrm{~s}$ before the pressure difference returned to near-zero. 
Table 11-1: Maximum compartment pressure differential.

\begin{tabular}{|c|c|c|c|}
\hline $\begin{array}{c}\text { Test } \\
\text { Number }\end{array}$ & $\begin{array}{c}\text { Nominal Heat } \\
\text { Release (MW) }\end{array}$ & Ventilation System & $\begin{array}{c}\text { Maximum Compartment } \\
\text { Pressure Increase (Pa)* }\end{array}$ \\
\hline 1 & 0.35 & Off & 59.7 \\
\hline 2 & 1 & Off & 293.1 \\
\hline 4 & 1 & On & 59.8 \\
\hline 7 & 0.35 & Off & 48.3 \\
\hline 8 & 1 & Off & 193.7 \\
\hline 10 & 1 & On & 243.2 \\
\hline 13 & 2 & Off & 114.8 \\
\hline 16 & 2 & On & 198.1 \\
\hline 17 & 1 & Off & \\
\hline * combined expanded uncertainty $= \pm 40 \mathrm{~Pa}$ & & \\
\hline
\end{tabular}

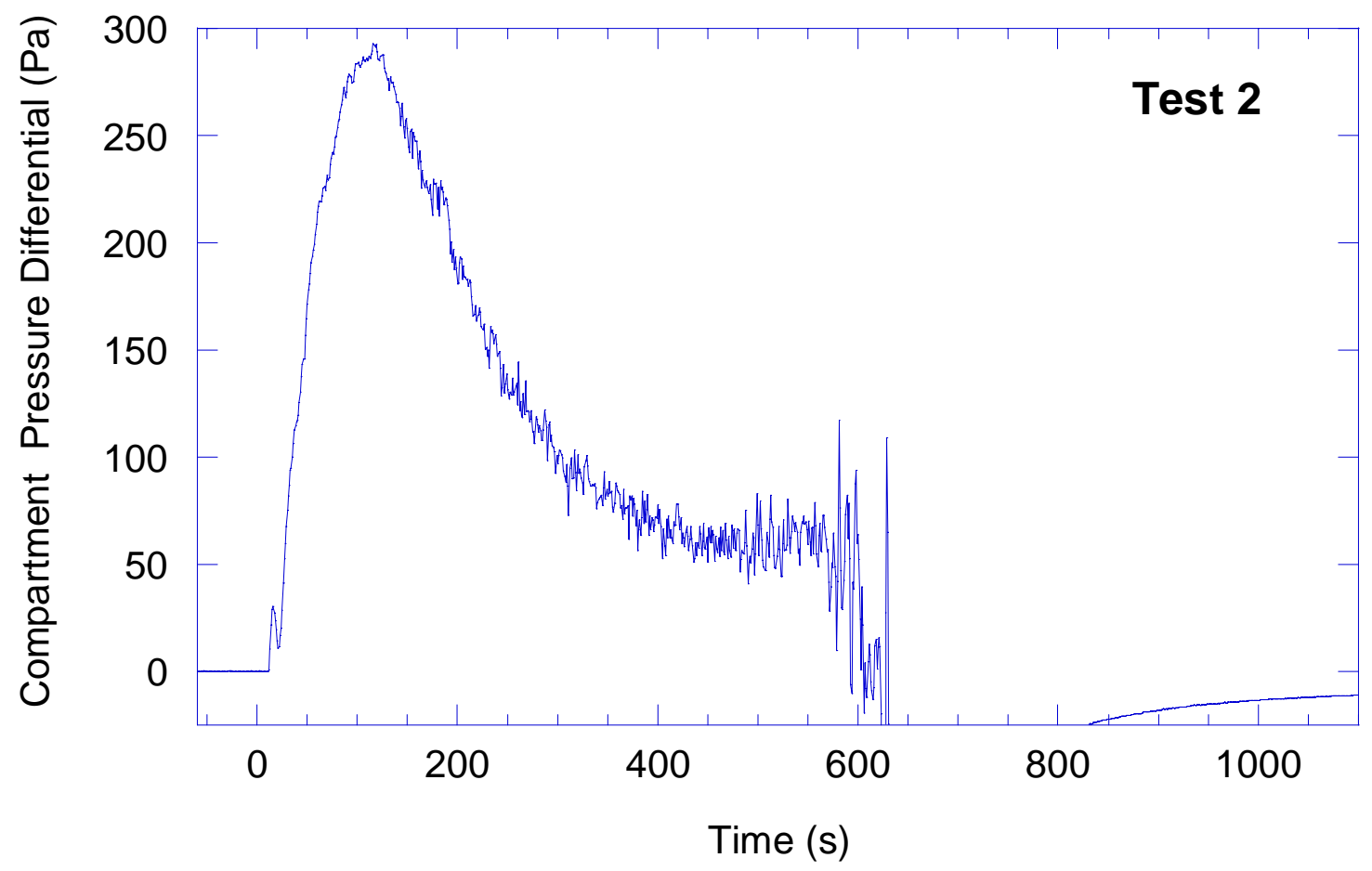

Figure 11-1: Differential pressure for Test 2, door closed, ventilation off. 


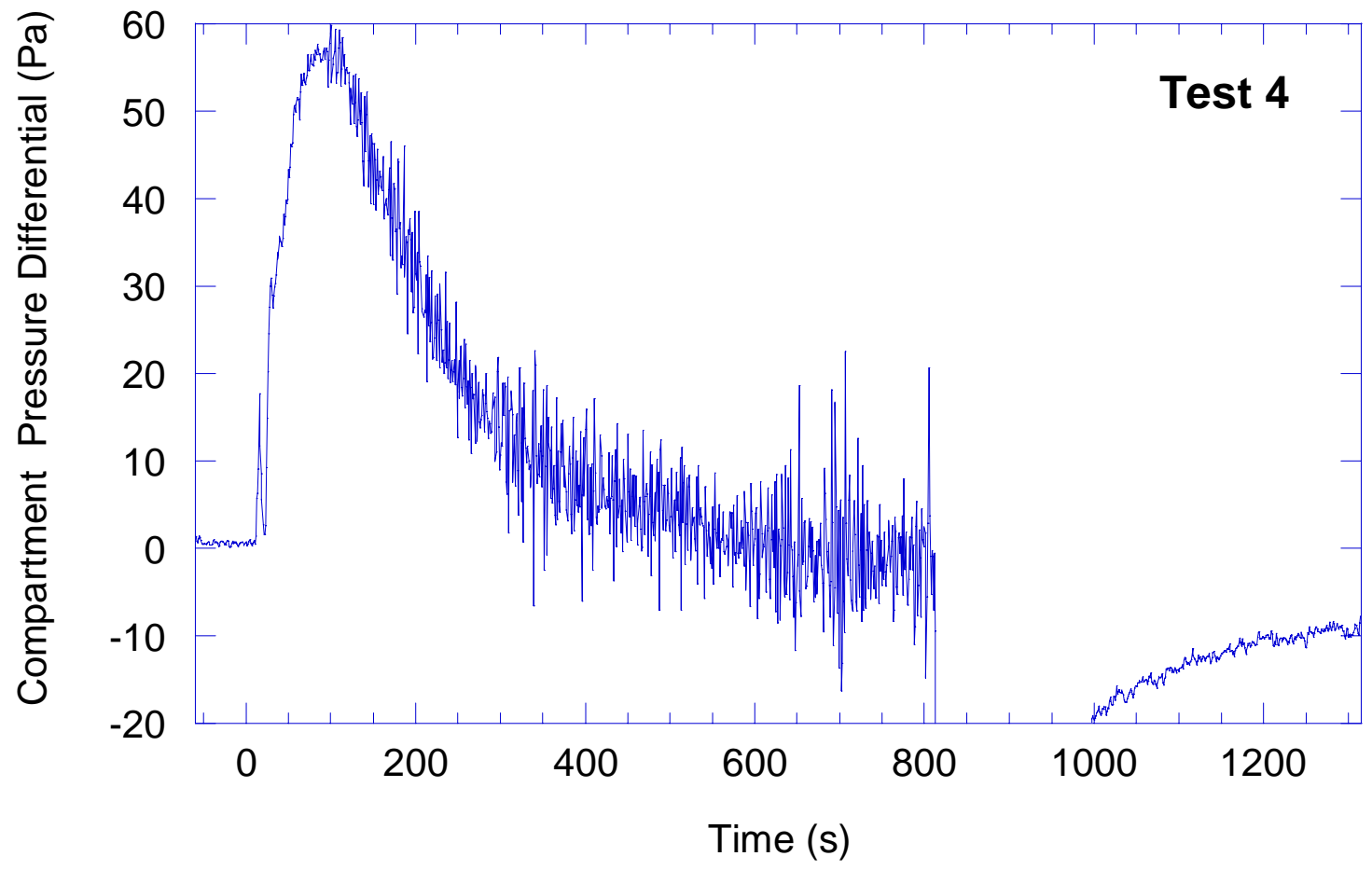

Figure 11-2: Differential pressure for Test 4, door closed, ventilation on. 



\section{SUMMARY AND CONCLUSIONS}

Measurements from the ICFMP Benchmarking and Validation Exercise \#3 are reported here. The accompanying electronic data set includes thirty files, two corresponding to each of the fifteen tests, in tab-delimited column format. The finite instrument response time for several of the measurements such as the HRR, gas concentrations, and the thermocouple temperature measurements, suggest that computer simulations should be time-averaged for appropriate comparison with the data. 



\section{ACKNOWLEDGEMENTS}

This work was co-sponsored by the Nuclear Regulatory Commission (NRC) and NIST. The authors are indebted to Rodney Bryant, Edward Hnetovsky, Jack Lee, Mike Selepak, Roy McLane, Jay McElroy, Tyler Smith, and Lauren DeLauter for providing excellent technical assistance and to Kevin McGrattan and Tom Ohlemiller for helpful discussions regarding experimental design. The authors are grateful to Jason Dreisbach (NRC Project Manager) and Monideep Dey (NRC) for providing support for many aspects of the experiments and this report. 



\section{References}

Bryant, R., Ohlemiller, T., Johnsson, E., Hamins, A., Grove, B., Guthrie, W.F., Maringhides, A., and Mulholland, G., The NIST 3 Megawatt Quantitative Heat Release Rate Facility, NIST Special Publication 1007, National Institute of Standards and Technology. Gaithersburg, MD, December 2003.

Bryant, R., Ohlemiller, T., Johnsson, E., Hamins, A., Grove, B., Guthrie, W.F., Maringhides, A., and Mulholland, G., The NIST 3 Megawatt Quantitative Heat Release Rate Facility Description and Procedures, NISTIR 7052, National Institute of Standards and Technology. Gaithersburg, MD, September 2004.

Bundy, M., NIST, Gaithersburg, MD, personal communication, 2005. (see Appendix J).

DIPPR Data Compilation of Pure Compound Properties Database, V9.02, NIST Standard Reference Data Program \#11, National Institute of Standards and Technology, Gaithersburg MD (1995).

Hamins, A., Donnelly, M., Johnsson, R., and Maranghides, A., Report of Test on Experimental Conditions and Preliminary Results for the International Fire Model Benchmarking and Validation Exercise \#3, NISTIR 7024, June 2003a (see http://techconf.llnl.gov).

Hamins, A., Maranghides, M., and Mulholland, G., “The Global Combustion Behavior of 1 MW to 3 MW Hydrocarbon Spray Fires Burning in an Open Environment," National Institute of Standards and Technology (NIST) Internal report NISTIR 7013, Gaithersburg, MD, June 2003b.

Hamins, A., Johnsson, E., and Donnelly, M., "Energy Balance in a Large Compartment Fire,” Proceedings of the 8th International Association of Fire Safety Science (IAFSS), p. 1616, 2005.

Hanssen, L., Report of Optical Test Data, Optical Physics Division, National Institute of Standards and Technology (NIST), Gaithersburg, MD, March 2003.

Harris, R., personal communication, Fire Research Division, National Institute of Standards and Technology (NIST), 2003. (see Appendix J).

He, Y. P.; Fernando, A.; Luo, M. C., “Determination of interface height from measured parameter profile in enclosure fire experiment,” Fire Safety Journal, 31:19-38, 1998.

Huggett, C., "Estimation of the Rate of Heat Release by Means of Oxygen Consumption,” Journal of Fire and Materials, 12: 61-65 (1980). 
Janssens M., Parker, W. J., “Oxygen Consumption Calorimetry,” Heat Release in Fires, Babrauskas, V., Grayson, S. J., Eds. (E \& FN Spon.), pp. 31-59 London, UK, 1995.

McCaffrey, B.J., and Heskestad, G., "Robust Bidirectional Low-Velocity Probe for Flame and Fire Application,” Combust. Flame, 26:125-127 (1976).

McGrattan, K. B.; Baum, H. R.; Rehm, R. G.; Hamins, A.; Forney, G. P.; Floyd, J. E.; Hostikka, S., "Fire Dynamics Simulator (Version 2) - Technical Reference Guide," National Institute of Standards and Technology (NIST) Internal Report NISTIR 6783, Gaithersburg MD, 44 p. November 2001.

Mulholland, G. and Croarkin, C., "Specific Extinction Coefficient of Flame Generated Smoke," Fire and Materials, 24: 227-230, (2000).

OMEGA, "Comparison of Time Constant vs. Overall Outside Diameter of Bare Thermocouple Wires or Grounded Junction Thermocouples in Air,” The Temperature Handbook, Technical Reference Section, p.Z51, Omega Engineering, Inc., Stamford, CT, 2000.

Parker, W. J., "Calculations of the Heat Release Rate by Oxygen Consumption for Various Applications,” National Bureau of Standards (NBS) Internal report NBSIR 81-2427, 1982.

Pitts, W. M., Braun, E., Peacock, R. D., Mitler, H. E., Johnsson, E. L., Reneke, P. A., and Blevins, L. G., “Temperature Uncertainties for Bare-Bead and Aspirated Thermocouple Measurements in Fire Environments,” National Institute of Standards and Technology (NIST) Internal Report NISTIR 6242, October 1998.

Reid R.C., Prausnitz, J.M., and Poling, B.E., The Properties of Gases and Liquids, $4^{\text {th }}$ Ed. McGraw Hill, NY, 1987.

SFPE Handbook of Fire Protection Engineering, NFPA. Quincy MA, 1990.

Taylor, B.N., and Kuyatt, C.E., "Guidelines for Evaluating and Expressing the Uncertainty of NIST Measurement Results,” National Institute of Standards and Technology (NIST) Technical Note 1297, 1994.

Taylor, R.E., Groot, H., and Ferrier, J., “Thermophysical Properties of PVC, PE and Marinite,” Report TPRL 2958, April 2003. 


\section{A material and optical properties}

\section{A.1 Cables}

Four types of cables were used during the experiments. They are schematically shown in Figures A-1 - A-4 and described in Table A-1. The cables all have a complex morphology and are composed of an outer insulating jacket and three or seven copper conductors each with an insulating jacket. The jacket and insulation material used in the cables are listed in the table. The power cables have a ground wire and many tiny $0.180 \mathrm{~mm}$ (0.007 in) (outer diameter) bristle in portions of the interstitial space that provide additional insulation. To better understand heat transfer within the electrical cables, it is beneficial to have knowledge of their optical and thermal properties.

Table A-1: Cable types used in the experiments.

\begin{tabular}{|l|l|l|l|l|l|l|}
\hline$\#$ & Conductors & AWG & Insulator & Jacket & Ground & Nominal O.D. (cm) \\
\hline 1 & 7 & 14 & XPE $^{1}$ & Hypalon & N & 1 \\
\hline 2 & 7 & 14 & PVC/Nylon & PVC & N & $1.3 \pm 0.1$ \\
\hline 3 & 3 & 6 & XPE & Hypalon & Y & $1.9 \pm 0.1$ \\
\hline 4 & 3 & 6 & PVC/Nylon & PVC & Y & $1.6 \pm 0.1$ \\
\hline $\begin{array}{l}1 \text { flame retarded crosslinked polyethylene } \\
\text { 2 Hypalon is a registered DuPont trademark for chlorosulfinated polyethylene (CSPE) }\end{array}$ \\
\hline
\end{tabular}

Thermal property information including the specific heat $\left(c_{p}\right)$, the thermal diffusivity $(\alpha)$, the thermal conductivity $(\mathrm{K})$ of the PVC and XPE cable insulation has been determined using ASTM E1269 and ASTM E1461 ${ }^{1}$ and are reproduced in Table A-2 below.

Table A-2 also includes the spectrally integrated value of the emissivity $(\varepsilon)$. This was determined by normalizing the measured ambient temperature spectral hemispherical reflectance (from $1.5 \mu \mathrm{m}$ to $19.2 \mu \mathrm{m})^{2}$ with the Planck function at $1200 \mathrm{~K}\left(1700^{\circ} \mathrm{F}\right)$. The spectral range of the data $(1.5 \mu \mathrm{m}$ to $19.2 \mu \mathrm{m})$ covers a major fraction ( 95 \%) of the intensity of a $1200 \mathrm{~K}\left(1700^{\circ} \mathrm{F}\right)$ blackbody.

\footnotetext{
1 Taylor, R.E., Groot, H., and Ferrier, J., “Thermophysical Properties of PVC, PE and Marinite,” Report TPRL 2958, April 2003.

${ }^{2}$ Hanssen, L., Report of Optical Test Data, Optical Physics Division, National Institute of Standards and

Technology (NIST), Gaithersburg, MD, March 2003.
} 


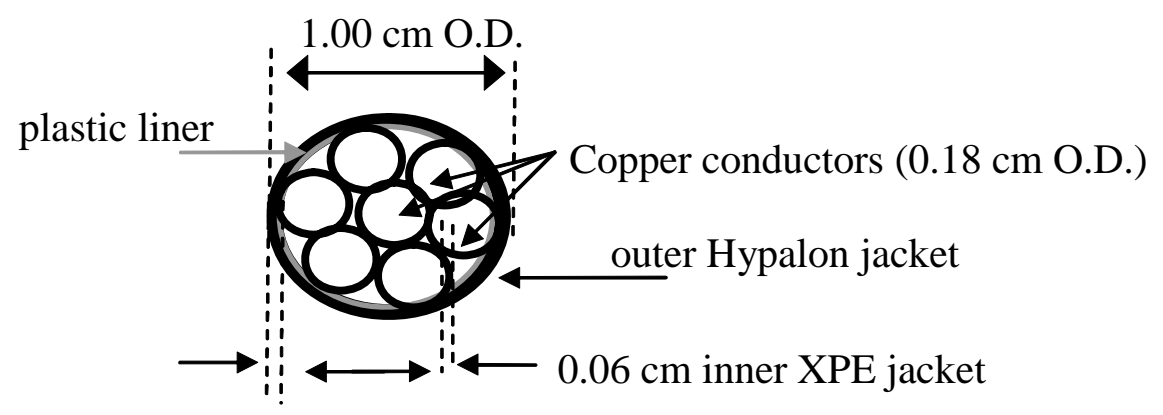

Figure A-1: Morphology of a 7/C \#14 AWG Control Cable (Cable 1 in Table A-1).

$0.14 \mathrm{~cm} \pm 0.01$ outer jacket

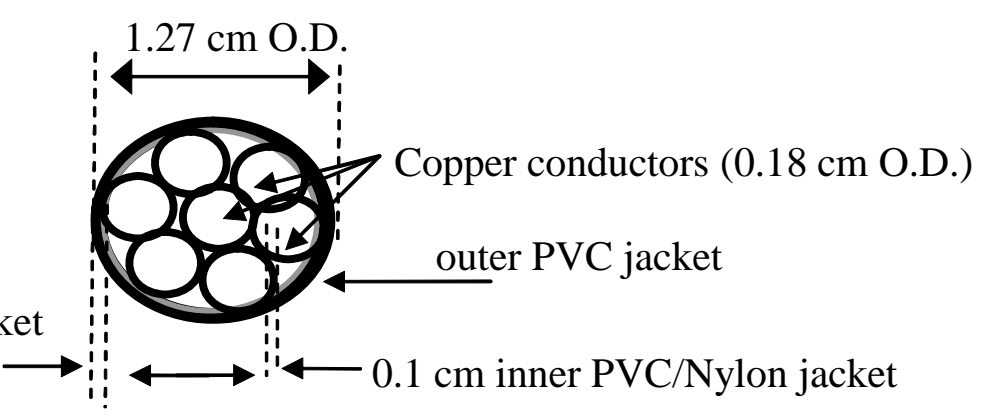

Figure A-2: Morphology of a 7/C \#14 AWG Control Cable (Cable 2 in Table A-1).

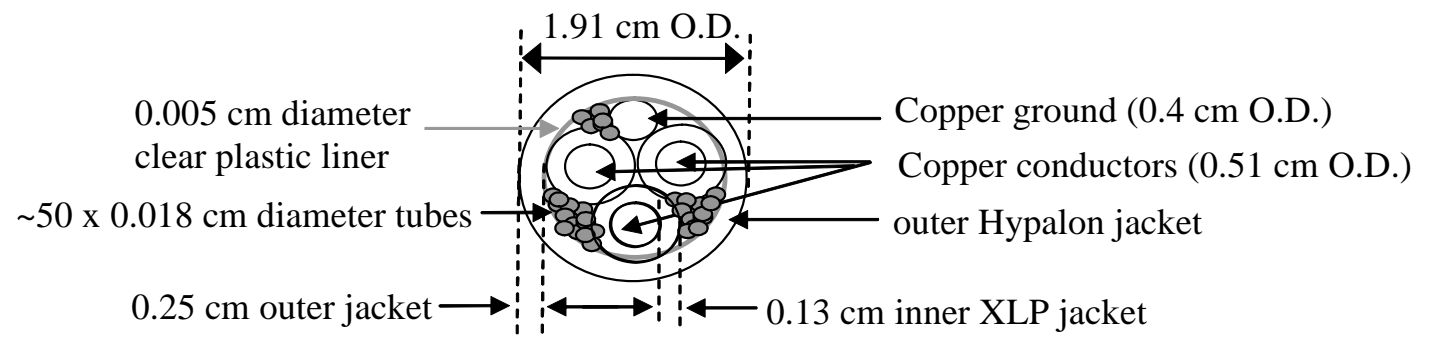

Figure A-3: Morphology of a 3/C \#6 AWG Power Cable (Cable 3 in Table A-1).

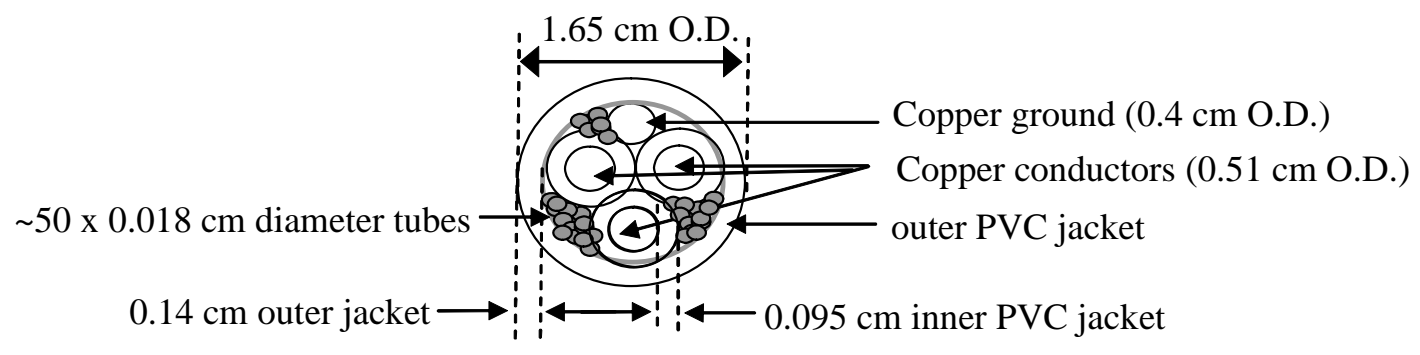

Figure A-4: Morphology of a 3/C \#6 AWG Power Cable (Cable 4 in Table A-1). 
Table A-2: Material and optical properties of the cable materials.

\begin{tabular}{|c|c|c|c|c|}
\hline \multicolumn{5}{|c|}{ Properties of the PVC Cable } \\
\hline $\mathrm{T}\left({ }^{\circ} \mathrm{C}\right)$ & $\mathrm{k}(\mathrm{W} / \mathrm{m} \mathrm{K}) *$ & $\alpha\left(\mathrm{m}^{2} / \mathrm{s}\right) *$ & $\mathrm{c}_{\mathrm{p}}(\mathrm{J} / \mathrm{kg} \mathrm{K}) *$ & $\varepsilon^{* *}$ \\
\hline 23 & 0.192 & $1.08 \times 10^{-7}$ & 1289 & $0.95 \pm 0.01$ \\
\hline 50 & 0.175 & $9.4 \times 10^{-8}$ & 1353 & - \\
\hline 75 & 0.172 & $8.9 \times 10^{-8}$ & 1407 & - \\
\hline 100 & 0.147 & $7.3 \times 10^{-8}$ & 1469 & - \\
\hline 125 & 0.141 & $6.7 \times 10^{-8}$ & 1530 & - \\
\hline 150 & 0.134 & $6.2 \times 10^{-8}$ & 1586 & - \\
\hline \multicolumn{5}{|c|}{ Properties of the XLP Cable } \\
\hline $\mathrm{T}\left({ }^{\circ} \mathrm{C}\right)$ & $\mathrm{k}(\mathrm{W} / \mathrm{m} \mathrm{K}) *$ & $\alpha\left(\mathrm{m}^{2} / \mathrm{s}\right) *$ & $\mathrm{c}_{\mathrm{p}}(\mathrm{J} / \mathrm{kg} \mathrm{K}) *$ & $\varepsilon^{* *}$ \\
\hline 23 & 0.235 & $1.23 \times 10^{-7}$ & 1390 & $0.95 \pm 0.01$ \\
\hline 50 & 0.232 & $1.14 \times 10^{-7}$ & 1476 & - \\
\hline 75 & 0.223 & $1.06 \times 10^{-7}$ & 1526 & - \\
\hline 100 & 0.210 & $9.8 \times 10^{-8}$ & 1560 & - \\
\hline 125 & 0.190 & $8.7 \times 10^{-8}$ & 1585 & - \\
\hline 150 & 0.192 & $8.7 \times 10^{-8}$ & 1607 & - \\
\hline \multicolumn{5}{|c|}{$\begin{array}{l}\text { * Taylor, R.E., Groot, H., and Ferrier, J., Thermophysical Properties of PVC, PE and Marinite, Report } \\
\text { TPRL 2958, April 2003. } \\
\text { ** Hanssen, L., Report of Optical Test Data, Optical Physics Division, National Institute of Standards and } \\
\text { Technology (NIST), Gaithersburg, MD, March } 2003 .\end{array}$} \\
\hline
\end{tabular}

\section{A.2 Properties of Gypsum, Marinite, Feraloy, and the PVC Slab E}

The compartment walls and ceiling were composed of marinite, while the floor was composed of gypsum. The temperature dependent thermal properties and room temperature emissivity of marinite are listed in Table A-3, which were determined in the same manner as the marinite (see Table A-2). The properties of gypsum are listed in Table A-4. The PVC slab (Target E) was made of PVC insulation from the cables used in this study. 
Table A-3: Material and optical properties of marinite.

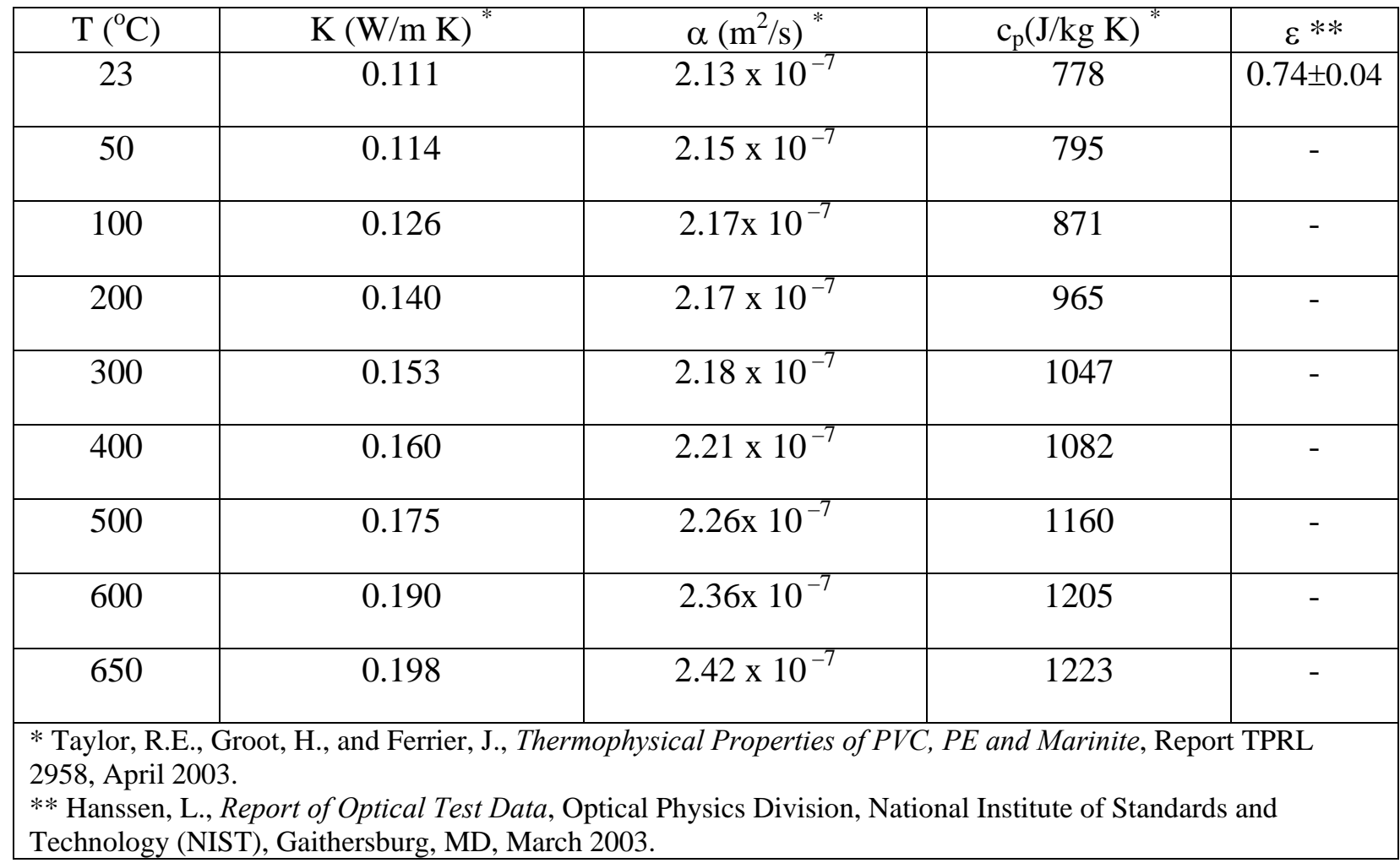

Table A-4: Material and optical properties of feraloy and gypsum at ambient temperature.

\begin{tabular}{|c|c|c|c|c|}
\hline Material & $\mathrm{K}(\mathrm{W} / \mathrm{m} \mathrm{K})$ & $\rho\left(\mathrm{kg} / \mathrm{m}^{3}\right)$ & $\mathrm{C}_{\mathrm{p}}(\mathrm{J} / \mathrm{kg} \mathrm{K})$ & $\varepsilon$ \\
\hline Feraloy* & $78.2^{* *}$ & $787^{* *}$ & $456^{* *}$ & - \\
\hline Gypsum & $0.16^{+}$ & $790^{+}$ & $900^{+}$ & $0.9^{+}$ \\
\hline $\begin{array}{l}* \quad \text { assumed to have properties similar to iron. } \\
\text { ** Smithells Metals Reference Book. } 7^{\text {th }} \text { Ed., Ed.: E.A. Brandes and G.B. Brook, Elsevier, } 1998 . \\
+ \text { from the CFAST database (http://fast.nist.gov/ })\end{array}$
\end{tabular}




\section{B AMBIENT HUMIDITY AND TEMPERATURE DURING TESTING}

A Dickson Humidity and Temperature Logger was used to monitor ambient conditions before each test. Manufacturer instrument accuracy is listed at $\pm 5 \%$ for humidity and $\pm 1{ }^{\circ} \mathrm{C}\left(2{ }^{\circ} \mathrm{F}\right.$ ) in temperature. The measurement results and expanded uncertainty are listed in Table B-1.

Table B-1: Humidity and temperature in the large fire lab.

\begin{tabular}{|l|c|c|}
\hline Test Number & $\begin{array}{c}\text { Ambient Temperature } \\
\left({ }^{\circ} \mathrm{C}\right)\end{array}$ & Humidity (\%) \\
\hline Test 1 & $22 \pm 2$ & $32 \pm 10$ \\
\hline Test 2 & $26 \pm 2$ & $36 \pm 10$ \\
\hline Test 3 & $30 \pm 2$ & $34 \pm 10$ \\
\hline Test 4 & $27 \pm 2$ & $44 \pm 10$ \\
\hline Test 5 & $28 \pm 2$ & $37 \pm 10$ \\
\hline Test 7 & $24 \pm 2$ & $58 \pm 10$ \\
\hline Test 8 & $25 \pm 2$ & $63 \pm 10$ \\
\hline Test 9 & $27 \pm 2$ & $62 \pm 10$ \\
\hline Test 10 & $27 \pm 2$ & $63 \pm 10$ \\
\hline Test 13 & $31 \pm 2$ & $52 \pm 10$ \\
\hline Test 14 & $28 \pm 2$ & $61 \pm 10$ \\
\hline Test 15 & $18 \pm 2$ & $95 \pm 10$ \\
\hline Test 16 & $26 \pm 2$ & $55 \pm 10$ \\
\hline Test 17 & $29 \pm 2$ & $45 \pm 10$ \\
\hline Test 18 & $27 \pm 2$ & $40 \pm 10$ \\
\hline
\end{tabular}





\section{C compartment leakage area}

Experimental enclosure leakage measurements were performed before tests 1, 2, 8 and 13 . The measurements were conducted with a commercial INFLILTEC Model E-3 Blower Door and E3DM4 Digital Blower Door Micro-manometer. Sensor accuracy is rated as $1 \%$ of the measured pressure according to manufacturer literature and $3 \%$ for the leakage area. The measurements consist of using a fan to blow a controlled amount of air into a compartment and then measure the pressure rise. Two fan flow rates are used, creating two values of pressure differential. The digital manometer measures the pressure and the Equivalent Leakage Area $\left(\mathrm{A}_{\text {equiv }}\right)$ at that pressure is then calculated.

The experimental procedure involved closing both the compartment door and the supply and exhaust ventilation ducts. The instrument frame was installed in an access opening and the fan was installed in the frame. A digital manometer was connected. Readings were taken for low and high fan flow, which were then converted to an Equivalent Leakage Area ( $\mathrm{A}_{\text {equiv }}$ ). The calculation involved solving for the two unknowns, the flow coefficient $(C)$ and the flow exponent $(n)$ of the enclosure, from the two measurements and the following equations. Equation C.1 is used to solve for the constant n, then Eq. C.2 is used to solve for the constant C using the existing experimental Pressure and leakage area values. The equivalent leakage area at $50 \mathrm{~Pa}\left(1 \mathrm{lb} / \mathrm{ft}^{2}\right)$ is then determined from Eq. C.2.

$$
\begin{gathered}
\mathrm{A}_{\text {equiv1 }} / \mathrm{A}_{\text {equiv2 }}=\left(\text { Comp. Pressure1/Comp. Pressure 2) }{ }^{\mathrm{n}-0.5}\right. \\
\mathrm{A}_{\text {equiv }}=C(\text { Comp. Pressure })^{\mathrm{n}-0.5}
\end{gathered}
$$

The measured values for Pressure and Leakage area are listed in Table C-1. Table C-2 lists the C and $\mathrm{n}$ coefficient values together with the calculated leakage area at $50 \mathrm{~Pa}\left(1 \mathrm{lb} / \mathrm{ft}^{2}\right)$.

Table C-1: Measured Pressure, Leakage Area and Air Flow Rate.

\begin{tabular}{|l|l|l|}
\hline Test & Pressure $(\mathrm{Pa})$ & Leakage Area $\left(\mathrm{cm}^{2}\right)$ \\
\hline 1 & 118 & 710 \\
\hline 1 & 210 & 800 \\
\hline 2 & 115 & 710 \\
\hline 2 & 215 & 826 \\
\hline 7 & 107 & 903 \\
\hline 7 & 192 & 1084 \\
\hline 8 & 114 & 832 \\
\hline 8 & 200 & 987 \\
\hline 13 & 105 & 1019 \\
\hline 13 & 180 & 1110 \\
\hline
\end{tabular}


Table C-2: Calculated $C$ and $n$ values, compartment equivalent leakage area and expanded uncertainty.

\begin{tabular}{|l|l|l|l|}
\hline Test & $\begin{array}{l}\text { Flow Coefficient } \\
C\end{array}$ & $\begin{array}{l}\text { Flow Exponent } \\
n\end{array}$ & $\begin{array}{l}\text { Equivalent Leakage } \\
\text { Area }\left(\mathrm{cm}^{2}\right) \text { at 50 Pa }\end{array}$ \\
\hline 1 & 263 & 0.708 & $593 \pm 42$ \\
\hline 2 & 223 & 0.744 & $580 \pm 40$ \\
\hline 7 & 210 & 0.812 & $712 \pm 50$ \\
\hline 8 & 198 & 0.803 & $645 \pm 45$ \\
\hline 13 & 450 & 0.657 & $833 \pm 58$ \\
\hline
\end{tabular}




\section{$D$ format of the electronic data}

The experimental data associated with this report is available on a companion set of thirty electronic files; fifteen pairs of files, two for each test. The data are electronically stored in tabdelimited column format. The columns are labeled and ordered in an identical manner for each of the fifteen tests. Some columns in the files do not contain data, either because no measurement was made or because an instrument was inoperative. In the case when a measurement was not made (e.g., when the ventilation and doorway were closed, no calorimetry HRR measurement was made), the symbol "999" is inserted in the first row of that column and the rest of the rows are filled with zeros. If an instrument was not functioning, the data columns are treated in the same manner. Non-functioning instruments are specified in Appendix E of this report.

The data were acquired at $1 \mathrm{~Hz}$, but are presented as average values over a $10 \mathrm{~s}$ interval. Time averaging the data over too long a period may cause loss of legitimate information. The selection of a $10 \mathrm{~s}$ averaging period is a compromise, but appears to be reasonable considering the time response of the instrumentation used in the experiments.

Tables D-1 and D-2 describe the electronic data files including a list of the assigned designation for each measurement and its units. The tables also contain information on the measurement type, the $(\mathrm{X}, \mathrm{Y}, \mathrm{Z})$ location of the instrument, and expressly for NIST use - the original NIST data channel number. For each data file, the data begins at time equal to $-60 \mathrm{~s}$, which provides $1 \mathrm{~min}$ of representative background information.

The format of the first file for each test is shown in Table D-1 and is comprised of 247 columns of data. The first column of data represents time during the experiment. Time equal to zero is the time of the initiation of the fuel spray. Ignition of the fuel spray typically occurred within a few seconds of time zero, but on occasion took as long as $10 \mathrm{~s}$ to $15 \mathrm{~s}$. Columns 2 to 37 represent uncooled heat flux gauges mounted on the surface of the compartment. Columns 38 to 107 represent thermocouples mounted on the seven thermocouple trees. Columns 108 to 179 represent wall-mounted thermocouples, either mounted directly on the compartment surface (designated by a “-2” suffix) or on the surface-mounted flux gauges (designated by a “-1” suffix). Columns 180 to 217 represent thermocouples mounted on and inside the insulation of the horizontal and vertical cables and the junction box. Columns 218 and 219 represent thermocouples near the ceiling mounted aspirated thermocouples. Columns 220 to 224 represent gas and smoke concentration measurements. Columns 225 to 234 represent heat flux to the target gauges near the cables. Column 235 is the differential pressure between inside of the compartment and the environment outside of the compartment. Columns 236 to 254 represent calculated information on the energy and average mass flow through the compartment openings including the supply and exhaust ventilation ducts and the door, heat losses to the walls, the HRR measured by calorimetry, and the layer height and average temperatures. 
The format of the second file for each test is shown in Table D-2. The format follows the first file. The first column of data represents time during the experiment. Columns 2 to 28 represent the thermocouples associated with the bi-directional probes in the doorway, the supply duct and on the ceiling. Columns 29 to 32 represent thermocouples in the exhaust. Columns 33 to 36 represent aspirated thermocouples in the doorway and the exhaust. Columns 37 to 51 represent the thermocouples mounted near, on, and outside the $2.5 \mathrm{~cm}$ (1.0 in) thick, $30.0 \mathrm{~cm} \mathrm{x} 30.0 \mathrm{~cm}$ (11.8 in x 11.8 in) wide single layer of marinite installed at five locations throughout the compartment. Columns 52 to 69 represent velocities measured by bi-directional probes in the doorway, supply, exhaust and near the ceiling.

Table D-1: Instrument channel number, designation, units, and location.

\begin{tabular}{|c|c|c|c|c|c|c|}
\hline \multirow[b]{2}{*}{ Designation } & \multicolumn{3}{|c|}{$\begin{array}{l}\text { NIST } \\
\text { data }\end{array}$} & \multicolumn{3}{|c|}{ Location } \\
\hline & Column & hannel & Units & $\mathbf{X}(\mathbf{m})$ & $\mathbf{Y}(\mathbf{m})$ & $\mathrm{Z}$ (m) \\
\hline Time & 1 & 1 & s & - & - & - \\
\hline $\begin{array}{l}\text { Wall Flux Gauges }{ }^{1} \\
\text { N,S,E,W,Ceiling,Floor }\end{array}$ & & & $\mathrm{kW} / \mathrm{m}^{2}$ & & & \\
\hline North U-1 & 2 & 32 & $\mathrm{~kW} / \mathrm{m}^{2}$ & 3.91 & 7.04 & 1.49 \\
\hline North U-2 & 3 & 33 & $\mathrm{~kW} / \mathrm{m}^{2}$ & 3.91 & 7.04 & 3.82 \\
\hline North U-3 & 4 & 34 & $\mathrm{~kW} / \mathrm{m}^{2}$ & 9.73 & 7.04 & 1.86 \\
\hline North U-4 & 5 & 35 & $\mathrm{~kW} / \mathrm{m}^{2}$ & 12.15 & 7.04 & 1.86 \\
\hline North U-5 & 6 & 36 & $\mathrm{~kW} / \mathrm{m}^{2}$ & 17.79 & 7.04 & 1.49 \\
\hline North U-6 & 7 & 37 & $\mathrm{~kW} / \mathrm{m}^{2}$ & 17.79 & 7.04 & 3.82 \\
\hline South U-1 & 8 & 38 & $\mathrm{~kW} / \mathrm{m}^{2}$ & 3.91 & 0 & 1.49 \\
\hline South U-2 & 9 & 39 & $\mathrm{~kW} / \mathrm{m}^{2}$ & 3.91 & 0 & 3.82 \\
\hline South U-3 & 10 & 40 & $\mathrm{~kW} / \mathrm{m}^{2}$ & 9.73 & 0 & 1.86 \\
\hline South U-4 & 11 & 41 & $\mathrm{~kW} / \mathrm{m}^{2}$ & 12.15 & 0 & 1.86 \\
\hline South U-5 & 12 & 42 & $\mathrm{~kW} / \mathrm{m}^{2}$ & 17.79 & 0 & 1.49 \\
\hline South U-6 & 13 & 43 & $\mathrm{~kW} / \mathrm{m}^{2}$ & 17.79 & 0 & 3.82 \\
\hline East U-1 & 14 & 337 & $\mathrm{~kW} / \mathrm{m}^{2}$ & 21.66 & 1.59 & 1.12 \\
\hline East U-2 & 15 & 338 & $\mathrm{~kW} / \mathrm{m}^{2}$ & 21.66 & 1.59 & 2.42 \\
\hline East U-3 & 16 & 339 & $\mathrm{~kW} / \mathrm{m}^{2}$ & 21.66 & 5.76 & 1.12 \\
\hline East U-4 & 17 & 340 & $\mathrm{~kW} / \mathrm{m}^{2}$ & 21.66 & 5.76 & 2.42 \\
\hline West U-1 & 18 & 44 & $\mathrm{~kW} / \mathrm{m}^{2}$ & 0 & 1.59 & 1.12 \\
\hline West U-2 & 19 & 45 & $\mathrm{~kW} / \mathrm{m}^{2}$ & 0 & 1.59 & 2.42 \\
\hline West U-3 & 20 & 46 & $\mathrm{~kW} / \mathrm{m}^{2}$ & 0 & 5.76 & 1.12 \\
\hline West U-4 & 21 & 47 & $\mathrm{~kW} / \mathrm{m}^{2}$ & 0 & 5.76 & 2.42 \\
\hline Floor U-1 & 22 & 48 & $\mathrm{~kW} / \mathrm{m}^{2}$ & 3.04 & 3.58 & 0 \\
\hline Floor U-2 & 23 & 49 & $\mathrm{~kW} / \mathrm{m}^{2}$ & 9.11 & 1.99 & 0 \\
\hline Floor U-3 & 24 & 50 & $\mathrm{~kW} / \mathrm{m}^{2}$ & 9.11 & 5.96 & 0 \\
\hline Floor U-4 & 25 & 51 & $\mathrm{~kW} / \mathrm{m}^{2}$ & 10.85 & 2.38 & 0 \\
\hline Floor U-5 & 26 & 52 & $\mathrm{~kW} / \mathrm{m}^{2}$ & 10.85 & 5.16 & 0.10 \\
\hline Floor U-6 & 27 & 53 & $\mathrm{~kW} / \mathrm{m}^{2}$ & 13.02 & 1.99 & 0 \\
\hline Floor U-7 & 28 & 54 & $\mathrm{~kW} / \mathrm{m}^{2}$ & 13.02 & 5.96 & 0 \\
\hline Floor U-8 & 29 & 55 & $\mathrm{~kW} / \mathrm{m}^{2}$ & 18.66 & 3.58 & 0 \\
\hline Ceiling U-1 & 30 & 56 & $\mathrm{~kW} / \mathrm{m}^{2}$ & 3.04 & 3.58 & 3.82 \\
\hline
\end{tabular}




\begin{tabular}{|c|c|c|c|c|c|c|}
\hline \multirow[b]{2}{*}{ Designation } & \multicolumn{3}{|c|}{ NIST } & \multicolumn{3}{|c|}{ Location } \\
\hline & Column & $\begin{array}{l}\text { data } \\
\text { hannel }\end{array}$ & Units & $X(\mathbf{m})$ & $\mathbf{Y}(\mathbf{m})$ & $\mathrm{Z}(\mathbf{m})$ \\
\hline Ceiling C-2 & 31 & 57 & $\mathrm{~kW} / \mathrm{m}^{2}$ & 9.11 & 1.99 & 3.82 \\
\hline Ceiling C-3 & 32 & 58 & $\mathrm{~kW} / \mathrm{m}^{2}$ & 9.11 & 5.96 & 3.82 \\
\hline Ceiling C-4 & 33 & 59 & $\mathrm{~kW} / \mathrm{m}^{2}$ & 10.85 & 2.38 & 3.82 \\
\hline Ceiling C-5 & 34 & 60 & $\mathrm{~kW} / \mathrm{m}^{2}$ & 10.85 & 5.16 & 3.82 \\
\hline Ceiling C-6 & 35 & 61 & $\mathrm{~kW} / \mathrm{m}^{2}$ & 13.02 & 1.99 & 3.82 \\
\hline Ceiling C-7 & 36 & 62 & $\mathrm{~kW} / \mathrm{m}^{2}$ & 13.02 & 5.96 & 3.82 \\
\hline Ceiling U-8 & 37 & 63 & $\mathrm{~kW} / \mathrm{m}^{2}$ & 18.66 & 3.58 & 3.82 \\
\hline Thermocouple Trees & & & ${ }^{\circ} \mathrm{C}$ & & & \\
\hline Tree 1-1 & 38 & 64 & ${ }^{\circ} \mathrm{C}$ & 5 & 3.58 & 0.35 \\
\hline Tree $1-2$ & 39 & 65 & ${ }^{\circ} \mathrm{C}$ & 5 & 3.58 & 0.70 \\
\hline Tree 1-3 & 40 & 66 & ${ }^{\circ} \mathrm{C}$ & 5 & 3.58 & 1.05 \\
\hline Tree 1-4 & 41 & 67 & ${ }^{\circ} \mathrm{C}$ & 5 & 3.58 & 1.40 \\
\hline Tree 1-5 & 42 & 68 & ${ }^{\circ} \mathrm{C}$ & 5 & 3.58 & 1.75 \\
\hline Tree 1-6 & 43 & 69 & ${ }^{\circ} \mathrm{C}$ & 5 & 3.58 & 2.10 \\
\hline Tree 1-7 & 44 & 70 & ${ }^{\circ} \mathrm{C}$ & 5 & 3.58 & 2.45 \\
\hline Tree 1-8 & 45 & 71 & ${ }^{\circ} \mathrm{C}$ & 5 & 3.58 & 2.80 \\
\hline Tree 1-9 & 46 & 72 & ${ }^{\circ} \mathrm{C}$ & 5 & 3.58 & 3.15 \\
\hline Tree $1-10$ & 47 & 73 & ${ }^{\circ} \mathrm{C}$ & 5 & 3.58 & 3.50 \\
\hline Tree 2-1 & 48 & 74 & ${ }^{\circ} \mathrm{C}$ & 10.85 & 6.85 & 0.35 \\
\hline Tree 2-2 & 49 & 75 & ${ }^{\circ} \mathrm{C}$ & 10.85 & 6.85 & 0.70 \\
\hline Tree 2-3 & 50 & 76 & ${ }^{\circ} \mathrm{C}$ & 10.85 & 6.85 & 1.05 \\
\hline Tree 2-4 & 51 & 77 & ${ }^{\circ} \mathrm{C}$ & 10.85 & 6.85 & 1.40 \\
\hline Tree 2-5 & 52 & 78 & ${ }^{\circ} \mathrm{C}$ & 10.85 & 6.85 & 1.75 \\
\hline Tree 2-6 & 53 & 79 & ${ }^{\circ} \mathrm{C}$ & 10.85 & 6.85 & 2.10 \\
\hline Tree 2-7 & 54 & 80 & ${ }^{\circ} \mathrm{C}$ & 10.85 & 6.85 & 2.45 \\
\hline Tree 2-8 & 55 & 81 & ${ }^{\circ} \mathrm{C}$ & 10.85 & 6.85 & 2.80 \\
\hline Tree 2-9 & 56 & 82 & ${ }^{\circ} \mathrm{C}$ & 10.85 & 6.85 & 3.15 \\
\hline Tree 2-10 & 57 & 83 & ${ }^{\circ} \mathrm{C}$ & 10.85 & 6.85 & 3.50 \\
\hline Tree 3-1 & 58 & 84 & ${ }^{\circ} \mathrm{C}$ & 10.85 & 2.2 & 0.35 \\
\hline Tree 3-2 & 59 & 85 & ${ }^{\circ} \mathrm{C}$ & 10.85 & 2.2 & 0.70 \\
\hline Tree 3-3 & 60 & 86 & ${ }^{\circ} \mathrm{C}$ & 10.85 & 2.2 & 1.05 \\
\hline Tree 3-4 & 61 & 87 & ${ }^{\circ} \mathrm{C}$ & 10.85 & 2.2 & 1.40 \\
\hline Tree 3-5 & 62 & 88 & ${ }^{\circ} \mathrm{C}$ & 10.85 & 2.2 & 1.75 \\
\hline Tree 3-6 & 63 & 89 & ${ }^{\circ} \mathrm{C}$ & 10.85 & 2.2 & 2.10 \\
\hline Tree 3-7 & 64 & 90 & ${ }^{\circ} \mathrm{C}$ & 10.85 & 2.2 & 2.45 \\
\hline Tree 3-8 & 65 & 91 & ${ }^{\circ} \mathrm{C}$ & 10.85 & 2.2 & 2.80 \\
\hline Tree 3-9 & 66 & 92 & ${ }^{\circ} \mathrm{C}$ & 10.85 & 2.2 & 3.15 \\
\hline Tree 3-10 & 67 & 93 & ${ }^{\circ} \mathrm{C}$ & 10.85 & 2.2 & 3.50 \\
\hline Tree 4-1 & 68 & 94 & ${ }^{\circ} \mathrm{C}$ & 10.85 & 1.35 & 0.35 \\
\hline Tree 4-2 & 69 & 95 & ${ }^{\circ} \mathrm{C}$ & 10.85 & 1.35 & 0.70 \\
\hline Tree 4-3 & 70 & 96 & ${ }^{\circ} \mathrm{C}$ & 10.85 & 1.35 & 1.05 \\
\hline Tree 4-4 & 71 & 97 & ${ }^{\circ} \mathrm{C}$ & 10.85 & 1.35 & 1.40 \\
\hline Tree 4-5 & 72 & 98 & ${ }^{\circ} \mathrm{C}$ & 10.85 & 1.35 & 1.75 \\
\hline
\end{tabular}




\begin{tabular}{|c|c|c|c|c|c|c|}
\hline \multirow[b]{2}{*}{ Designation } & \multicolumn{3}{|c|}{ NIST } & \multicolumn{3}{|c|}{ Location } \\
\hline & Column & Channel & Units & $X(m)$ & $\mathbf{Y}(\mathbf{m})$ & $\mathrm{Z}(\mathrm{m})$ \\
\hline Tree 4-6 & 73 & 99 & ${ }^{\circ} \mathrm{C}$ & 10.85 & 1.35 & 2.10 \\
\hline Tree 4-7 & 74 & 100 & ${ }^{\circ} \mathrm{C}$ & 10.85 & 1.35 & 2.45 \\
\hline Tree 4-8 & 75 & 101 & ${ }^{\circ} \mathrm{C}$ & 10.85 & 1.35 & 2.80 \\
\hline Tree 4-9 & 76 & 102 & ${ }^{\circ} \mathrm{C}$ & 10.85 & 1.35 & 3.15 \\
\hline Tree 4-10 & 77 & 103 & ${ }^{\circ} \mathrm{C}$ & 10.85 & 1.35 & 3.50 \\
\hline Tree 5-1 & 78 & 104 & ${ }^{\circ} \mathrm{C}$ & 10.85 & 0.55 & 0.35 \\
\hline Tree 5-2 & 79 & 105 & ${ }^{\circ} \mathrm{C}$ & 10.85 & 0.55 & 0.70 \\
\hline Tree 5-3 & 80 & 106 & ${ }^{\circ} \mathrm{C}$ & 10.85 & 0.55 & 1.05 \\
\hline Tree 5-4 & 81 & 107 & ${ }^{\circ} \mathrm{C}$ & 10.85 & 0.55 & 1.40 \\
\hline Tree 5-5 & 82 & 108 & ${ }^{\circ} \mathrm{C}$ & 10.85 & 0.55 & 1.75 \\
\hline Tree 5-6 & 83 & 109 & ${ }^{\circ} \mathrm{C}$ & 10.85 & 0.55 & 2.10 \\
\hline Tree 5-7 & 84 & 110 & ${ }^{\circ} \mathrm{C}$ & 10.85 & 0.55 & 2.45 \\
\hline Tree 5-8 & 85 & 111 & ${ }^{\circ} \mathrm{C}$ & 10.85 & 0.55 & 2.80 \\
\hline Tree 5-9 & 86 & 112 & ${ }^{\circ} \mathrm{C}$ & 10.85 & 0.55 & 3.15 \\
\hline Tree 5-10 & 87 & 113 & ${ }^{\circ} \mathrm{C}$ & 10.85 & 0.55 & 3.50 \\
\hline Tree 6-1 & 88 & 114 & ${ }^{\circ} \mathrm{C}$ & 11.95 & 3.58 & 0.35 \\
\hline Tree 6-2 & 89 & 115 & ${ }^{\circ} \mathrm{C}$ & 11.95 & 3.58 & 0.70 \\
\hline Tree 6-3 & 90 & 116 & ${ }^{\circ} \mathrm{C}$ & 11.95 & 3.58 & 1.05 \\
\hline Tree 6-4 & 91 & 117 & ${ }^{\circ} \mathrm{C}$ & 11.95 & 3.58 & 1.40 \\
\hline Tree 6-5 & 92 & 118 & ${ }^{\circ} \mathrm{C}$ & 11.95 & 3.58 & 1.75 \\
\hline Tree 6-6 & 93 & 119 & ${ }^{\circ} \mathrm{C}$ & 11.95 & 3.58 & 2.10 \\
\hline Tree 6-7 & 94 & 120 & ${ }^{\circ} \mathrm{C}$ & 11.95 & 3.58 & 2.45 \\
\hline Tree 6-8 & 95 & 121 & ${ }^{\circ} \mathrm{C}$ & 11.95 & 3.58 & 2.80 \\
\hline Tree 6-9 & 96 & 122 & ${ }^{\circ} \mathrm{C}$ & 11.95 & 3.58 & 3.15 \\
\hline Tree 6-10 & 97 & 123 & ${ }^{\circ} \mathrm{C}$ & 11.95 & 3.58 & 3.50 \\
\hline Tree 7-1 & 98 & 124 & ${ }^{\circ} \mathrm{C}$ & 16.7 & 3.58 & 0.35 \\
\hline Tree 7-2 & 99 & 125 & ${ }^{\circ} \mathrm{C}$ & 16.7 & 3.58 & 0.70 \\
\hline Tree 7-3 & 100 & 126 & ${ }^{\circ} \mathrm{C}$ & 16.7 & 3.58 & 1.05 \\
\hline Tree 7-4 & 101 & 127 & ${ }^{\circ} \mathrm{C}$ & 16.7 & 3.58 & 1.40 \\
\hline Tree 7-5 & 102 & 128 & ${ }^{\circ} \mathrm{C}$ & 16.7 & 3.58 & 1.75 \\
\hline Tree 7-6 & 103 & 129 & ${ }^{\circ} \mathrm{C}$ & 16.7 & 3.58 & 2.10 \\
\hline Tree 7-7 & 104 & 130 & ${ }^{\circ} \mathrm{C}$ & 16.7 & 3.58 & 2.45 \\
\hline Tree 7-8 & 105 & 131 & ${ }^{\circ} \mathrm{C}$ & 16.7 & 3.58 & 2.80 \\
\hline Tree 7-9 & 106 & 132 & ${ }^{\circ} \mathrm{C}$ & 16.7 & 3.58 & 3.15 \\
\hline Tree 7-10 & 107 & 133 & ${ }^{\circ} \mathrm{C}$ & 16.7 & 3.58 & 3.50 \\
\hline Wall TCs ${ }^{2}$ & & & & & & \\
\hline TC North U-1-1 & 108 & 134 & ${ }^{\circ} \mathrm{C}$ & 3.91 & 7.04 & 1.49 \\
\hline TC North U-1-2 & 109 & 135 & ${ }^{\circ} \mathrm{C}$ & 3.85 & 7.04 & 1.49 \\
\hline TC North U-2-1 & 110 & 136 & ${ }^{\circ} \mathrm{C}$ & 3.91 & 7.04 & 3.70 \\
\hline TC North U-2-2 & 111 & 137 & ${ }^{\circ} \mathrm{C}$ & 3.86 & 7.04 & 3.71 \\
\hline TC North U-3-1 & 112 & 138 & ${ }^{\circ} \mathrm{C}$ & 9.52 & 7.04 & 1.86 \\
\hline TC North U-3-2 & 113 & 139 & ${ }^{\circ} \mathrm{C}$ & 9.48 & 7.04 & 1.86 \\
\hline TC North U-4-1 & 114 & 140 & ${ }^{\circ} \mathrm{C}$ & 12.11 & 7.04 & 1.86 \\
\hline
\end{tabular}




\begin{tabular}{|c|c|c|c|c|c|c|}
\hline \multirow[b]{2}{*}{ Designation } & & \multicolumn{3}{|c|}{ Location } \\
\hline & Column & hannel & Units & $X(m)$ & $\mathbf{Y}(\mathbf{m})$ & $\mathrm{Z}(\mathrm{m})$ \\
\hline TC North U-4-2 & 115 & 141 & ${ }^{\circ} \mathrm{C}$ & 12.07 & 7.04 & 1.88 \\
\hline TC North U-5-1 & 116 & 142 & ${ }^{\circ} \mathrm{C}$ & 17.74 & 7.04 & 1.49 \\
\hline TC North U-5-2 & 117 & 143 & ${ }^{\circ} \mathrm{C}$ & 17.69 & 7.04 & 1.49 \\
\hline TC North U-6-1 & 118 & 144 & ${ }^{\circ} \mathrm{C}$ & 17.74 & 7.04 & 3.69 \\
\hline TC North U-6-2 & 119 & 145 & ${ }^{\circ} \mathrm{C}$ & 17.69 & 7.04 & 3.69 \\
\hline TC South U-1-1 & 120 & 146 & ${ }^{\circ} \mathrm{C}$ & 3.92 & 0 & 1.49 \\
\hline TC South U-1-2 & 121 & 147 & ${ }^{\circ} \mathrm{C}$ & 3.86 & 0 & 1.49 \\
\hline TC South U-2-1 & 122 & 148 & ${ }^{\circ} \mathrm{C}$ & 3.92 & 0 & 3.82 \\
\hline TC South U-2-2 & 123 & 149 & ${ }^{\circ} \mathrm{C}$ & 3.86 & 0 & 3.82 \\
\hline TC South U-3-1 & 124 & 150 & ${ }^{\circ} \mathrm{C}$ & 9.54 & 0 & 1.86 \\
\hline TC South U-3-2 & 125 & 151 & ${ }^{\circ} \mathrm{C}$ & 9.54 & 0 & 1.86 \\
\hline TC South U-4-1 & 126 & 152 & ${ }^{\circ} \mathrm{C}$ & 12.12 & 0 & 1.86 \\
\hline TC South U-4-2 & 127 & 154 & ${ }^{\circ} \mathrm{C}$ & 12.08 & 0 & 1.86 \\
\hline TC South U-5-1 & 128 & 155 & ${ }^{\circ} \mathrm{C}$ & 17.74 & 0 & 1.50 \\
\hline TC South U-5-2 & 129 & 156 & ${ }^{\circ} \mathrm{C}$ & 17.69 & 0 & 1.50 \\
\hline TC South U-6-1 & 130 & 157 & ${ }^{\circ} \mathrm{C}$ & 17.74 & 0 & 3.70 \\
\hline TC South U-6-2 & 131 & 158 & ${ }^{\circ} \mathrm{C}$ & 17.74 & 0 & 3.70 \\
\hline TC East U-1-1 & 132 & 159 & ${ }^{\circ} \mathrm{C}$ & 21.66 & 1.60 & 1.12 \\
\hline TC East U-1-2 & 133 & 160 & ${ }^{\circ} \mathrm{C}$ & 21.66 & 1.52 & 1.12 \\
\hline TC East U-2-1 & 134 & 161 & ${ }^{\circ} \mathrm{C}$ & 21.66 & 1.60 & 2.42 \\
\hline TC East U-2-2 & 135 & 162 & ${ }^{\circ} \mathrm{C}$ & 21.66 & 1.52 & 2.40 \\
\hline TC East U-3-1 & 136 & 163 & ${ }^{\circ} \mathrm{C}$ & 21.66 & 5.75 & 1.12 \\
\hline TC East U-3-2 & 137 & 164 & ${ }^{\circ} \mathrm{C}$ & 21.66 & 5.68 & 1.13 \\
\hline TC East U-4-1 & 138 & 165 & ${ }^{\circ} \mathrm{C}$ & 21.66 & 5.76 & 2.42 \\
\hline TC East U-4-2 & 139 & 166 & ${ }^{\circ} \mathrm{C}$ & 21.66 & 5.70 & 2.42 \\
\hline TC West U-1-1 & 140 & 167 & ${ }^{\circ} \mathrm{C}$ & 0 & 1.59 & 1.12 \\
\hline TC West U-1-2 & 141 & 168 & ${ }^{\circ} \mathrm{C}$ & 0 & 1.59 & 1.12 \\
\hline TC West U-2-1 & 142 & 169 & ${ }^{\circ} \mathrm{C}$ & 0 & 1.59 & 2.42 \\
\hline TC West U-2-2 & 143 & 170 & ${ }^{\circ} \mathrm{C}$ & 0 & 1.59 & 2.42 \\
\hline TC West U-3-1 & 144 & 171 & ${ }^{\circ} \mathrm{C}$ & 0 & 5.76 & 1.12 \\
\hline TC West U-3-2 & 145 & 172 & ${ }^{\circ} \mathrm{C}$ & 0 & 5.70 & 1.12 \\
\hline TC West U-4-1 & 146 & 173 & ${ }^{\circ} \mathrm{C}$ & 0 & 5.77 & 2.42 \\
\hline TC West U-4-2 & 147 & 174 & ${ }^{\circ} \mathrm{C}$ & 0 & 5.70 & 2.42 \\
\hline TC Floor U-1-1 & 148 & 175 & ${ }^{\circ} \mathrm{C}$ & 3.03 & 3.51 & 0 \\
\hline TC Floor U-1-2 & 149 & 176 & ${ }^{\circ} \mathrm{C}$ & 3.08 & 3.51 & 0 \\
\hline TC Floor U-2-1 & 150 & 177 & ${ }^{\circ} \mathrm{C}$ & 9.08 & 1.99 & 0 \\
\hline TC Floor U-2-2 & 151 & 178 & ${ }^{\circ} \mathrm{C}$ & 9.08 & 1.94 & 0 \\
\hline TC Floor U-3-1 & 152 & 179 & ${ }^{\circ} \mathrm{C}$ & 9.11 & 5.97 & 0 \\
\hline TC Floor U-3-2 & 153 & 180 & ${ }^{\circ} \mathrm{C}$ & 9.06 & 5.97 & 0 \\
\hline TC Floor U-4-1 & 154 & 181 & ${ }^{\circ} \mathrm{C}$ & 10.84 & 2.39 & 0 \\
\hline TC Floor U-4-2 & 155 & 182 & ${ }^{\circ} \mathrm{C}$ & 10.86 & 2.38 & 0 \\
\hline TC Floor C-5-1 & 156 & 183 & ${ }^{\circ} \mathrm{C}$ & 10.89 & 5.20 & 0.01 \\
\hline TC Floor C-5-2 & 157 & 184 & ${ }^{\circ} \mathrm{C}$ & 10.93 & 5.20 & 0.01 \\
\hline TC Floor U-6-1 & 158 & 185 & ${ }^{\circ} \mathrm{C}$ & 13.09 & 1.99 & 0 \\
\hline
\end{tabular}




\begin{tabular}{|c|c|c|c|c|c|c|}
\hline \multirow[b]{2}{*}{ Designation } & \multicolumn{3}{|c|}{ NIST } & \multicolumn{3}{|c|}{ Location } \\
\hline & Column & Channel & Units & $X(m)$ & $\mathbf{Y}(\mathbf{m})$ & $\mathrm{Z}(\mathbf{m})$ \\
\hline TC Floor U-6-2 & 159 & 186 & ${ }^{\circ} \mathrm{C}$ & 13.13 & 1.99 & 0 \\
\hline TC Floor U-7-1 & 160 & 187 & ${ }^{\circ} \mathrm{C}$ & 13.00 & 5.98 & 0 \\
\hline TC Floor U-7-2 & 161 & 188 & ${ }^{\circ} \mathrm{C}$ & 13.00 & 5.92 & 0 \\
\hline TC Floor U-8-1 & 162 & 189 & ${ }^{\circ} \mathrm{C}$ & 18.63 & 3.58 & 0 \\
\hline TC Floor U-8-2 & 163 & 190 & ${ }^{\circ} \mathrm{C}$ & 18.63 & 3.54 & 0 \\
\hline TC Ceiling U-1-1 & 164 & 191 & ${ }^{\circ} \mathrm{C}$ & 3.06 & 3.52 & 3.82 \\
\hline TC Ceiling U-1-2 & 165 & 192 & ${ }^{\circ} \mathrm{C}$ & 3.04 & 3.60 & 3.82 \\
\hline TC Ceiling C-2-1 & 166 & 193 & ${ }^{\circ} \mathrm{C}$ & 9.03 & 1.97 & 3.82 \\
\hline TC Ceiling C-2-2 & 167 & 194 & ${ }^{\circ} \mathrm{C}$ & 8.99 & 2.00 & 3.82 \\
\hline TC Ceiling C-3-1 & 168 & 195 & ${ }^{\circ} \mathrm{C}$ & 9.08 & 5.96 & 3.82 \\
\hline TC Ceiling C-3-2 & 169 & 196 & ${ }^{\circ} \mathrm{C}$ & 9.03 & 5.97 & 3.82 \\
\hline TC Ceiling C-4-1 & 170 & 197 & ${ }^{\circ} \mathrm{C}$ & 10.85 & 2.38 & 3.82 \\
\hline TC Ceiling C-4-2 & 171 & 198 & ${ }^{\circ} \mathrm{C}$ & 10.79 & 2.38 & 3.82 \\
\hline TC Ceiling C-5-1 & 172 & 199 & ${ }^{\circ} \mathrm{C}$ & 10.83 & 5.20 & 3.82 \\
\hline TC Ceiling C-5-2 & 173 & 200 & ${ }^{\circ} \mathrm{C}$ & 10.79 & 5.20 & 3.82 \\
\hline TC Ceiling C-6-1 & 174 & 201 & ${ }^{\circ} \mathrm{C}$ & 13.01 & 2.03 & 3.82 \\
\hline TC Ceiling C-6-2 & 175 & 202 & ${ }^{\circ} \mathrm{C}$ & 13.00 & 2.07 & 3.82 \\
\hline TC Ceiling C-7-1 & 176 & 203 & ${ }^{\circ} \mathrm{C}$ & 12.88 & 6.00 & 3.82 \\
\hline TC Ceiling C-7-2 & 177 & 204 & ${ }^{\circ} \mathrm{C}$ & 12.84 & 5.98 & 3.82 \\
\hline TC Ceiling U-8-1 & 178 & 205 & ${ }^{\circ} \mathrm{C}$ & 18.63 & 3.58 & 3.82 \\
\hline TC Ceiling U-8-2 & 179 & 206 & ${ }^{\circ} \mathrm{C}$ & 18.71 & 3.54 & 3.82 \\
\hline \multicolumn{7}{|l|}{ Cable TCs } \\
\hline C - Ts-1 & 180 & 233 & ${ }^{\circ} \mathrm{C}$ & 6.85 & 2.25 & 3.2 \\
\hline C - Tc-2 & 181 & 234 & ${ }^{\circ} \mathrm{C}$ & 6.85 & 2.25 & 3.2 \\
\hline D - Ts-3 & 182 & 235 & ${ }^{\circ} \mathrm{C}$ & 6.85 & 2.03 & 3.22 \\
\hline B - Ts-4 & 183 & 236 & ${ }^{\circ} \mathrm{C}$ & 6.85 & 1.4 & 2.7 \\
\hline A - Ts-6 & 184 & 238 & ${ }^{\circ} \mathrm{C}$ & 6.85 & 0.65 & 2.19 \\
\hline F - Ts-7 & 185 & 239 & ${ }^{\circ} \mathrm{C}$ & 6.85 & 0.5 & 2.175 \\
\hline C - Ts-8 & 186 & 240 & ${ }^{\circ} \mathrm{C}$ & 8.85 & 2.25 & 3.2 \\
\hline C - Тс-9 & 187 & 241 & ${ }^{\circ} \mathrm{C}$ & 8.85 & 2.25 & 3.2 \\
\hline C - Ts-10 & 188 & 242 & ${ }^{\circ} \mathrm{C}$ & 10.83 & 2.27 & 3.2 \\
\hline C - Tc-11 & 189 & 243 & ${ }^{\circ} \mathrm{C}$ & 10.83 & 2.27 & 3.2 \\
\hline D - Ts-12 & 190 & 244 & ${ }^{\circ} \mathrm{C}$ & 10.83 & 2.03 & 3.22 \\
\hline D - Tc-13 & 191 & 245 & ${ }^{\circ} \mathrm{C}$ & 10.83 & 2.03 & 3.22 \\
\hline B - Ts-14 & 192 & 246 & ${ }^{\circ} \mathrm{C}$ & 10.83 & 1.4 & 2.7 \\
\hline B - Tc-15 & 193 & 247 & ${ }^{\circ} \mathrm{C}$ & 10.83 & 1.4 & 2.7 \\
\hline E - Ts-16 bottom & 194 & 248 & ${ }^{\circ} \mathrm{C}$ & 10.83 & 1.25 & 2.7 \\
\hline E - Tc-17 middle & 195 & 249 & ${ }^{\circ} \mathrm{C}$ & 10.83 & 1.25 & 2.7 \\
\hline E - Ts-16' top & 196 & 237 & ${ }^{\circ} \mathrm{C}$ & 10.83 & 1.25 & 2.7 \\
\hline A - Ts-18 & 197 & 250 & ${ }^{\circ} \mathrm{C}$ & 10.83 & 0.65 & 2.19 \\
\hline A - Tc-19 & 198 & 251 & ${ }^{\circ} \mathrm{C}$ & 10.83 & 0.65 & 2.19 \\
\hline F - Ts-20 & 199 & 252 & ${ }^{\circ} \mathrm{C}$ & 10.83 & 0.5 & 2.175 \\
\hline F - Tc-21 & 200 & 253 & ${ }^{\circ} \mathrm{C}$ & 10.83 & 0.5 & 2.175 \\
\hline
\end{tabular}




\begin{tabular}{|c|c|c|c|c|c|c|}
\hline \multirow[b]{2}{*}{ Designation } & & \multicolumn{3}{|c|}{ Location } \\
\hline & Column & hannel & Units & $\mathbf{X}(\mathbf{m})$ & $\mathbf{Y}(\mathbf{m})$ & $\mathrm{Z}$ (m) \\
\hline C - Ts-22 & 201 & 254 & ${ }^{\circ} \mathrm{C}$ & 12.85 & 2 & 3.2 \\
\hline C - Tc-23 & 202 & 255 & ${ }^{\circ} \mathrm{C}$ & 12.85 & 2 & 3.2 \\
\hline C - Ts-24 & 203 & 256 & ${ }^{\circ} \mathrm{C}$ & 14.85 & 2.25 & 3.2 \\
\hline C - Tc-25 & 204 & 257 & ${ }^{\circ} \mathrm{C}$ & 14.85 & 2.25 & 3.2 \\
\hline D - Ts-26 & 205 & 258 & ${ }^{\circ} \mathrm{C}$ & 14.85 & 2.03 & 3.22 \\
\hline B - Ts-27 & 206 & 259 & ${ }^{\circ} \mathrm{C}$ & 14.85 & 1.4 & 2.7 \\
\hline A - Ts-29 & 207 & 261 & ${ }^{\circ} \mathrm{C}$ & 14.85 & 0.65 & 2.2 \\
\hline F - Ts-30 & 208 & 262 & ${ }^{\circ} \mathrm{C}$ & 14.85 & 0.5 & 2.2 \\
\hline Vertical Cable Ts-31 & 209 & 263 & ${ }^{\circ} \mathrm{C}$ & 10.79 & 7.04 & 0.35 \\
\hline Vertical Cable Ts-32 & 210 & 264 & ${ }^{\circ} \mathrm{C}$ & 10.79 & 7.04 & 0.7 \\
\hline Vertical Cable Ts-33 & 211 & 265 & ${ }^{\circ} \mathrm{C}$ & 10.79 & 7.04 & 1.75 \\
\hline Vertical Cable Tc-34 & 212 & 266 & ${ }^{\circ} \mathrm{C}$ & 10.79 & 7.04 & 1.75 \\
\hline Vertical Cable Ts-35 & 213 & 267 & ${ }^{\circ} \mathrm{C}$ & 10.79 & 7.04 & 2.45 \\
\hline Vertical Cable Ts-36 & 214 & 268 & ${ }^{\circ} \mathrm{C}$ & 10.79 & 7.04 & 3.15 \\
\hline $\begin{array}{l}\text { Junction Box TC-37 } \\
\text { (inside) }\end{array}$ & 215 & 269 & ${ }^{\circ} \mathrm{C}$ & 17.66 & 3.44 & 3.76 \\
\hline $\begin{array}{l}\text { Junction Box TS-38 } \\
\text { (bottom) }\end{array}$ & 216 & 270 & ${ }^{\circ} \mathrm{C}$ & 17.66 & 3.44 & 3.70 \\
\hline $\begin{array}{l}\text { Junction Box TS-39 } \\
\text { (west) }\end{array}$ & 217 & 271 & ${ }^{\circ} \mathrm{C}$ & 17.51 & 3.44 & 3.76 \\
\hline Aspirated TCs & & & & & & \\
\hline ATC -5 & 218 & 276 & ${ }^{\circ} \mathrm{C}$ & 10.85 & 0.55 & 1.05 \\
\hline ATC -6 & 219 & 277 & ${ }^{\circ} \mathrm{C}$ & 10.85 & 0.55 & 2.76 \\
\hline Gas/Smoke Conc. & & & & & & \\
\hline $\mathrm{O} 2-1$ & 220 & 331 & Vol. Frac. & 6.85 & 3.52 & 3.20 \\
\hline $\mathrm{O} 2-2$ & 221 & 332 & Vol. Frac. & 6.85 & 3.52 & 0.50 \\
\hline $\mathrm{CO}-3$ & 222 & 333 & Vol. Frac. & 6.85 & 3.52 & 3.20 \\
\hline $\mathrm{CO} 2-4$ & 223 & 335 & Vol. Frac. & 6.85 & 3.52 & 3.20 \\
\hline $\begin{array}{l}\text { Smoke Obs./Conc. } \\
\text { Rad and Total Flux } \\
\text { Gauges }\end{array}$ & 224 & 354 & $\mathrm{mg} / \mathrm{m}^{3}$ & 21.11 & 0.5 & 3.57 \\
\hline Cable Rad Gauge 1 & 225 & 341 & $\mathrm{~kW} / \mathrm{m}^{2}$ & 10.81 & 0.44 & 2.05 \\
\hline Cable Total Flux 2 & 226 & 342 & $\mathrm{~kW} / \mathrm{m}^{2}$ & 10.87 & 0.44 & 2.05 \\
\hline Cable Rad Gauge 3 & 227 & 343 & $\mathrm{~kW} / \mathrm{m}^{2}$ & 10.81 & 1.25 & 2.52 \\
\hline Cable Total Flux 4 & 228 & 344 & $\mathrm{~kW} / \mathrm{m}^{2}$ & 10.87 & 1.25 & 2.52 \\
\hline Cable Rad Gauge 5 & 229 & 345 & $\mathrm{~kW} / \mathrm{m}^{2}$ & 10.81 & 1.40 & 2.54 \\
\hline Cable Total Flux 6 & 230 & 346 & $\mathrm{~kW} / \mathrm{m}^{2}$ & 10.87 & 1.40 & 2.54 \\
\hline Cable Rad Gauge 7 & 231 & 347 & $\mathrm{~kW} / \mathrm{m}^{2}$ & 10.81 & 2.00 & 3.04 \\
\hline Cable Total Flux 8 & 232 & 348 & $\mathrm{~kW} / \mathrm{m}^{2}$ & 10.87 & 2.00 & 3.04 \\
\hline Cable Total Flux 9 & 233 & 349 & $\mathrm{~kW} / \mathrm{m}^{2}$ & 10.81 & 6.85 & 1.75 \\
\hline Cable Rad Gauge 10 & 234 & 350 & $\mathrm{~kW} / \mathrm{m}^{2}$ & 10.87 & 6.85 & 1.76 \\
\hline Comp Pressure & & & & & & \\
\hline CompP & 235 & 351 & $\mathrm{~Pa}$ & 10.85 & 0.10 & 0.10 \\
\hline
\end{tabular}




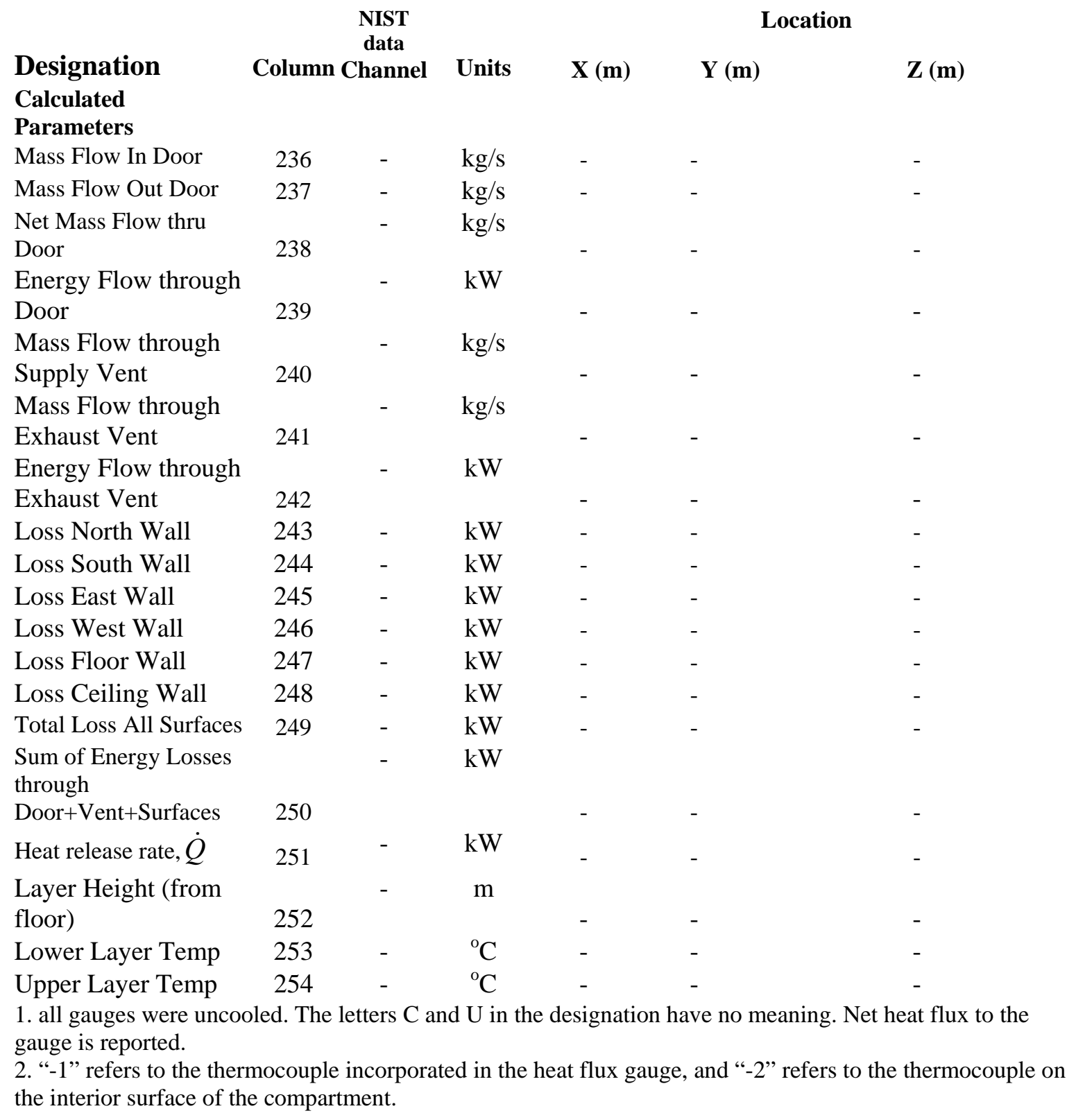

Table D-2: Instrument channel number, designation, units, and location for the second data file.

\begin{tabular}{|c|c|c|c|c|c|c|}
\hline \multirow{2}{*}{ Measurement } & \multicolumn{3}{|c|}{ NIST data } & \multicolumn{3}{|c|}{ Location } \\
\hline & Column & Channel & Units & $X(m)$ & $\mathbf{Y}(\mathbf{m})$ & $\mathrm{Z}(\mathrm{m})$ \\
\hline Time & 1 & 1 & s & - & - & - \\
\hline \multicolumn{7}{|c|}{ Bidirectional Probe TCs $^{1}$} \\
\hline TC Door -1 & 2 & 207 & ${ }^{\circ} \mathrm{C}$ & 0.10 & 2.72 & 0.21 \\
\hline TC Door -2 & 3 & 208 & ${ }^{\circ} \mathrm{C}$ & 0.10 & 2.72 & 0.61 \\
\hline TC Door -3 & 4 & 209 & ${ }^{\circ} \mathrm{C}$ & 0.10 & 2.72 & 1.01 \\
\hline TC Door -4 & 5 & 210 & ${ }^{\circ} \mathrm{C}$ & 0.10 & 2.72 & 1.21 \\
\hline
\end{tabular}




\begin{tabular}{|c|c|c|c|c|c|c|}
\hline \multirow[b]{2}{*}{ Measurement } & \multicolumn{3}{|c|}{ NIST data } & \multicolumn{3}{|c|}{ Location } \\
\hline & Column & Channel & Units & $\mathrm{X}(\mathrm{m})$ & $\mathbf{Y}(\mathbf{m})$ & $\mathrm{Z}$ (m) \\
\hline TC Door -5 & 6 & 211 & ${ }^{\circ} \mathrm{C}$ & 0.10 & 2.72 & 1.41 \\
\hline TC Door -6 & 7 & 212 & ${ }^{\circ} \mathrm{C}$ & 0.10 & 2.72 & 1.61 \\
\hline TC Door -7 & 8 & 213 & ${ }^{\circ} \mathrm{C}$ & 0.10 & 2.72 & 1.81 \\
\hline TC Door -8 & 9 & 214 & ${ }^{\circ} \mathrm{C}$ & 0.10 & 2.72 & 1.91 \\
\hline TC Door -9 & 10 & 215 & ${ }^{\circ} \mathrm{C}$ & 0.10 & 3.52 & 0.21 \\
\hline TC Door -10 & 11 & 216 & ${ }^{\circ} \mathrm{C}$ & 0.10 & 3.52 & 0.61 \\
\hline TC Door -11 & 12 & 217 & ${ }^{\circ} \mathrm{C}$ & 0.10 & 3.52 & 1.01 \\
\hline TC Door -12 & 13 & 218 & ${ }^{\circ} \mathrm{C}$ & 0.10 & 3.52 & 1.21 \\
\hline TC Door -13 & 14 & 219 & ${ }^{\circ} \mathrm{C}$ & 0.10 & 3.52 & 1.41 \\
\hline TC Door -14 & 15 & 220 & ${ }^{\circ} \mathrm{C}$ & 0.10 & 3.52 & 1.61 \\
\hline TC Door -15 & 16 & 221 & ${ }^{\circ} \mathrm{C}$ & 0.10 & 3.52 & 1.81 \\
\hline TC Door -16 & 17 & 222 & ${ }^{\circ} \mathrm{C}$ & 0.10 & 3.52 & 1.91 \\
\hline TC Door -17 & 18 & 223 & ${ }^{\circ} \mathrm{C}$ & 0.10 & 4.32 & 0.21 \\
\hline TC Door -18 & 19 & 224 & ${ }^{\circ} \mathrm{C}$ & 0.10 & 4.32 & 0.61 \\
\hline TC Door -19 & 20 & 225 & ${ }^{\circ} \mathrm{C}$ & 0.10 & 4.32 & 1.01 \\
\hline TC Door -20 & 21 & 226 & ${ }^{\circ} \mathrm{C}$ & 0.10 & 4.32 & 1.21 \\
\hline TC Door -21 & 22 & 227 & ${ }^{\circ} \mathrm{C}$ & 0.10 & 4.32 & 1.41 \\
\hline TC Door -22 & 23 & 228 & ${ }^{\circ} \mathrm{C}$ & 0.10 & 4.32 & 1.61 \\
\hline TC Door -23 & 24 & 229 & ${ }^{\circ} \mathrm{C}$ & 0.10 & 4.32 & 1.81 \\
\hline TC Door -24 & 25 & 230 & ${ }^{\circ} \mathrm{C}$ & 0.10 & 4.32 & 1.91 \\
\hline TC Supply Vent $-25^{2}$ & 26 & 231 & ${ }^{\circ} \mathrm{C}$ & 11.22 & 0 & 2.41 \\
\hline TC C4 gas Bidir & 27 & 285 & ${ }^{\circ} \mathrm{C}$ & 10.85 & 2.38 & 3.82 \\
\hline TC C5 gas Bidir & 28 & 286 & ${ }^{\circ} \mathrm{C}$ & 10.85 & 5.27 & 3.82 \\
\hline \multicolumn{7}{|l|}{ Exhaust TCs } \\
\hline Exhaust TC 1 & 29 & 367 & ${ }^{\circ} \mathrm{C}$ & 11.22 & 7.04 & 2.20 \\
\hline Exhaust TC 2 & 30 & 368 & ${ }^{\circ} \mathrm{C}$ & 11.22 & 7.04 & 2.40 \\
\hline Exhaust TC 3 & 31 & 369 & ${ }^{\circ} \mathrm{C}$ & 11.22 & 7.04 & 2.55 \\
\hline Exhaust TC 4 & 32 & 370 & ${ }^{\circ} \mathrm{C}$ & 11.22 & 7.04 & 2.65 \\
\hline \multicolumn{7}{|l|}{ Aspirated TCs } \\
\hline ATC Door -1 & 33 & 272 & ${ }^{\circ} \mathrm{C}$ & 0.10 & 3.61 & 0.20 \\
\hline ATC Door -2 & 34 & 273 & ${ }^{\circ} \mathrm{C}$ & 0.10 & 3.61 & 1.00 \\
\hline ATC Door -3 & 35 & 274 & ${ }^{\circ} \mathrm{C}$ & 0.10 & 3.61 & 1.80 \\
\hline ATC Exhaust $-4^{3}$ & 36 & 275 & ${ }^{\circ} \mathrm{C}$ & 11.22 & 7.27 & 2.39 \\
\hline \multicolumn{7}{|l|}{ Marinite Wall TCs } \\
\hline TC N U outside $1 / 2$ “ & 37 & 278 & ${ }^{\circ} \mathrm{C}$ & 9.55 & 7.07 & 1.86 \\
\hline TC N U inside 1” & 38 & 279 & ${ }^{\circ} \mathrm{C}$ & 9.95 & 7.04 & 1.86 \\
\hline TC N outside 1” & 39 & 280 & ${ }^{\circ} \mathrm{C}$ & 9.95 & 7.07 & 1.86 \\
\hline TC S outside 1/2 “ & 40 & 371 & ${ }^{\circ} \mathrm{C}$ & 9.48 & -0.03 & 1.86 \\
\hline TC S inside 1” & 41 & 372 & ${ }^{\circ} \mathrm{C}$ & 9.74 & 0 & 1.86 \\
\hline TC S outside 1” & 42 & 373 & ${ }^{\circ} \mathrm{C}$ & 9.74 & -0.03 & 1.86 \\
\hline TC W outside $1 / 2$ “ & 43 & 287 & ${ }^{\circ} \mathrm{C}$ & -0.03 & 5.71 & 2.43 \\
\hline TC W inside 1” & 44 & 288 & ${ }^{\circ} \mathrm{C}$ & 0 & 6.03 & 2.43 \\
\hline TC W outside $1 ”$ & 45 & 289 & ${ }^{\circ} \mathrm{C}$ & -0.03 & 6.03 & 2.43 \\
\hline TC C outside $1 / 2$ " & 46 & 290 & ${ }^{\circ} \mathrm{C}$ & 3.10 & 3.52 & 3.85 \\
\hline
\end{tabular}




\begin{tabular}{|c|c|c|c|c|c|c|}
\hline \multirow[b]{2}{*}{ Measurement } & \multicolumn{3}{|c|}{ NIST data } & \multicolumn{3}{|c|}{ Location } \\
\hline & Column & Channel & Units & $X(m)$ & $\mathbf{Y}(\mathbf{m})$ & $\mathrm{Z}(\mathbf{m})$ \\
\hline TC C inside 1” & 47 & 291 & ${ }^{\circ} \mathrm{C}$ & 2.80 & 3.58 & 3.82 \\
\hline TC C outside 1” & 48 & 292 & ${ }^{\circ} \mathrm{C}$ & 2.80 & 3.58 & 3.85 \\
\hline TC C outside $1 / 2$ “ & 49 & 293 & ${ }^{\circ} \mathrm{C}$ & 11.45 & 5.18 & 3.85 \\
\hline TC C outside 1" & 50 & 294 & ${ }^{\circ} \mathrm{C}$ & 11.66 & 5.24 & 3.85 \\
\hline TC C inside 1” & 51 & 295 & ${ }^{\circ} \mathrm{C}$ & 11.66 & 5.24 & 3.82 \\
\hline \multicolumn{7}{|l|}{ Bidirectional Probes } \\
\hline BP Door -1 & 52 & 305 & $\mathrm{~m} / \mathrm{s}$ & 0.10 & 2.72 & 0.19 \\
\hline BP Door -2 & 53 & 307 & $\mathrm{~m} / \mathrm{s}$ & 0.10 & 2.72 & 0.58 \\
\hline BP Door -3 & 54 & 308 & $\mathrm{~m} / \mathrm{s}$ & 0.10 & 2.72 & 1.00 \\
\hline BP Door -4 & 55 & 309 & $\mathrm{~m} / \mathrm{s}$ & 0.10 & 2.72 & 1.39 \\
\hline BP Door -5 & 56 & 310 & $\mathrm{~m} / \mathrm{s}$ & 0.10 & 2.72 & 1.80 \\
\hline BP Door -6 & 57 & 311 & $\mathrm{~m} / \mathrm{s}$ & 0.10 & 3.52 & 0.19 \\
\hline BP Door -7 & 58 & 312 & $\mathrm{~m} / \mathrm{s}$ & 0.10 & 3.52 & 0.6 \\
\hline BP Door -8 & 59 & 313 & $\mathrm{~m} / \mathrm{s}$ & 0.10 & 3.52 & 1.00 \\
\hline BP Door -9 & 60 & 314 & $\mathrm{~m} / \mathrm{s}$ & 0.10 & 3.52 & 1.4 \\
\hline BP Door -10 & 61 & 315 & $\mathrm{~m} / \mathrm{s}$ & 0.10 & 3.52 & 1.79 \\
\hline BP Door -11 & 62 & 316 & $\mathrm{~m} / \mathrm{s}$ & 0.10 & 4.32 & 0.21 \\
\hline BP Door -13 & 63 & 318 & $\mathrm{~m} / \mathrm{s}$ & 0.10 & 4.32 & 1.01 \\
\hline BP Door -14 & 64 & 319 & $\mathrm{~m} / \mathrm{s}$ & 0.10 & 4.32 & 1.40 \\
\hline BP Door -15 & 65 & 320 & $\mathrm{~m} / \mathrm{s}$ & 0.10 & 4.32 & 1.80 \\
\hline BP Supply Vent -16 & 66 & 321 & $\mathrm{~m} / \mathrm{s}$ & 11.22 & 0 & $2.35^{4}$ \\
\hline BP Exhaust Vent & 67 & 317 & $\mathrm{~m} / \mathrm{s}$ & 11.22 & 7.04 & 2.40 \\
\hline Ceiling C-4-V & 68 & 323 & $\mathrm{~m} / \mathrm{s}$ & 10.85 & 2.38 & 3.82 \\
\hline Ceiling C-5-V & 69 & 324 & $\mathrm{~m} / \mathrm{s}$ & 10.85 & 5.27 & 3.82 \\
\hline
\end{tabular}

1. thermocouples mounted near bi-directional probes (PC4 \& PC5) on ceiling in middle of compartment

2. Although specified in the original test plan, a bi-directional probe was not put in the plane of the exhaust duct. Instead, several probes were positioned downstream in the duct.

3. Although specified in the original test plan, an aspirated thermocouple was not put in the plane of the supply duct.

4. The $\mathrm{Z}$ location of the bi-directional probe was changed for Tests 10 and 16 to $2.20 \mathrm{~m}$. For Tests 4 and 5 the $\mathrm{Z}$ location was $2.35 \mathrm{~m}$. 


\section{$E$ inoperative instruments duRING test SERIES}

Table 2-2 lists some observations noted during the experiments, including among other things, the status of the data acquisition system, the instrumentation, and the measurements. A number of instruments did not function properly or displayed signals that were suspect (signal dropout, noise, odd behavior, etc.). The accompanying electronic data files do not include data that are clearly not meaningful. This information is documented in Tables E-1 - E-3 for each test.

Table E-1: List of inoperative instruments during the test series.

\begin{tabular}{|c|c|c|c|c|}
\hline \multirow[b]{2}{*}{$\begin{array}{l}\text { Test } \\
\text { Order }\end{array}$} & \multirow[b]{2}{*}{$\begin{array}{l}\text { Test } \\
\text { No. }\end{array}$} & \multicolumn{3}{|c|}{ Inoperative Instrument } \\
\hline & & Slab E TCs & Cable TCs & Tree TCs \\
\hline 1 & 1 & & D-Ts-12 ** & $4-3 *, 4-9 * *$ \\
\hline 2 & 2 & & & $4-9 * *$ \\
\hline 3 & 5 & & & $4-9 * *$ \\
\hline 4 & 4 & E-Ts-16,16',17 ** & & $4-9 * *, 3-10 *$ \\
\hline 5 & 3 & E-Ts-16,16',17 ** & & $4-9 * *$ \\
\hline 6 & 8 & E-Ts-16,16',17 ** & & $4-9 * *$ \\
\hline 7 & 9 & E-Ts-16,16',17 ** & & $4-9 * *, 5-9 *$ \\
\hline 8 & 13 & E-Ts-16,16',17 ** & C-Tc-11, C-Ts-10 & $4-9 * *, 5-9 *$ \\
\hline 9 & 14 & E-Ts-16,16',17 ** & C-Tc-11, C-Ts-10 & $4-9 * *, 5-9 *$ \\
\hline 10 & 18 & E-Ts-16,16',17 ** & $\begin{array}{c}\text { A-Ts-18, Vertical Cables Ts-35; } \\
\text { Ts-36 *** }\end{array}$ & $\begin{array}{c}4-9 * * \\
\text { TC Door- } 17 * \\
\end{array}$ \\
\hline 11 & 7 & & & $4-9 * *$ \\
\hline 12 & 10 & & & $4-9 * *$ \\
\hline 13 & 16 & E-Ts-16,16',17 ** & $* * *$ & $4-9 * *$ \\
\hline 14 & 15 & E-Ts-16,16',17 ** & $* * *$ & 4-all*,5-9* \\
\hline 15 & 17 & E-Ts-16,16',17 ** & $* * *$ & $4-9 * *$ \\
\hline
\end{tabular}


Table E-2: List of inoperative instruments during the test series.

\begin{tabular}{|c|c|c|c|c|}
\hline \multirow[b]{2}{*}{$\begin{array}{l}\text { Test } \\
\text { Order }\end{array}$} & \multirow[b]{2}{*}{$\begin{array}{l}\text { Test } \\
\text { No. }\end{array}$} & \multicolumn{3}{|c|}{ Inoperative Instrument $*$} \\
\hline & & $\begin{array}{l}\text { Flux } \\
\text { Gauge }\end{array}$ & Wall Flux Gauges* and Associated TCs & $\begin{array}{l}\text { Additional } \\
\text { Wall Flux } \\
\text { Gauge TCs }\end{array}$ \\
\hline 1 & 1 & 8,9 & North U-2, North U-4 & TC South U-3-1 \\
\hline 2 & 2 & 9 & North U-2 & \\
\hline 3 & 5 & & North U-2 & \\
\hline 4 & 4 & & North U-2 & \\
\hline 5 & 3 & 7 & $\begin{array}{c}\text { North U-2, North U-3 }(\mathrm{t}>1176 \mathrm{~s})^{* *} \text {, South U-3 (t>1280s), } \\
\text { South U-4 ( }>1113 \mathrm{~s})^{* *}\end{array}$ & $\begin{array}{l}\text { TC East U-1-1 } \\
(996<t<1068 \\
t>1750)^{* *}\end{array}$ \\
\hline 6 & 8 & & North U-2, North U-3, South U-3, South U-4 & $\begin{array}{l}\text { TC East U-1-1; } \\
\text { Ceiling C-2-1 ** }\end{array}$ \\
\hline 7 & 9 & & $\begin{array}{l}\text { North U-2, North U-3, South U-3, South U-4, East U-2, East } \\
\text { U-4, West U-2, West U-4, Ceiling U-1, Ceiling U-8, Floor U- } \\
\text { 4, Floor U-5 }\end{array}$ & TC East U-1-1 \\
\hline 8 & 13 & & All Gauges*** & \\
\hline 9 & 14 & & $\begin{array}{c}\text { North U-2, North U-3, North U-6 ( } \mathrm{t}>1185)^{* *} \text {, South U-3, } \\
\text { South U-4, East U-4, West U-4, Ceiling C-4, Ceiling C-5, } \\
\text { Floor U-4, Floor U-5 }\end{array}$ & TC East U-1-1 \\
\hline 10 & 18 & 5,7 & $\begin{array}{c}\text { North U-2, North U-3, North U-6, South U-3, South U-4, } \\
\text { South U-6 ( }>1054)^{* *} \text {, East U-2, East U-4, West U-4, Ceiling } \\
\text { U-1, Ceiling C-4, Ceiling U-8 (t>1288)**, Floor U-4, Floor } \\
\text { U-5 }\end{array}$ & TC East U-1-1 \\
\hline 11 & 7 & & $\begin{array}{l}\text { North U-6, South U-6, East U-2, East U-4, Ceiling C-4, } \\
\text { Ceiling C-5, Ceiling C-6, Ceiling U-8, Floor U-6, Floor U-7 }\end{array}$ & TC East U-1-1 \\
\hline 12 & 10 & & $\begin{array}{l}\text { North U-6, South U-6, Ceiling C-4, Ceiling C-5, Ceiling C-6, } \\
\text { Ceiling U-8, Floor U-6, Floor U-7 }\end{array}$ & TC East U-1-1 \\
\hline 13 & 16 & & All Gauges*** & \\
\hline 14 & 15 & 7 & $\begin{array}{l}\text { North U-1 }(171<\mathrm{t}<190)^{* *} \text {, North U-3, North U-6, South U-2 } \\
(\mathrm{t}>1302)^{* *} \text {, South U-4 }(\mathrm{t}>760)^{* *} \text {, South U-6, East U-4, West } \\
\text { U-4, Ceiling U-1, Ceiling C-4, Ceiling C-5, Ceiling U-8, } \\
\text { Floor U-4 }(\mathrm{t}>602) \text {, Floor U-5, Floor U-6, Floor U-7 }\end{array}$ & $\begin{array}{l}\text { TC East U-1-1, } \\
\text { TC South U-4-1 } \\
(\mathrm{t}>508)^{* *}\end{array}$ \\
\hline 15 & 17 & 5 & $\begin{array}{l}\text { North U-3, North U-6, South U-2, South U-4, South U-6, East } \\
\text { U-4, West U-4, Ceiling U-1, Ceiling C-4, Ceiling C-5, Ceiling } \\
\text { U-8, Floor U-4, Floor U-5, Floor U-6, Floor U-7 }\end{array}$ & TC East U-1-1 \\
\hline
\end{tabular}


Table E-3: List of inoperative instruments during the test series.

\begin{tabular}{|c|c|c|c|}
\hline \multirow{2}{*}{$\begin{array}{c}\text { Test } \\
\text { Order }\end{array}$} & \multirow{2}{*}{$\begin{array}{l}\text { Test } \\
\text { No. }\end{array}$} & \multicolumn{2}{|c|}{ Inoperative Instrument } \\
\hline & & Bi-directional probes & Gas Analyzer \\
\hline 1 & 1 & & $\mathrm{CO} *$ \\
\hline 2 & 2 & & $\mathrm{CO} * *$ \\
\hline 3 & 5 & BP Door $-12 *$ & $\mathrm{CO} *$ \\
\hline 4 & 4 & & $\mathrm{CO} *$ \\
\hline 5 & 3 & BP Door $-12 *$ & $\mathrm{CO} *$ \\
\hline 6 & 8 & & $\mathrm{CO}(90<\mathrm{t}<120)^{* *}$ \\
\hline 7 & 9 & BP Door $-12 ; 13 ; 15 *$ & $\mathrm{CO} *$ \\
\hline 8 & 13 & & \\
\hline 9 & 14 & BP Door $-12 *$ & $\mathrm{CO} *$ \\
\hline 14 & 18 & BP Door $-12 ; 13$ * & $\mathrm{CO} * * ; \mathrm{O}_{2}-2(\mathrm{t}>350)^{* *}$ \\
\hline 11 & 7 & & $\mathrm{CO} *$ \\
\hline 12 & 10 & & $\mathrm{CO} *$ \\
\hline 15 & 16 & & $\mathrm{CO} * *$ \\
\hline 13 & 15 & BP Door $-12 ; 13$ * & \\
\hline 10 & 17 & & \\
\hline
\end{tabular}





\section{F response to questions AND COMMENTS FROM JULY WPI INTERNATIONAL PEER REVIEW MEETING}

The following questions or comments regarding the test configuration and preliminary report of results for Benchmark Exercise \# 3 were made during the meeting of peers in the International Collaborative Project on Fire Modelling at Worcester Polytechnic University (WPI) in July 2003. The response to the questions was provided by NIST.

1. What is the standard sampling frequency of the measurements? $1 \mathrm{~Hz}$; see Section 1 of this report.

2. The location of slab $E$ and its TCs are not consistent in the specification document and addenda, and needs to be clarified.

The designation of the thermocouples in Figure 6-1 has been modified. The thermocouple locations are listed in Appendix D of this report.

3. Were the emissivity measurements taken only at room temperature?

Yes; see Appendix A of this report.

4. The equations in the test report that describe the relationship between compartment pressure and leakage area are not sufficient to reduce the measured data to values that can be used as input for fire models.

Appendix $\mathrm{C}$ of this report includes a relation between compartment pressure and leakage area.

5. The design of the supply ventilation system should have accounted for the length of duct necessary between the fan and the vent in order to ensure straight flow out of the vent into the compartment.

The rule of thumb for straightening flow from a simple open duct is 10 to 12 diameters. To straighten an intensely swirling flow, flow strengtheners of some sort would be needed to condition the flow and the number of diameters downstream from the strengtheners would likely be significantly greater than 12 diameters. Space limitations in the NIST Large Fire Laboratory precluded using this approach for the $0.7 \mathrm{~m} \mathrm{x} 0.7 \mathrm{~m}(2.3 \mathrm{ft} \times 2.3 \mathrm{ft})$ supply duct.

6. The radiative fraction for heptane needs to be clarified; different reports and addenda have identified two values.

The radiative fraction for the spray fire burning in the open was measured to be 0.45 , whereas the radiative fraction for a heptane pool fire burning in the open is 0.3 according to previous studies. 
7. The footnote to the test matrix for the planned time should be clarified. The duration of the fuel flow is stipulated in Table 3-1 of this report.

8. The observation of the melting of Slab $\mathbf{E}$ after Test $\mathbf{2}$ should be noted in the test report. Table 2-2 of this report highlights the status of Slab E during the test series.

9. The types of heat flux gauges used for the wall and cables should be discussed. The discussion should include whether the gauge is measuring net or incident heat flux. The reference temperature for measurements of convective heat flux, i.e., Ts in Qconv. = $\mathrm{h}(\mathrm{Tg}$-Ts) should be specified. In general the discussion of heat flux measurements should be comprehensive, accurate, and clear.

A detailed discussion of the gauges is given in Sections 4 and 10 of this report. The reference temperature for the cooled total heat flux gauges on the Targets was $75^{\circ} \mathrm{C}\left(167^{\circ} \mathrm{F}\right)$. The reference temperature for the surface total heat flux gauges was the gauge temperature, which was measured as it changed during the experiment.

10. The $20 \%$ discrepancy between the heat release measured using fuel mass flow and calorimetry should be investigated further.

This has been completed. An experiment was conducted to determine the effect of fuel line heat-up on the fuel flow. The corrected fuel flow was then used to estimate the HRR. This value was compared to the HRR determined from calorimetry. The difference between the HRR estimated by the fuel flow and that measured using oxygen consumption calorimetry differs for each test. For Test 4, for example, the difference was approximately $100 \mathrm{~kW}$, which was well-within the combined experimental uncertainties of the two measurements.

11. Spray fires used in the test series may not be the most suitable fire source for model validation because of the difficulty of accurately measuring the heat release rate. Pool fires in a pan, which can be mounted on a weighing device, may be a more appropriate fuel source since the heat release rate can be more accurately measured.

The above statement is subject to discussion. There are measurement issues associated with pool fires as well as spray fires. A pool fire burning down in a pan (and mounted on a weighing device) as suggested in the question will lead to a non-steady fuel burning rate. Also, water vapor from the gas phase can be transported by diffusion into the fuel pan, leading to significant systematic errors in the mass weight loss measurement for some fuel types. Depending on the pool size and the fuel type, the local mass flux of fuel on the surface of the pan can vary significantly. Planning for future experimentation should revisit this issue.

12. The data used for the heat release rate calorimetry should be included in the data set for the tests.

The calorimetry determination incorporates over thirty measurements including gas temperatures, velocities, and gas concentrations. The data used for the HRR calorimetry is not included in the accompanying data set as it would be of little utility without an understanding of the measurement system, procedures and the software required to process 
the information. A complete discussion of the measurement and its uncertainty is given in Bryant et al [2003]. The calorimetry data can be made available upon special request.

13. Is the specific heat of air or gas used for calculating the heat released through the door? The specific heat of air was used.

14. Does the uncertainty (standard deviation) stated for the measurements include systematic and random errors?

The analysis typically includes both systematic and non-systematic contributions to measurement uncertainty as appropriate for each particular measurement and as described in the text.

15. Can the fan curves for the supply system be provided?

The manufacturer fan curve that relates the static pressure to the blowing volume for various values of the fan power is included in Appendix G of this report. The fan had a $1 / 2$ hp motor. The static pressure represents the pressure difference at the fan between ambient and the compartment pressure. This pressure was measured as described in Section 11 of this report.

16. It is important to measure the temperature of the insulation near the internal copper conductors of the cables since this temperature has been found to be a good indicator of cable dysfunction.

As specified in the original Test Plan, which was open to comment, thermocouples were placed just inside the outer cable insulation (see Section 6 in this report). The sequence of the tests and the point when the thermoset cables were replaced with thermoplastic cables should be indicated.

Table 1-2 shows the test sequence and notes that the cables were changed before Test 7 . Table 1-1 lists the cable type present during each of the tests.

17. It would have been useful to measure mass in addition to extinction coefficient to confirm the smoke measurements.

The limited resources were expended to make more important measurements.

18. The calculation of an interface height using a 2-layer method when two distinctive layers do not exist may not have any physical meaning, especially when the compartment is filled with hot gas.

We agree. The 2-layer method calculation was computed as defined and is subject to interpretation.

19. There is a discrepancy between the TS 3-3 and TN 3-3 temperature, which are located in symmetrical positions on the wall.

The difference varies from test to test. Figure 10-15 (section 10) presents differences in the peak temperatures of TS 3-3 and TN 3-3 during Tests 2-4. The reasons for the differences are not clear, but may be influenced by an asymmetric flow field induced by ventilation, or asymmetric heat flux due to the off-center fire pan position used in many of the tests. 
20. Is there any measurement or indicator of how much soot was deposited on the walls? No, the quantity of soot deposited on the walls was not quantified. Some observations, however, were made. The walls were black after the toluene experiment and were darkened after the heptane tests. Observations suggest that only small amounts of soot were deposited on the walls. 


\section{G CuRvE For VENTILATON SUPPLY FAN}

The manufacturer fan curves that relate the static pressure to the blowing volume for various values of the fan power is found below. The fan had a $1 / 2 \mathrm{hp}$ motor. The static pressure represents the pressure difference at the fan between ambient and the compartment pressure, which is discussed in Section 11 of this report. 


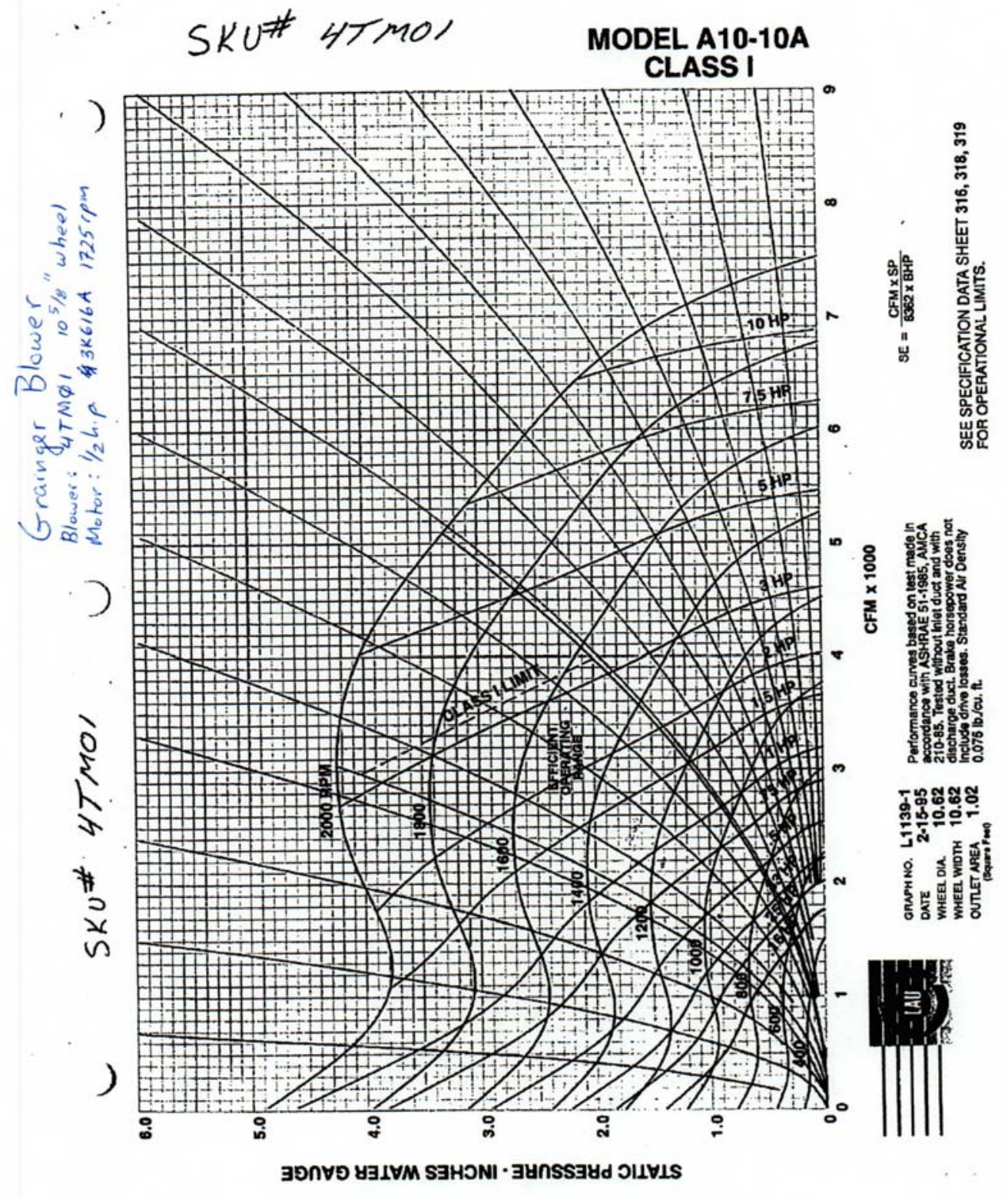

Figure G-1: The manufacturer supplied fan curve that relates the static pressure to the blowing volume for various values of the fan power. 


\section{$\boldsymbol{H}$ Junction Box}

An electrical junction box made of Feraloy was present in the ceiling of the compartment during the tests. The junction box was mounted on the ceiling and located on the compartment centerline, with its center 17.7 meters (58.1 feet) from the door. A drawing of the box is shown in Figure H-1. Feraloy is a proprietary manufactured product that is a gray-iron alloy. Its properties are somewhat similar to iron and are listed in Table A-4. The box was $30.0 \mathrm{~cm} \times 30.0$ $\mathrm{cm} \times 10.0 \mathrm{~cm}$ (11.8 in x $11.8 \mathrm{in} \times 3.9 \mathrm{in})$ in dimension with walls that were $7 \mathrm{~mm}(0.3$ in) thick. Three type $\mathrm{K}$ thermocouples were placed in the box center and on the middle of the bottom and west surfaces.

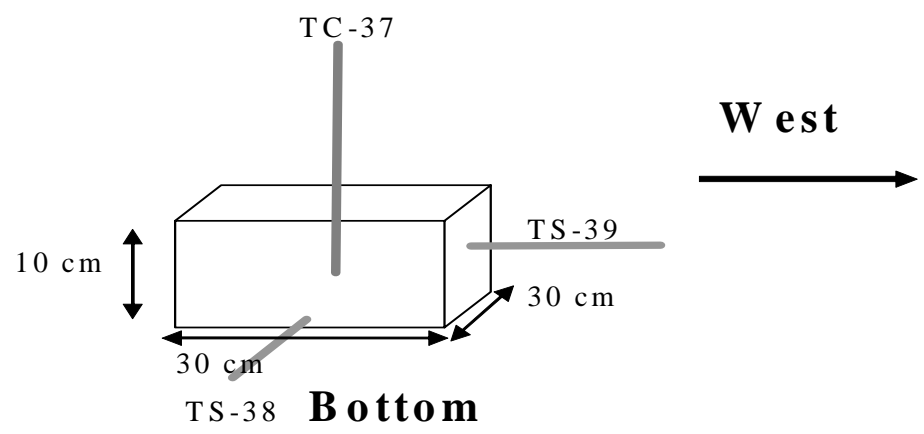

Figure H-1: Thermocouples in and on the surface of the junction box $(30 \mathrm{~cm} \times 30 \mathrm{~cm} \times 10$ $\mathrm{cm})$ measuring temperatures in the box center and on the middle of the bottom and west surfaces. 



\section{FUEL FLOW CORRECTION}

An experiment was conducted at the end of the test series to determine the effect of compartment heat-up on the fuel flow rate. It was hypothesized that the fuel flow during the experiment was not equal to the fuel flow during the ambient temperature fuel flow calibration, which was conducted before the tests. An experiment was conducted to test this hypothesis.

The experiment was essentially a repeat of Test 2, which was nominally a 1 MW heptane fire with the door closed and the ventilation off. The only difference between the experiment and Test 2 was that the compartment was shorter by 3.66 meters ( 12.0 feet) or about $15 \%$. Test 2 was representative of the fire scenarios in the test series, as eleven of the fifteen tests used the same nominal heptane fuel flow rate. The compartment door was closed and the ventilation off, since that scenario yielded the highest floor temperatures for a given fire size in the lower part of the compartment and therefore represented a worst-case scenario in terms of impact on the fuel flow.

An in-line flow meter was placed downstream of the fuel pump, located just outside of the test compartment. Thermocouples were placed on the fuel line and at a location just upstream of the nozzle (by adding an in-line tee) to monitor the fuel temperature as it flowed through the $1.2 \mathrm{~cm}$ (0.50 in.) outer diameter copper tubing. A video camera was used to record the fire behavior.

Figure I-1 shows the experimental results for the flow rate and the fuel temperature at two locations: just upstream of the nozzle and on the fuel line in the middle of the compartment. At early times in the experiment, the flow rate ramped-up from zero. An irregularity occurred at about $200 \mathrm{~s}$, when the flow fell to near zero for a brief period. At that time, the video record shows that the spray fire nearly stopped. Figure I- 1 shows that the temperature of the fuel near the nozzle at that time was greater than the boiling point of heptane, which is about $100{ }^{\circ} \mathrm{C}(212$ ${ }^{\circ} \mathrm{F}$ ). An interpretation of these events was that the fuel near the nozzle reached temperatures that exceeded the boiling point, and that a vapor lock of the flow occurred, essentially stopping the fuel flow. While this type of fire behavior was observed during this particular experiment, it was not observed during the test series. This may have been due to extra heat transfer to the fuel line caused by the addition of the thermocouple and the stainless steel tee just upstream of the nozzle. At $220 \mathrm{~s}$, the fuel flow increased to about $1.8 \mathrm{~L} / \mathrm{min}\left(0.06 \mathrm{ft}^{3} / \mathrm{min}\right)$, which was somewhat less than the target fuel flow of $1.93 \mathrm{~L} / \mathrm{min}\left(0.07 \mathrm{ft}^{3} / \mathrm{min}\right)$. At the same time, the fuel temperature near the nozzle decreased below the fuel boiling point and maintained nearly the same value for the remainder of the experiment. Figure I- 1 also shows that the fuel flow reached a fairly steady value for $\mathrm{t}>300 \mathrm{~s}$, with the average value during that period equal to $1.9 \mathrm{~L} / \mathrm{min}\left(0.07 \mathrm{ft}^{3} / \mathrm{min}\right)$, which was greater than the target fuel flow by a factor of about 1.09 .

The temperature of the fuel flowing near the nozzle almost certainly played a key role in the rate of the fuel flow. As the temperature near the fuel nozzle decreased, the fuel flow tended to 
increase, and vice- versa. The measurement of the temperature on the fuel line near the middle of the compartment, increased nearly monotonically, attaining a maximum temperature of $65{ }^{\circ} \mathrm{C}$ $\left(149^{\circ} \mathrm{F}\right)$. The fuel temperature next to the fuel nozzle was always higher. As the temperature of a hydrocarbon liquid increases, the viscosity decreases. The viscosity of heptane decreases by approximately a factor of two as the temperature increases from $20{ }^{\circ} \mathrm{C}$ to $90{ }^{\circ} \mathrm{C}\left(68{ }^{\circ} \mathrm{F}\right.$ to 194 $\left.{ }^{\circ} \mathrm{F}\right)^{3}$. For flow through a pipe for the Reynolds numbers estimated in the fuel line, a decrease in the fuel viscosity would lead to a reduced friction factor, a reduced pressure drop, and an increased flow rate.

Although the exact values of the temperature and the heat flux in the compartment differed for the open door and closed door tests, and for the tests with different fire sizes, the compartment temperature increased in all of the tests. While it is not possible to model the change in flow during the various tests, because not enough information about the local transient fuel temperature or fuel pump behavior is available, the increased fuel flow measured in the compartment during the supplementary experiment is regarded here as representative.

Table 3-2 shows the effect of the fuel flow correction on the estimated HRR if the correction factor is applied to all of the tests.

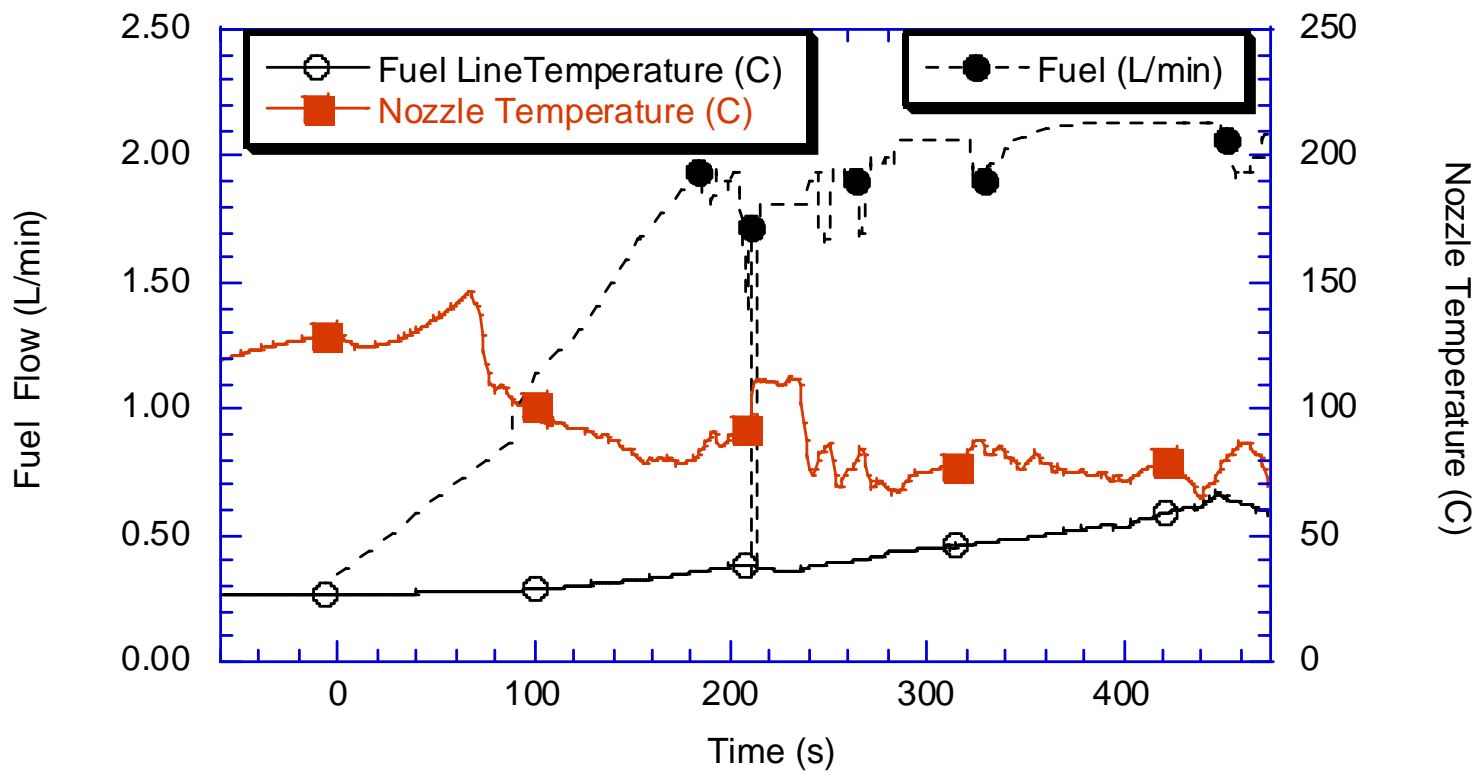

Figure I-1: The measured fuel flow and nozzle temperature as a function of time during the 1MW closed door compartment experiment.

\footnotetext{
${ }^{3}$ Reid R.C., Prausnitz, J.M., and Poling, B.E., The Properties of Gases and Liquids, $4^{\text {th }}$ Ed. McGraw Hill, NY, 1987.
} 


\section{J DOCUMENTATION OF PERSONAL COMMUNICATIONS}

Bundy, Matthew, NIST, Gaithersburg, MD. Conversation at NIST, May 2005, on determination of the HRR calibration of the calorimetric measurement in the NIST Large Fire Laboratory. Examination of gas chromatographic concentration measurements provided by the natural gas supplier, the Washington Gas Company, the caloric value of the natural gas was found to vary by approximately $1.3 \%$ over a six-month period.

Harris, Richard, NIST, Gaithersburg, MD. Conversation at NIST in March 2003. Mr. Harris manufactured the PVC slab, and observed that the softening temperature of the PVC was approximately $180{ }^{\circ} \mathrm{C}\left(356^{\circ} \mathrm{F}\right)$. 